Great Basin Integrated Landscape Monitoring Project

\title{
Conceptual Ecological Models to Guide Integrated Landscape Monitoring of the Great Basin
}

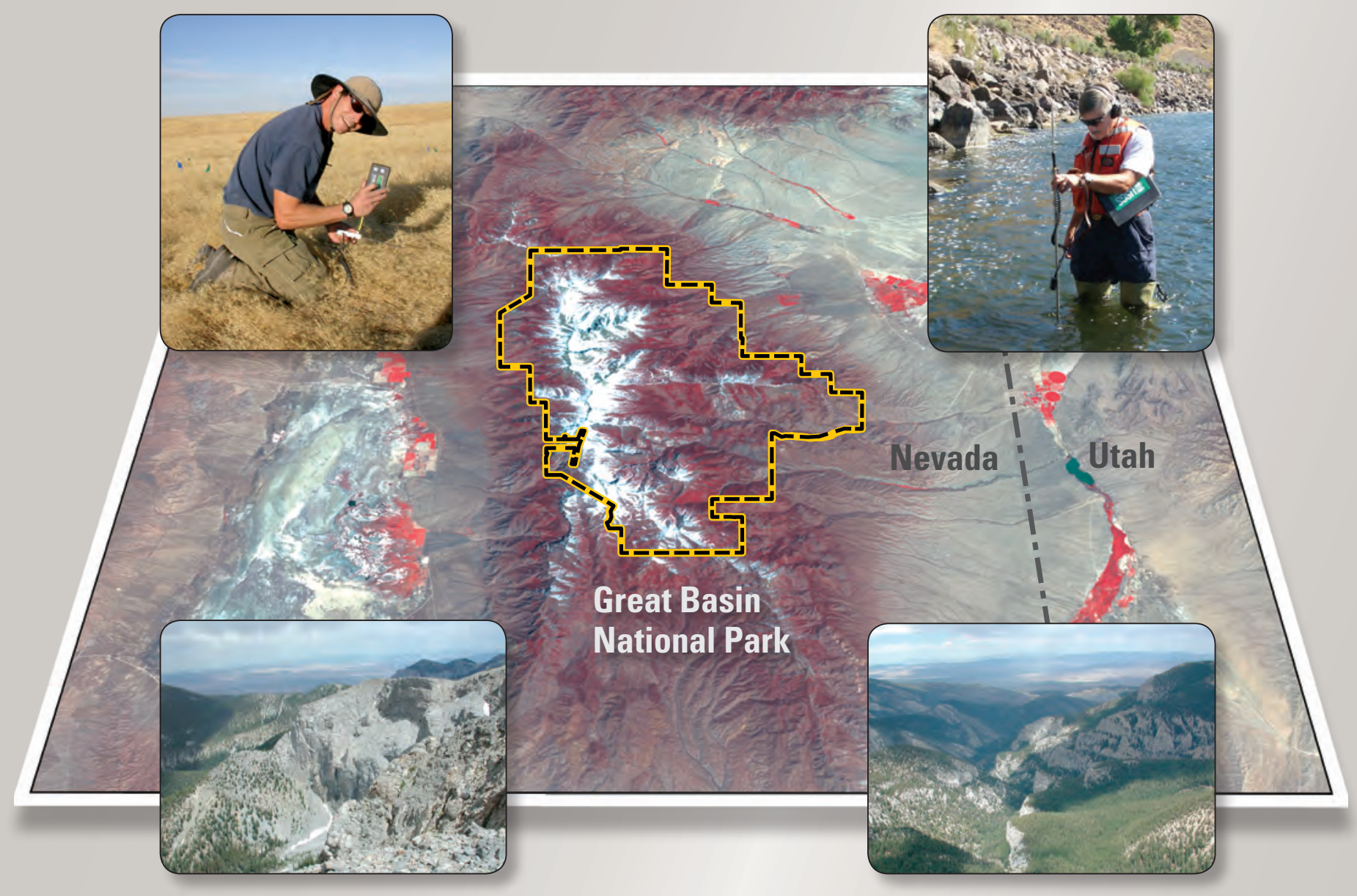

Scientific Investigations Report 2010-5133 
Cover: Satellite image is a Landsat scene acquired from U.S. Geological Survey's Earth Resources Observation and Science (EROS) Center. Photographs are from the files of the U.S. Geological Survey. 


\section{Conceptual Ecological Models to Guide Integrated Landscape Monitoring of the Great Basin}

Great Basin Integrated Landscape Monitoring Project

By D.M. Miller, S.P. Finn, Andrea Woodward, Alicia Torregrosa, M.E. Miller, D.R. Bedford, and A.M. Brasher

Scientific Investigations Report 2010-5133 


\title{
U.S. Department of the Interior \\ KEN SALAZAR, Secretary
}

\section{U.S. Geological Survey \\ Marcia K. McNutt, Director}

\section{U.S. Geological Survey, Reston, Virginia: 2010}

\author{
For more information on the USGS — the Federal source for science about the Earth, its natural and living resources, \\ natural hazards, and the environment, visit http://www.usgs.gov or call 1-888-ASK-USGS \\ For an overview of USGS information products, including maps, imagery, and publications, \\ visit http://www.usgs.gov/pubprod \\ To order this and other USGS information products, visit http://store.usgs.gov
}

Any use of trade, product, or firm names is for descriptive purposes only and does not imply endorsement by the U.S. Government.

Although this report is in the public domain, permission must be secured from the individual copyright owners to reproduce any copyrighted materials contained within this report.

Suggested citation:

Miller, D.M., Finn, S.P., Woodward, Andrea, Torregrosa, Alicia, Miller, M.E., Bedford, D.R., and Brasher, A.M., 2010, Conceptual ecological models to guide integrated landscape monitoring of the Great Basin: U.S. Geological Survey Scientific Investigations Report 2010-5133, 134 p. 


\section{Contents}

\section{Chapter 1. Conceptual Models for Landscape Monitoring}

By D.M. Miller, S.P. Finn, Andrea Woodward, and Alicia Torregrosa .............................................1

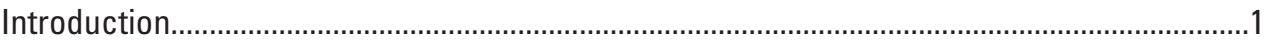

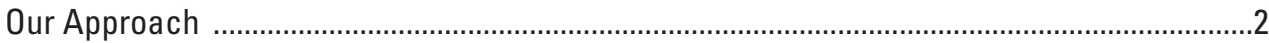

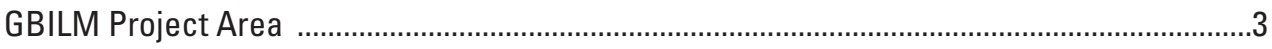

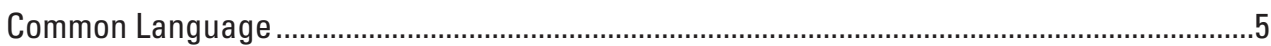

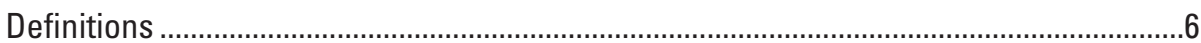

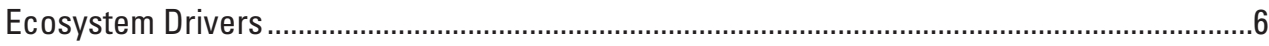

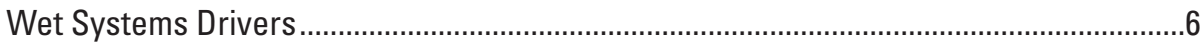

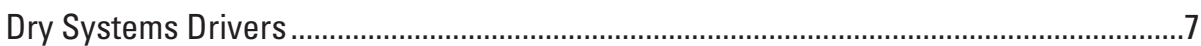

Cumulative Effects of Ecosystem Drivers ............................................................................

Structure of Conceptual Models ........................................................................................

\section{Chapter 2: Framework and System Models}

By D.M. Miller, S.P. Finn, Andrea Woodward, Alicia Torregrosa, M.E. Miller, D.R. Bedford, and

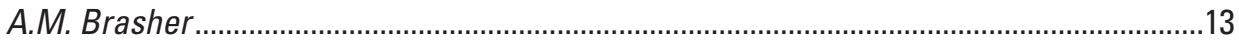

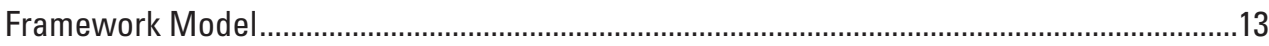

Atmospheric System Model By D.M. Miller and M.E. Miller..................................................14

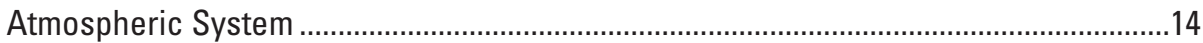

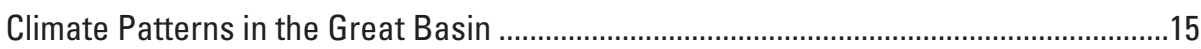

Climate Change and Forecasts...................................................................................

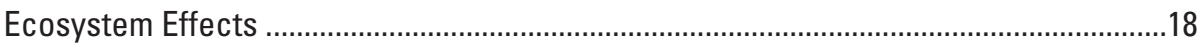

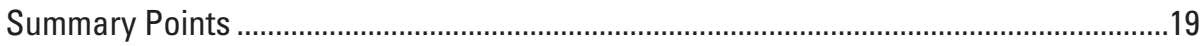

Human-Social System Model By Alicia Torregrosa.........................................................19

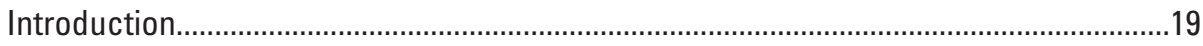

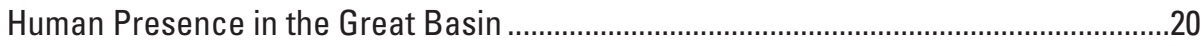

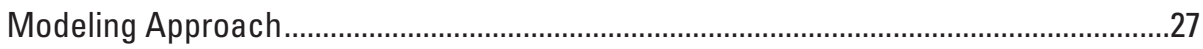

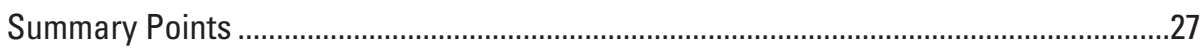

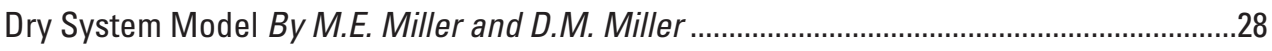

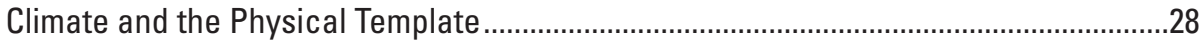

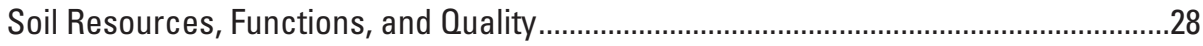

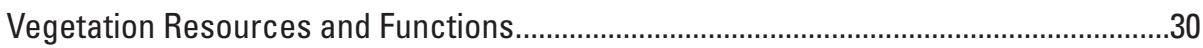

Wildlife and Habitat Quality ...........................................................................................

Wet System Model By D.M. Miller, D.R. Bedford, and A.M. Brasher ......................................32

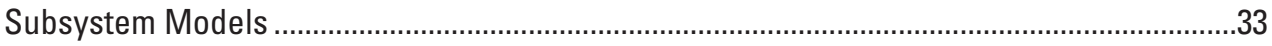




\section{Chapter 3: Subsystem Models for the Dry System}

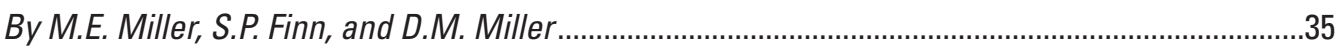

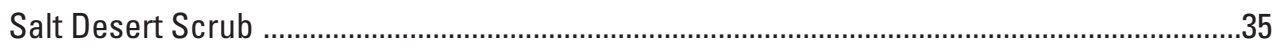

Sagebrush Steppe and Pinyon-Juniper Ecosystems By M.E. Miller ......................................35

Distribution and Management Significance ...................................................................35

Ecosystem Components and Processes............................................................................36

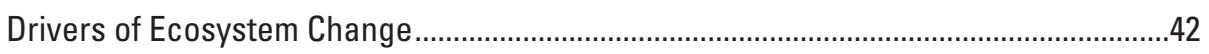

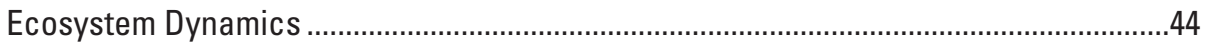

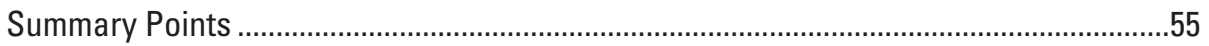

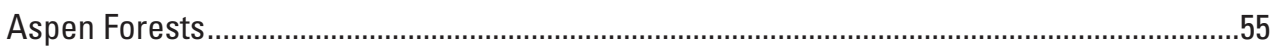

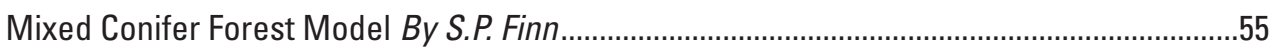

Distribution and Management Significance ………………………………………......55

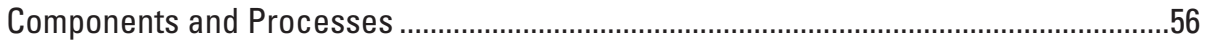

Drivers of Ecosystem Change.....................................................................................60

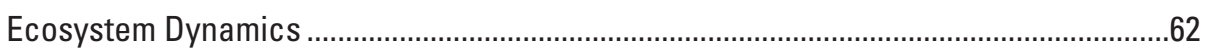

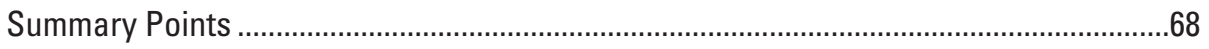

Alpine Tundra Models By D.M. Miller ………………......................................................69

Distribution and Management Significance .................................................................69

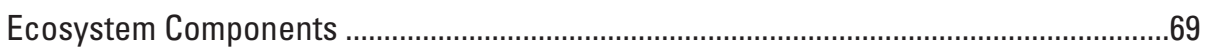

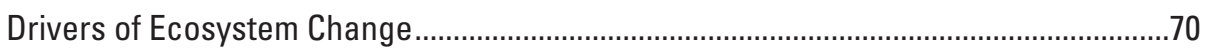

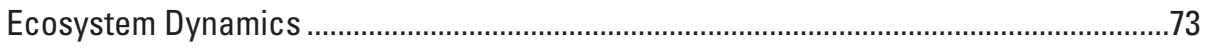

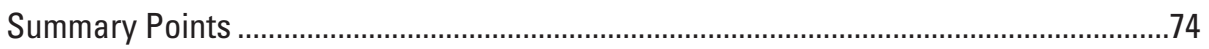

\section{Chapter 4: Subsystem Models for the Wet System}

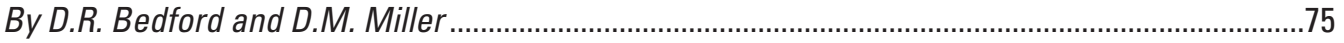

Groundwater Model By D.M. Miller and D.R. Bedford ....................................................75

Distribution and Management Significance ……………..........................................75

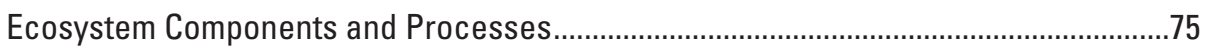

Drivers of Ecosystem Change......................................................................................

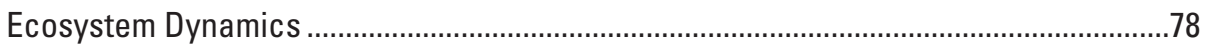

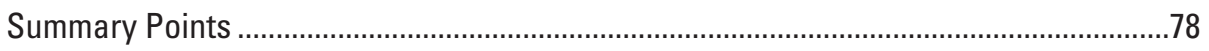

Wetland and Spring Models By D.R. Bedford and D.M. Miller .............................................78

Distribution and Management Significance ...............................................................78

Ecosystem Components and Processes.......................................................................79

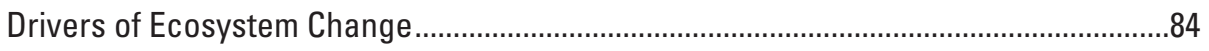

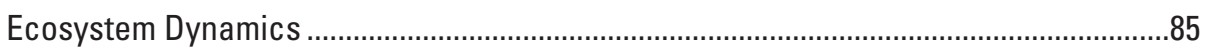

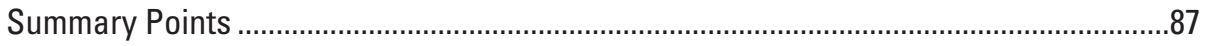

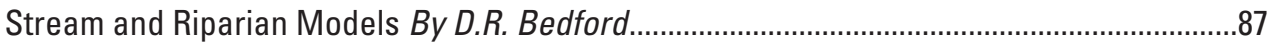

Distribution and Management Significance …………...............................................87

Ecosystem Components and Processes....................................................................8

Drivers of Ecosystem Change...................................................................................94

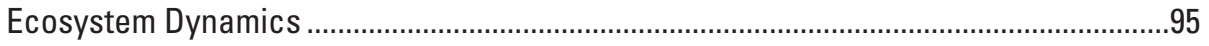

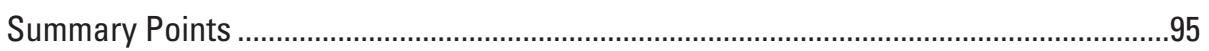

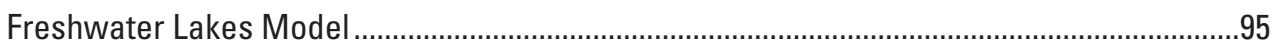

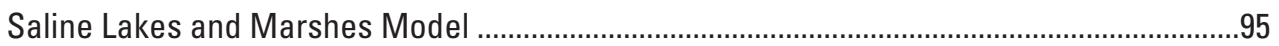




\section{Chapter 5: Integration Models}

By Alicia Torregrosa and Andrea Woodward ...............................................................................97

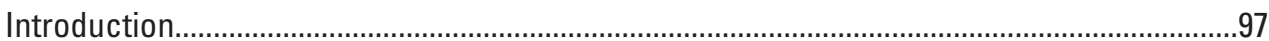

Integrated Ecosystem Framework .....................................................................................97

Models for Monitoring Landscape Change.........................................................................104

Summary Points ...................................................................................................................... 108

\section{Chapter 6: Summary and Conclusions}

By Andrea Woodward, S.P. Finn, and D.M. Miller........................................................................109

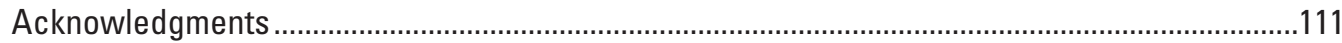

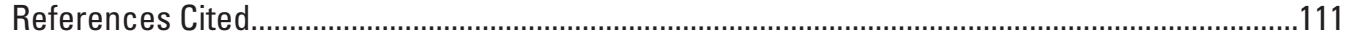

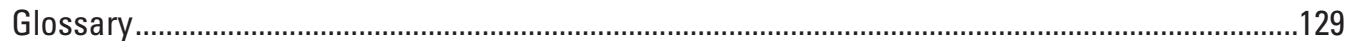

Appendix A. Ratings of System Drivers ....................................................................................133

\section{Conversion Factors and Datums}

Inch/Pound to SI

\begin{tabular}{lccl}
\hline & Multiply & By & To obtain \\
\hline foot $(\mathrm{ft})$ & & 0.3048 & meter $(\mathrm{m})$ \\
\hline
\end{tabular}

SI to Inch/Pound

\begin{tabular}{lll}
\hline \multicolumn{1}{c}{ Multiply } & By & \multicolumn{1}{c}{ To obtain } \\
\hline millimeter $(\mathrm{mm})$ & 0.03937 & inch (in.) \\
meter $(\mathrm{m})$ & 3.281 & foot $(\mathrm{ft})$ \\
kilometer $(\mathrm{km})$ & 0.6214 & mile $(\mathrm{mi})$ \\
hectare $($ ha) & 0.003861 & square mile $\left(\mathrm{mi}^{2}\right)$ \\
square kilometer $\left(\mathrm{km}^{2}\right)$ & 0.3861 & square mile $\left(\mathrm{mi}^{2}\right)$ \\
\hline
\end{tabular}

Temperature in degrees Celsius $\left({ }^{\circ} \mathrm{C}\right)$ may be converted to degrees Fahrenheit $\left({ }^{\circ} \mathrm{F}\right)$ as follows:

$$
{ }^{\circ} \mathrm{F}=\left(1.8 \times{ }^{\circ} \mathrm{C}\right)+32 .
$$

Temperature in degrees Fahrenheit $\left({ }^{\circ} \mathrm{F}\right)$ may be converted to degrees Celsius $\left({ }^{\circ} \mathrm{C}\right)$ as follows:

$$
{ }^{\circ} \mathrm{C}=\left({ }^{\circ} \mathrm{F}-32\right) / 1.8 \text {. }
$$

Concentrations of chemical constituents in water are given either in milligrams per liter (mg/L) or micrograms per liter ( $\mu \mathrm{g} / \mathrm{L})$.

\section{Datums}

Vertical coordinate information is referenced to the North American Vertical Datum of 1988 (NAVD 88)

Horizontal coordinate information is referenced to North American Datum of 1983 (NAD 83). Altitude, as used in this report, refers to distance above the vertical datum. 


\section{Acronyms and Abbreviations}

$\begin{array}{ll}\text { AMO } & \text { Atlantic Multidecadal Oscillation } \\ \text { BSCs } & \text { biological soil crusts } \\ \mathrm{CO}_{2} & \text { carbon dioxide } \\ \text { ENSO } & \text { the El Niño - Southern Oscillation } \\ \text { GBILM } & \text { Great Basin Integrated Landscape Monitoring Project } \\ \text { GIS } & \text { geographic information system } \\ \text { ILM } & \text { Integrated Landscape Monitoring } \\ \text { NRCS } & \text { Natural Resource Conservation Service } \\ \text { PDO } & \text { Pacific Decadal Oscillation } \\ \text { SSTs } & \text { sea-surface temperatures } \\ \text { TDS } & \text { total dissolved solids } \\ \text { USDA } & \text { U.S. Department of Agriculture } \\ \text { USGS } & \text { U.S. Geological Survey } \\ \text { UNFCCC } & \text { United Nations Framework Convention on Climate Change } \\ \text { UV } & \text { ultraviolet }\end{array}$




\section{Conceptual Ecological Models to Guide Integrated Landscape Monitoring of the Great Basin}

By D.M. Miller, S.P. Finn, Andrea Woodward, Alicia Torregrosa, M.E. Miller, D.R. Bedford, and A.M. Brasher

\section{Chapter 1. Conceptual Models for Landscape Monitoring}

By D.M. Miller, S.P. Finn, Andrea Woodward, and Alicia Torregrosa

\section{Introduction}

The Integrated Landscape Monitoring Pilot Project (ILM) was developed by the U.S. Geological Survey (USGS) in response to the need of its partner agencies for a monitoring and predictive capability that addresses changes in broad landscapes and waterscapes. Human communities and needs are nested within landscapes formed by interactions among the hydrosphere, geosphere, and biosphere. Understanding the complex processes that shape landscapes and deriving ways to manage them sustainably while meeting human needs require sophisticated modeling and monitoring. The long-term goals of the ILM are to

1. Identify, evaluate, and validate system components that are indicators of landscape change;

2. Provide feedback to land managers on the results of management actions in the context of ecosystem change through synthesis of data, models, and other decision support tools;

3. Define the unique ability of USGS to respond to customer needs in the area of landscape monitoring; and

4. Lay out a vision for the future that will make use of USGS' capabilities to design and implement monitoring networks, understand and model ecosystem change, and forecast landscape change.

The Great Basin was selected as one of four national pilot landscape areas for integrated landscape monitoring effort because (1) there is a well-defined need by Federal, State, and local community groups for monitoring and ecosystem understanding at the landscape scale; and (2) USGS has significant capability, ongoing work, robust partnerships, and regional datasets in place. In response to the national directive, the Great Basin Integrated Landscape Monitoring Project (GBILM) was formed with participation from the five USGS disciplines and several Department of Interior partner agencies.
In this document, we summarize and organize current understanding of ecosystem structure and function in the Great Basin using conceptual models. Communicating this understanding is fundamental to developing monitoring programs and can be done with clarity using the pictorial format of conceptual models. Conceptual models are not ends in themselves but are helpful organizers of thought, information, and ideas, and represent tools for communication and inquiry among scientists, managers, and the interested public. Consequently, the conceptual models in this report can be thought of as maps or flowcharts that help navigate a progression of scientific thought that starts with determining key ecological components and ends with a summary of mechanisms for the causal influences and relations among them. Eventually, conceptual models can provide a structure for designing monitoring programs, interpreting monitoring and other data, and assessing the accuracy of our understanding of ecosystem functions and processes. Additionally, the models can guide the identification of a few important attributes that provide information about multiple aspects of ecosystem status (Noon, 2003) and are efficient indicators to monitor.

In summary, conceptual models inform monitoring programs in the following ways (Maddox and others, 1999):

1. Models summarize the most important ecosystem descriptors, spatial and temporal scales of major biological processes, and current and potential threats to the system. They provide feedback to, and help formulate, goals, objectives, indicators, management strategies, results, and research needs. A model should not be expected to be complete and all-encompassing; rather, it should illuminate components of the ecosystem that relate to management and its impacts. Models facilitate discussion and debate about the nature of the system and important management issues and questions. 
2. Ecological models play an important role in determining indicators for monitoring. The model is a statement of important biological and physical components and processes. It therefore identifies aspects of the ecosystem that should be measured.

3. Ecological models can provide useful tools to help interpret monitoring results and explore alternative courses of management. Monitoring results should be used to update and improve the ecological model, which is the summary statement or framework of the system. Monitoring results may support or conflict with current understanding, thereby contributing to evolution of knowledge and understanding. Models are expected to evolve over time as they are developed, tested, and informed by new data and knowledge.

There is no single model that adequately describes an entire system or even a part of a system, because it is impossible to achieve both model generality and model realism. Model generality is needed to characterize broadscale influences and relationships among resources. In contrast, model realism is needed to identify specific potential expressions of change that could be effective monitoring indicators, which requires considerable detail. Consequently, integrative general models and more detailed specific models are needed to represent systems of the spatial extent and ecologic complexity of the Great Basin. Models that have the generality to describe an entire region will include few details about individual ecosystem components and will instead provide a broad overview of how those components interact. Achieving model realism necessary for understanding local-scale processes can be likened to moving a magnifying glass around to focus on individual ecological systems or management issues. With each change in position, some elements are brought into sharp focus while others become less distinct.

Recognizing that a group of related models is needed to describe the complexity of the Great Basin at different levels of detail, the GBILM project developed a set of conceptual ecosystem models to: identify key ecological functions and services; develop an overarching model of landscape function; inform regional monitoring strategy development that integrates existing capabilities; and identify critical gaps in our knowledge of ecosystem function. This report is a first step in the process; it:

- Describes the process that the Conceptual Modeling Team used to develop the conceptual models,

- Develops the framework for ecosystem models,

- Identifies the most important ecosystem drivers,

- Presents and describes our set of conceptual models, and

- Illustrates our approach of scaling from a framework model to system-specific models and integrating the component pieces.
This document provides a conceptual framework for many of the unique ecosystems within the Great Basin and includes conceptual models of 'reference-states' and the drivers and stressors particular to each biophysical system. The document develops models at different levels of specificity to illustrate our approach. A conceptual model also has been developed to address landscape integration, such as interactions among ecosystems and cumulative impacts of multiple drivers, and approaches for scaling from local to landscape-level understandings. Fine-scale models for several biophysical subsystems are not developed, but will be developed pending future focus of project staff on these subsystems. This document is presented to help develop a broad-scope monitoring strategy that, when implemented, will provide data to help answer the resource management questions that catalyzed the creation of the GBILM.

The indicators developed through this effort function as measurement points that can be used to test the validity of the models and refine research paths needed to better understand change within the Great Basin.

The GBILM models are intended to help identify the natural and anthropogenic drivers/stressors of a system, serve as a structure to interpret data and assess the accuracy of our understanding of ecosystem functions and processes, and facilitate communication with partners about how decisions for indicators, priorities, and protocols in monitoring programs are determined. In response to Department of the Interior agency and partner needs, the GBILM models will place strong emphasis on management relevance and societal values.

\section{Our Approach}

Models in this document were developed using a systematic process that defined our goals and limitations; identified key systems, subsystems, and system drivers; and characterized primary linkages among systems in the Great Basin. We loosely followed a set of tasks for developing conceptual models described by Gross (2003). These tasks are:

1. Determine the goals of the conceptual models.

2. Identify bounds of the system of interest.

3. Define a common language.

4. Identify key model components, subsystems, and interactions.

5. Develop control models of key systems and subsystems.

6. Identify natural and anthropogenic stressors.

7. Describe relationships of stressors, ecological factors, and responses.

8. Articulate key questions or alternative approaches.

9. Identify inclusive list of indicators.

10. Prioritize indicators.

11. Review, revise, and refine models. 
The process was initiated through a series of conference calls leading to a 2-day workshop held in June 2006, during which team members provided expert knowledge on systems and linkages and identified knowledge gaps amongst the team members. The workshop was followed by regular communication among several subteams, each focused on ecosystem-specific models. Subteams continued to communicate when using and refining the models with the intention of keeping the models relevant and updated. In this conceptual modeling phase, the group did not stress the systematic identification and prioritization of indicators, although many are identified in the model narratives. The Conceptual Modeling Team articulated the following goal:

We will develop conceptual ecosystem models that describe ecosystem components, external drivers, and interactions of the components, drivers, and processes in such a way that components and processes can be prioritized with regard to importance for monitoring.

We identified the relevant spatial, systemic, and temporal bounds of the Great Basin by iterative review and discussion within the interdisciplinary team in consultation with agency partners. We reviewed 11 existing descriptions of the Great Basin's spatial extent, mapped these descriptions, and explored and described which geographic boundaries best encompassed the potential critical components for which managers most need monitoring information. Next we constructed a two-way matrix of subsystems versus key ecosystem components, stressors, drivers, and potential monitoring attributes to make initial predictions regarding which subsystems were significantly impacted by multiple (or intense) stressors and therefore were good candidate focal systems for conceptual models. We identified a 50 -year future time span of consideration for the ensuing models based on this matrix, our knowledge of Great Basin landscape change, and resource manager needs. We later considered the legacy of land-use impacts (200-year bound) and pre-historic impacts by people and climate changes ( $2-5$ millennia) as important precursor time windows. We maintained a common language throughout the process by agreeing to specific definitions for all terms and concepts used during the process (see sections "Common Language" and "Glossary").

Team members identified key model components, subsystems, and interactions by reviewing existing models describing arid and aquatic ecosystems in the Western United States and cross-referencing them to our system-driver matrix. As part of the iterative process, we reevaluated potential model components, subsystems, and interactions in an expert roundtable discussion at the 2-day workshop.

An overall model structure was developed using a hierarchical approach. Based on the system-driver matrix we drafted a 'Framework Model' that coarsely describes systems and interactions operating in the Great Basin. One important principle that emerged during discussions was the significance of water to systems throughout the Great Basin and the distinction between precipitation-event-driven systems ('dry' systems) and surface- and groundwater systems ('wet' systems, which respond to precipitation at long time scales). We reviewed the prevalence and importance of key dry and wet subsystems at local and regional scales and identified where system-specific models would be most useful to managers. The team agreed that key models for an integrated understanding of landscape level functioning of the Great Basin are: stream and riparian areas, groundwater dominated wetlands and springs, freshwater lakes and marshes, saline lakes and marshes, salt desert scrub, sagebrush steppe, pinyonjuniper woodlands, aspen forests, conifer forests, and alpine tundra. This list excludes several systems such as dry and wet playas, sand dunes, caves, hot springs, and badlands, all of which play important ecological roles but have smaller spatial footprints.

During the expert roundtable discussion, the team identified a suite of 30 natural and anthropogenic drivers and stressors (appendix A). We selected a subset of nine stressors as being critical to Great Basin ecosystem functioning and as being top priorities for further monitoring. These nine stressors are: water extraction, flow regime, livestock grazing, invasive exotic species, fire regime, invasive plant-fire interactions, land treatments, motor vehicle use, and climate change and variability. Next, we described the relationships of the top stressors to each of the 10 subsystems independent of the previous system-driver matrix to validate our assumptions and identify draft components of the subsystem models.

Finally, we identified teams to develop subsystem models for six focal subsystems: sagebrush steppe/pinyon-juniper woodlands; mixed conifer forest; alpine tundra; groundwater; stream and riparian; and wetlands and springs. These models: (1) serve as stand-alone models for the respective subsystems, (2) provide 'straw men' for further iterative critique and review of our process, and (3) are representative examples for modeling the other key subsystems.

\section{GBILM Project Area}

The Great Basin forms a wedge between the Sierra Nevada and Rocky Mountains (fig. 1.1). Bounded to the north by the Columbia Plateau and Snake River Plain and to the south by the Mojave Desert, the defining feature of the region is its internally draining surface hydrology. This closed hydrographic system exceeds $500,000 \mathrm{~km}^{2}$ in area and includes nearly all of Nevada, and parts of eastern California, western Utah, southeastern Oregon, and southern Idaho. The Great Basin may be spatially defined by hydrologic, geologic, biologic, or cultural definitions which all vary slightly. Anthropologists define the region by cultural attributes of the aboriginal inhabitants (d'Azavedo, 1986), botanists by species composition of the vegetation (Billings, 1951; Vasek and Barbour, 1977), geologists by the structure of the land 


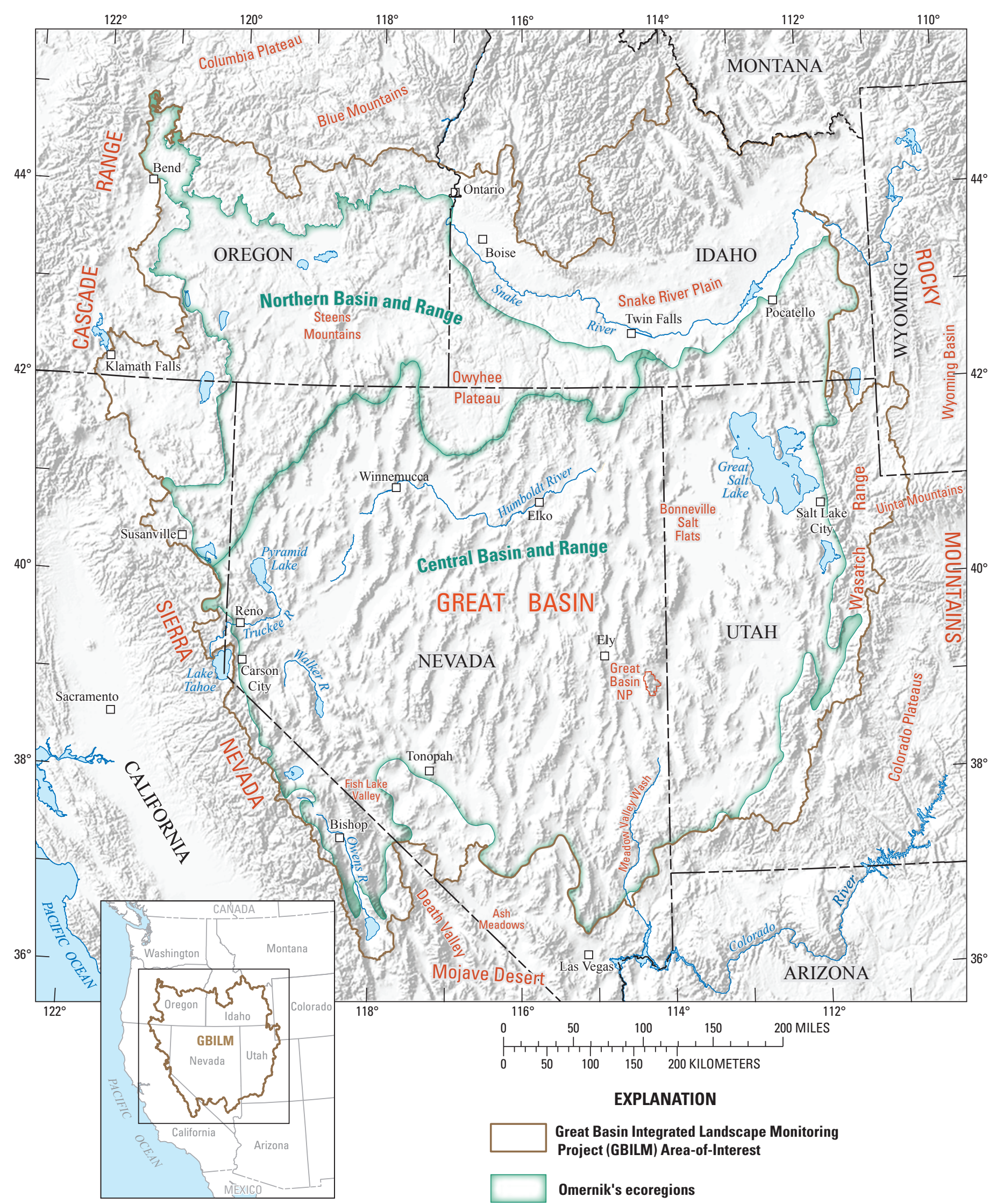

Figure 1.1. Map showing GBILM Area-of-Interest including the Great Basin and the floristically similar Snake River Plain. Area was delineated by overlapping Omernik's northern and central Basin and Range provinces (Omernik, 1987) with the Bureau of Land Management's (BLM) Great Basin Restoration Initiative focal area. 
(Hunt, 1967), and hydrologists by the position of aquifers and surface-water flow. For regional monitoring, GBILM defines an area-of-interest that includes an overlay of Omernik's (1987) northern and central Basin and Range Provinces and the Great Basin Restoration Initiative's focal area [http:/www. blm.gov/id/st/en/prog/gbri/map.html] (fig. 1.1). GBILM's boundary includes areas outside of but adjacent to the hydrologic Great Basin that are floristically and ecologically similar to the interior basins. Throughout this document, we will refer to the area depicted in figure 1.1 as the 'Great Basin.'

Topographic relief in the Great Basin creates elevation gradients and associated gradients in air density, solar radiation, and precipitation. The interaction of these factors creates many temperature and moisture regimes, which significantly affects plant distribution (Billings, 1970) and animals that depend on them (Hall, 1946). The high, cold (relative to other American deserts) Great Basin desert historically has received most of its moisture as snow (McMahon, 1988; see Chapter 2, section "Atmospheric System Model" for more climate details).

The mountainous terrain, paleo-history, varied climate, and human settlement in the Great Basin provides many opportunities and challenges for a multitude of organisms with diverse life strategies. The composition of biota in the region is a blend of species in common with surrounding regions and a suite of endemic species specifically adapted to life in this cold desert. This combination produces high biological diversity but poses threats to some species' existence. For example, the Great Basin contains more than 130 endemic plant species or subspecies, 95 of which are imperiled. A driver of this high endemism is the patchy nature of many habitat types and the fluidity of patch connectivity across the landscape over geological time. Within $20 \mathrm{~km}$, a single basin-range unit can host environments that range from treeless alpine bogs and rocky slopes to montane coniferous forests, diverse mountain shrublands, woodlands of pinyon pine (Pinus edulis) or juniper (Juniperus spp.), lower slopes of sagebrush (Artemisia spp.) and grasses, lake shores that support an entirely different array of shrubs and flowers, barren sand dunes, and playas. Dozens of montane habitat islands in the region now are separated from each other by arid lowlands. Major metropolitan areas are connected by transportation and utility arteries, which contrast with the sparse ranch and farm land uses in much of the Great Basin.

\section{Common Language}

The degree of interdisciplinary cross-fertilization used by groups as they meet multidisciplinary challenges has been shown to affect the type of product that results (Westly and Miller, 2003; Lawrence and Despres, 2004; Hinkel, 2008; Klein, 2008). Teams that strongly adhere to disciplinary boundaries tend to merge their results into an overarching model after the individual disciplinary results are finalized. An example is the traditional approach to flood control which first engineers a flood-control (dam/reservoir) structure based on watershed drainage and subsequently mitigates the negative effects on salmonids using measures such as fish ladders. Teams that encourage more flexibility between disciplinary structures tend to use whole-systems approaches that take into account seemingly disparate causal relationships. A well documented example is the recent tobacco research that investigates the effects of smoking from genetic, neurobiological, social, and economic perspectives to conclude that previous understanding of addiction was inadequate to address the problem of tobacco usage by informing effective public policy (Stokols and others, 2003).

The group challenge of developing a common language is especially acute for teams with disciplines that use terms (or jargon) in incompatible ways and where the terms have a long or strong theoretical disciplinary basis that is at odds. For example, the term 'scale' to a geographer refers to the ratio between a map and the landscape it represents. To a geographer, a map at 1:24,000 scale is at a much larger scale than map at 1:1,000,000 scale. For scientists in many other disciplines, a large-scale map refers to a map that shows a large area, necessitating a small map scale. These two opposed uses of the term 'scale' illustrate the potential difficulty in thinking across disciplines and foreshadows the shifts in perspective that can make way for new and different types of conceptualization.

The interdisciplinary nature of the GBILM team required that we agree to a common language drawn from a monitoring literature that is replete with terms and distinctions that vary among users. Consequently, we explicitly defined a vocabulary for this report and in the process we became more discerning in our use of terms such as 'stressor' and 'driver'. 


\section{Definitions}

We define landscape change to be changes in the types, relative proportions, and 'condition' (health, integrity, resiliency, functioning) of Great Basin biophysical systems, particularly as these changes relate to mandates and/or management objectives of land managers. Landscape changes include changes to soils, geomorphic processes, hydrologic systems, and atmosphere as they pertain to ecosystems.

We define ecosystem (system) drivers, both natural and anthropogenic, as the events and processes that are most responsible for ecosystem change in the Great Basin. These may be related to global or regional climate, natural disturbance regimes, nutrient cycling, or human activities.

Control models describe our present understanding of how ecosystems and their subsystems respond to the drivers. At the point that drivers exceed the range of variation beyond which the current biological communities can survive (commonly taken as exceeding the long-term or reference range of variation), the drivers become stressors to the system. Examples include extreme climate change (driver) that results in the conversion of shrub lands to grasslands or polluting levels of nitrogen fertilizers (driver) in streams that results in oxygen deprivation of the aquatic subsystems. Although we do not define precise thresholds beyond which drivers become stressors, we use stressor models to hypothesize what kind of ecosystem changes we expect the driver to cause. The predictions from stressor models and the critical processes, components, and drivers described in control models can inform the choice of monitoring indicators.

We define drivers as 'natural' when the ecosystem has evolved with their effects. Natural drivers commonly are quasi-cyclical and in a state of dynamic equilibrium in the absence of excessive human pressures. In contrast, 'anthropogenic' is used when we wish to highlight that the driver is a result of human activities. Although anthropogenic activities are in many cases accompanied by losses in biodiversity or functional integrity, they also can have positive effects, for example restoration and mitigation. Making a distinction between natural and anthropogenic drivers is fraught with the potential for disagreement and good arguments can be made that any human action is natural. We make the distinction to allow us to make simpler models with better explanatory power.

Implicit in the 'natural' aspect of these definitions is the need to identify ecosystem-specific reference conditions that are framed with respect to a particular time period and place (White and Walker, 1997; Landres and others, 1999). In addition to these temporal and spatial bounds, it is desirable to explicitly identify associated goals, assumptions, and value judgments when adopting a particular set of reference conditions as the "natural" standard for management and monitoring (Truett, 1996; Landres and others, 1999). LateHolocene, pre-European conditions often are identified as the standard for defining natural disturbance regimes, although it is important to recognize the potentially important role of preEuropean human populations in shaping disturbance regimes and ecosystem conditions before European contact (Anderson and Moratto, 1996; White and others, 1999). In addition, periods of climate variability during the late Holocene such as the Medieval Warm Period (ca. 800-1350 AD) and Little Ice Age (ca. 1350-1850 AD) caused significant changes in hydrological systems (for example, lake levels and river flow) and human adaptations to the environment (for example, shifts in subsistence mechanisms and locus of habitation) (Benson and others, 1990). The dynamic nature of ecosystems is a vital concept for understanding the Great Basin.

\section{Ecosystem Drivers}

We listed and prioritized system drivers based on expert opinion in order to focus our conceptual models on those parts of Great Basin ecosystems most subject to change (appendix A). We rated every driver according to its scope or magnitude as a factor contributing to management relevant landscape change across the Great Basin. The final list of high priority drivers (five for wet systems, six for dry) is given below along with justifications. We recognize that this prioritized list may be too ambitious, and that further stakeholder input and changing societal conditions may change the priorities. Nevertheless, this list provides focus for developing the current subsystem models.

\section{Wet Systems Drivers}

Water Extraction. Withdrawal of groundwater is widespread in the Great Basin in agricultural settings and for municipal use. Groundwater withdrawal lowers water tables because recharge rates generally are very low, and the lowered water table can lead to loss of springs and wetlands. The possibility of accelerated groundwater withdrawal associated with urban development highlights this driver as one of special concern.

Flow Regime. Diversion of streams for irrigation, disruption of streamflow by roads and levees, channel changes for flood control or other reasons, and climate change resulting in changing precipitation and altered snowmelt patterns all contribute to altered flow regime. Flow Regime describes stream function and therefore biotic habitat condition.

Livestock Grazing. Livestock trample streambanks and wetlands, altering habitat in these critical riparian zones and changing hydrologic function. In addition, livestock may alter species composition and water quality by nutrient loading. Most of the Great Basin is subject to livestock grazing and large areas host feral horses.

Invasive Exotics. Introduction of invasive aquatic species has altered most water systems in the Great Basin. Specifically, sport fish have been introduced to nearly every stream. Invasive plants have altered the structure, function, and habitat value of many riparian and wetland systems. 
Climate Change and Variability. Global warming and accompanying increased climate variability has altered snowmelt periods, reducing water available for stream flow and lakes, and increasing impacts from intense storms, such as floods.

\section{Dry Systems Drivers}

Fire Regime. Altered fire regimes attributable to past livestock grazing (fuel removal) and fire-suppression efforts have caused significant changes in vegetation structure and the function of associated ecosystem processes. Mediated by changes in vegetation structure, ecosystem-level consequences of altered fire regimes can include diminished hydrologic functioning and increased erosion rates, as well as increased ecosystem susceptibility to drought (Miller, 2005).

Invasive-Fire Interaction. Introduction of Mediterranean annual grasses has led to infilling of intershrub spaces with highly combustible grass, increasing intensity and frequency of fire in shrublands of the Great Basin. Increased fire frequency alters natural fire cycles, promoting invasive grasslands over native shrubs, impacting soil properties, and altering wildlife habitat.

Livestock Grazing. Grazing alters species composition, vegetation structure, and animal habitat through many mechanisms. Trampling by livestock destabilizes soils, alters hydrologic processes and nutrient cycling, and facilitates the establishment of invasive exotic plants.

Land Treatments. This driver ranges widely in type and scope but all treatments are meant to improve land utility. Examples of land treatments are roads and trails, agriculture, crested wheatgrass and other introduced grass plantings, chained shrublands and woodlands, timber harvested forests, and even flood-control basins. All treatments cause vegetation change, alter wildlife habitat, and alter soils and nutrient cycling.

Motor Vehicle Use. Motor vehicles, used on road and off, are potential vectors for invasive species and toxic contaminants, and effectively introduce refuse and accelerated human visitation in all but the most remote mountain areas. Off-road vehicle use promotes soil compaction, plant mortality, soil erosion, increased carbon dioxide $\left(\mathrm{CO}_{2}\right)$ and dust emissions, and reduced air quality.

Climate Change and Variability. Global atmospheric changes attributable to anthropogenic emissions of $\mathrm{CO}_{2}$ and other greenhouse gases are expected to have significant environmental consequences during this century (Houghton and others, 2001). Increasing levels of atmospheric $\mathrm{CO}_{2}$, increasing soil and air temperatures, and altered precipitation patterns (including a potential increase in the frequency of extreme events) are likely to affect physiological processes and competitive relationships of vascular plants, nutrient cycles, hydrologic processes, and disturbance regimes. All these changes have the potential to greatly alter the structure and functioning of dryland ecosystems and the sensitivity of these systems to other anthropogenic stressors (Miller, 2005).

\section{Cumulative Effects of Ecosystem Drivers}

Developing a predictive understanding of the effects of ecosystem drivers in the Great Basin requires the realization that drivers typically have effects that interact and accumulate in space and time. Depending on the temporal and spatial circumstances, these cumulative effects can appear as a stressor accumulating over space (for example, low levels of a water pollutant in tributaries accumulating in a river), a stressor accumulating over time (for example, repeated land treatments of the same area), and combinations of single and multiple stressors (fig. 1.2) accumulating over time and space. Interactions also can occur between natural and anthropogenic drivers or disturbances (White and others, 1999; Archer and Stokes, 2000). Because disturbance cycles play such an important role in shaping the structure and functioning of ecosystems (for example, by strongly interacting with soil resources and vegetation structure), disturbance-regime alteration is one of the most significant ways by which human activities affect ecosystems (Chapin and others, 1996).

The climate change/variability driver interacts with nearly all other key drivers, mostly by influencing how they operate on the landscape (fig. 1.2). For example, long-term changes in precipitation in the region, as well as changes in timing of snowmelt and intensity of storms, are likely to affect base streamflow rates causing changes in flow regimes and in the volume of water available to extract. Similarly, changing air temperatures influence evapotranspiration rates causing changes in soil and fuel moisture, and potentially influencing fire return intervals. Climate change also may create favorable conditions for the proliferation of disruptive species that previously were limited by water or air temperature. In general, relatively persistent shifts among ecosystem states commonly are triggered by synergistic interactions between two or more drivers of ecosystem change (Paine and others, 1998; Scheffer and others, 2001; Folke and others, 2004). Characteristically, one driver acts to decrease system tolerance of another driver and thus enables subsequent changes (for example, soil disturbance can reduce ecosystem resistance to the establishment of invasive exotic grasses).

Interactions among stressors and drivers are scale dependent and may accumulate to affect multiple systems. Fine scale (site-specific) drivers, generally anthropogenic, also are likely to interact, and the results accumulate to potentially significant consequences at the landscape-scale and in systems other than those in which they occur. For example, livestock grazing in sagebrush-steppe may alter plant species composition, potentially increasing vulnerability to invasion by exotic species and, perhaps, altering fire and flow regimes. The altered fire and flow regimes in turn impact other systems, such as pinyon-juniper, riparian, and salt desert scrub communities. Some widespread effects (for example, climate change) also may have differing impacts in different systems depending on the dynamics of cumulative effects within or among subsystems. Therefore, we need to consider the relative scale at which stressors and processes work, 


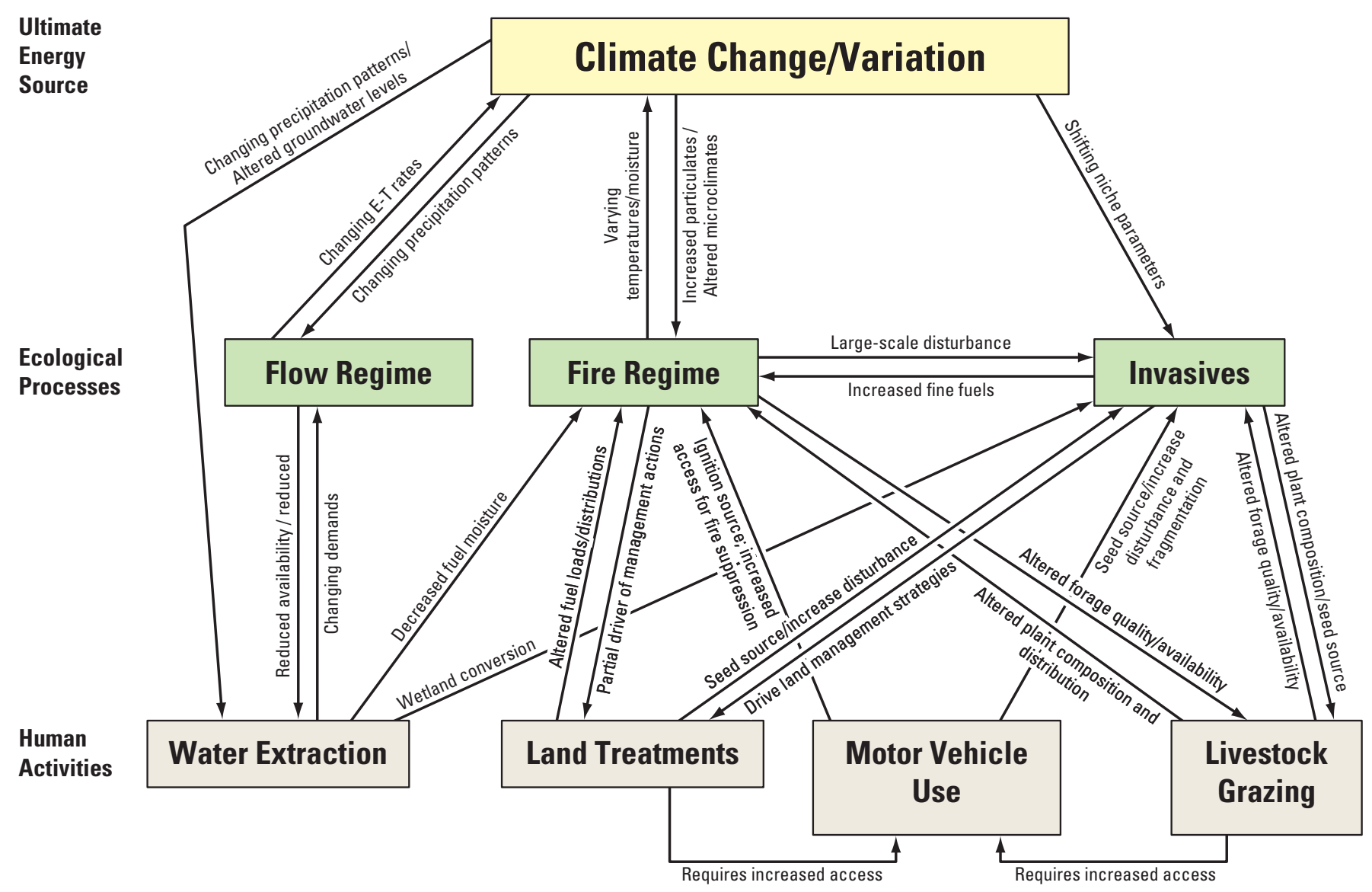

Figure 1.2. Diagram of principal interactions among ecosystem drivers in the Great Basin.

and their functional relationships (for example, non-linear, exponential, etc.). For example, fine-scale stressors such as land treatments could affect fire regime and invasion dynamics leading to changes in vegetation structure and composition in the surrounding landscape.

Our stylized conceptual model of stressor and driver interactions (fig. 1.2) identifies potential interactions among systems to better understand how to efficiently approach monitoring the changing landscape, to stimulate hypothesis development, and to identify gaps in our knowledge of ecosystem processes. We acknowledge the incompleteness of this diagram, which is due to the limitations of graphically portraying interactions of such complexity, and more significantly, a lack of current knowledge of the relevant interactions among many drivers. Two urgent questions require investigation. First, will Great Basin ecosystems be able to respond to increasing $\mathrm{CO}_{2}$ concentrations, temperature, and changing precipitation regimes without irreversible change? Second, will the response of Great Basin ecosystems to changing climatic and atmospheric conditions be excessively compromised by the multiple drivers associated with human land-use activities?

\section{Structure of Conceptual Models}

Multiple conceptual models are required to describe the Great Basin in enough detail to suggest and justify monitoring indicators. Consequently, we divided the Great Basin into hierarchical units that we described with sufficient detail to model the effects of the priority drivers. The hierarchy includes four levels (fig. 1.3).

Framework Model. The highest level of the hierarchy is the overall model, which we termed the Framework Model. It identifies the major biotic and abiotic systems of the Great Basin and how they are related.

System Models. We created a system-level model for each of the four systems described in the Framework Model. These are graphic and narrative models that describe how the system operates at the broad landscape scales and how it is divided into subsystems by major abiotic gradients, such as elevation and precipitation.

Subsystem Models. These models describe our understanding of the important components and drivers of each subsystem and present our current understanding of the processes that shape the subsystem. In some respects, these models are aspatial in that they ignore interactions 


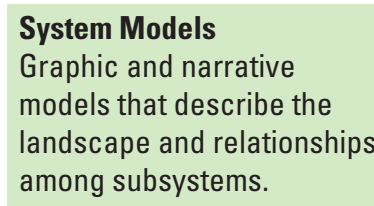

Subsystem Models Aspatial descriptive models of subsystem components drivers and dynamics.

Integration Model
Spatial model enabling
accumulation of drivers and
stressors, and transfer of
information across spatial
and temporal scales.

Integration Model Spatial model enabling stressors, and transfer of and temporal scales.

\section{Framework Model}

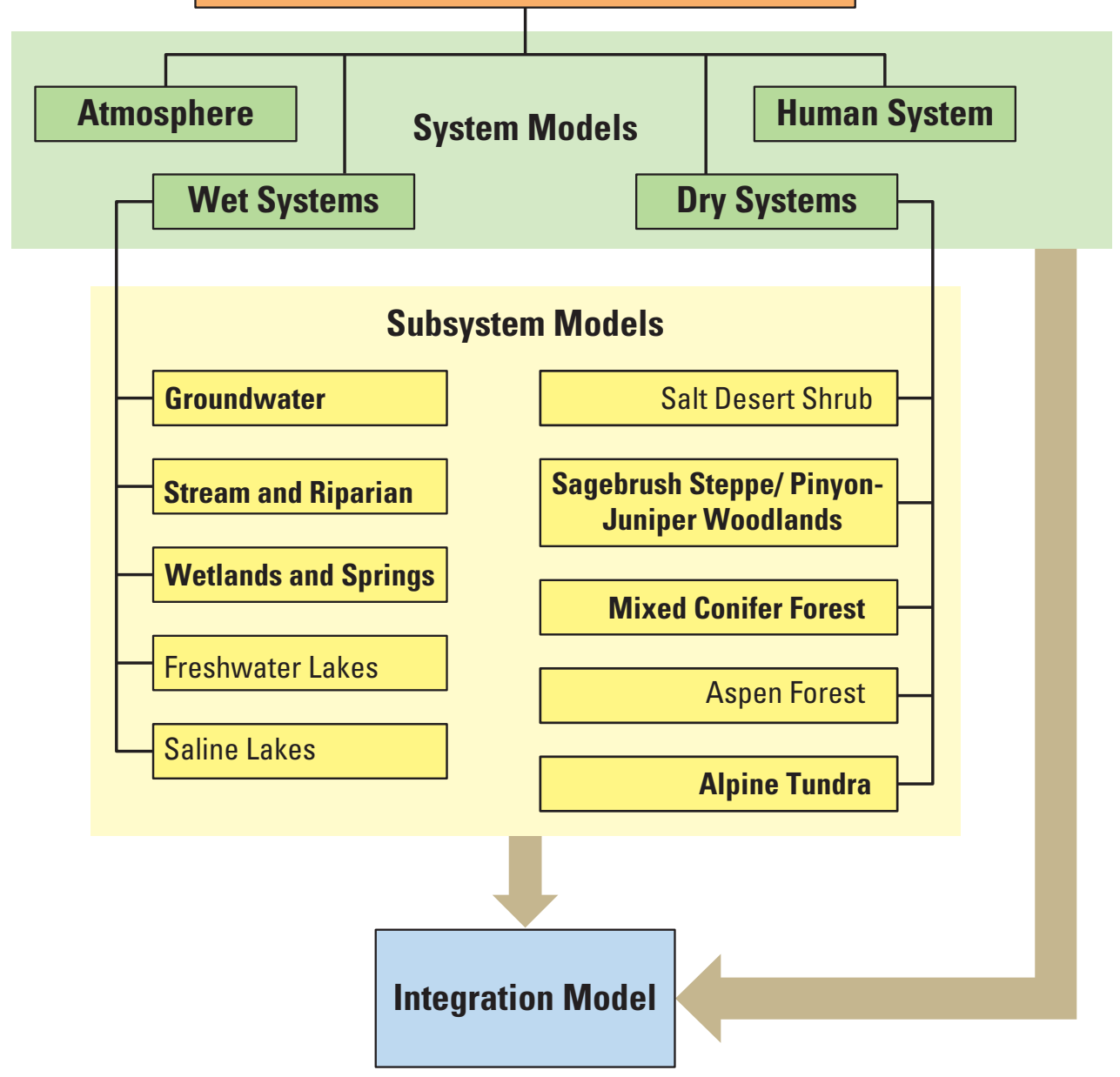

Figure 1.3. Hierarchy of conceptual models used to explain and justify the choice of monitoring questions and indicators. The hierarchy consists of one framework model, four system models, ten subsystems, and one model that integrates the others. Models developed in this report are shown in bold.

among adjacent systems and may de-emphasize aspects of geographic distribution that are important for understanding the subsystem. Each subsystem is modeled using some or all the following model structures: structural control model, state-and-transition model, and mechanistic stressor model (fig. 1.4).

Control Model. Different drivers predominate in each subsystem and each subsystem responds to different suites of drivers in different ways. Control Models describe our understanding of how the subsystems work in response to the inherent variation of drivers by depicting the principal components and processes of the subsystem. These models were built with a focus on the priority drivers.

State-and-Transition Model. Ecological systems are naturally dynamic as they respond to effects of stressors and drivers and to inherent cycles. Ecosystem changes occur along a continuum of time and space, but for the purposes of quantitative modeling, it is helpful to categorize the changes in terms of discrete potential states. Subsystem categories essentially do this for ecosystems in space; state-and-transition models make it possible to illustrate these changes in time. Mechanisms for switching between ecosystem states are provided by the control and stressor models.

Stressor Model. For most Control Models, there is at least one Stressor Model describing how the subsystem is expected to respond to changes induced by drivers that are out of the reference range of variation (stressors). The number of models for each subsystem will depend on how well we understand the subsystem and how adequately one model can describe all relevant stressors (ig. 1.3). 


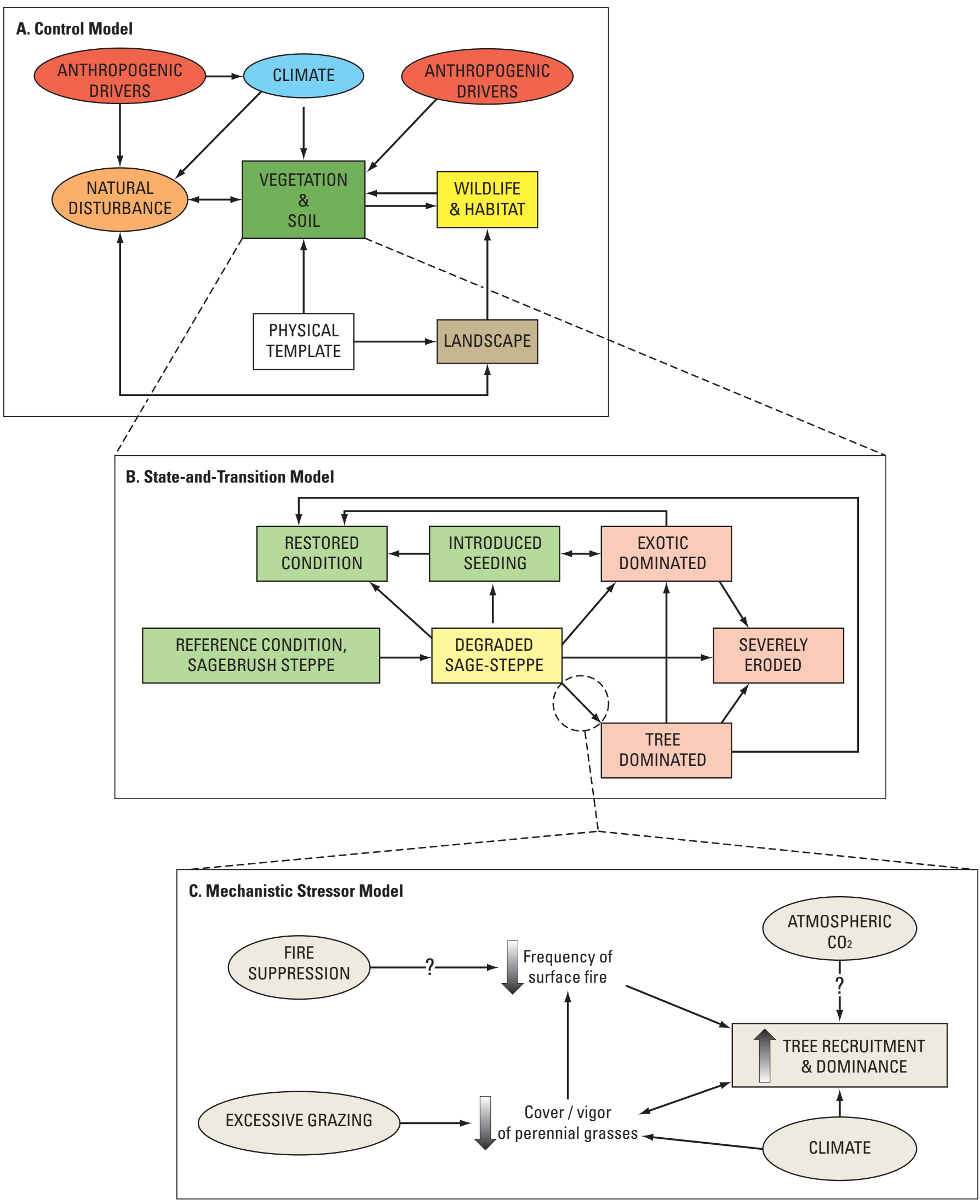

Figure 1.4. Diagrams illustrating relations among control, stressor, and integration models used to describe the structure and dynamics of sagebrush steppe and pinyon-juniper ecosystems in this report. 
Integration Model. We recognize the need to accumulate and integrate the effects of multiple stressors and drivers through time and space. Without doing so, we will miss such effects as those of patch dynamics on wildlife, including the proportional amount and distribution of habitat types, and the soil and climate constraints on ecosystem potential. Integration includes scaling, such as transferring data across the range of spatial scales, between the scales at which data are collected and then applied, and scaling to the appropriate level to address the management questions being asked. Integration provides templates for addressing the multiple temporal scales at which ecosystem processes, drivers, and stressors operate. In Chapter 5, we provide a conceptual model for how we intend to accomplish these integration steps.

One of the modeling challenges faced by the GBILM team was to conceptualize the human dimension. Chapter 2 describes the human dimension at the System Model level along with the other three models (atmosphere, dry systems, and wet systems) that are relevant at this level. Although subsystem models within the dry and wet systems are developed in greater detail, models of the atmospheric and human dimension are not developed in comparable detail. This is not to imply that atmospheric or human-induced effects are not included within control and stressor models; to the contrary, anthropogenic activities and climate are acknowledged as important factors in all Great Basin ecosystems and in all subsystem models. Nevertheless, we recognize that, especially for the human dimension, more needs to be done to effectively integrate an understanding of anthropogenic drivers into the conceptual models to guide the GBILM effort.
This document includes the framework model, system models, several subsystem models for parts of the Dry and Wet Systems, and the Integration Model. With this hierarchical approach, we aim to focus on the effects of our high priority drivers in an efficient manner while acknowledging those parts of the Great Basin we will not be addressing. This model structure forms the basis for quantitative models that can be developed in order to create local, landscape, and regional predictions of ecological change. Similarly, the conceptual and quantitative models can be used to identify, justify, and explain monitoring indicators.

Dividing the landscape into discrete units based on water sources and outlets, dominant plant species, or elevational bands is convenient for conceptual modeling. However, we recognize this approach also can be misleading because systems and their shared ecotones are interdependent at multiple spatial and temporal scales. Thus, the Great Basin more accurately may be characterized as a continuum with constant exchange of materials and energy among systems and subsystems where each species responds uniquely to underlying environmental gradients (Austin and Smith, 1989; Shugart, 1998; Euliss and others, 2004). By using discrete, system-based models, we do not imply that systems lack interaction, nor do we wish to blur important connections within or among systems. Rather our deconstructions in Chapters 2 to $\underline{4}$ attempt to simplify our conceptualization of the ecological continuum and focus system-specific management and monitoring targets. More incisive analyses and holistic reconstructions of Great Basin ecosystems are presented in $\underline{\text { Chapter } 5}$. 
12 Conceptual Ecological Models to Guide Integrated Landscape Monitoring of the Great Basin

This page left intentionally blank 


\title{
Chapter 2: Framework and System Models
}

\author{
By D.M. Miller, S.P. Finn, Andrea Woodward, Alicia Torregrosa, M.E. Miller, D.R. Bedford, and A.M. Brasher
}

\section{Framework Model}

As an organizational tool, we have adopted a simple conceptual framework describing systems and domains of integration encompassed by the GBILM project (fig. 2.1). We represent the patterns and processes of landscape change in the Great Basin as they are reflected by complex interactions and feedbacks among four systems - the atmospheric system, dry and wet ecosystems, and human social systems. To effectively meet science-information needs of Great
Basin decision makers during a period of rapid social and environmental change, landscape-level monitoring requires integration across all these systems and the multiple spatial and temporal scales that span their interactions. This challenge can best be met through the collaborative integration of all USGS disciplines. This conceptual framework model provides a foundation for organizing ideas and communicating with diverse stakeholders. More detailed scale- and processspecific conceptual models at subsystem levels, presented in Chapters 3 and $\underline{4}$, are used to identify monitoring indicators and their ecological underpinnings (Noon, 2003).

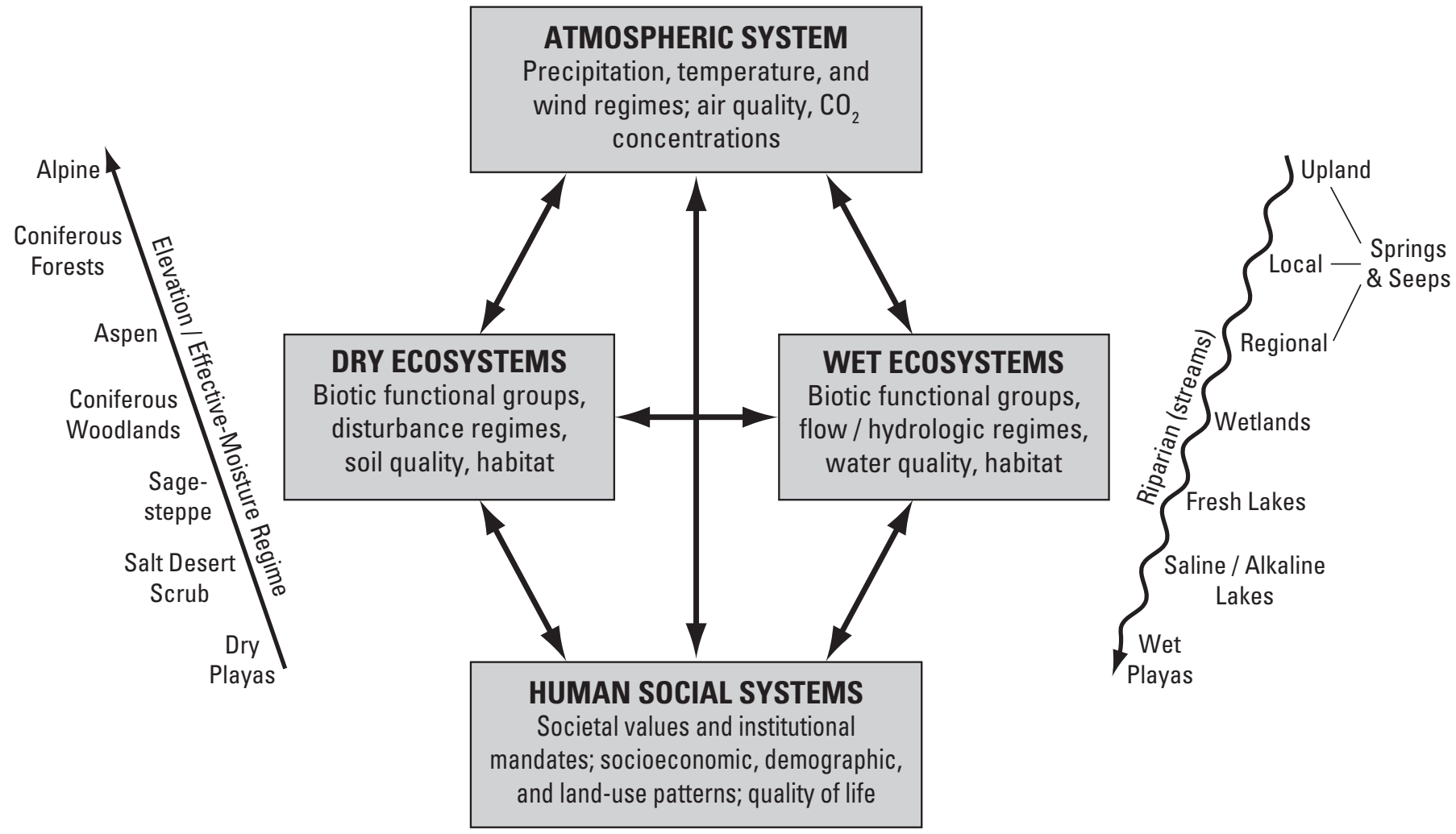

Figure 2.1. Framework model diagram illustrating the overall conceptual framework for the Great Basin project. 
Ecosystems of the Great Basin can be described effectively by the interactions between climate and geology, which creates a template of water availability for biota. The framework model describes the fundamental division of ecosystems based on the fate of climatic resource inputs (precipitation) as runoff and recharge (wet systems) or as infiltrated soil moisture (dry systems). Similar partitioning of water affects surface sediment fluxes, and thus surface stability. The model therefore identifies the amount, persistence, and state (saturated versus unsaturated) of water as a basic structuring driver for Great Basin ecosystems. The ecosystems structured on a broad scale by water are modified in many ways by climatic, orographic, pedeologic, human, and biotic factors that combine with water to control the flow of energy and resources in Great Basin ecosystems.

Within each of these "wet system" and "dry system" divisions, a range of amount and quality of water, including the timing of when it is available, serve to subdivide them into finer categories. We describe the system models in this section and the critical subsystem models in Chapters 3 and $\underline{4}$. A few submodels are developed more fully to illustrate how the models can be used to develop monitoring goals. Remaining subsystem models will be developed in the future.

\section{Atmospheric System Model}

\author{
By D.M. Miller and M.E. Miller
}

\section{Atmospheric System}

The atmospheric system drives weather, whose longterm behavior is described as climate, and it is the system that conducts most mass and energy, including pollution, to and from the Great Basin (fig. 2.2). The atmospheric system therefore is a fundamental driver for the ecosystems of the Great Basin, but it is also highly dynamic at all temporal and spatial scales, making prediction (forecasting) a challenge. The atmosphere receives solar radiation (insolation), a process which is mediated by reflective aerosols and absorbent trace gases before reaching Earth's surface. It also receives water vapor from evaporation at the surface of oceans and the land, where heat exchange influences the vertical temperature gradient in the atmosphere (Bradley, 1985; Monin and Shishkov, 2000). Heat trapped by trace gases further modifies the temperature gradient. Although the atmosphere has low heat capacity, it couples with water bodies of much higher heat capacity, resulting in atmospheric energy being driven primarily by oceans and their circulation patterns. Interactions

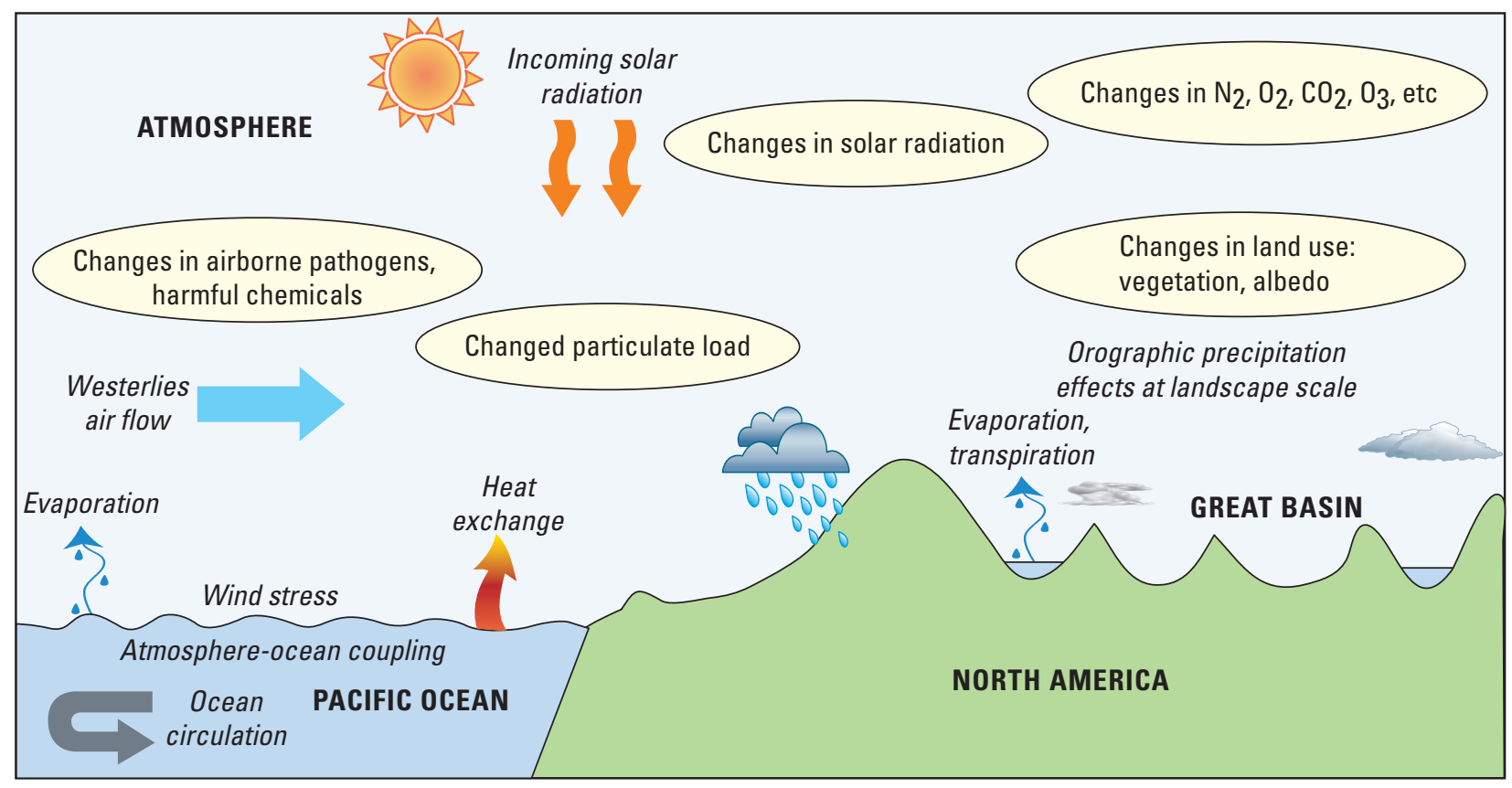

Figure 2.2. Sketch of the atmosphere system, depicting major components and processes, and some of the major changes in the atmospheric system that drive climate variability and change. 
between the atmosphere and land include evaporation, reflected radiation, precipitation, wind, and heat exchange; albedo, plant cover and soil moisture are each important factors that interact with atmospheric systems.

The climate of the Earth as a whole depends on factors that influence the radiation balance, such as atmospheric composition, solar radiation, and volcanic eruptions. Insolation varies with orbital mechanics of many periods, from the familiar daily and annual cycles to millennial and longer periods. Because insolation is greater at the tropics than the poles, latitudinal zones exist within the atmosphere. Vertical zones, defined by temperature, moisture, trace gases, and dynamic properties, also exist. The atmosphere has low inertia, so it quickly responds to changes in ocean temperature. It also stirs the near-surface ocean and deposits evaporated water as rain and snow on land.

A number of trace gases, such as $\mathrm{CO}_{2}$, methane $\left(\mathrm{CH}_{4}\right)$, nitrous oxide $\left(\mathrm{N}_{2} \mathrm{O}\right)$, ozone $\left(\mathrm{O}_{3}\right)$, and chlorofluorocarbons, absorb and emit infrared radiation. These so-called greenhouse gases, along with water vapor, play an essential role in the Earth's energy budget. Because these greenhouse gases absorb the infrared radiation emitted by the Earth and emit infrared radiation upward and downward, they tend to raise the temperature near the Earth's surface.

Components of the atmospheric system described in figure 2.2 and in above paragraphs are linked, and feedback among the components can dampen or amplify perturbations (that is, negative or positive feedbacks). Increased $\mathrm{CO}_{2}$ and other trace gases induce a positive feedback by increasing absorption of terrestrial radiation, which increases atmosphere temperature. Increasing temperature in turn increases release of $\mathrm{CO}_{2}$ by increasing ocean water temperature, creating positive feedback sometimes referred to as the "runaway greenhouse effect." Oceans can dampen perturbations because of their enormous heat capacity. The energy balance in the atmosphere results from a complex interplay of insolation (its reflection by clouds and water, ice, and land surfaces; its absorption by gases, dust, water vapor, and Earth's surface) and radiated heat from the Earth and its absorption by water vapor and gases. The complexity provides many opportunities for non-linear feedback processes, which makes it difficult to simulate atmospheric condition.

\section{Climate Patterns in the Great Basin}

Desert conditions prevail across the Great Basin because the region lies in a rainshadow created by the Sierra Nevada and the Cascade Range of California and Oregon. As air masses leaving the coast meet the mountain ranges they rise and cool, causing atmospheric moisture to condense and precipitate (fig. 2.2). East of the mountains, moisturedeficient air masses descend and warm. The rain and snow that precipitates on the Sierra and Cascades partly enters watersheds that drain into the Great Basin; the Truckee,
Walker, and Owens Rivers are examples. Valley bottoms of the Great Basin receive as little as $100 \mathrm{~mm}$ of annual precipitation on average, whereas a few of the tallest mountains receive more than $1,000 \mathrm{~mm}$.

Climate is influenced at the landscape and local scales by topography. The rainshadow created by Sierra Nevada and Cascade Range, in combination with other regional factors, creates a moisture gradient with drier conditions prevailing in the western part of the Great Basin grading toward somewhat greater total annual precipitation to the east. To the west, precipitation mostly results from regional winter storms originating over the North Pacific Ocean (fig. 2.3). Toward the east, there is increasing likelihood of summer precipitation resulting from localized convective storms originating in subtropical seas (fig. 2.3). During winter, several gradients related to freezing temperatures also are strong determinants of ecosystem condition. In general, winter temperatures decrease with increasing elevation and increasing latitude; average temperature decreases about $6{ }^{\circ} \mathrm{C}$ for every 1,000 $\mathrm{m}$ increase in elevation (Rickleffs, 1990). Thus, effective moisture varies with elevation, producing patterns of plant distributions that were described in a conceptual model more than 100 years ago (Merriam, 1890). The result is a regional mosaic of temperature, precipitation, and seasonality of precipitation that drives plant community patterns (vegetation zones).

Temporal variability in precipitation is attributable to at least three different factors. First among these is random fluctuation (Baldwin, 2003). Random, interannual variability in precipitation tends to increase with decreasing mean annual precipitation; arid environments typically have the greatest relative degree of variability (Noy-Meir, 1973; Ehleringer and others, 1999). A second source of precipitation variability is the El Niño - Southern Oscillation (ENSO) phenomenon that is driven by variations in sea-surface temperatures (SSTs) in the eastern tropical Pacific Ocean (Cayan and others, 1999). ENSO influences the latitudinal position of winter storm tracks across western North America; thus, ENSO effects on winter precipitation in the Great Basin tend to vary latitudinally (Baldwin, 2003). The warm ENSO phase (El Niño) tends to result in relatively warm, dry winters in the northern Great Basin and relatively wet winters in the southern Great Basin. The opposite pattern occurs during the cold ENSO phase ( $\mathrm{La}$ Nina), although ENSO effects in the Great Basin generally are much weaker than in the Pacific Northwest and the Southwest (Baldwin, 2003). There is some evidence that warm-season (April-October) precipitation is above average in the Great Basin during El Niño episodes (Ropelewski and Halpert, 1986). ENSO periodicity ranges from 2 to 7 years (Baldwin, 2003). The third source of variability operates over decadalscale time periods, creating spatial and temporal patterns in precipitation across the conterminous United States related to phenomena known as the Pacific Decadal Oscillation (PDO) and the Atlantic Multidecadal Oscillation (AMO; Mantua and Hare, 2002; McCabe and others, 2004). The AMO is 


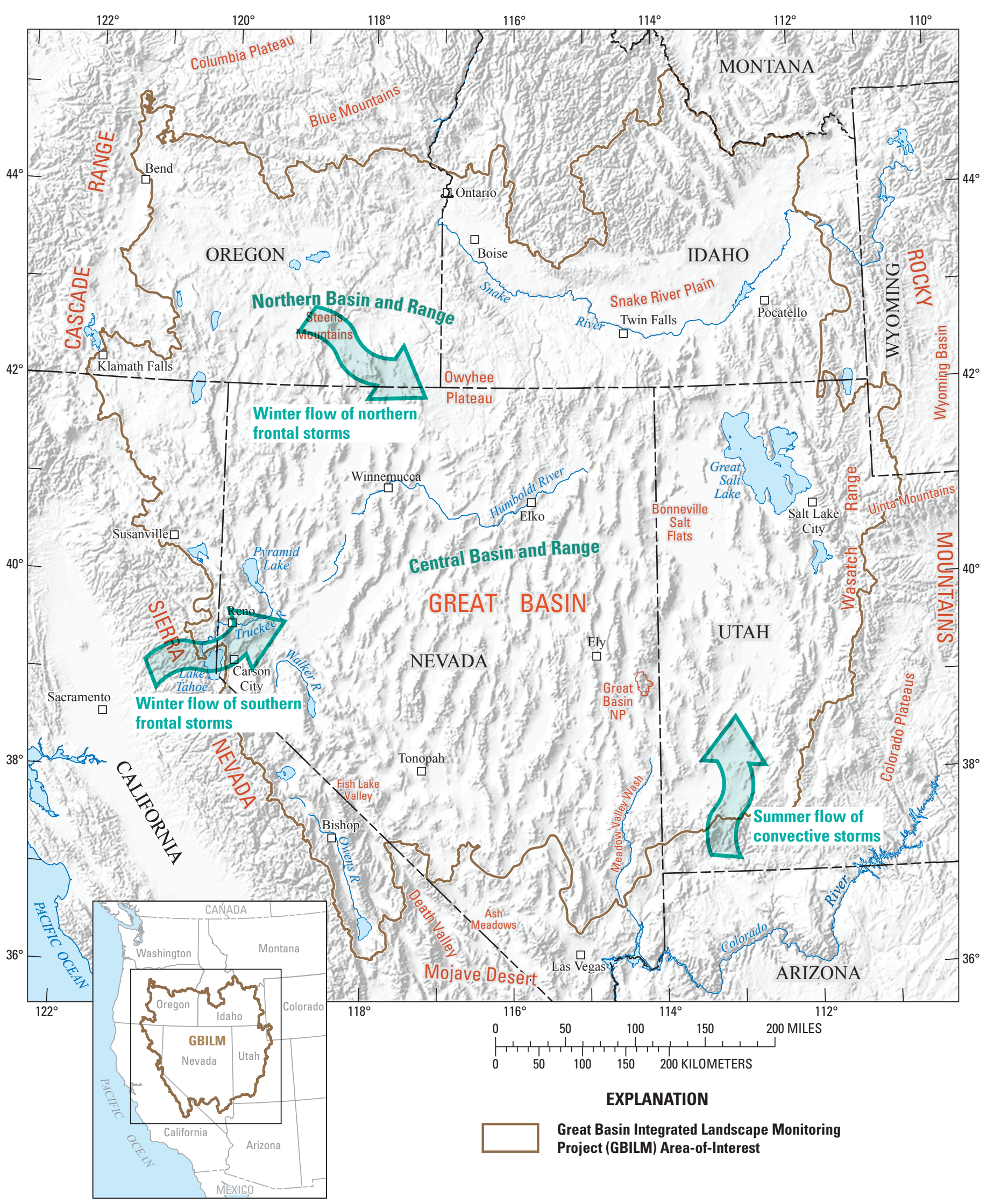

Figure 2.3. Major weather patterns of the Great Basin, showing the distinction between winter storms derived from the Pacific Northwest and those from the southwest, and the locus of enhanced summer convective storm precipitation in the eastern Great Basin. 
an index of SST variations over the North Atlantic Ocean, whereas the PDO reflects SST variations over the North Pacific Ocean (Mantua and Hare, 2002; McCabe and others, 2004). The PDO and AMO are quasiperiodic and may be caused by internal variations in oceanic circulation patterns and associated patterns of heat transport (McCabe and others, 2004). In their analyses of 20th-century data, McCabe and others (2004) determined that 52 percent of the spatial and temporal variance in multidecadal drought frequency across the conterminous United States was attributable to variations in these two SST indexes.

In addition, closed basins such as the Basin and Range physiographic province cause temperature inversions. During nighttime, cold air descends from the surrounding mountains and accumulates in valleys, creating an atmospheric inversion of cold air under warmer air. As a result, nighttime low temperatures commonly increase with increasing elevation above valleys, then decrease toward the tops of mountain ranges. This temperature inversion can affect the elevational distribution of plants, but may disappear toward the northern Great Basin due to strong winter storms that mix the air more thoroughly and disrupt the inversions (Grayson, 1993).

Atmosphere dynamics also control patterns for air quality. Regional storm and air flow from coastal areas partition much of the pollution, haze, and particulate matter from central California, Reno, and Salt Lake City into patterns of wet and dry deposition, reduced visibility, and pollutants that can be monitored on the regional scale. Local variations in these air quality indexes must be monitored with local topography and atmosphere dynamics in mind.

\section{Climate Change and Forecasts}

Climate and weather vary with time scale, for example from changing wind direction in minutes, brief intense storms in hours, to wet winters, to multi-year drought, to multi-decade wet periods, and Little Ice Age cool periods. This climatic variability creates a complex framework for understanding past, current, and future climate-dependent features in the Great Basin, such as plant viability, plant-animal interactions, soil moisture availability, groundwater levels, and persistence of ephemeral and perennial streams. Additionally, short- and long-term human effects of climate change are superimposed on the background of natural climate variability. Examples include heat islands in and near cities, insulating effects of increased $\mathrm{CO}_{2}$ and other gases, and decreased solar radiation by haze. We follow the United Nations Framework Convention on Climate Change by defining climate change as:

"a change of climate which is attributed directly or indirectly to human activity that alters the composition of the global atmosphere and which is in addition to natural climate variability observed over comparable time periods."
"Climate change" thus is attributable to human activities altering the atmospheric composition, and "climate variability" is attributable to natural causes. Climate variability refers to variations in the mean state and other statistics (such as standard deviations, the occurrence of extremes, etc.) of the climate on all temporal and spatial scales beyond that of individual weather events (fig. 2.4). Isolating the effects of climate change from climate variability is an essential, but daunting, requirement for managing Great Basin ecosystems. In addition to climate variability and change, singular events such as volcanic eruptions can cause short-term cooling by adding particulates and gases to the atmosphere, which reflect solar radiation.

Variability and change in climate have effects that we can measure locally, and these effects multiply and combine in complex patterns that potentially affect entire populations, species, and ecosystems at the regional level. Great Basin plant and animal communities can provide useful insight into long-term variations in climate variability. Plants in these communities are adapted to the short-term variability in climate but community composition is, in part, driven by longterm changes. Historical ecology is a particularly important approach to understanding climate variability to which plant communities respond (Swetnam and others, 1999) over time scales of centuries to a few millennia. Climate change has potential to drive many ecosystem processes outside the reference range of variability and Great Basin biota can serve as indicators for such change.

The net effect of human-caused climate change has become quite clear: global warming at an unprecedented rate (Giorgi and others, 2001). Many climate models predict increased temperatures and drier conditions for the Southwestern United States, but the various modeling approaches yield some variation in results. Three categories of models are used: analogs with past conditions, processbased models of climatic conditions with variable inputs of greenhouse gases, and models of the effects of land-use change.

Studies that are based on past analogs and on regional climate models using increased atmospheric $\mathrm{CO}_{2}$ predict that dry conditions will prevail during the next couple of decades. Some predictions stem from observations that the PDO recently appeared to change phase (see http://topex-www.jpl. nasa.gov/science/pdo.html). The previous similar phase of the PDO was accompanied by prolonged dry conditions in the Southwest during the middle 20th century. By extrapolation, some climatologists predict future drought in the Southwest (Swetnam and Betancourt, 1998; Cole and others, 2002). Frequency of flooding, particularly in larger river systems, may decrease, and eolian activity in the Southwest may increase (Schmidt and Webb, 2001). Dynamic models of future climate that simulate physical oceanic and atmospheric systems can link global models with regional climate models to better address topographic complexity of areas such as the Great Basin. Most of these studies evaluated the effect of increased $\mathrm{CO}_{2}$ in the atmosphere, and generally predicted that 


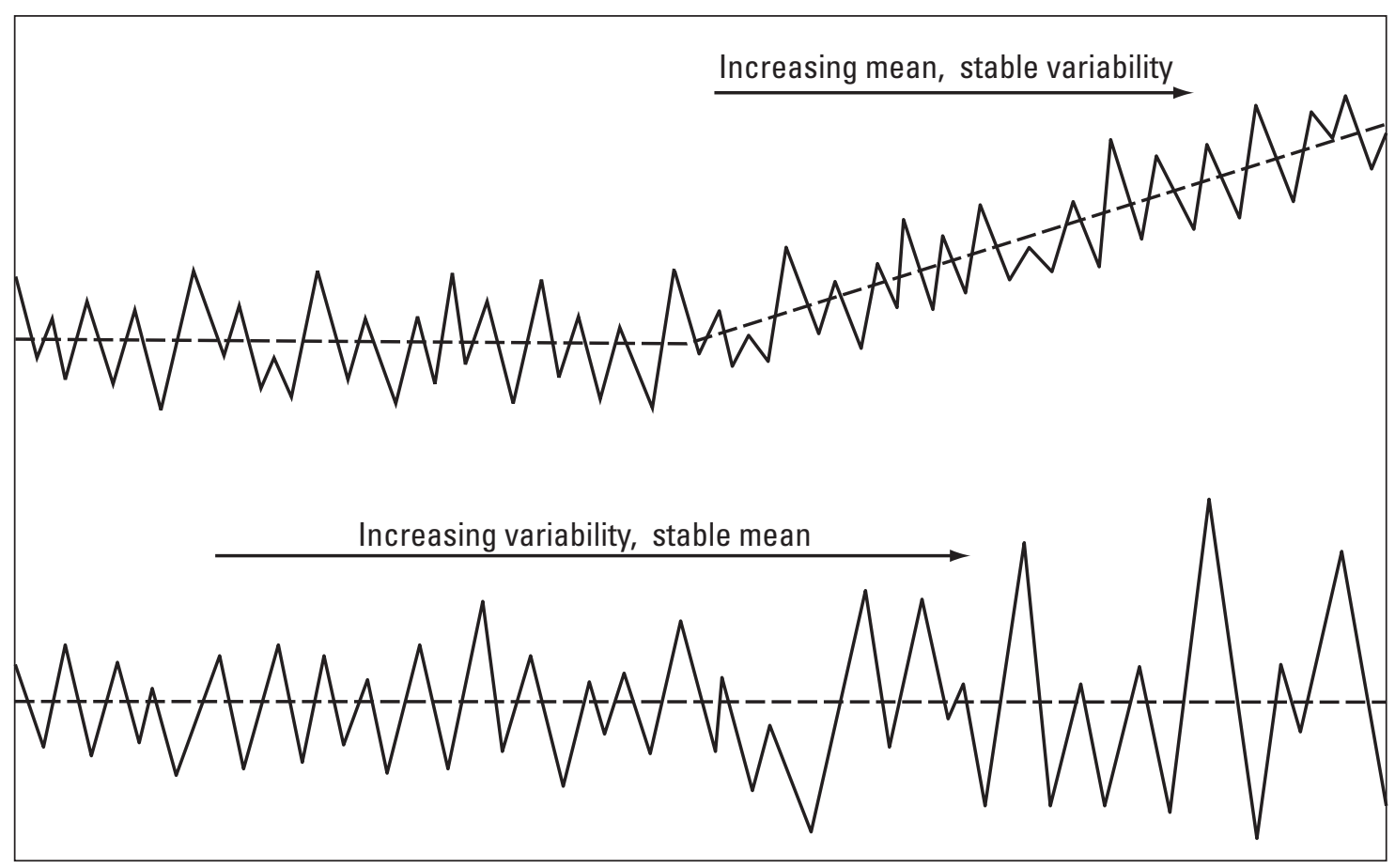

Figure 2.4. Representation of the concepts of variability and mean climate conditions. Climate forecasting models indicate that increases in mean temperature and increases in variability of many climate parameters are likely to occur as a result of anthropogenic alteration of the atmosphere. (Adapted from Bradley, 1985.)

dry conditions will prevail. These models are calibrated by running "hindcasts" to evaluate how well they simulate past climate changes and by comparing them among themselves. The hindcasts tend to show good fidelity for temperature predictions and less fidelity for precipitation predictions. The models provide insight into possible future changes in climate driven by greenhouse gases. A summary of the results indicated by both kinds of models includes:

- More intense, more frequent, and longer heat waves (Meehl and Tebaldi, 2004).

- Increased temperature of stream water (Thompson and others, 1998).

- Increased temperature and decreased precipitation in all seasons (Giorgi and others, 1998b; Thompson and others, 1998).

- Some simulations predicted increased temperature and precipitation (http://www.gcrio.org/ NationalAssessment/index.htm, accessed June 22, 2009).

- Winter warming, reduced snowpack, more extreme winter storms (Leung and others, 2004).

- Winter warming, no change in precipitation, reduced snowpack (Snyder and Sloan, 2005).

- Increased storm intensity (Groisman and others, 2004).
Another approach for examining future climate is to model the effects of land cover change, such as expanded woodlands and decreased urban vegetation cover. One study predicted increased temperature due to modeled changes in land cover (Goddard Space Flight Center, 2004).

Although future climate trends are imperfectly predicted because climate systems are exceedingly complex and future scenarios are speculative, the model studies tend to agree on trends during the future 50 years toward climate that is warmer and probably drier, accompanied by increased storm intensity, increased precipitation variability, less snowpack, and earlier spring melting and runoff. The implications for ecological systems are considerable, underscoring the need for monitoring meteorological conditions as one way to evaluate and anticipate changes in the ecosystem.

\section{Ecosystem Effects}

Climate variability is the primary natural factor driving ecosystem patterns in the Great Basin (fig. 2.1). Precipitation regime is of particular significance because of the importance of precipitation inputs for driving water-limited ecological processes such as primary production, nutrient cycling, and plant reproduction (Noy-Meir, 1973; Comstock and Ehleringer, 1992; Whitford, 2002). Precipitation seasonality 
(that is, timing in relation to the annual cycle of potential evapotranspiration) and form (that is, snow versus rain) are key attributes because they strongly control the partitioning of precipitation among various compartments of the hydrologic budget - evaporation, transpiration, runoff, recharge, and soil-water storage. Because of their effects on hydrologic partitioning, precipitation seasonality and form are major determinants of ecosystem dominance by different vegetative life forms and functional groups (Comstock and Ehleringer, 1992). The prevalence of cool-season precipitation results in effective soil-moisture recharge and relatively reliable growing conditions during spring (Caldwell, 1985; Comstock and Ehleringer, 1992; West and Young, 2000).

Despite being remarkably adapted to the harsh and variable climate conditions of the Great Basin, biota nevertheless are limited by temperature extremes and precipitation timing (that is, seasonality and lengths of drought). Changes in climate created by anthropogenic increases in $\mathrm{CO}_{2}$, particulates, aerosols, and other pollution have the potential to drive many ecosystem processes outside the reference range of variability (the range of variation during a reference period of consideration; see discussion in Chapter 1). If climatic conditions persist outside the reference range, novel ecosystem trajectories can be expected.

Plant and animal population distributions reflect recent climate, dispersal patterns, and a complex integration of past climate changes and disturbances. As a result, time scales of decades to millennia of past conditions are relevant to addressing modern threats to biota.

\section{Summary Points}

The relationship between climate, topography, and Great Basin landscape configuration is relatively well understood within the context of historic ranges of variation. However, many aspects of climatic effects on Great Basin systems are unknown despite a growing understanding of regional climate-change patterns. Global climate models generally are too coarse for local or regional analysis and 'downscaling' techniques (for example, Murphy, 1999) to regionalize climate models are partially limited by the scarcity of climate stations in the Great Basin. Data for many climate stations is of short duration, limiting knowledge over long climate cycles. Additional weather stations would enable more accurate regional and local models and, in turn, improve regional models. Establishing relations between local climate and soil moisture-runoff-recharge balances would significantly advance modeling capabilities for Great Basin ecosystems.

\section{Human-Social System Model}

\author{
By Alicia Torregrosa
}

\section{Introduction}

Humans (Homo sapiens sapiens) comprise a complex agent of change in the Great Basin (fig. 2.5) over multiple spatial and temporal scales. Unlike most other dominant ecosystem species, humans have extensive social constructions that use symbolic language, abstract thinking, and cultural inheritance. These constructs give rise to things such as money, property boundaries, institutions, and conceptual paradigms that in turn produce enduring physical infrastructure such as fences, irrigation canals, farms, factories, cities, roads, power grids, and telecommunication networks.

Human-induced landscape change is a sociocultural phenomenon (fig. 2.6). The way we think about the land governs our interactions with our environment and is shaped by our cultural, socioeconomic, and political systems. Evolving conceptual paradigms, social agreements, institutions, and regulations abet and constrain land ownership and land uses. For example, a social construct of the early 20th century was that fire destroys forests, which generated an institutional policy of fire suppression. The ecosystem response was a shift in vegetation composition and biomass which in many cases led later to uncontrollable fires. As managers and scientists investigated the response, a new understanding of the relationship between fires and forests led to a paradigm shift that fire is a part of healthy ecosystems. This new understanding has translated into management activities that include prescribed burns, thinning of trees within forests to mimic the effects of fire, and legislation such as the 2003 Healthy Forests Restoration Act (fig. 2.7).

From a biophysical perspective, the niche space occupied by humans is unusual compared to other species. Individual humans have the ability to harness the technological capacity built by extensive social systems and alter any ecological niche of the Great Basin. The importance of human impacts to the reproductive success of other species led Alberti and others (2003) to propose a reconceptualization of niche theory that explicitly integrates human effects into a species' realized niche (fig. 2.8). 


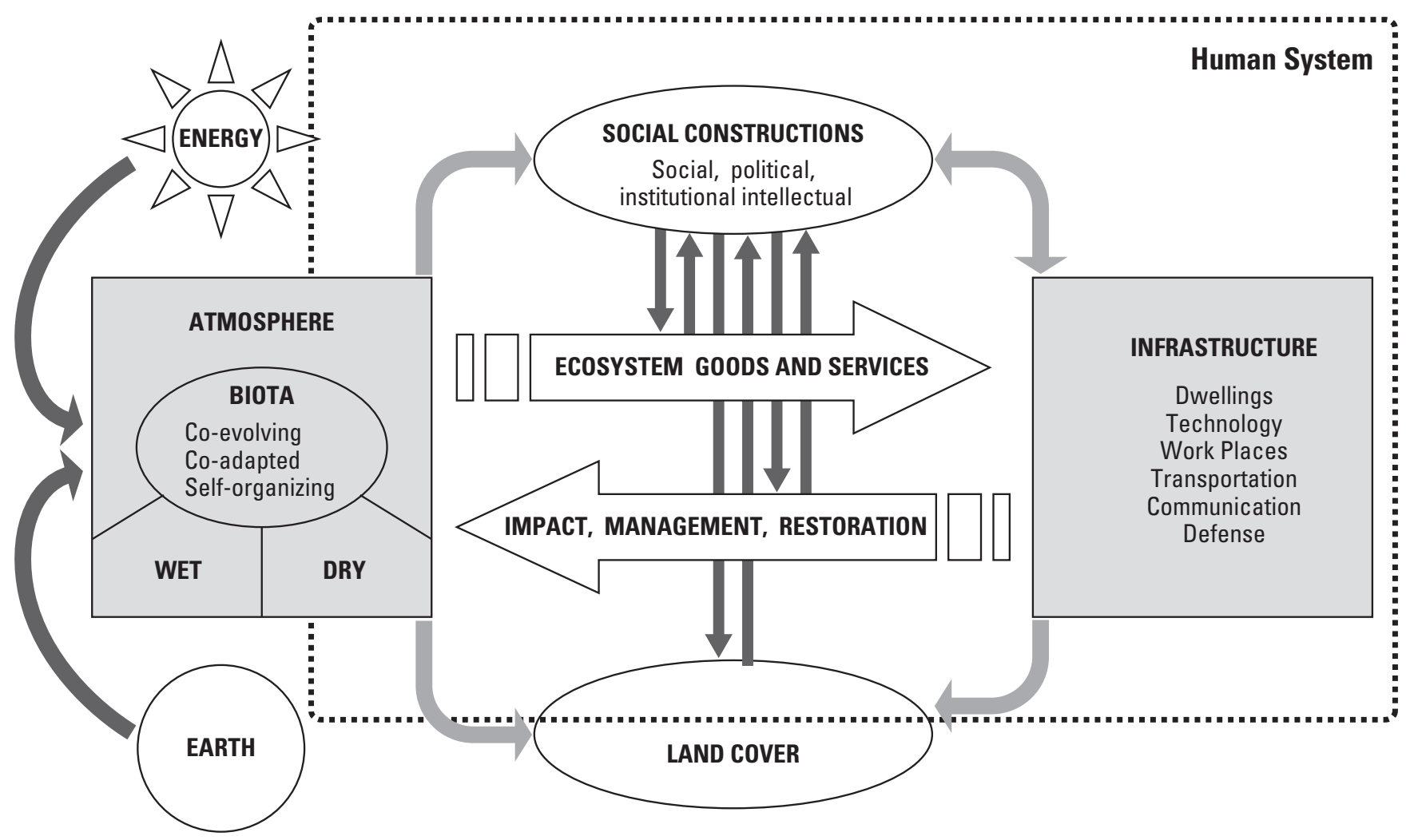

Figure 2.5. Human Systems model. The box on the left represents the Great Basin system at the framework model level (fig. 2.1), conceptualized by the team as an open system driven by solar energy and structured through Earth processes with four main conceptual components: atmosphere, wet and dry systems, and the human system. Homo sapiens sapiens is one of many biological species in the biota of the Great Basin, a system of biogeophysical interactions. An expanded view of the human social system is enclosed by the dashed line. Ecosystems goods and services (top block arrow) stem from social constructions that assign value to the natural capital of the Great Basin used by the human system including minerals, soil fertility, water, water purification, and biomass. Changes on the landscape are driven by social constructions (top oval) and its resultant anthropogenic activities such as the creation of infrastructure (box on the right of diagram), resource management and restoration activities (bottom block arrow). Only some landcover change is a direct result of the human system; therefore, the dashed line does not cover the entire oval on the bottom of the figure representing landcover.

The human impact on the realized niche of species in the Great Basin is a function of the density of the human population and the intensity of anthropogenic impact from activities, such as agriculture, irrigation, infrastructure construction, and resource extraction. In addition to changing the available niche space for locally occurring species, anthropogenic introductions of species from regions outside the Great Basin has resulted in the emergence of new combinations of species. These novel ecosystems (Hobbs and others, 2006) have no known analogs. Understanding the persistence and dynamics of these novel ecosystems is a challenge and deciding how to manage them is even more challenging.

\section{Human Presence in the Great Basin}

People have lived in the Great Basin for millennia but what effect have they had on ecosystems? Evidence exists that aboriginal populations made extensive use of fire to manipulate landscape conditions for resource management (Miller and others, 1995; Vale, 2002; Anderson, 2005). The statistical analysis of lightning fires by Kay (2007) indicates that there were far too few natural incendiary events to account for documented fire frequencies. This information is relevant for understanding dynamics between sage brush steppe and juniper woodlands especially in the context of restoration efforts. 


\section{\begin{tabular}{c|}
\hline SOCIAL \\
CONSTRUCTIONS
\end{tabular}}

Values

Attitudes

Lifestyles

Affiliations

Visions

Goals

Knowledge

\section{LANDSCAPE MODIFYING ACTIVITIES}

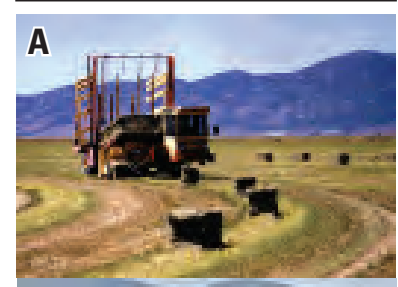

B

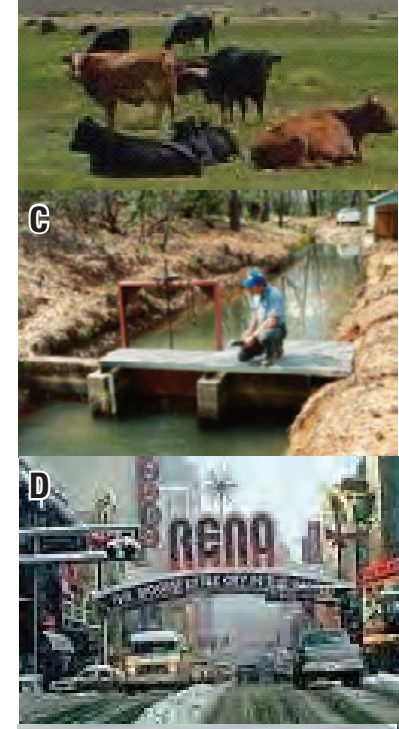

E

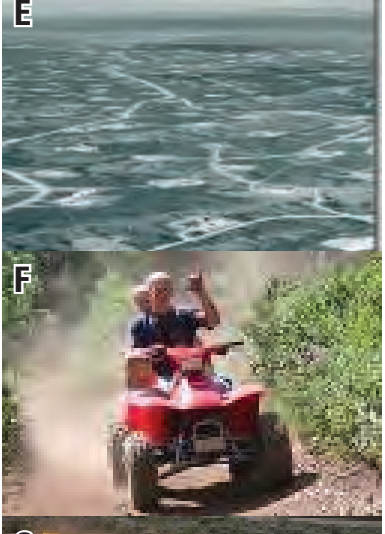

G

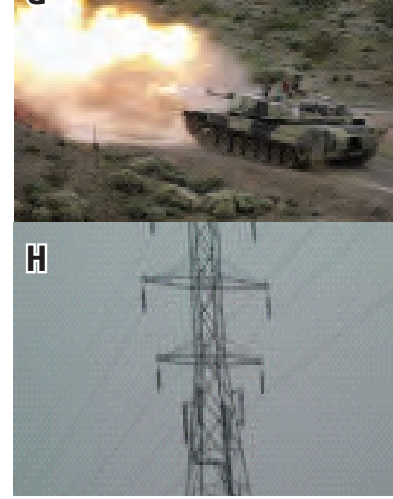

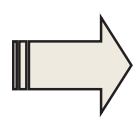

RESULTING HUMAN FOOTPRINT ON THE LANDSCAPE

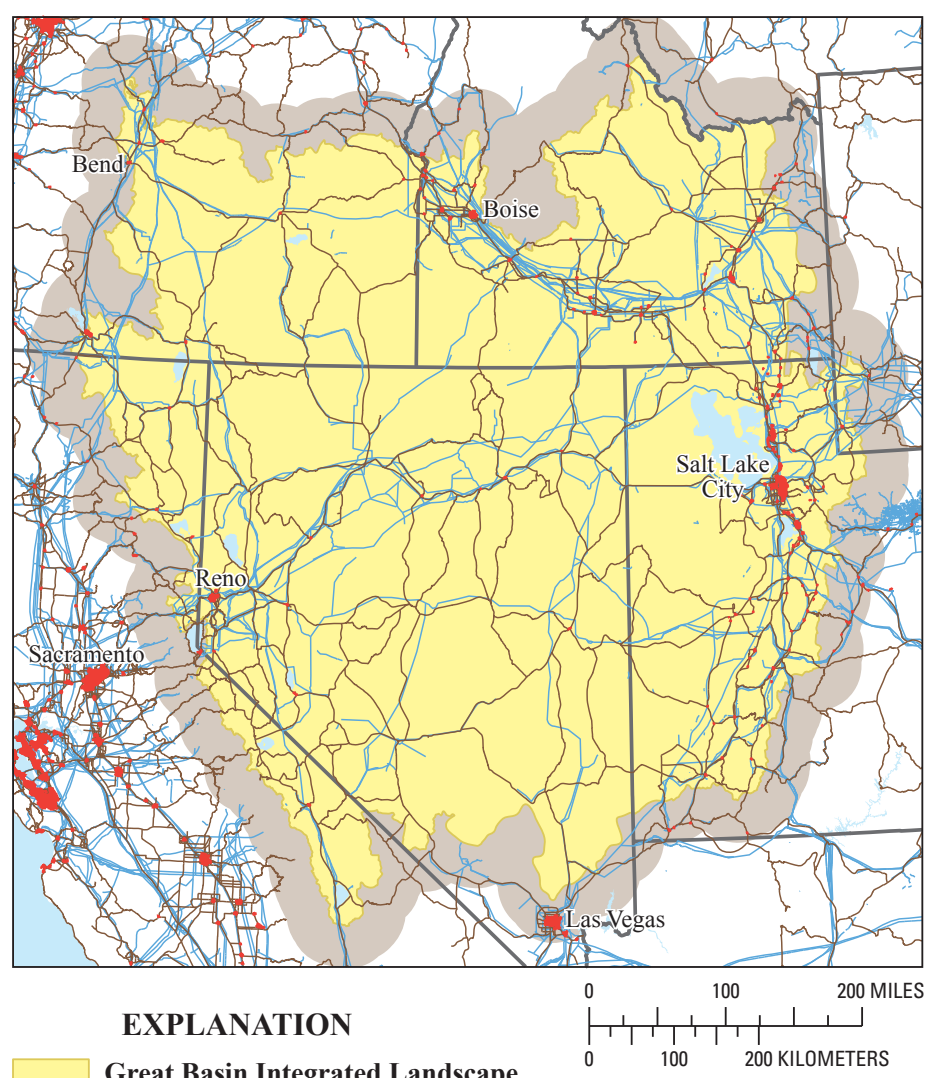
Monitoring Project (GBILM) Area-of-Interest

GBILM with 50-kilometer buffer

Urban areas

Major roads

Powerlines

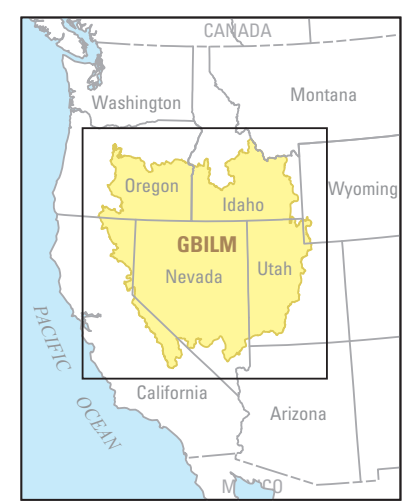

Figure 2.6. Illustrations of landscape change. Human social constructions within culturally defined norms govern interactions with the environment, leading to common landscape modifying activities such as $(A)$ agriculture, $(B)$ livestock production, $(C)$ irrigation, $(D)$ urbanization, $(E)$ oil and gas production, $(F)$ recreational vehicle use, $(G)$ defense training exercises, and $(H)$ energy distribution. These activities can be mapped to quantify the human footprint on the landscape, shown in the third panel by major highways and utility corridors connecting urban centers. 


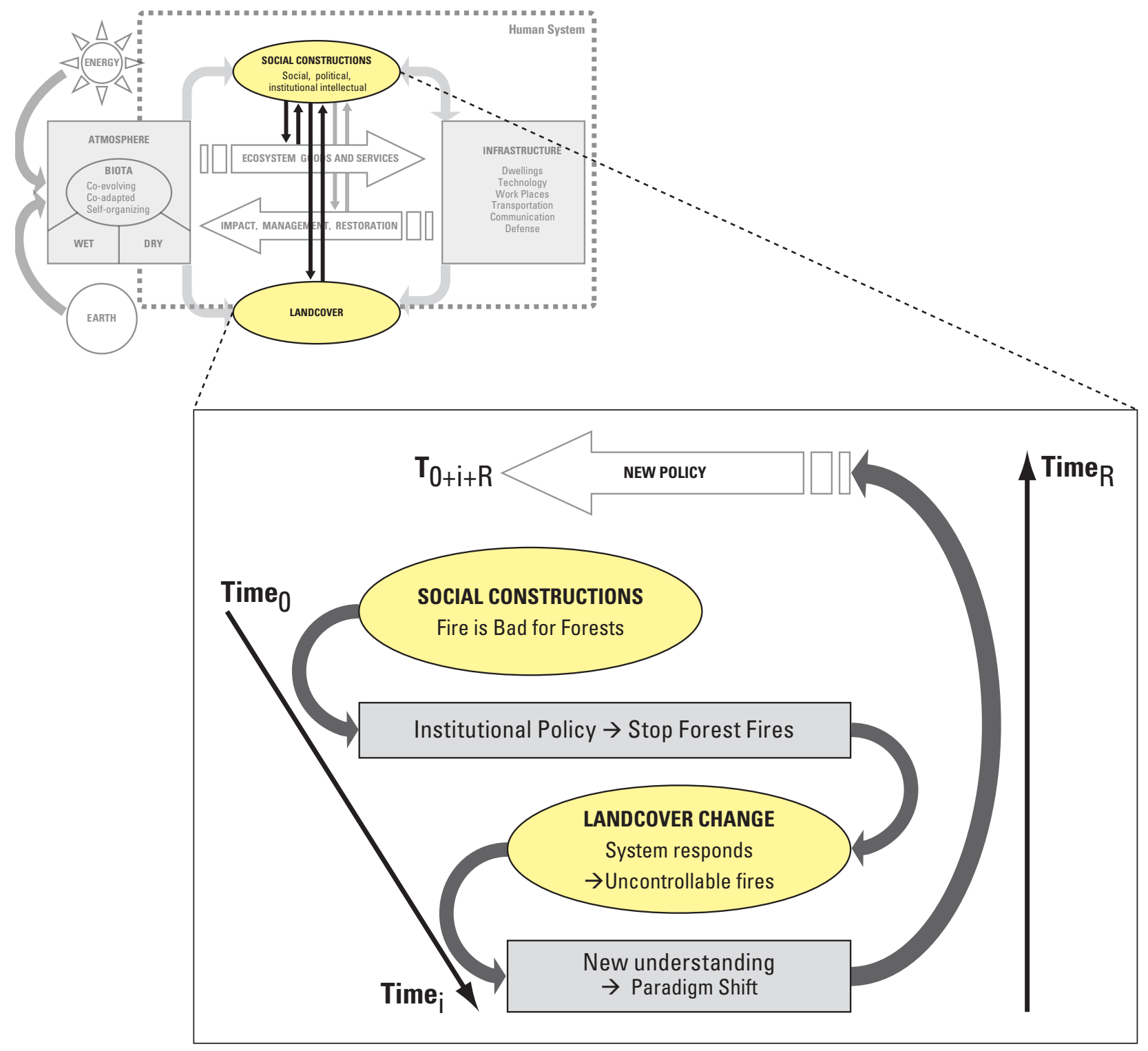

Figure 2.7. Social construction as a Great Basin ecosystem driver. An example of the linkage between social constructions and land cover (highlighted in the upper left box representing fig. 2.5) is the understanding of fire. The temporal dimension of this social model

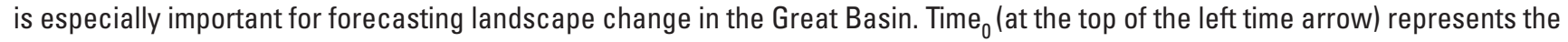
emergence of the social construction. Time $e_{i}$ represents the time interval for (1) managers to implement the first social construction, (2) the ecosystem to respond, and (3) an understanding of the results of fire suppression. Time $e_{R}$ represents how long it takes for new understandings to effect change on the initial policy of forest suppression. Exploring cycles of paradigm shifts can lead to calculations of the total time required to change policy or social thinking $\left(T_{0+1+R}\right)$. This would provide insights on how to realistically calculate Time $_{R}$, which could potentially improve adaptive management efforts. 


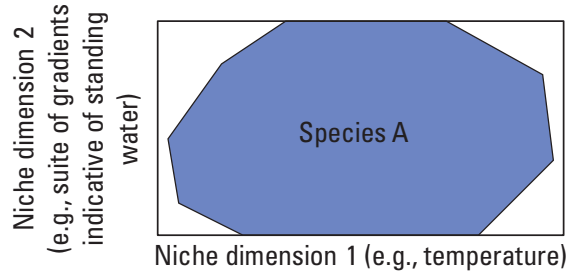

A. Fundamental niche

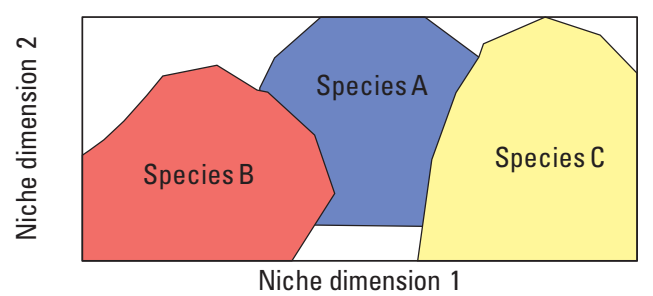

B. Realized niche (without people)

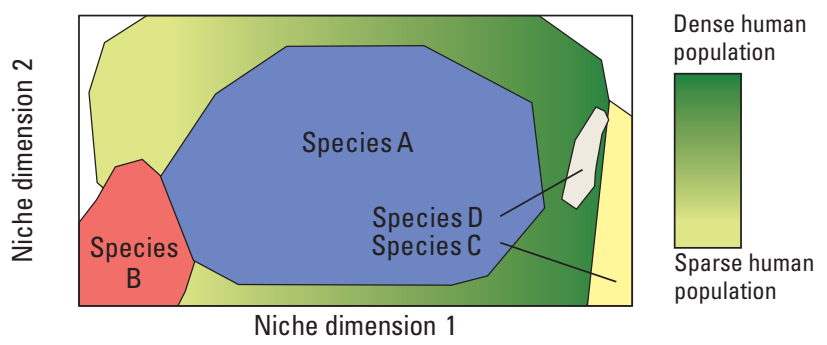

C. Realized niche (with people)

(Reproduced by permission, BioScience, December 2003, v. 53, no. 12, p. 1174, figure 5.)

Figure 2.8. The fundamental niche of a species is n-dimensional, with each environmental gradient relevant to a species represented by one dimension (Hutchinson, 1957). (A) A twodimensional view for species $A$. $(B)$ The Hutchinsonian realized niche is that part of the fundamental niche not preempted by competitors, shown here for three species in the absence of people. (C) A realized niche with human involvement, in which Species A expands to fill its fundamental niche in the presence of people. Species B has a restricted distribution because the human-subsidized species A out-competes it. Species $C$ is intolerant of humans and is confined to a small part of its fundamental niche where people do not exist. Species $D$ is imported by humans into the geographic niche space.

Estimates of Native American populations in the Great Basin prior to the $18^{\text {th }}$ century range from 26,000 (Kroeber, 1937) to almost three times that number (Snipp, 1989).

The current (2008) Great Basin population is estimated at 4.5 million and population is expected to increase 50 percent in the next 10 to 30 years (Population Profile of the United States, accessed June 22, 2009, at http://www.census.gov/ population/www/pop-profile/natproj.html).
This massive population influx of the 20th century (fig. 2.9) was an outgrowth of two pivotal social constructions that strongly shaped land and water patterns in the Great Basin: the 1862 Homestead Act and the 1902 Reclamation Act. The Homestead Act framed modern American views of private and public property and continues to have a major impact on land management, land use, and urban planning. The Reclamation Act facilitated large irrigation and water reclamation projects and represented Congress' rejection of John Wesley Powell's recommendation to develop the arid lands of the West based on a local watershed stewardship model (Stegner, 1992). Water law is critical to the ecosystems of the Great Basin and the precedent-setting act of 1902 continues to dictate the boundaries of water law (Worster, 1985). A recent Supreme Court ruling (Hage versus United States, 2003) reaffirmed Congress' intent for States to define water rights irrespective of greater public benefit. The extraction of water, accomplished through precedent-setting laws, for human needs including agricultural irrigation, is a significant anthropogenic driver within the Great Basin and can be seen as land-cover change at the landscape level (fig. 2.10).

Historical events can be used as markers for the direction and timing associated with the anthropogenic drivers that result in ecosystem change. To better conceptualize these events, we developed timelines that relate to land use patterns and commodity production and water resources (fig. 2.11) with a focus on the Great Basin's wet and dry systems. Although these timelines describe separate historical events, many are interrelated and cumulative. The historic ecological perspective can be important for assessing the cumulative impacts of these events over time as well as to help to shape the dialogue for restoration efforts.

The extent to which human activity alters ecosystem function is not completely understood. For example, urban development alters ecosystem function by eliminating and altering habitats but what effect does exurban development have? Exurban expansion, characterized by large lots of 5-40 acres with a single dwelling per lot, is positively correlated with habitat fragmentation, but the direct and indirect impact of this expansion on biological communities is still a matter of controversy (Hansen and others, 2005; Bock and others, 2008; Milder and others, 2008).

Many anthropogenic impacts have a long temporal footprint, both physically and culturally. Roads and trails last a long time in the arid environments of the Great Basin, affecting drainage and erosion, encouraging off-road use, and facilitating development. Landscape alterations, such as riparian areas altered by livestock grazing, affect the additional ecosystem services that can be expected, which in turn impacts land values. A conceptual model that includes humans as an agent of change can better explore the effects of these changes on ecosystem sustainability. Models can generate exploratory scenarios of the future even in the absence of sufficient data for numerical computational approaches. 


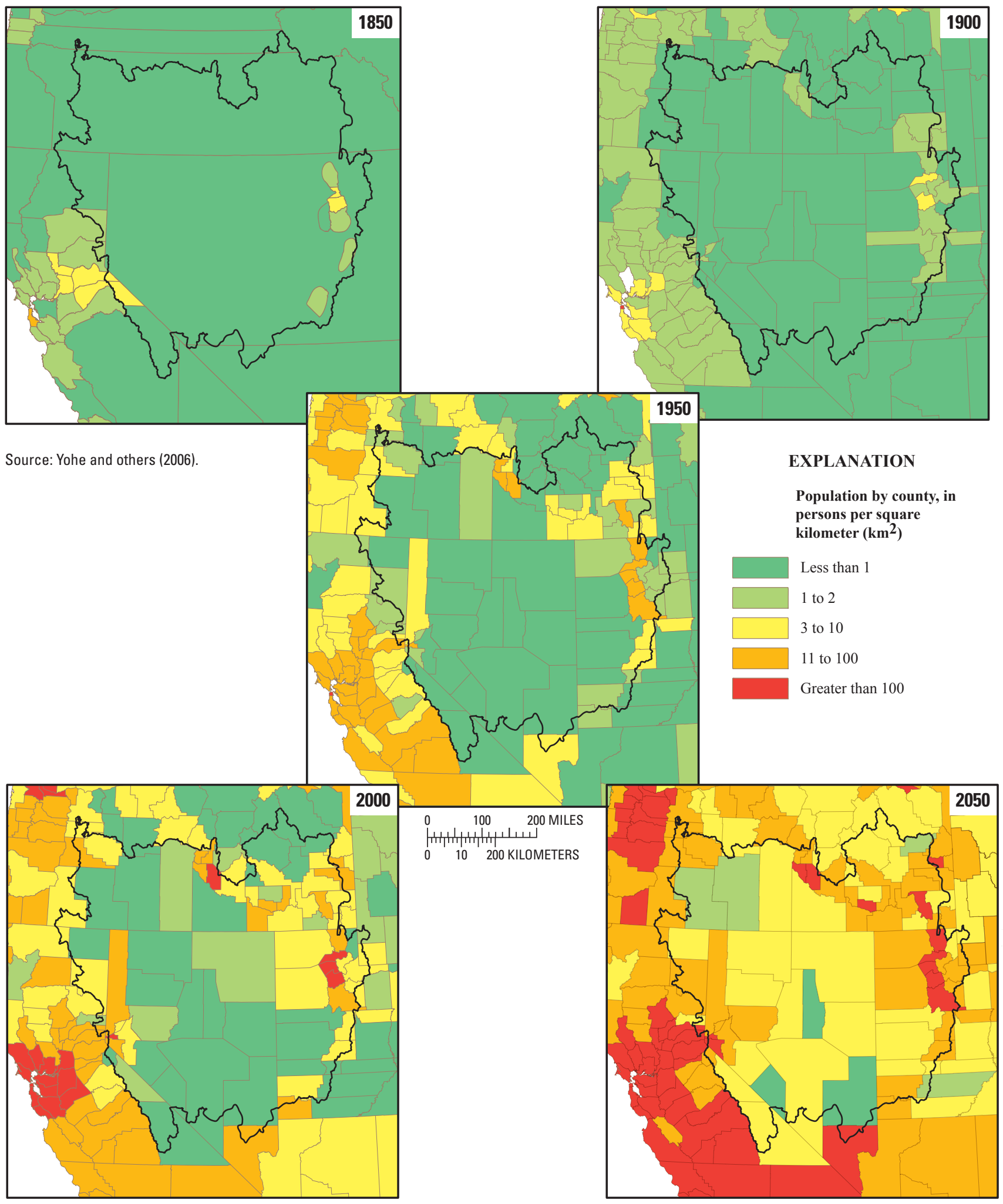

Figure 2.9. Maps showing population change in the Great Basin from 1850 to 2050 by county or territory. The Great Basin study area is shown as a black boundary in each pane. In 1850, most of the Great Basin did not have statehood and comprised portions of the Oregon, Utah, and New Mexico territories. Some county boundaries changed between time periods. Population totals for the study area are: 1850 - 42,374; 1900 - 333,867; 1950—275,000; 2000-3.6 million; 2008, 4.5 million. (Historical source data from the Minnesota Population Center, 2004. Recent population data from the U.S. Census Bureau, Population Division.) 


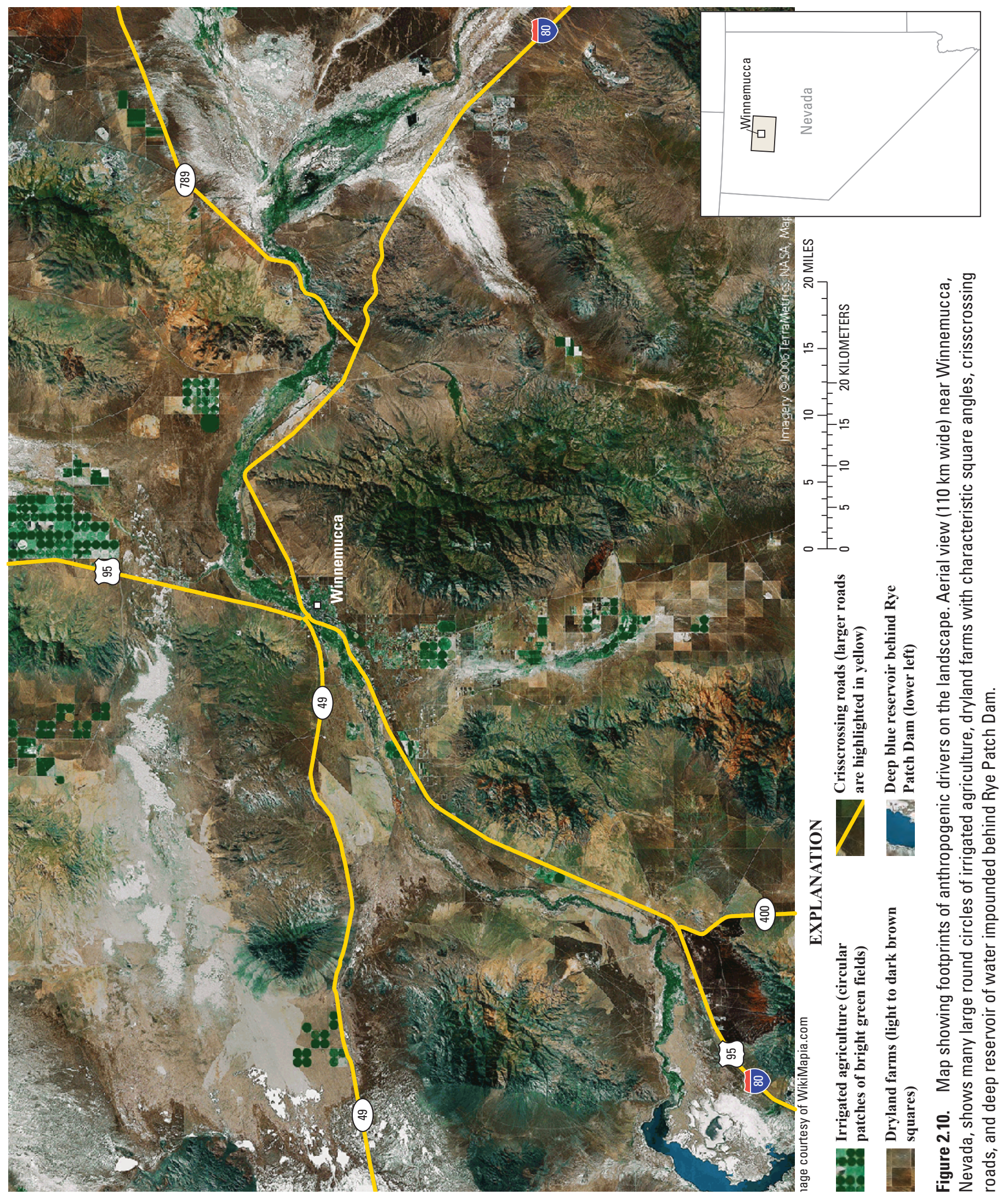




\section{LAND USE AND COMMODITY TIMELINE}

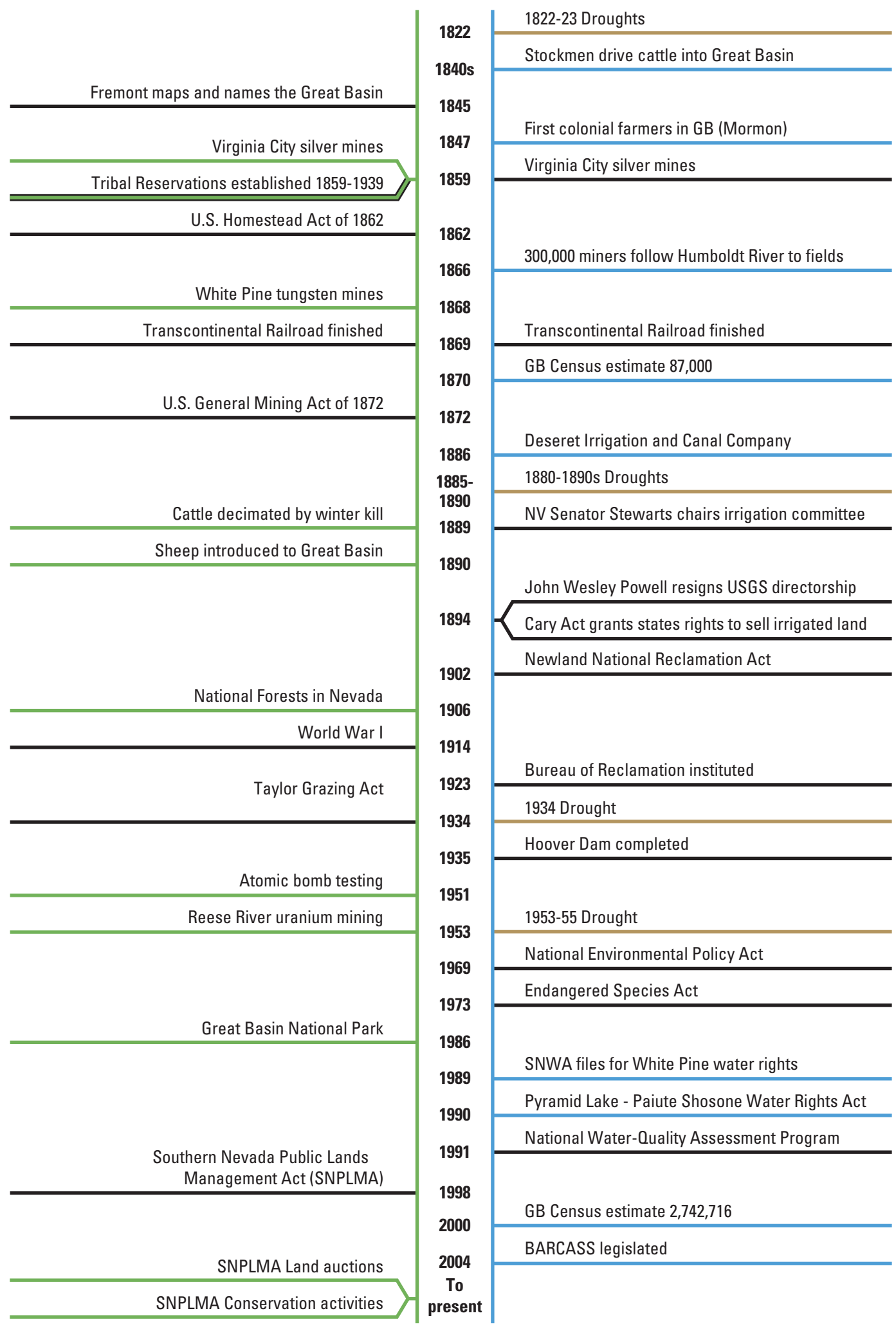

Figure 2.11. Diagrams showing timeline of events that shaped land-use patterns, commodity production, and water use in the Great Basin over the last two centuries. Most events are interwoven. For instance, the severe droughts of the 1880-1890s that led to the introduction of sheep and cheatgrass are pivotal events with increasing impacts on vegetation community structure a century later. Water related needs at the local and regional level resulted in national scale events that continue to affect Great Basin wet systems and water use (Lamm and McCarthy, 1982; Worster, 1985; United States, Western Water Policy Review Advisory Commission, 1998). 


\section{Modeling Approach}

There are several approaches for including human activities within ecosystem models. Early Urban-Long Term Ecological Research approaches modeled ecosystem processes without an explicit human social systems component, adding anthropogenic activities as modifiers to the flows or processes between major components (Grimm and Redman, 2004). This modifier approach is useful for studies that focus on biogeochemical flows or changes in the rates and sources of nutrients, water, pollution, and other materials (Grimm and others, 2004). An alternative approach is to separate human activities into a submodel within the modeling diagram (fig. 2.5). This approach is especially useful for applying a systems science approach to human activities, framing humans as a component of the biotic community interacting with other ecosystem components (Plotkin, 2003; Robbins, 2004), and for modeling social mechanisms that impact ecosystems such as institutional directives and paradigm shifts. The GBILM team advocates this latter approach because of the need to address scientifically and politically difficult issues that are more tractable if framed through explicit attention on human activities.

Conceptualizing a human dimension to ecosystems by using a human systems approach also is useful for scaling between the spatial hierarchy of site $\rightarrow$ region $\rightarrow$ nation and the hierarchical parallel with human social units of individual $\rightarrow$ group $\rightarrow$ institution. All these levels need to be considered if one accepts the premise that understanding regional scale processes must include an understanding of the next larger and next smaller hierarchical system levels (Allen and Starr, 1982; Giampietro, 2003).

Information exchange and collaboration is an important human activity rarely integrated into models of ecosystem management. Collaborative environmental problem solving is increasingly being incorporated into monitoring and adaptive management activities. Collaboration and communication can be measured as an indicator of social capacity and approached as a social driver for problem-solving and decision-making processes. The social structures that are built over time, such as networks, organizations, and institutions (important components of social capital), and the ecosystem impacting processes these structures mediate, are important elements for a model of human social system.

Social capacity is an element in several models such as the Sustainable Rangeland Roundtable (Hamilton and others, 2003; Tanaka and others, 2003; Maczko and others, 2004). Recent examples of collaboration on Great Basin management issues include the Bureau of Land Management (BLM) Final Grazing Rule (http://edocket.access.gpo.gov/2006/pdf/065788.pdf), which improved relations between BLM and permit or lease holders, and the U.S. Fish and Wildlife Service's
Protocol for Evaluating Conservation Effort (http://www. fws.gov/endangered/pdfs/FR/PECE-final.pdf), an important driver for local involvement in sage grouse conservation. The challenge in these examples of social capacity is to conceptualize the links among the social constructions, management objectives, and ecosystem responses.

\section{Summary Points}

The social systems model seeks to link the biophysical environment and the human dimension guided by four principles: (1) humans are part of the Great Basin ecosystem; (2) anthropogenic activities result from social constructionswhich can be changed; (3) models should include only as much as is needed to understand the drivers and forecast landscape change; and (4) building upon existing research and knowledge best creates a model that is useful to the monitoring community.

Unlike the "wet" and "dry" system models that have considerable pre-existing modeling material to draw on, social system research and modeling to forecast ecosystem change at the landscape level is in its infancy. High priority objectives for further model development would include:

- Define and expand on the social system components that link to ecosystem functioning and integrate these with the model.

- Geographically map social structures that are drivers for models.

- Develop an approach to incorporate processes acting at different spatial and temporal rates, extents, or domains into models.

- Explore how a better understanding of social processes could improve a monitoring framework that tracks ecosystem change, such as by tracking policy measures.

Distinguishing direct and indirect human impacts on the Great Basin landscape from those caused by other drivers is one of the greatest challenges, despite improved systems science models (Gunderson, 1999; Warfield, 2006). Progress is being made to integrate social system processes into global systems to generate climate change scenarios, plan sustainable agriculture, and conduct natural hazard vulnerability research (deGroot and others, 2003). Scaling these models down to the region still needs considerable work. Creating a model of ecosystem drivers in the Great Basin also will require addressing non-resolvable uncertainties (Ritchey, 2002) and "complex judgments about the level of abstraction at which to define the problem" (Buckingham Shum, 1997).

Models that can meet these challenges will help resource managers better understand the leverage points within the whole system and perhaps discover unsuspected links between social constructions and ecosystem functioning for improved decision making. 


\section{Dry System Model}

\section{By M.E. Miller and D.M. Miller}

We define dryland ecosystems as those ecosystems that are not dependent on the availability of groundwater or surface water, in contrast with wetland, riparian, and aquatic ecosystems. As a communication tool and to guide the development of more detailed conceptual models, we have adopted a general model for dry ecosystems (fig. 2.12 A) that is patterned after the dryland ecosystem model developed by Miller (2005). A premise of this model is that regional climatic and atmospheric conditions, biotic functional groups, disturbance regimes, and soil resources are key factors that interactively control ecosystem structure, function, and sustainability in relation to human use and other drivers of ecosystem change (Chapin and others, 1996). At the center of the model are soil (including biotic and abiotic components) and vegetation, which are tightly coupled through interactive effects on hydrologic (soil moisture) and biogeochemical (nutrient cycling) processes. Soil, vegetation, and landscape configuration (the spatial arrangement of vegetation patches or ecosystem types) influence habitat quality for wildlife (vertebrates and invertebrates), and wildlife in turn affect soil and vegetation in many ways (fig. 2.12A), including seed dispersal, herbivory, pollination, soil disturbance, and excavation. Elevation and soil-geomorphic setting (including topographic position and soil-profile characteristics) provide the physical template for landscape-level spatial variations in ecosystem structure and function through effects on soil water and nutrient regimes experienced by soil biota and vegetation (Monger and Bestelmeyer, 2006), as well as by temperature controls.

\section{Climate and the Physical Template}

The extreme topographic relief of Great Basin landscapes creates diverse ecosystem patterns and processes due to greater precipitation, lower temperatures, and lower potential evapotranspiration rates at high elevations compared to low elevations. These elevation-dependent factors are responsible for the predictable sequence of dryland ecosystems that is repeated along elevational-moisture gradients from lowland environments to tops of mountains. Along this gradient, major types of upland ecosystems include salt desert scrub, sagebrush steppe, pinyon-juniper woodlands, aspen and conifer forests, and alpine meadows and tundra (figs. 2.12 B, 2.13). Within each of these systems, climate (for example, interannual and decadal variations in precipitation and temperature) and disturbance (for example, fire and insect outbreaks) are major natural drivers of change and temporal variability. The model reflects the fact that vegetation structure and landscape configuration affect and are affected by most types of natural disturbances.

Abiotic factors including regional climate, elevation, and soil-geomorphic setting determine the potential distribution, biotic structure, and dynamics of terrestrial ecosystems through their combined effects on environmental conditions and resources (Jenny, 1980; Stephenson, 1990; Monger and Bestelmeyer, 2006; fig. 2.12). Climate encompasses a dynamic suite of variables that drives temporal patterns of ecosystem change and variability (Bonan, 2002; see Chapter 2, section "Atmospheric System Model" and fig. 2.2). In contrast, the physical template is a relatively static (or inherent) determinant of potential ecosystem and landscape structure and thus provides a useful spatial framework for ecosystem assessment, monitoring, and management (Rowe, 1997; Herrick and others, 2005; Pellant and Lysne, 2005; Herrick and others, 2006). The concept of the physical template encompasses elevation, topography, and soil physical and mineralogical properties controlled by parent material, geomorphic processes, and pedogenic processes (Monger and Bestelmeyer, 2006). Together, these abiotic factors exert strong control over biogeochemical and hydrologic processes that structure ecosystems through effects on soil water and nutrient regimes experienced by soil biota and vegetation. As determinants of potential ecosystem structure and landscape configuration, climate and the physical template are the basis for the ecological site land-type classification system of the U.S. Department of Agriculture (USDA) Natural Resource Conservation Service (NRCS; accessed June 22, 2009, at http://esis.sc.egov.usda.gov/) that serves as a powerful method for describing the landscape.

\section{Soil Resources, Functions, and Quality}

Soils (including soil organic matter and biota) are responsible for the regulation of hydrologic processes and the cycling of mineral nutrients in dryland ecosystems. As the primary medium for storage and delivery of water and nutrients, soils are essential for sustaining the existence and productivity of plant and animal populations. The capacity of a specific kind of soil to perform these functions is described by the concept of soil quality (Karlen and others, 1997; Herrick and others, 2002; Norfleet and others, 2003). Soil functioning and soil quality are determined in part by inherent soil properties such as texture, depth, mineralogy, and profile development that are determined by parent 

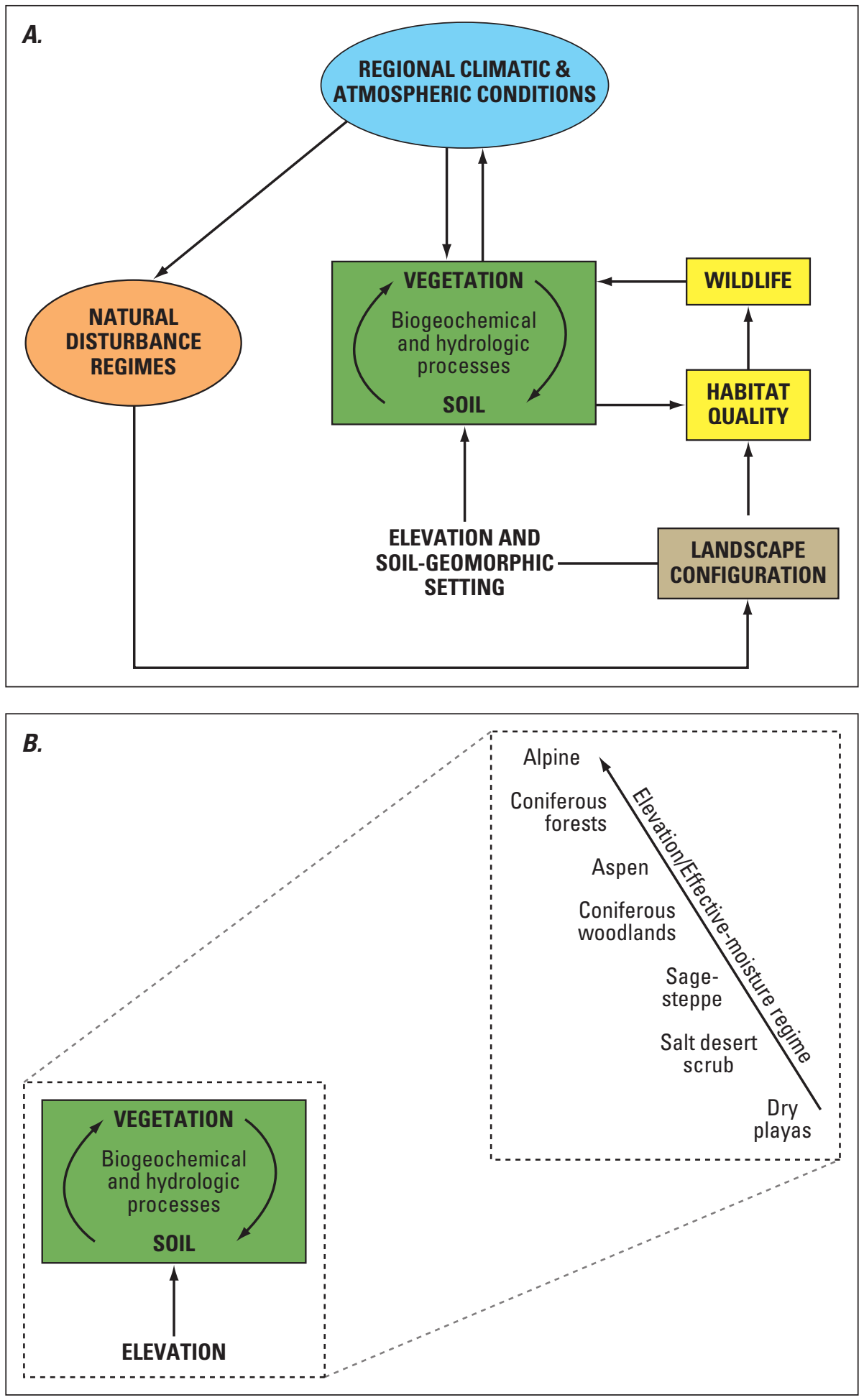

Figure 2.12. Diagrams showing general conceptual model of dry ecosystems. Panel $(A)$ illustrates key structural components (rectangles), major drivers of ecosystem change and temporal variability (ovals), and functional relationships (arrows) (adapted from Miller, 2005). Structural components and drivers are ecological factors that are relatively dynamic at the centennial time scale, thus representing potential foci for long-term monitoring. Elevation and soil-geomorphic setting provide the underlying physical template that determines the potential structure, functioning, and spatial configuration of dry ecosystems in the Great Basin. Panel $(B)$ examines the elevation-vegetation relationship, illustrating the typical zonation of dry ecosystems in the Great Basin along gradients of elevation and effective-moisture regimes. 


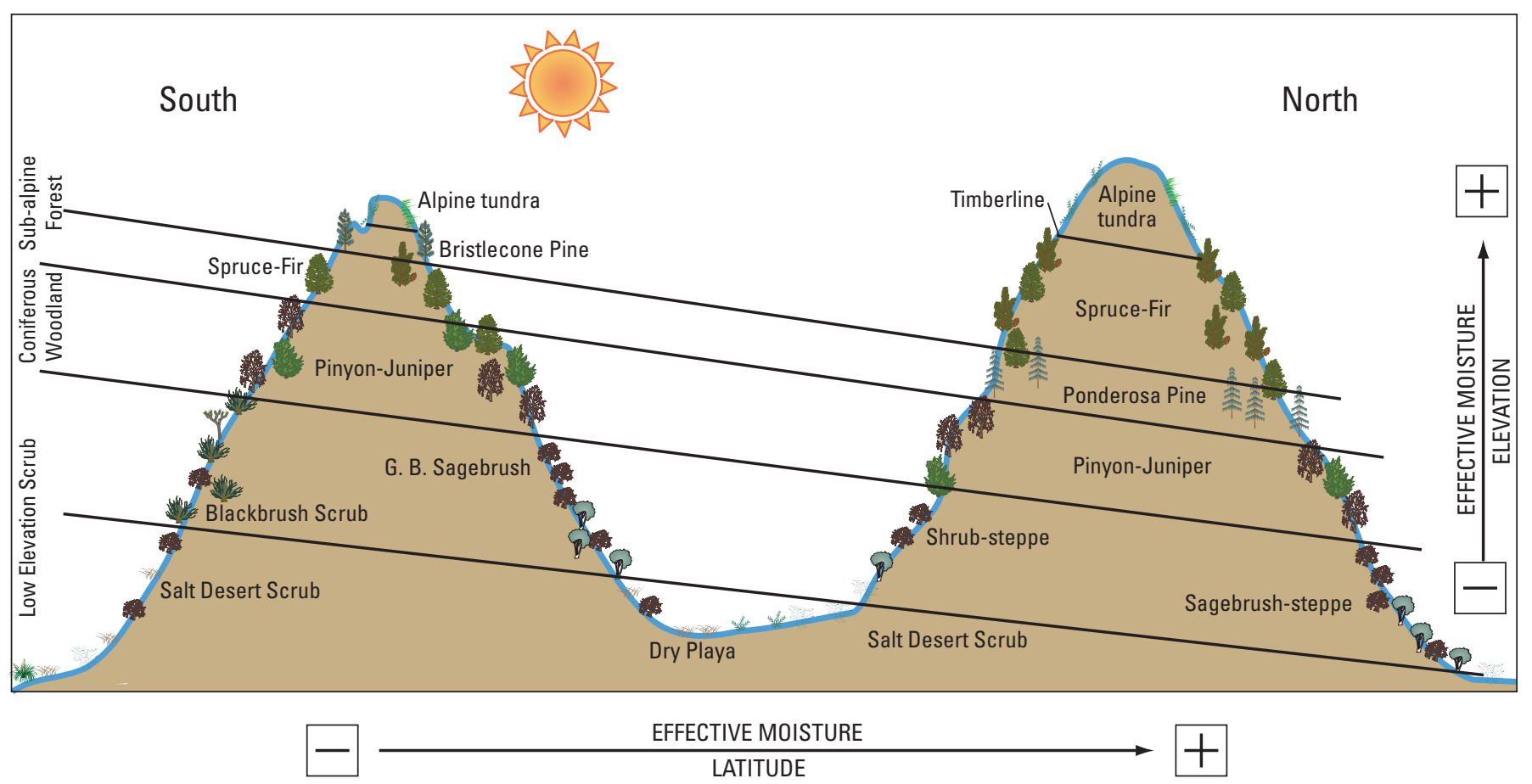

Figure 2.13. Diagram showing vegetation zones in the Great Basin. As latitude increases, vegetation zones descend in elevation due to decreasing temperature and increasing available moisture. Total vegetative cover is generally greater northward and upward, except at very high elevations.

materials, geomorphic processes, and soil formation (elements of the physical template, described above). For example, due to differences in geologic parent materials and past patterns of landscape evolution, Great Basin soils generally are characterized by finer soil texture and higher inherent fertility than soils of adjoining areas such as the Colorado Plateau (Comstock and Ehleringer, 1992). These differences in inherent soil properties have important implications for soil functioning and ecosystem dynamics, and may contribute to the high susceptibility of Great Basin ecosystems to invasion by exotic annual grasses such as Cheatgrass (Bromus tectorum) and Medusahead (Taeniatherum caput-medusae) (Blank and Sforza, 2007; Norton and others, 2007). Although inherent soil properties are considered to be relatively static, soil texture and depth can change and influence ecosystem structure and dynamics over relatively short time scales in response to land uses and management activities that reduce erosion resistance (for example, Neff and others, 2005).

Soil functioning and soil quality also are determined by dynamic soil properties that respond to land use, natural disturbances, and climatic fluctuations. For purposes of ecosystem management and monitoring, dynamic soil properties are particularly important because they represent a key pathway by which land use and management affect the condition of rangeland ecosystems (Seybold and others, 1999; Herrick, 2000; Herrick and others, 2002). Dynamic soil properties that are particularly important for sustaining hydrologic processes, nutrient cycling, plant growth, and erosion resistance include organic matter content, aggregate stability, surface roughness, and structure.

\section{Vegetation Resources and Functions}

Vascular plants perform important functional roles in dryland ecosystems (fig. 2.12). In addition to conducting photosynthesis, aboveground structures of plants protect soils from erosive raindrops, obstruct erosive wind and overland water flow, and thus enhance the capture and retention of soil resources. Litter from plants further reduces the erosive impacts of rainfall on soil surfaces and provides inputs to soil organic matter for soil stabilization and nutrient cycling. Roots stabilize soils, are conduits for resource acquisition and redistribution, and provide organic-matter inputs to soil food webs. Vegetation also provides fuel for fire, as well 
as resources and habitat structure for below-ground and above-ground organisms ranging from fungi and bacteria to birds and large mammals (Wardle, 2002; Whitford, 2002). Carbon storage and the mediation of earth-atmosphere energy and water balances are additional vegetation functions that are increasingly emphasized by researchers investigating processes of global climate change (Breshears and Allen, 2002; Asner and others, 2003). Plants and litter also intercept solar radiation and precipitation, thereby altering microclimatic conditions, mediating spatial and temporal patterns of soil water content and temperature (Breshears and others, 1997), and strongly affecting soil-resource conditions experienced by other organisms. Interspecific competition often is emphasized as an important factor shaping the composition and structure of plant communities (Goldberg, 1990). But facilitation also can be an important process in dryland ecosystems due to ameliorating effects of overstory plants on environmental conditions or herbivory experienced by understory plants (Callaway, 1995; Archer and Bowman, 2002; Brooker and others, 2008).

\section{Wildlife and Habitat Quality}

Vertebrates and invertebrates perform numerous functions in Great Basin dryland ecosystems. Activities related to granivory and herbivory are among those that have the greatest ecosystem-level consequences in dryland ecosystems because of their many effects on vegetation structure and soil processes. Through selective harvesting, consumption, and dispersal by caching and defecation, granivores can have considerable effects on the abundance, composition, and spatial distribution of the seed bank (Whitford, 2002). Over time, these seed-bank effects can be reflected in the composition and spatial structure of plant communities. For example, seed caching by birds and rodents is the primary mechanism of seed dispersal for pinyon pine and thus contributes to the dynamics and distributional patterns of pinyon populations in the Great Basin and elsewhere (Chambers and others, 1999; Chambers, 2001). Seed ingestion and defecation by frugivorous birds and mammals are important for the dynamics and distributional patterns of juniper populations (Chambers and others, 1999).

Large herbivores can affect individual plants directly and indirectly through various mechanisms. Direct impacts include altered physiological function and morphology attributable to defoliation and trampling (Briske, 1991; Briske and Richards,
1994). Defoliation and trampling by large herbivores may indirectly influence plant performance as a consequence of altered microenvironmental conditions, soil properties (Thurow, 1991), mycorrhizal relations (Bethlenfalvay and Dakessian, 1984), competitive relations, and through effects on ecosystem processes such as nutrient cycling and hydrology. Over time, combined direct and indirect impacts can result in altered plant population dynamics (for example, altered rates of reproduction, recruitment, and mortality) and consequent changes in plant community composition, structure, and distribution (Crawley, 1983; Archer and Smeins, 1991; Archer, 1994; Miller and others, 1994; Bich and others, 1995). Because of strong interactions of vegetation with nutrient cycling, hydrologic processes, disturbance regimes, and geomorphic processes, herbivore-driven changes in vegetation structure can have cascading effects on multiple ecosystem processes and properties.

The alteration of competitive relations among defoliated or differentially defoliated plants is one of the most significant ways in which herbivory affects the structure of plant populations and communities (Archer and Smeins, 1991; Briske, 1991; Briske and Richards, 1994; Crawley, 1997). Plants that possess a greater capacity for regrowth following defoliation experience a competitive advantage over defoliated competitors that possess a lesser capacity for regrowth. Similarly, plants that are defoliated less frequently or less intensively experience a competitive advantage relative to plants that are defoliated more frequently or more intensively due to relative differences in accessibility or palatability. For an individual plant, the most significant benefit arising from herbivory is the relative advantage gained when a neighboring plant has been reduced in size and competitive ability by an herbivore (for example, Caldwell and others, 1987). Through time, altered competitive relations eventually can be expressed in population dynamics and plant community structure (Briske, 1991).

Some workers have hypothesized that trampling by large herbivores has beneficial impacts on infiltration (Savory and Parsons, 1980; Savory, 1988). However, hydrologic research has failed to support this hypothesis (Spaeth and others, 1996; Holechek and others, 2000), indicating instead that trampling tends to result in lower infiltration rates, which leads to a deterioration of soil structure (Thurow, 1991). Hydrologic impacts of trampling by large herbivores vary with soil type, soil water content, seasonal climatic conditions, vegetation type, and the magnitude of trampling (Thurow, 1991). 


\section{Wet System Model}

By D.M. Miller, D.R. Bedford, and A.M. Brasher

The wet systems of the Great Basin include springs, wetlands, streams, wet playas, and lakes (fig. 2.14). These components have in common the presence of "free" water on or near the ground surface. Despite their relatively small size and scarce distribution, aquatic and riparian systems play a critical role in the semi-arid Great Basin. As a result of abundant water, these locations constitute biological "hotspots" where biological diversity and abundance are concentrated into relatively small areas. Many drivers of Great Basin ecosystems relate to the wet components of the deserts, indicating their importance. Nearly all aspects of the wet systems are intimately interconnected to the groundwater regime, and groundwater systems control the behavior of wet features including the temporal and spatial availability of surface water and water chemistry. Thus, we feature groundwater systems in the model (fig. 2.15) as a basis for understanding the responses of aquatic and riparian habitat to hydrologic drivers and stressors.

Groundwater systems can be classified as one of three types based on their size: upland, local, and regional (figs. 2.14 and 2.15). Each occupies characteristic parts of the landscape and its underlying geology and these systems interact with each other as well as with surface-water systems. Surface water can result from point discharge of groundwater, such as springs, or broader areas of discharge such as gaining streams, wetlands and wet (discharging) playas. Gradients in groundwater systems often govern many characteristics of surface-water systems, and all are tied to climate parameters, land topography, geology, and human consumptive uses (fig. 2.15). Lakes are relatively rare in the Great Basin, but occur in alpine settings where they are fed by local snowmelt and runoff, and as terminal lakes fed by stream runoff. Groundwater recharge, transport and storage, and discharge are the key characteristics needed for understanding many wet systems features, as well as for predicting impacts.

Stream and streambank (riparian) ecosystems have attributes such as floodplain, channel bank, channel bed, and channel, the composition of which are important to vegetation, aquatic fauna, and wildlife. The function and distribution of these ecosystem components are driven by temporal and spatial variations in water flow discharge over time, commonly summarized as flow regime. These variations occur on many scales, from general longitudinal and lateral changes in discharge, flow, and streambed form, to temporal variations in discharge (for example, floods). Large streams and rivers are also complex networks in which the organization of channels and their tributaries uniquely shape flow characteristics (Benda and others, 2004). The flow regime shapes habitats through bed friction and sediment transport, temperature and light variations, and water chemistry (including nutrient concentrations) (Scott and others, 2005). Streams and riparian zones commonly are used by narrowly endemic and wideranging wildlife (such as mule deer and a wide variety of birds) and can act as corridors for invasive species such as tamarisk.

Springs and seeps can be classified according to a gradient in flow persistence, which is related to groundwater characteristics such as discharge and response time (fig. 2.15). Great Basin spring-fed systems can be broadly characterized as pools, streams, wetlands, wet meadows, and muddy or boggy areas. Extensive wetlands and multiple spring pools form where a regional aquifer system discharges, such as the carbonate aquifer discharging in the southern Great Basin. Springs tend to have smaller pools or marshy areas where associated with local aquifers. Upland aquifers most commonly exhibit wet meadows and small springs. Due in part to their isolation, springs are habitat for rare and endemic species, such as species of springsnails, frogs, and fish. Wet playas and alkaline seeps may occur low in desert basins. Orographic precipitation and snowmelt feed streams that flow off high peaks, forming small alpine lakes, disappearing into fissures in carbonate rocks and valley fill sediments along the outflowing streams.

Spring-fed wetlands form a wide variety of important riparian and aquatic habitat (Stevens and Springer, 2004). Biological diversity generally is correlated with the size of the wet area - brook length for flowing streams and size of pools - which are in turn a function of spring discharge. Groundwater discharge at springs is thus a key indicator of riparian biologic health and integrity. The factors influencing groundwater discharge at landscape levels primarily are climate and partitioning between recharge and runoff. More locally, discharge is affected by groundwater extraction, distribution of contaminants, and disturbance-especially paving and diversion — of recharge zones. Because streams in arid lands are intimately connected to groundwater, they are affected by the same drivers and stressors, but also are susceptible to surface diversions and contamination. Springfed wetlands and stream systems are affected by invasive plants [for example, tamarisk (Tamarix ramosissima)] and animals [for example, mosquitofish (Gambusia affinis) and Asian tapeworm (Bothriocephalus acheilognathi)], as well as by direct human disturbance and fire. Many of the drivers for wet systems are important for endemic and at-risk populations of fish, amphibians, and riparian bird and aquatic macroinvertebrate communities. 


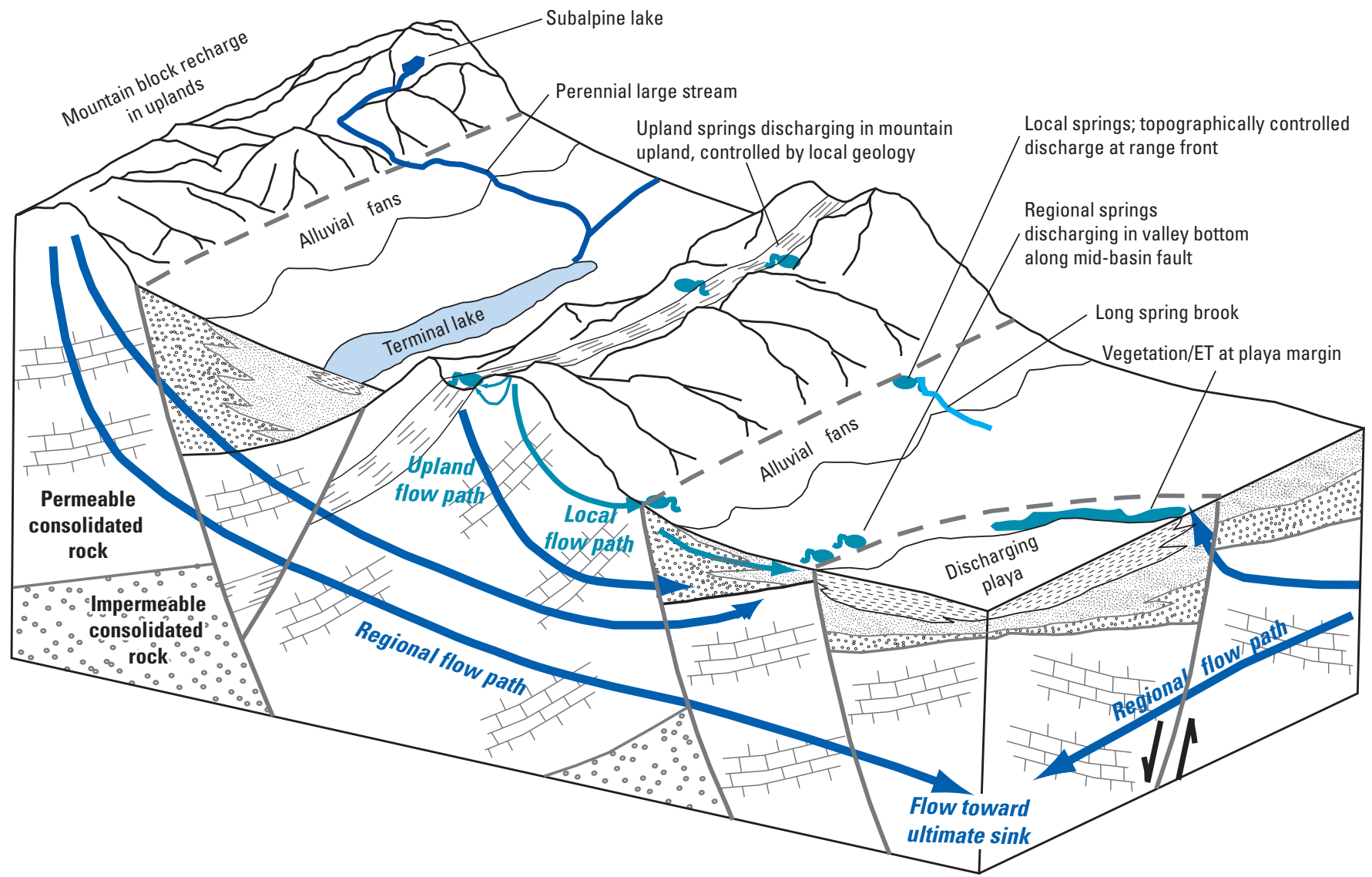

Figure 2.14. Block diagram showing flow systems associated with groundwater and surface water parts of the wet systems, illustrating how the systems are connected between ground and surface in some cases and compartmentalized in other cases between basins and parts of the highlands.

\section{Subsystem Models}

Control models present mechanistic views of the operation of subsystems within the wet and dry systems that are useful for developing monitoring methods for the key drivers. The models describe the linkages among system components and how processes will change with influence by drivers, and provide a basis for developing stressor models. Chapters 3 and $\underline{4}$ present control and stressor models for highest priority ecosystems and those with the greatest knowledge levels. For clarity of communication and for eventual quantitative models of these systems, it is helpful to include state-and-transition models, as exemplified by the sagebrush steppe and pinyon-juniper models. Subsystem models presented in Chapters 3 and $\underline{4}$ vary widely in level of detail, which reflects a combination of: (1) resources with GBILM for developing the model, (2) status of knowledge, and (3) importance of the subsystem for Great Basin land managers. 


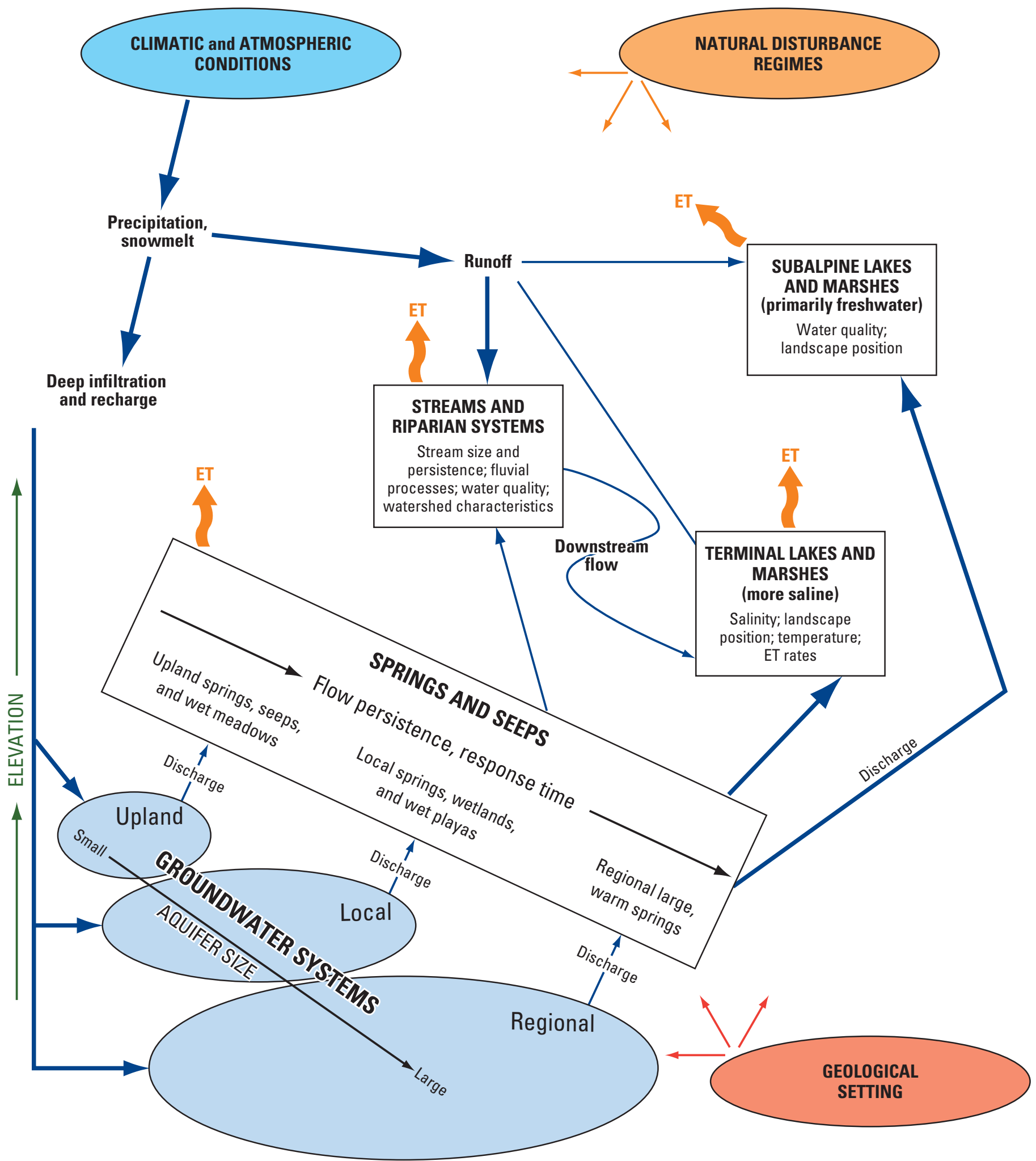

Figure 2.15. Diagram showing wet systems model. Groundwater is a major driver for many wet systems of the Great Basin, thus recharge for upland, local, and regional aquifers is a key process. Important variables to monitor are noted for main surface-water systems. 


\title{
Chapter 3: Subsystem Models for the Dry System
}

\author{
By M.E. Miller, S.P. Finn, and D.M. Miller
}

As described in the Dry System model, we partitioned the Great Basin dry system into vegetation zones for the creation of subsystem models to capture the importance of plant communities for ecosystem function. The subsystem models are ordered from low elevation, relatively dry zones to high elevation zones that are colder and have more moisture (figs. 1.3 and 2.13). We acknowledge that the following subsystem models are uneven in level of detail. We did not undertake a Salt Desert Scrub model due to time constraints and lesser management concern regarding this system. Models for Sagebrush Steppe and Pinyon-Juniper ecosystems are fairly detailed due to the broad extent of these biomes in the Great Basin and implications for many landscape-level land-management issues. The Conifer Forest models are less detailed partly because of lack of information. Aspen forests, although decreasing rapidly in parts of the Great Basin, were not modeled at this time. The alpine tundra has received relatively little study in the Great Basin, and the model is correspondingly brief.

\section{Salt Desert Scrub}

Salt desert scrub, or alkali desert scrub, vegetation consists of xerophytic and halophytic species such as shadscale (Atriplex confertifolia) and winterfat (Krascheninnikovia lanata), most of which are members of the Chenopodiaceae (West and Young, 2000). It is widespread on desert floors of Great Basin valleys, where it commonly grades downslope into phreatophytic communities dominated by species such as greasewood (Sarcobatus vermiculatus) or to dry playas, and upslope into sagebrush steppe ecosystems dominated by varieties of big sagebrush (Artemisia tridentata). Developing a specific set of conceptual models for this system is beyond the scope of this study.

\section{Sagebrush Steppe and Pinyon-Juniper Ecosystems}

\section{By M.E. Miller}

This section provides an overview of the structure, function, and dynamics of sagebrush steppe and pinyon-juniper ecosystems in the Great Basin. Many of the following generalizations about dryland structure and function also apply to salt desert scrub as well as to dryland ecosystems characteristic of the nearby Colorado Plateau (Miller, 2005) and Mojave Desert (Belnap and others, 2008). However, specific patterns of ecosystem dynamics vary widely among dryland ecosystems within and among the dryland regions of North America due to differences in environmental setting (climate and soil-geomorphic properties), structural and functional attributes of component species, and types and degrees of human land-use activities.

\section{Distribution and Management Significance}

As defined for this project, the Great Basin covers a spatial extent of about 61.7 million ha. Within this region, the three dominant types of low-elevation dryland ecosystems are salt desert scrub (10.4 million ha, or 17.0 percent of the region), sagebrush steppe (28.2 million ha, or 46.1 percent), and pinyon-juniper (coniferous) woodlands ( 8.1 million ha, or 13.2 percent). (Estimated spatial coverages are based on revisions to Küchler's [1970] map of potential natural vegetation types [U.S. Department of Agriculture, Forest Service, 2001] and do not consider land-cover alterations attributable to human land use.) In Great Basin landscapes, these three ecosystems typically are arrayed sequentially along a gradient of increasing soil moisture availability as controlled by soil properties, elevation, and geomorphic setting (see figs. 2.1 and 2.13; West and Young, 2000). Typical elevations for these systems range from $1,200 \mathrm{~m}$ in basins to $2,100 \mathrm{~m}$ on piedmont alluvial fans and mountain slopes. Pinyon-juniper and sagebrush steppe ecosystems occur as high as $2,500 \mathrm{~m}$ on south-facing slopes. These are the two primary types of upland ecosystems managed by the Bureau of Land Management (BLM) throughout the Great Basin; extensive areas dominated by pinyon-juniper woodlands also are managed by the U.S. Department of Agriculture (USDA) Forest Service. These dryland ecosystems support a tremendous diversity of plants, animals, and other organisms (for example, Rosentreter and Belnap, 2003; Welch, 2005). In addition, they provide livestock forage, watershed services, and wildland recreational opportunities. Pinyon-juniper ecosystems also provide substantial fuel-wood resources to local communities. Because of their spatial extent and the breadth of ecosystem services they provide, they have great significance for management and society. 


\section{Ecosystem Components and Processes}

Climate and the Physical Template - Determinants of Site Potential

Dynamic and relatively static abiotic factors including regional climate, elevation, and soil-geomorphic setting determine the potential distribution, biotic structure, and dynamics of terrestrial ecosystems through their combined effects on environmental conditions and resources (Jenny, 1980; Stephenson, 1990; Monger and Bestelmeyer, 2006; fig. 3.1). Climate was described in Chapter 2. Great Basin landscapes are characterized by a diversity of parent materials, landforms, and soils that contribute to the physical template and thus the characteristics of sagebrush steppe and pinyonjuniper ecosystems. Geologic parent materials range from Tertiary basalt and andesite on volcanic plateaus to Mesozoic and Paleozoic igneous rocks and marine and continental sedimentary rocks in uplifted fault-block mountain ranges (Hunt, 1974; U.S. Department of Agriculture, Natural Resources Conservation Service, 2006). Piedmont slopes are

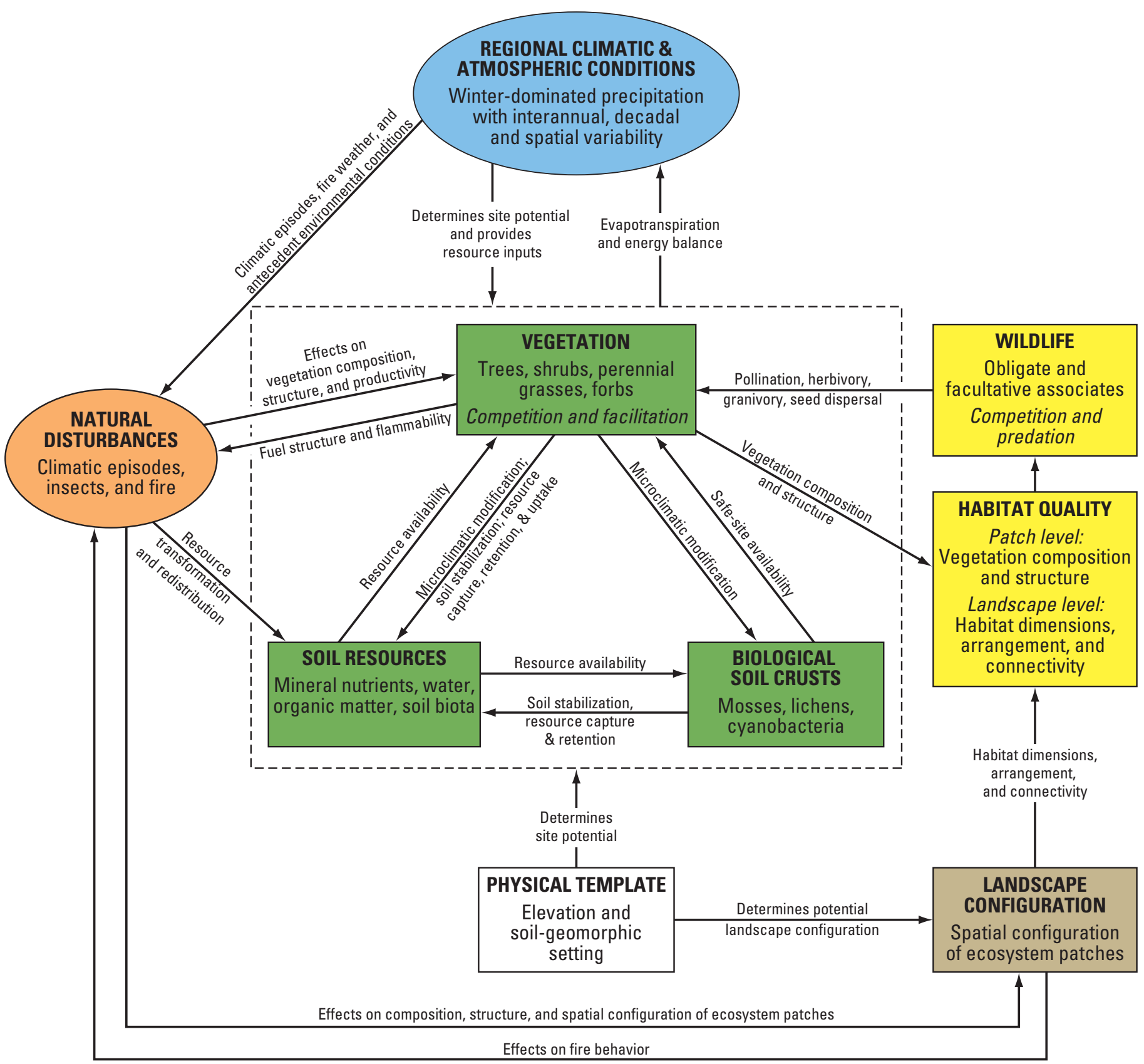

Figure 3.1. Diagram showing control model illustrating key components (rectangles), natural drivers of temporal change and variability (ovals), and functional relations (arrows) of Great Basin sagebrush steppe and pinyon-juniper ecosystems, excluding major human influences. The dashed box bounding vegetation, soil resources, and biological soil crusts emphasizes strong feedbacks among these three components that together form the foundation of dryland ecosystems. (Adapted from Miller, 2005.) 
mantled and intermontane basins are filled with Quaternary alluvium and other deposits with physical and mineralogical properties inherited from these parent materials and modified by geomorphic processes and soil formation. In basins formerly occupied by pluvial lakes, basin-floor soils are formed in lacustrine sediments as well as alluvium. Deposits and resultant soils generally become progressively deeper and finer in texture downslope from mountain fronts to basin floors. Although these are useful generalizations, spatial patterning of key soil properties such as depth, particle-size distribution, and degree of profile development are far more complex in actual Great Basin landscapes (Peterson, 1981). This spatial complexity is attributable to differences in the origins and ages of major types of landforms (for example, mountain-valley fans, alluvial fans, fan piedmonts, alluvial flats, and alluvial plains) that comprise piedmont slopes and basin floors (Peterson, 1981). In the Great Basin, these landforms developed primarily during or before the late Pleistocene, and since that time have been repeatedly modified during recurrent periods of erosion and deposition as well as by soil formation during periods of greater landscape stability (Peterson, 1981). As a consequence, different types of soils (that is, in terms of depth, particle size, and degree of development) and ecosystems (that is, in terms of structure and dynamics) tend to be associated with different landforms as well as with finer-scale components and elements of landforms (Peterson, 1981; Monger and Bestelmeyer, 2006). Aridisols, Mollisols, and Entisols generally are the dominant soil orders associated with sagebrush steppe and pinyonjuniper ecosystems in the Great Basin (U.S. Department of Agriculture Natural Resources Conservation Service, 2006).

\section{Vegetation, Biological Soil Crusts, and Soil Resources- The Foundation for Sagebrush Steppe and Pinyon-Juniper Ecosystems}

Vegetation.-Vegetation, biological soil crusts, and soil resources are tightly coupled components of dryland ecosystems in the Great Basin (fig. 3.1; Whitford, 2002) including those dominated by big sagebrush, pinyon, and juniper. Big sagebrush is widely distributed across the Great Basin (fig. 3.2; Little, 1976) and is perhaps the single plant species that best characterizes the region. Three of five known varieties of big sagebrush are prevalent throughout the region (West and Young, 2000). These three taxaWyoming big sagebrush (A. t. var. wyomingensis), basin big sagebrush (A. t. var. tridentata), and mountain big sagebrush (A. $t$. var. vaseyana) — generally shift in relative abundance along gradients of decreasing soil temperature and increasing soil moisture (West and Young, 2000). Of these three, Wyoming big sagebrush has the most extensive distribution as a shrubsteppe dominant in deep, salt-free soils below the elevation of pinyon-juniper woodlands. Basin big sagebrush commonly is restricted to deep alluvial soils along stream courses, although it is a shrubsteppe dominant in some settings. Mountain big sagebrush typically occurs as a shrubsteppe dominant in forest clearings and meadows above or in more mesic topographic settings than pinyon-juniper woodlands. In their treatment of vegetation communities of the Intermountain West, West and Young (2000) differentiated sagebrush steppe from Great Basin sagebrush — with the former type having a greater proportion of perennial grass cover and a more northerly distribution in the sagebrush biome relative to the latter type. In this report, we do not retain this coarse-scale distinction because community composition and especially the shrub:grass ratio also varies widely with soil-geomorphic properties, climatic conditions, and disturbance history at finer spatial scales. These factors as well as regional biogeographical patterns together result in considerable variability in the composition, structure, and dynamics of sagebrush steppe ecosystems across the Great Basin. Depending on these many factors, a large variety of shrubs (for example, Ericameria nauseosa, Ephedra viridis, Krascheninnikovia lanata, and Purshia tridentata), perennial bunchgrasses (for example, Pseudoroegneria spicata, Pascopyrum smithii, Poa secunda, and Festuca idahoensis), perennial forbs (for example, Astragalus spp., Balsamorhiza sagittata, Eriogonum spp., and Phlox spp.), and annuals can be important components of sagebrush steppe (Holmgren, 1972). The issue of variability is a particularly important one for monitoring and management, and it is addressed later in this section.

Like sagebrush steppe, pinyon-juniper woodlands are extremely variable across the broad range of this general vegetation type. In the Great Basin, singleleaf pinyon (Pinus monophylla) and Utah juniper (Juniperus osteosperma) are the most widely distributed woodland species (fig. 3.2 $B$ and 3.2D). Western juniper (Juniperus occidentalis) occurs along the western margin and particularly in the northwestern corner of the Great Basin (fig. 3.2E), whereas Colorado pinyon ( $P$. edulis) is restricted to the southeastern corner of the region (fig. 3.2C). In large areas of the region, junipers occur in the absence of pinyon. In landscapes where they co-occur, juniper tends to dominate at lower and upper ends of elevational gradients, whereas pinyon dominates middle elevation due to lesser tolerance for dry (low elevation) and cold (high elevation) conditions (West, 1999). As with sagebrush steppe ecosystems, the composition and structure of understory shrub and herbaceous communities varies greatly in relation to woodland structure and successional stage, soil-geomorphic setting, climatic conditions, and disturbance history (West, 1999).

Interspecific competition and facilitation are important types of plant interactions in dryland ecosystems (Archer and Bowman, 2002). Much research has focused on the importance of competition as a process affecting plant community structure in drylands (Fowler, 1986; Reichenberger and Pyke, 1990; Booth and others, 2003), 


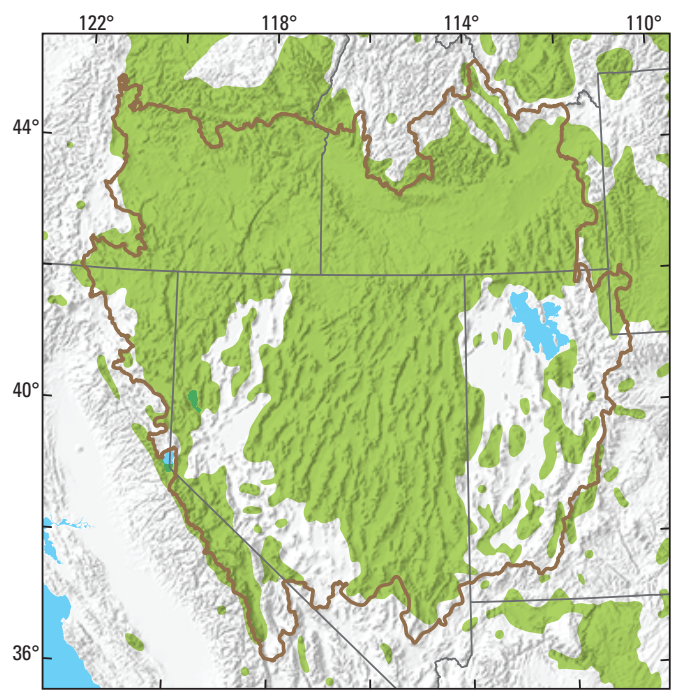

A. Artemisia tridentata

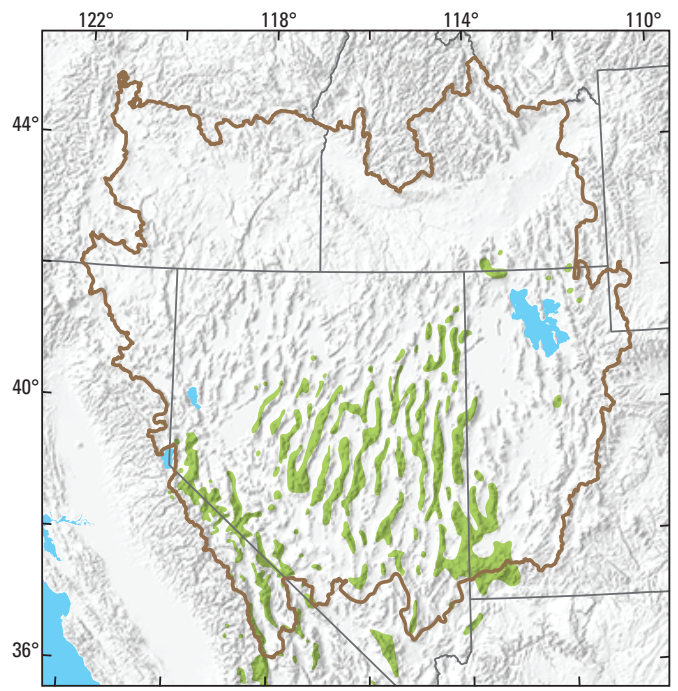

B. Pinus monophylla

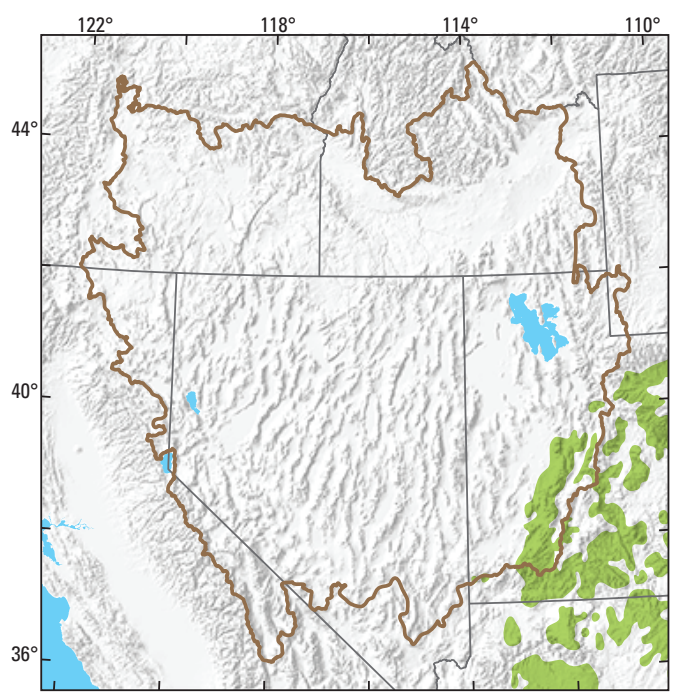

C. Pinus edulis

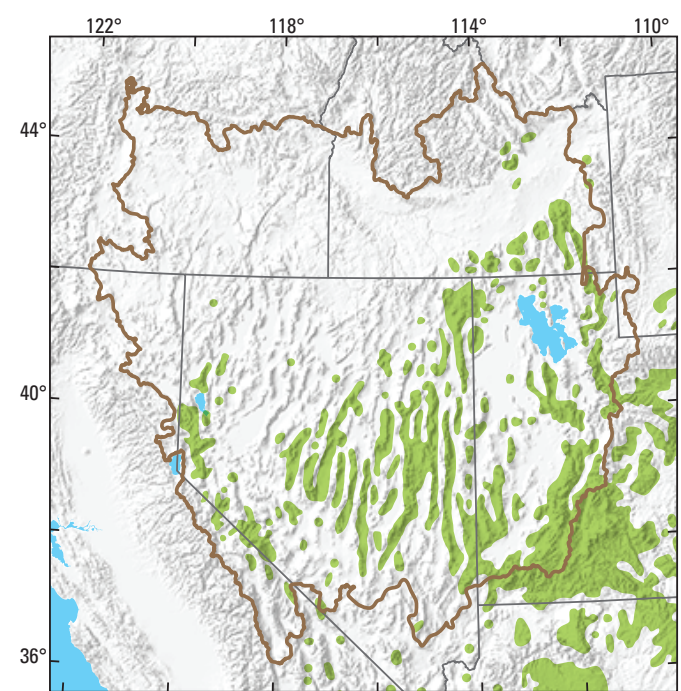

D. Juniperus osteosperma

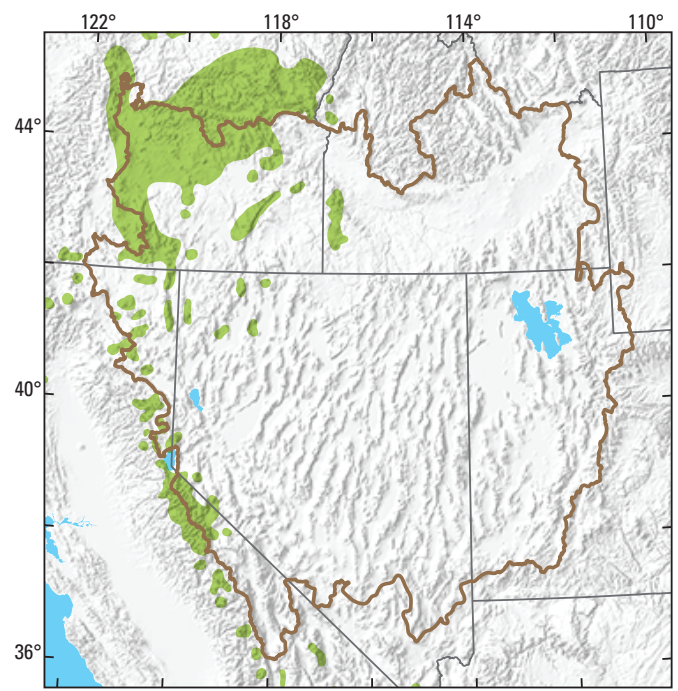

E. Juniperus occidentalis

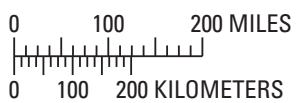

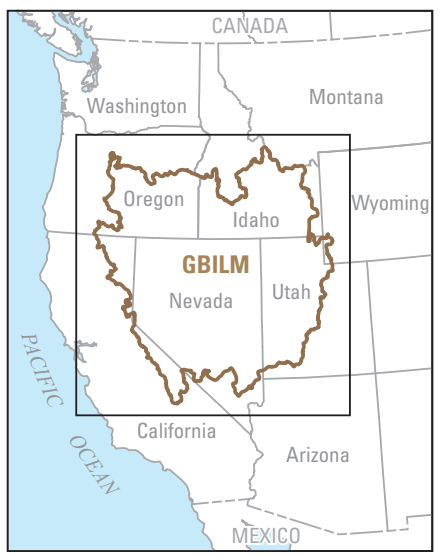

Figure 3.2. Distribution of $(A)$ Artemisia tridentata, $(B)$ Pinus monophylla, $(C)$ Pinus edulis, $(D)$ Juniperus osteosperma, and (E) Juniperus occidentalis in the Great Basin (derived from Little, 1971,1976; U.S. Geological Survey, 1999). 
with particular emphasis on interactions between woody plants and perennial grasses (Archer, 1994; West and Young, 2000). But there is increasing recognition that facilitation also can be an important process in drylands due to ameliorating effects of overstory plants on environmental conditions or herbivory experienced by understory plants (Callaway, 1995; Archer and Bowman, 2002; Brooker and others, 2008). For example, sagebrush has been determined to facilitate establishment and persistence of perennial grasses under some conditions (Davies and others, 2007). The tendency for pinyons to establish beneath junipers (Chambers, 2001) also indicates an important role for facilitation in woodlands. The relative importance of competition versus facilitation can vary depending on characteristics of interacting species, environmental conditions such as aridity, and other factors such as grazing intensity (Brooker and others, 2008). Recent work also indicates that greater consideration of facilitative interactions between plants could enhance restoration success in the context of harsh environmental conditions (Pueyo and others, 2008).

Biological Soil Crusts.-Biological soil crusts (BSCs) play important functional roles in sagebrush and pinyonjuniper ecosystems of the Great Basin (fig. 3.1). BSCs are biotic communities composed of cyanobacteria, algae, microfungi, mosses, and lichens that occur on and within a few millimeters of the soil surface (Belnap and Lange, 2003). These diverse communities are characteristic biotic components of ecosystems where environmental conditions limit the development of closed-canopy vascular plant communities or thick layers of surface litter (Belnap and Lange, 2003; Rosentreter and Belnap, 2003). In addition to their contributions to biological diversity, BSCs are major contributors to soil stability because they aggregate soil particles, thereby reducing the susceptibility of soil to erosion by wind and water (Williams and others, 1995a, 1995b). BSCs also roughen the soil surface, thereby facilitating the capture and retention of wind-blown dust that can be a significant source of mineral nutrients in dryland ecosystems (Reynolds and others, 2001; Belnap and Lange, 2003). BSCs similarly can capture and enhance ecosystem retention of windborne and waterborne organic matter and seeds (Belnap and Lange, 2003).

Hydrologic effects of BSCs are complex. Regardless of crust or soil type, BSCs stabilize soils and reduce water erosion by reducing the detachment of soil particles by erosive raindrops and overland water flow. In this function, cyanobacteria and algae are less effective than mosses and lichens. However, BSC organisms also can clog soil pores and inhibit infiltration. In undisturbed settings of the Great Basin, BSCs typically are characterized by a rolling surface morphology (Rosentreter and Belnap, 2003). Where BSCs roughen the soil surface in this way, they increase the residence time of runoff on hillslopes, thereby increasing infiltration and offsetting the inhibitive effects of BSCs on infiltration (Belnap, 2006). Organic carbon produced by BSC organisms also contributes to the formation of stable soil aggregates that increase the ratio of macropores to micropores and thus enhance infiltration. The presence of heavy, shrinkswell clays overrides the local hydrologic effects of BSCs.

In addition to enhancing soil stability and nutrient retention, BSCs contribute to dryland nutrient cycles in other ways. Mosses, cyanobacteria, green algae, and lichens are photosynthetic and thus are significant sources of carbon in dryland ecosystems, particularly in interspaces among vascular plants where soil crusts can attain 100 percent cover (Lange, 2003). Cyanobacteria (for example, Nostoc and Scytonema spp.) and cyanolichens (for example, Collema spp.) also are capable of fixing atmospheric nitrogen into a mineral form that can be used by vascular plants (Evans and Lange, 2003). Consequently, BSCs can be the dominant source of nitrogen in many dryland regions (Evans and Ehleringer, 1993; Belnap, 2002). BSC organisms are significant sources of carbon for other soil biota, which are more abundant and diverse beneath BSCs than beneath bare soils (Belnap, 2003). BSCs also increase nutrient cycling rates of soil food webs through their effects on near-surface moisture availability, soil structure, soil aeration, and soil temperature, thus increasing soil nutrient availability (Belnap, 2003).

BSCs have numerous effects on vascular plants. Where their presence results in roughened soil surfaces, BSCs generally enhance seed catchment and retention. Following seed catchment, BSC effects on plant establishment are dependent on crust composition and morphology, plant species (propagule morphology and germination requirements), and site conditions (Belnap and others, 2003; Escudero and others, 2007). Serpe and others (2006) determined that short mosses characteristic of the Great Basin reduced germination of four grasses (Festuca idahoensis, Festuca ovina, Elymus wawawaiensis, and Bromus tectorum) relative to bare soil. In contrast, tall mosses increased time to germination relative to bare soil but did not have an effect on final germination percentages for these same species. In a similar experiment, a lichen crust dominated by Diploschistes muscorum reduced germination of the exotic annual grass Bromus tectorum and the native annual grass Vulpia microstachys by two-thirds relative to bare soil (Deines and others, 2007). A mixed lichen-moss crust had no effects on germination relative to bare soil, with similar results for both grass species. Following the establishment phase, plants growing in soils with BSCs generally have greater biomass and lower root:shoot ratios than comparable plants growing in soils without BSCs, indicating greater availability of soil resources in the presence of BSCs (Belnap and others, 2003). Relative to plants growing in soils without BSCs, plants growing in association with nitrogen-fixing cyanobacteria and cyanolichens consistently have high nitrogen concentrations in tissues and usually have high concentrations of the plant-essential nutrients potassium, magnesium, copper, and zinc (Harper and Belnap, 2001). 
In contrast, plants growing in soils with BSCs commonly have low concentrations of phosphorus and iron than plants growing in soils without BSCs, indicating that plants and BSCs may compete for these elements. Nutritional differences between plants grown in soils with and without BSCs are greatest in shallow-rooted herbaceous species, probably because the plants are rooted in near-surface soils that are most directly influenced by BSCs (Harper and Belnap, 2001).

Soil Resources and Functions. - Soils are the third element constituting the foundation of dryland ecosystems because they are important for sustaining hydrologic processes, nutrient cycling, and plant establishment and growth, and erosion resistance in sagebrush steppe and pinyon-juniper. Key dynamic properties affecting these processes include organic matter content, aggregate stability, surface roughness, and structure. General soil characteristics and their importance to dryland ecosystems are discussed in Chapter 2.
Because soils and their geomorphic, elevation, and climatic setting are fundamental to determining potential ecosystem structure and function, including many aspects of ecosystem resistance and resilience to drivers of change (Monger and Bestelmeyer, 2006), they can provide a basis for subdividing and classifying upland ecosystems into ecological land units for purposes of ecosystem management, assessment and monitoring, and associated research. One such system that has been widely applied in the Great Basin is the ecological site system developed and managed by NRCS. Ecological sites are land units that are delineated on the basis of soil properties (soil texture and mineralogy through the profile), climate (latitude, elevation, and aspect), and geomorphic setting (landform association and topographic / hillslope position; fig. 3.3; table 3.1). These units have potential to produce specific kinds and amounts of vegetation and distinct responses to management, climate, and other drivers of change (Society for Range Management Task Group on Unity in

Table 3.1. Dominant soil, ecological site, and generalized type of upland ecosystem associated with soil map units.

[Map units are ordered as they are encountered along a cross-valley transect from west to east (see fig. 3.3). Soil and ecological site information were compiled from U.S. Department of Agriculture Natural Resource Conservations Service, Soil Survey of Box Elder County, Western Part. Dominant ecological site: Descriptions of these ecological sites are available online at http://www.ut.nrcs.usda.gov/technical/technology/range/ecosites.html]

\begin{tabular}{|c|c|c|c|c|c|}
\hline \multirow{2}{*}{$\begin{array}{c}\text { Soil map } \\
\text { unit }\end{array}$} & \multicolumn{2}{|c|}{ Dominant soil } & \multicolumn{2}{|c|}{ Dominant ecological site } & \multirow{2}{*}{ Generalized type } \\
\hline & Taxonomic class & Landform & Name & No. & \\
\hline 68 & $\begin{array}{l}\text { Loamy-skeletal, } \\
\text { mixed, frigid Lithic } \\
\text { Haploxerolls }\end{array}$ & Hills & $\begin{array}{l}\text { Upland Shallow Loam } \\
\text { (Utah Juniper) }\end{array}$ & R025XY324UT & Pinyon-juniper \\
\hline 11 & $\begin{array}{l}\text { Loamy-skeletal, mixed, } \\
\text { mesic Haploxerollic } \\
\text { Durargids }\end{array}$ & Fan remnants & $\begin{array}{l}\text { Semidesert Gravelly } \\
\text { Loam (Wyoming Big } \\
\text { Sagebrush) North }\end{array}$ & R028AY215UT & Sagebrush steppe \\
\hline 45 & $\begin{array}{l}\text { Coarse-loamy, mixed, } \\
\text { mesic Durixerollic } \\
\text { Calciorthids }\end{array}$ & Fan remnants & $\begin{array}{l}\text { Semidesert Alkali Loam } \\
\text { (Black Greasewood) }\end{array}$ & R028AY202UT & Salt desert scrub \\
\hline 82 & $\begin{array}{l}\text { Coarse-silty, mixed } \\
\text { (calcareous), mesic } \\
\text { Typic Torriorthents }\end{array}$ & Lake plains and terraces & Desert Loam (Shadscale) & R028AY124UT & Salt desert scrub \\
\hline 47 & $\begin{array}{l}\text { Coarse-loamy, mixed, } \\
\text { superactive, mesic } \\
\text { Xeric Argidurids }\end{array}$ & Fan remnants & $\begin{array}{l}\text { Semidesert Loam } \\
\text { (Wyoming Big } \\
\text { Sagebrush) }\end{array}$ & R028AY220UT & Sagebrush steppe \\
\hline 64 & $\begin{array}{l}\text { Loamy, mixed } \\
\text { (calcareous), mesic, } \\
\text { shallow Xeric } \\
\text { Torriorthents }\end{array}$ & Ridges on hillslopes & $\begin{array}{l}\text { Semidesert Shallow } \\
\text { Hardpan (8-10 “ } \\
\text { precip.) }\end{array}$ & R028AY231UT & Sagebrush steppe \\
\hline 23 & $\begin{array}{l}\text { Coarse-loamy, mixed, } \\
\text { frigid Haploxerollic } \\
\text { Durorthids }\end{array}$ & Hillslopes & $\begin{array}{l}\text { Upland Juniper Savanna } \\
\text { (Utah Juniper) }\end{array}$ & R025XY322UT & Pinyon-juniper \\
\hline 59 & $\begin{array}{l}\text { Loamy-skeletal, } \\
\text { mixed Argic Pachic } \\
\text { Cryoborolls }\end{array}$ & Mountain slopes & $\begin{array}{l}\text { Mountain Gravelly } \\
\text { Loam (Mountain Big } \\
\text { Sagebrush) }\end{array}$ & R025XY4122UT & Sagebrush steppe \\
\hline
\end{tabular}




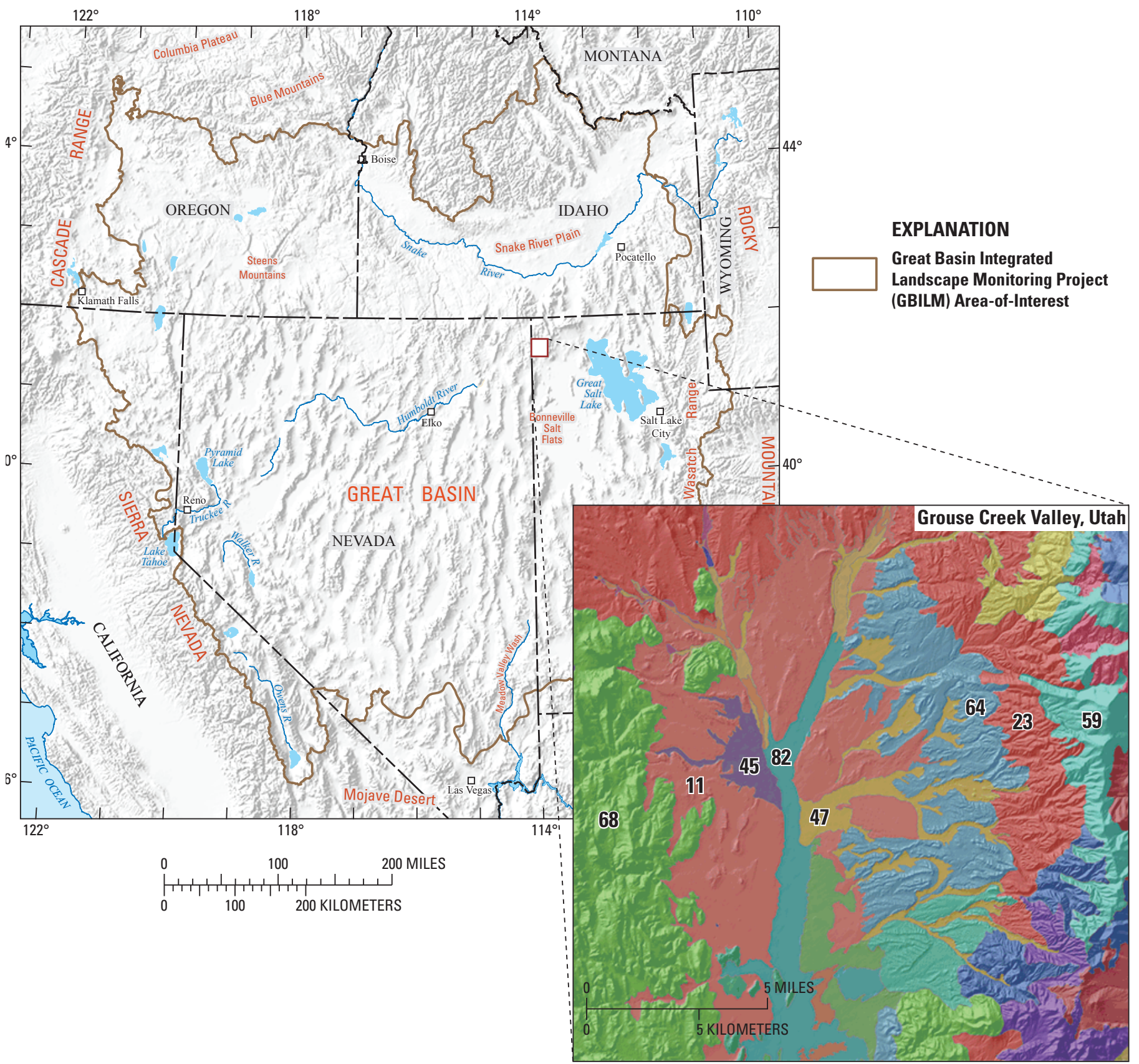

Soil map units from U.S. Department of Agriculture Natural Resource Conservation Service, Soil Survey of Box Elder County, Western Part, survey area UT601, accessed June 23, 2009, at http://websoilsurvey.nrcs.usda.gov/app

Figure 3.3. Soil map units in Grouse Creek Valley, Utah. A description of the eight numbered map units that occur along a cross-valley transect from west to east is shown in table 3.1.

Concepts and Terminology, 1995). In some cases, naming conventions for ecological sites include reference to one or more plant species that characterize the potential vegetation for the site (see table 3.1). Upland subsystems referred to in this report (for example, salt desert scrub, sagebrush steppe, and pinyon-juniper woodlands) represent coarse groupings of ecological sites, which incorporate considerable variation in classification factors and ecosystem responses. A map of actual vegetation differs from a map of ecological sites because the former reflects disturbance and fire history rather than the potential to respond to climate or land-use activities. 


\section{Wildlife and Habitat Quality}

Wildlife (including vertebrates and invertebrates) are significant contributors to the biological diversity and functioning of sagebrush steppe and pinyon-juniper woodlands of the Great Basin. Bird species that have obligate habitat associations with sagebrush steppe include greater sage-grouse (Centrocercus urophasianus), sage thrasher (Oreoscoptes montanus), sage sparrow (Amphispiza belli), and Brewer's sparrow (Spizella breweri) (Knick and others, 2003; Welch, 2005). Welch (2005), citing a long list of other researchers, identified 91 additional bird species that are facultative associates of sagebrush steppe. Mammals considered to be sagebrush obligates include the pygmy rabbit (Brachylagus idahoensis) and the sagebrush vole (Lagurus curtatus) (Welch, 2005). At least 88 mammal taxa have been identified as facultative sagebrush associates, including pronghorn (Antilocapra americana), mule deer (Odocoileus hemionus), elk (Cervus elaphus), and bighorn sheep (Ovis canadensis) (Welch, 2005). Depending on local habitat conditions, these same four species also have been determined to use pinyonjuniper woodlands on a facultative basis - with mule deer being the most important in terms of degree of woodland use for thermal cover and food (Frischknecht, 1975). In their study of pinyon-juniper woodlands in northeastern Utah (outside our Great Basin boundary), Paulin and others (1999) identified six bird species that they considered to be pinyon-juniper obligates - ash-throated flycatcher (Myiarchus cinerascens), blue-gray gnatcatcher (Polioptila caerulea), Bullock's oriole (Icterus bullockii), pinyon jay (Gymnorhinus cyanocephalus), western scrub-jay (Aphelocoma coerulescens), and Virginia's warbler (Vermivora virginiae). Periodic mast crops of pinyon and juniper seeds are particularly important resources for a wide range of birds and mammals (Frischknecht, 1975). Miller and others (2005) summarized the current understanding of habitat-use patterns of selected bird and mammal species in sagebrush steppe and western juniper woodlands in the northwestern Great Basin.

Vertebrates and invertebrates perform numerous functions (see Chapter 2, section "Wildlife and Habitat Quality") in sagebrush steppe and pinyon-juniper ecosystems, the most important of which is herbivory. Native herbivores in sagebrush steppe and pinyon-juniper ecosystems of the region include insects (grasshoppers, moth and butterfly larvae, bark beetles, and many others) and mammals such as woodrats (Neotoma spp.), desert cottontails (Sylvilagus audubonii), black-tailed jackrabbits (Lepus californicus), bighorn sheep, pronghorn, mule deer, and elk. Herbivorous insects and small to medium-size mammals can have significant effects on vegetation structure and ecosystem processes such as nutrient cycling. With the exception of infrequent insect outbreaks (discussed below in section "Insect Outbreaks"), the greatest ecosystem-level consequences of herbivory are those that can be caused by high densities of large-bodied browsers and grazers such as mule deer, elk, and domestic livestock.
Herbivorous animals influence plant community composition and vigor through selective defoliation, transport of plant materials and seeds, caching, defecation, and trampling. Through time, these effects can lead to altered competitive relations among plants which then are expressed in population dynamics and plant community structure (Briske, 1991).

\section{Drivers of Ecosystem Change}

\section{Natural Drivers}

Climate Variability. - Climate variability and disturbance processes are the two natural factors that are most responsible for driving temporal patterns of change and variability in sagebrush steppe and pinyon juniper systems. With respect to climate, precipitation seasonality (that is, timing in relation to the annual cycle of potential evapotranspiration) and form (that is, snow versus rain) are major determinants of ecosystem dominance by different vegetative life forms and functional groups because these climatic attributes strongly control the partitioning of precipitation among various compartments of the hydrologic budget - evaporation, transpiration, runoff, drainage (recharge), and soil-water storage (Comstock and Ehleringer, 1992). In the Great Basin, winter precipitation is predominant, with greater summer precipitation in the east (see Chapter 2, section "Climate Patterns in the Great Basin"). The prevalence of cool-season precipitation results in effective soil-moisture recharge and relatively reliable growing conditions in spring (Caldwell, 1985; Comstock and Ehleringer, 1992; West and Young, 2000). Annual temperature extremes also influence plant species distributions and therefore contribute to landscape configuration; for example, the upper elevational limit of pinyon pine appears to be defined by minimum annual temperatures (West, 1999). Pinyon pine and the other plant species defining the sagebrush steppe and pinyon-juniper zones exhibit adaptations to climate conditions that promote their local dominance.

\section{Natural Disturbance Regimes.-}

Extreme Climatic Events.-Episodic severe climatic events are major disturbances in dryland ecosystems (Walker, 1993; Whitford, 2002). Drought, extreme precipitation events and floods, and wind storms can induce long-term changes in ecosystem structure and function by causing widespread mortality or enabling establishment of long-lived plants that are structural dominants. The erosive energy of extreme precipitation and wind events also can result in ecologically significant transport and redistribution of soil resources, potentially inducing geomorphic changes that fundamentally alter site conditions. Event sequencing (for example, timing of flooding in relation to drought) is an important factor that can affect ecosystem resistance and resilience to episodic climatic events. Episodic, event-driven change is an important 
feature of many ecosystems (Holling, 1996; Scheffer and others, 2001), and is particularly characteristic of dryland ecosystems (Whitford, 2002). West and Young (2000) note that the occurrence of extremely wet springtime conditions or very cold winters without snow cover are climatic events that trigger sagebrush mortality and affect the ratio of shrubs to herbaceous species in sagebrush steppe ecosystems of the Great Basin. Climatic conditions and events can affect ecosystem susceptibility to other disturbances such as fire and insect outbreaks (Swetnam and Betancourt, 1998), as well as affect ecosystem resistance and resilience to anthropogenic drivers of change (Archer and Stokes, 2000; Scheffer and others, 2001).

Fire.-Wildfire is another type of natural disturbance that can have many direct and indirect effects on ecosystem structure and function, although there is considerable variability among dryland ecosystems in the specific characteristics of natural fire regimes. One of the most significant direct effects of fire is the alteration of vegetation composition and structure due to the selective reduction or elimination of fire-intolerant life forms or age classes (Whelan, 1995). Specific effects of fire on vegetation structure vary in relation to fire-regime characteristics (for example, frequency, intensity, seasonality, and spatial patterning) and fire responses of dominant vegetative life forms. Fireregime characteristics are strongly influenced by vegetation composition and structure, as well as by preceding and coincident weather conditions that affect fuel availability, fuel flammability, and fire behavior. In describing fire regimes, fire intensity refers to how hot a fire burns (energy output; Whelan, 1995) whereas fire severity refers to the degree of mortality in overstory woody plants (Baker and Shinneman, 2004). High-severity fires in woodlands and forests result in nearcomplete mortality of overstory trees, whereas low-severity fires consume primarily herbaceous surface fuels, litter, fire-sensitive understory trees, and shrubs. Mixed-severity fires result in a mosaic of high-severity and low-severity patches that can be caused by changes in weather during the fire, topographic heterogeneity, the relative abundance and distribution of fuels, and legacies of past fire (Noss and others, 2006).

Effects of fire on vegetation structure have multiple ecosystem-level consequences because of strong vegetation interactions with soil, hydrology, and geomorphic processes. Fire-caused reductions in ground cover and vegetation structure can result in significant erosional losses of soils, nutrients and organic matter by water and wind (Johansen and others, 2001; Whicker and others, 2002). Soil hydrophobicity caused by fire is another factor that can result in accelerated water-driven erosion because of decreased infiltration and increased runoff (Johansen and others, 2001; MacDonald and Huffman, 2004).

Fire also has significant ecosystem-level consequences due to effects on nutrient cycles (Raison, 1979; Blank and others, 1994a, 1994b). Depending on the type and intensity of fire events, fire can (1) increase nutrient bioavailability on a short-term basis due to ash deposition and accelerated rates of nutrient cycling, and (2) deplete total nutrient stocks due to gaseous losses (particularly nitrogen) and off-site transfers of ash (Raison, 1979). Nutrient losses in gases and ash generally are proportional to heat generated and organicmatter consumed by fire (Raison, 1979; Schlesinger, 1997). Depending on fire intensity, other soil characteristics can be affected by fire, including $\mathrm{pH}$ (typically increased by ash deposition), cation exchange capacity and infiltration capacity (both typically decreased by organic-matter losses and transformations; Raison, 1979), and erodibility (Whicker and others, 2002). Fire extent and spatial patterning affect and are affected by topography, wind, fuel moisture, and the spatial configuration of different fuel (vegetation) types across the landscape (fig. 3.1).

There is uncertainty regarding the characteristic frequency of fire in Great Basin sagebrush steppe prior to the time of Euro-American settlement. Some researchers have estimated that pre-settlement natural fire-return intervals in sagebrush steppe were 15-25 years in mountain big sagebrush ecosystems and 50-100 years in Wyoming big sagebrush ecosystems (Miller and others, 1994; Miller and Tausch, 2001). Following a critique of methodological issues associated with previous estimates, Baker (2006) concluded that these fire rotations (the time required for fire to burn once through a sagebrush landscape) may have been 70-200 years or more in mountain big sagebrush and 100-240 years in Wyoming big sagebrush. When fire does occur, all varieties and age classes of big sagebrush typically are killed irrespective of fire intensity (Welch, 2005). As a consequence, fire in sagebrush steppe tends to create a mosaic of burned and unburned patches rather than thinning the density of shrubs within patches (Baker, 2006). Fire frequency, size, and spatial patterning affect the spatial mosaic of vegetation patches and landscape-level habitat attributes for broad-ranging wildlife such as birds (fig. 3.1).

There is a similar degree of uncertainty regarding characteristics of pre-settlement fire regimes in pinyonjuniper ecosystems of the Great Basin. West and Young (2000) suggest that many intermountain pinyon-juniper ecosystems likely were characterized by low-severity surfacefire regimes that maintained savanna-like vegetation structure prior to Euro-American settlement. In contrast, Baker and Shinneman (2004) concluded from their systematic review of fire research in pinyon-juniper ecosystems that low-severity surface fires probably were uncommon in such ecosystems prior to Euro-American settlement. They also concluded that much additional area-specific research is needed to provide a foundation for science-based management and restoration of pinyon-juniper ecosystems. They are in agreement with other workers who have warned ecosystem managers not to rely uncritically on fire-regime generalizations derived from studies conducted elsewhere (for example, Romme and others, 2003; Veblen, 2003). 
In an effort to clarify issues associated with pinyonjuniper fire regimes, Romme and others (2007) compared two general types of pinyon-juniper ecosystems with areas of potential tree expansion and contraction based on canopy structure, understory characteristics, and historical disturbance regimes (table 3.2). Although there is a great deal of variability within each of these types as well (for example, variability corresponding with the large number of different pinyonjuniper ecological sites in the Great Basin), this general classification scheme provides a useful framework for future research regarding management, dynamics, and restoration of systems in which pinyon and juniper species occur. Following this scheme, pinyon-juniper ecosystems discussed in this report are considered to be classified as persistent woodlands. Sagebrush steppe ecosystems subject to tree encroachment are classified as areas of potential expansion and contraction following the scheme described in table 3.2.

Insect Outbreaks. - Insect outbreaks can represent significant natural disturbances in sagebrush steppe and pinyon-juniper ecosystems of the Great Basin (Bentz and others, 2008). For example, Gates (1964) reported that 4,0006,000 ha of sagebrush in eastern Oregon were killed through defoliation by the Aroga moth (Aroga websteri) in 1962, and more than 4.5 million ha of sagebrush steppe was infested by the moth to some degree by 1963. More recently, an Aroga moth outbreak was reported in northern and central Nevada during 2004-06 (Bentz and others, 2008). Recent outbreaks of grasshoppers and Mormon crickets (Orthoptera) also have occurred in portions of Utah and Nevada (Bentz and others, 2008). Factors controlling the frequency and magnitude of such outbreaks are poorly understood, but climate likely is a major driver. Hsiao (1986) reported that declines of Aroga moth populations were caused by high summer temperatures and host-plant desiccation during a 5-year study in Curlew Valley, Idaho. Climatic conditions can affect the occurrence of insect outbreaks directly through effects on insect metabolic processes and indirectly through effects on predation and food quality (Bentz and others, 2008).

The occurrence of insect outbreaks in tree-dominated ecosystems has been attributed to climatic conditions that diminish the vigor and insect resistance of host plants and/or affect life cycles and dispersal patterns of insect herbivores (Swetnam and Betancourt, 1998; Logan and others, 2003). In pinyon-juniper ecosystems, outbreaks of the bark beetle Ips confusus (pinyon ips) can be triggered by drought conditions that weaken host-tree populations (Leatherman and Kondratieff, 2003).

\section{Anthropogenic Drivers}

In addition to natural drivers, scoping for this project identified six high-priority anthropogenic drivers that currently affect sagebrush steppe and pinyon-juniper ecosystems in the Great Basin:. (1) fire-regime alteration, (2) invasive-fire interactions, (3) livestock grazing, (4) land treatments, (5) off-highway vehicle activity, and (6) climate change. These factors interact with one another and with natural drivers to affect change and temporal variability in Great Basin ecosystems (fig. 3.4). These interactive effects and their implications for ecosystem dynamics are discussed below.

\section{Ecosystem Dynamics}

General patterns of ecosystem dynamics are illustrated here with state-and-transition models (Westoby and others, 1989; Bestelmeyer and others, 2003; Stringham and others, 2003; Bestelmeyer and others, 2004; Briske and others, 2005, 2008). State-and-transition models are management-oriented tools for describing and classifying ecosystem conditions (or states) and posing hypotheses about ecological factors responsible for persistent changes (or transitions) among different states (Bestelmeyer and others, 2004). Such models increasingly are being developed and used by managers and researchers to organize information about the dynamics of rangeland ecosystems, qualitatively compare and evaluate the relative benefits and risks of different management actions, and consider the effects of other drivers such as climate, natural disturbances, and invasive exotic plants (Bestelmeyer and others, 2004). For maximum utility, such models are developed for and applied to specific ecological land units (for example, specific ecological sites) because of the importance of site-specific factors such as local climatic conditions, soil-geomorphic properties, and landscape configuration for determining ecosystem responses to management actions and other drivers of change. The general models presented here do not account for these site-specific factors and require modification for application to a specific type of land unit.

To further elaborate on hypothesized mechanisms of ecosystem change, state-and-transition models are supplemented with mechanistic stressor models. These conceptual models illustrate how various natural and anthropogenic drivers interact to cause particular types (or pathways) of change in sagebrush steppe and pinyon-juniper ecosystems. To facilitate the consideration of indicators for long-term ecological monitoring, these models emphasize pathways and processes of ecosystem change that typically are considered undesirable with respect to agency management objectives. Relations among control models, state-andtransition models, and mechanistic stressor models are depicted in figure 1.4.

\section{Sagebrush Steppe}

Figure 3.5 illustrates a general state-and-transition model for sagebrush steppe ecosystems of the Great Basin. (For other general models depicting state-and-transition dynamics of sagebrush steppe ecosystems, see Laycock, 1991; Miller and others, 1994; West and Young, 2000; Miller and Tausch, 2001; and Connelly and others, 2004). The model depicts seven 
Table 3.2. Selected attributes of two general types of pinyon-juniper ecosystems compared with areas of potential tree expansion and contraction (derived from Romme and others, 2007).

\begin{tabular}{|c|c|c|c|}
\hline Attributes & \multicolumn{2}{|c|}{ General type of pinyon-juniper ecosystem } & $\begin{array}{l}\text { Areas of potential expansion } \\
\text { and contraction }\end{array}$ \\
\hline Site conditions & $\begin{array}{l}\text { Soil and climate inherently } \\
\text { favorable for pinyon and/ } \\
\text { or juniper-typically } \\
\text { shallow, coarse-textured } \\
\text { soils. }\end{array}$ & $\begin{array}{l}\text { Usually on gentle upland and transitional } \\
\text { valley locations, where soil conditions } \\
\text { favor graminoids but can support some } \\
\text { tree cover-typically moderately deep, } \\
\text { coarse to fine-textured soils with a large } \\
\text { percentage of annual precipitation in } \\
\text { summer. }\end{array}$ & $\begin{array}{l}\text { Only intermittently suitable for pinyon } \\
\text { and/or juniper, with increased tree } \\
\text { establishment during moist climatic } \\
\text { periods or long disturbance-free intervals, } \\
\text { with subsequent die-back triggered by } \\
\text { drought, insect outbreaks, or fire-found } \\
\text { on a wide variety of substrates and } \\
\text { climatic conditions. }\end{array}$ \\
\hline $\begin{array}{l}\text { Characteristic } \\
\text { canopy } \\
\text { structure }\end{array}$ & $\begin{array}{l}\text { Highly variable, from sparse } \\
\text { stands of small trees } \\
\text { on poor substrates to } \\
\text { relatively dense stands of } \\
\text { large trees on productive } \\
\text { sites. }\end{array}$ & $\begin{array}{l}\text { Variable from sparse tree cover limited } \\
\text { by soil and climate conditions; to } \\
\text { sparse tree cover limited by herbaceous } \\
\text { competition, recurrent fire, drought, } \\
\text { or other disturbances; to denser } \\
\text { woodlands where tree recruitment has } \\
\text { increased historically due to release } \\
\text { from competition, favorable climatic } \\
\text { conditions, and/or lack of fire. }\end{array}$ & $\begin{array}{l}\text { Fluctuates between shrubland or grassland } \\
\text { structure and tree dominance. }\end{array}$ \\
\hline $\begin{array}{l}\text { Characteristic } \\
\text { understory }\end{array}$ & $\begin{array}{l}\text { Sparse herbaceous cover } \\
\text { even in absence of } \\
\text { livestock grazing. }\end{array}$ & $\begin{array}{l}\text { Variety of growth forms including grasses } \\
\text { and shrubs }\end{array}$ & Typically shrub dominated. \\
\hline $\begin{array}{l}\text { Disturbance } \\
\text { regimes and } \\
\text { dynamics }\end{array}$ & $\begin{array}{l}\text { Typical fire regimes } \\
\text { characterized by high- } \\
\text { severity fire with very long } \\
\text { rotations (for example, } 2 \text { to } \\
6 \text { centuries); low-severity } \\
\text { surface fires very rare; } \\
\text { woodlands often stable for } \\
\text { many hundreds of years } \\
\text { with stand dynamics often } \\
\text { driven more by drought } \\
\text { and insect outbreaks than } \\
\text { by fire. }\end{array}$ & $\begin{array}{l}\text { Some savannas may have been maintained } \\
\text { by relatively frequent low-severity } \\
\text { surface fires. Livestock grazing and fire } \\
\text { exclusion are important mechanisms } \\
\text { responsible for driving the post- } \\
\text { settlement conversion of savanna to } \\
\text { woodland structure in some but not all } \\
\text { areas. Climatic conditions also have } \\
\text { played a role in driving vegetation } \\
\text { changes in at least some areas. } \\
\text { Interactions and spatial variability in } \\
\text { these factors are poorly understood. }\end{array}$ & $\begin{array}{l}\text { Livestock grazing and fire exclusion } \\
\text { probably are important mechanisms } \\
\text { responsible for driving the post- } \\
\text { settlement expansion of trees into some } \\
\text { grasslands and shrublands, but not all. } \\
\text { Climate probably has played a role in } \\
\text { driving these changes in some areas. } \\
\text { Interactions and spatial variability in } \\
\text { these factors are poorly understood. } \\
\text { Tree expansion also occurred in some } \\
\text { areas prior to Euro-American settlement } \\
\text { and the phenomenon is not necessarily } \\
\text { attributable to past land use or fire } \\
\text { exclusion. Some drought-triggered tree } \\
\text { mortality has recently occurred on some } \\
\text { marginal sites. }\end{array}$ \\
\hline Distribution & $\begin{array}{l}\text { Throughout the West, } \\
\text { but particularly on the } \\
\text { Colorado Plateau. }\end{array}$ & $\begin{array}{l}\text { Especially prevalent in basins and foothills } \\
\text { of southern New Mexico, but relatively } \\
\text { rare in the Rocky Mountains, northern } \\
\text { Colorado Plateau, and the Great Basin. }\end{array}$ & $\begin{array}{l}\text { Throughout the West, but particularly in the } \\
\text { Great Basin. }\end{array}$ \\
\hline Research needs & $\begin{array}{l}\text { Develop a better } \\
\text { understanding of the } \\
\text { geographic distribution } \\
\text { of this type in relation to } \\
\text { environmental factors. }\end{array}$ & $\begin{array}{l}\text { Develop a better understanding of the } \\
\text { geographic distribution of this type } \\
\text { in relation to environmental factors; } \\
\text { disentangle mechanisms driving } \\
\text { tree expansions in former grasslands } \\
\text { and savannas (including geographic } \\
\text { variability). }\end{array}$ & $\begin{array}{l}\text { Develop a better understanding of the } \\
\text { geographic distribution of this type } \\
\text { in relation to environmental factors; } \\
\text { disentangle mechanisms driving tree } \\
\text { expansions in former grasslands and } \\
\text { shrublands (including geographic } \\
\text { variability). }\end{array}$ \\
\hline
\end{tabular}




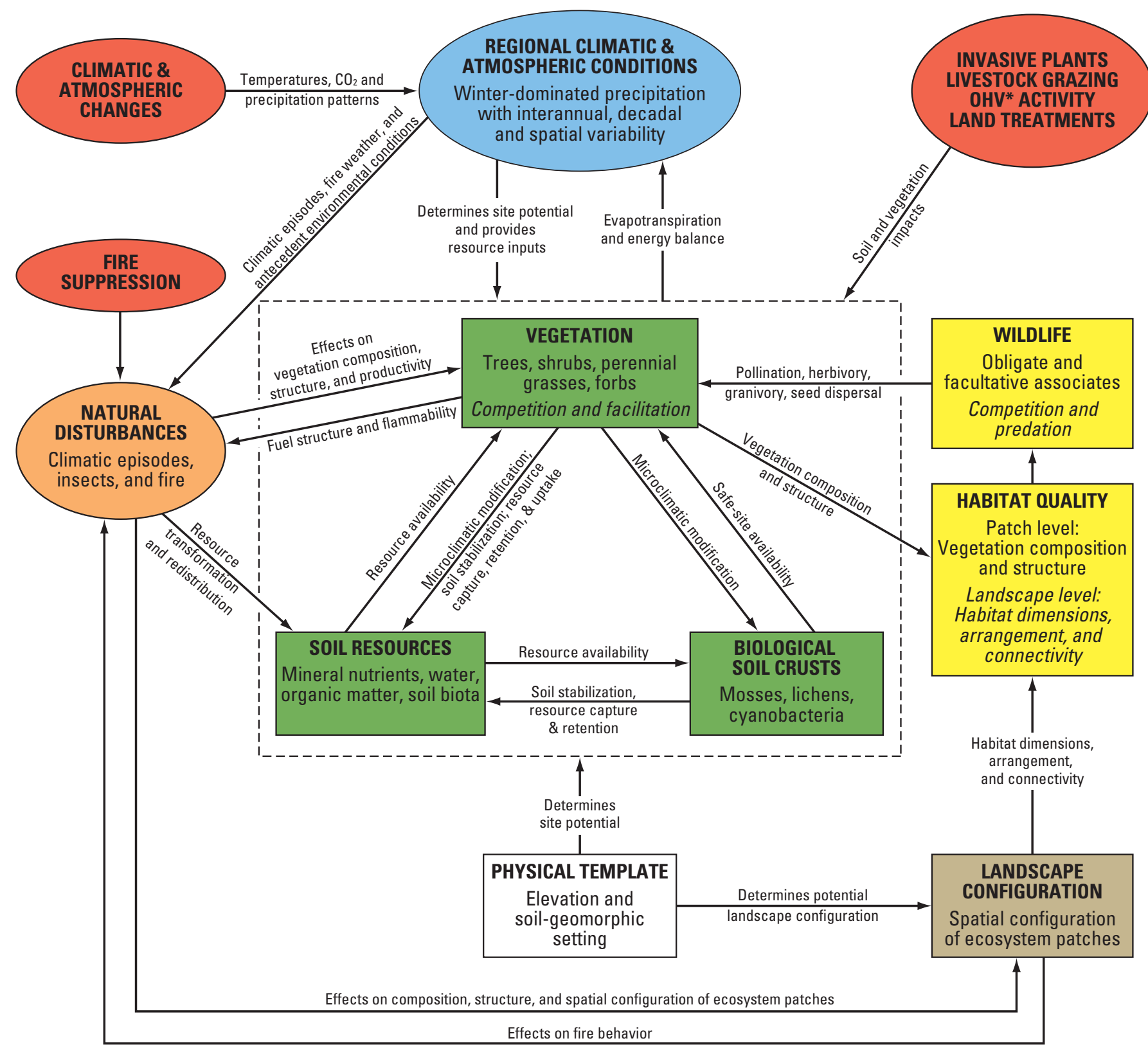

${ }^{*} \mathrm{OHV}=$ off-highway vehicle

Figure 3.4. Diagram showing control model illustrating key components (rectangles), drivers (ovals), and functional relations (arrows) of Great Basin sagebrush steppe and pinyon-juniper ecosystems, including high-priority anthropogenic drivers of ecosystem change and variability.

major states or persistent types of ecosystem condition, each of which is dynamic (rather than static) with temporal changes driven by climatic fluctuations, interactions among natural and anthropogenic drivers, and internal processes of change such as succession. In the Reference Condition (figure 3.5, Box Aideally defined on a site-specific basis according to climate and soil-geomorphic setting), biotic and abiotic ecosystem components and processes are present and functioning within their natural range of variability. These include processes and structures that confer resistance and resilience to natural and anthropogenic drivers of change, specifically soil structure and biological crusts; vegetative structure, species composition and competitive interactions; and the natural fire regime defined by frequency, intensity and severity. These are discussed in detail in the model descriptions below. 
As suggested above, the concept of "natural" commonly is defined on the basis of pre-settlement conditions. But it is important to recognize that changes in climate, atmospheric $\mathrm{CO}_{2}$ concentrations, and landscape structure will cause future ecosystem characteristics to drift away from historic patterns of variability even in the absence of local land-use effects, leading to the emergence of novel ecosystems characterized by new combinations of species and associated changes in ecosystem patterns and processes (Hobbs and others, 2006; Dukes, 2007; Seastedt and others, 2008). Thus, the concept of reference conditions must be sufficiently flexible to account for uncertain future environmental trajectories.

Despite uncertainties associated with current and future trajectories of change, six additional persistent conditions of sagebrush steppe ecosystems are pertinent for purposes of management and monitoring (fig. 3.5; table 3.3). Relative to reference conditions, five of these (conditions B-F) represent differing degrees of alteration attributable to effects of landtype conversions, invasive exotic plants, altered fire regimes, and land uses such as livestock grazing and off-road vehicle travel. Due to the extent to which sagebrush steppe ecosystems have been altered, the integrity of these systems and the long-term viability of several associated wildlife species are imperiled on a regional basis (Leopold, 1941; Billings, 1990; Miller and others, 1994; Noss and others, 1995; Miller and Rose, 1999; Beck and Mitchell, 2000; Knick and others, 2003; Connelly and others, 2004; Thines and others, 2004; Welch, 2005; Chambers, 2008). Depending on site-specific ecosystem properties and histories (for example, specific ecological sites), there may be numerous expressions and intergradations of these five basic types of altered sagebrush steppe ecosystems. Moreover, it may prove impossible for managers to perfectly restore ecosystems once they have been changed from the reference conditions, particularly in the context of climate change. Condition G (fig. 3.5) represents a restored condition that has resistance and resilience but differs from the reference condition.

Transition to Dominance by Exotic Annual Grasses. Figure 3.6 illustrates multiple drivers and processes that may lead to increasing dominance of exotic annual grasses such as cheatgrass (Bromus tectorum), red brome (B. rubens) and medusahead (Taenatherum caput-medusa) in sagebrush steppe and other types of dryland ecosystems. In addition to propagule availability (not depicted in the model), safe sites (Harper, 1977) and soil resources (water and mineral nutrients) are critical factors enabling the establishment and proliferation of invasive exotic grasses. Soil disturbance is a primary mechanism that increases the availability of safe sites for the establishment of exotic annual grasses in sagebrush steppe by damaging the functional integrity of biological soil crusts (Mack and Thompson, 1982).

Davis and others (2000) proposed a simple conceptual model illustrating their hypothesis that an ecosystem becomes more susceptible to invasion when there is an increase in the amount of resources that otherwise limit invasion. According to this model, factors that cause a pulse in resource supply (for example, precipitation events or fire) or a reduction in resource uptake (for example, episodic mortality of community dominants) may enable the rapid population expansion of responsive invaders that previously existed in the ecosystem at low levels. Other workers also have emphasized the importance of temporal and spatial patterns of resource availability as factors affecting ecosystem susceptibility to invasion and dominance by exotic species (Johnstone, 1986; With, 2002), including patterns of cheatgrass invasion in sagebrush steppe ecosystems of the Great Basin (Chambers and others, 2007; Norton and others, 2007).

Transition to Dominance by Trees.--"Encroachment" and increasing dominance of trees and/or shrubs in grasslands, savannas, and shrubsteppe vegetation is one of the most widely documented patterns of vegetation change in dryland ecosystems around the world (Archer, 1994; Miller and Rose, 1999; Archer and Stokes, 2000). Factors proposed most commonly as explanatory mechanisms include excessive grazing by domestic livestock, fire-suppression efforts, and climate (fig. 3.7). Elevated atmospheric $\mathrm{CO}_{2}$ also has been suggested as a factor (Polley and others, 1996, 1997), although Archer and others (1995) argued that $\mathrm{CO}_{2}$ enrichment is an insufficient explanation for observed patterns of vegetation dynamics. Climate plays an important role due to effects on population dynamics and competitive relations of herbaceous versus woody plants, but persistent excessive grazing by domestic livestock generally has been implicated as the most important driver of transitions involving increasing dominance of unpalatable woody plants (Archer and others, 1995).

Selective herbivory can affect the competitive relationships of plants, favoring the establishment and growth of unpalatable plants over those of palatable plants (Briske and Richards, 1994). The reduction of aboveground herbaceous biomass and litter by grazing also can reduce the availability of fine fuels required to support a regime of frequent surface fires. Where such a fire regime is important for constraining the dominance of fire-intolerant woody vegetation, the removal of fine fuels by grazing may be more important than reduced herbaceous competition or fire-suppression efforts as a driver of ecosystem change (Archer, 1994; Archer and others, 1995).

These same factors have been proposed as mechanisms enabling increases in tree establishment in sagebrush steppe ecosystems of the Great Basin (Miller and Tausch, 2001; Miller and others, 2005). In shrubsteppe ecosystems, tree establishment also can be facilitated by shrubs that ameliorate environmental conditions experienced by tree seedlings (Chambers, 2001). Fire-regime alteration has been suggested as a major driver of tree encroachment in the Great Basin (Miller and Tausch, 2001; Miller and others, 2005), but spatial variability in the relative importance of this factor is poorly understood (Baker, 2006; Romme and others, 2007). 


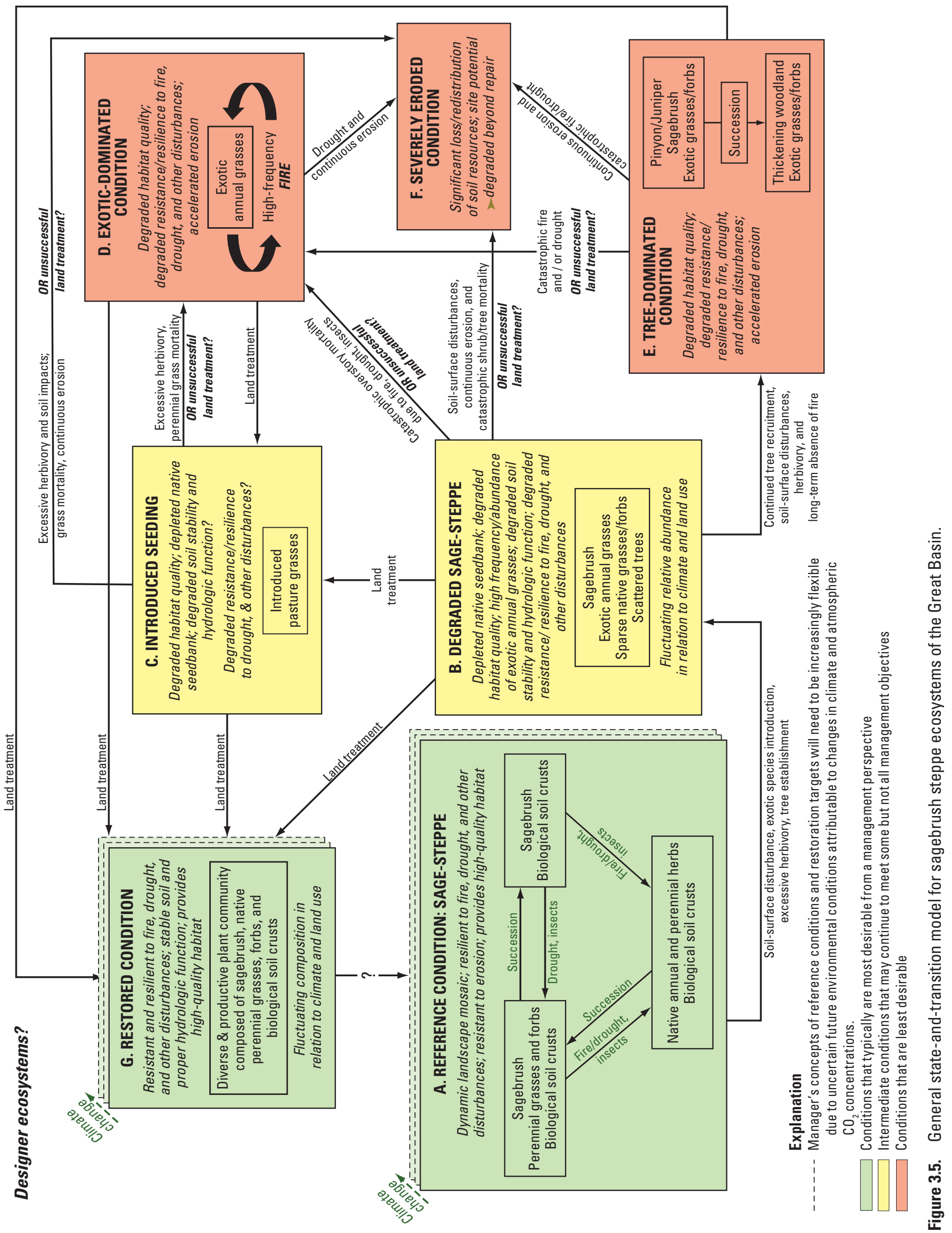


Table 3.3. Characteristics of six general persistent conditions of sagebrush steppe ecosystems in the Great Basin.

[Letters B-G refer to boxes depicted in figure 3.5]

\begin{tabular}{|c|c|}
\hline State & General characteristics \\
\hline D. Exotic dominated & $\begin{array}{l}\text { Dominated by exotic annual grasses such as cheatgrass and typically perpetuated by a positive feedback } \\
\text { between annual grass dominance and the occurrence of high-frequency surface fires (for example, } \\
\text { D'Antonio and Vitousek, 1992; Brooks and others, 2004). Habitat quality and native biodiversity are low } \\
\text { relative to reference conditions, and the potential for accelerated erosion may be high if ground cover } \\
\text { provided by annual grass populations fluctuates strongly in relation to climate. }\end{array}$ \\
\hline F. Severely eroded & $\begin{array}{l}\text { Characterized by an extreme loss or alteration of soil resources and biogeochemical / hydrologic processes. } \\
\text { Site conditions have been altered to the degree that characteristic species can no longer be supported on } \\
\text { the site. }\end{array}$ \\
\hline G. Restored & $\begin{array}{l}\text { Results from successful ecological restoration of key ecosystem components and processes that are required } \\
\text { for long-term sustainability of an ecosystem that is structurally and functionally similar to the reference } \\
\text { condition. Depending on site history (for example, legacies of past land-use activities), as well as on } \\
\text { ecological and socioeconomic constraints to restoration, it may not be possible to fully restore the } \\
\text { damaged ecosystem to reference conditions. But a successfully restored ecosystem should be able to } \\
\text { sustain a wide range of valued ecosystem services without further management intervention. As with the } \\
\text { reference condition, the prospects of changing climatic and atmospheric conditions indicate the need for a } \\
\text { flexible notion of restoration targets. Legacies of past land-use activities, multiple management objectives, } \\
\text { and shifting concepts of reference conditions and restoration targets suggest that managers and restoration } \\
\text { practitioners will increasingly be developing "designer ecosystems" as they seek to restore native diversity } \\
\text { and resilience to damaged ecosystems (Pimm, 1996; Palmer and others, 2006; Seastedt and others, 2008). }\end{array}$ \\
\hline
\end{tabular}




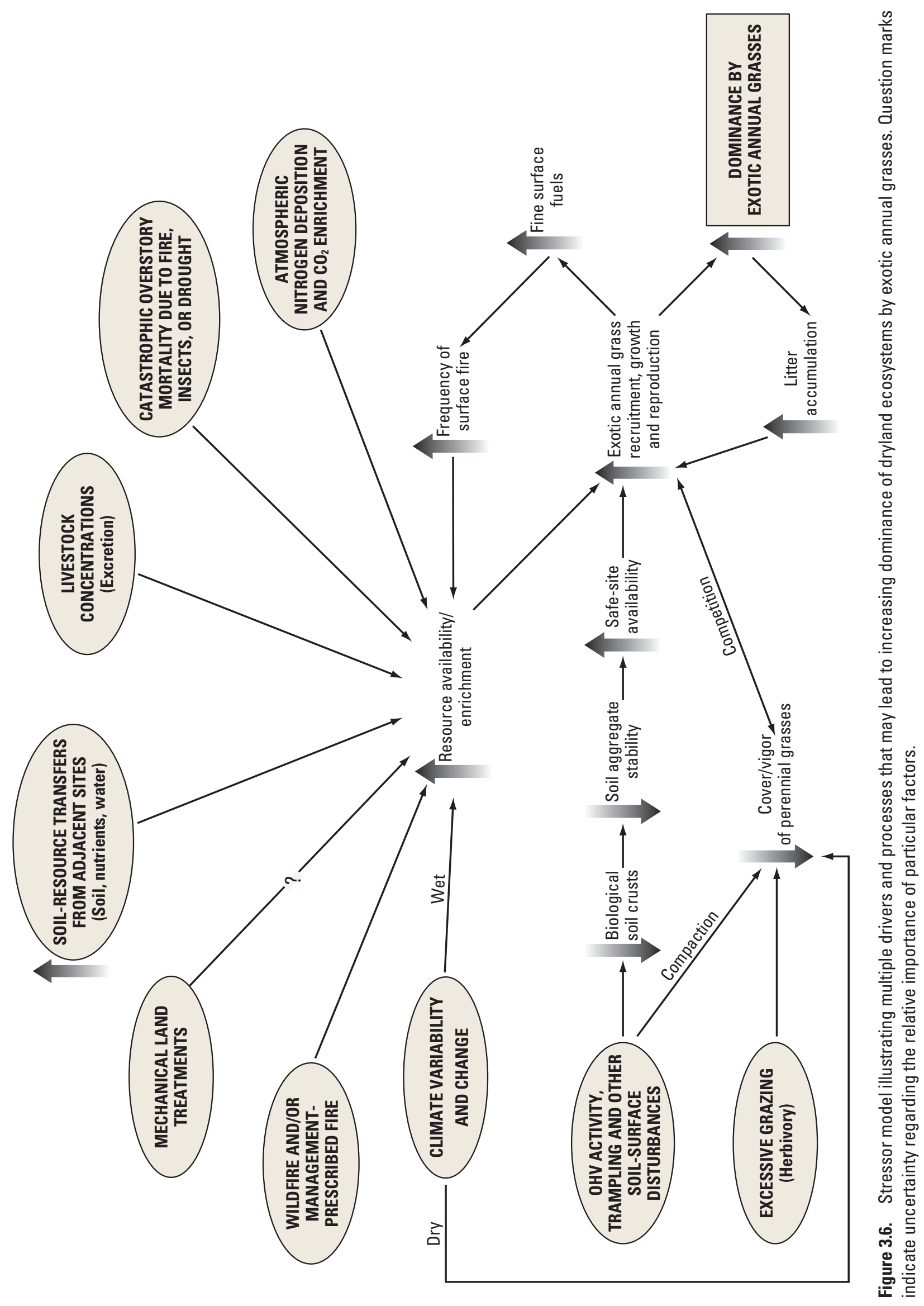




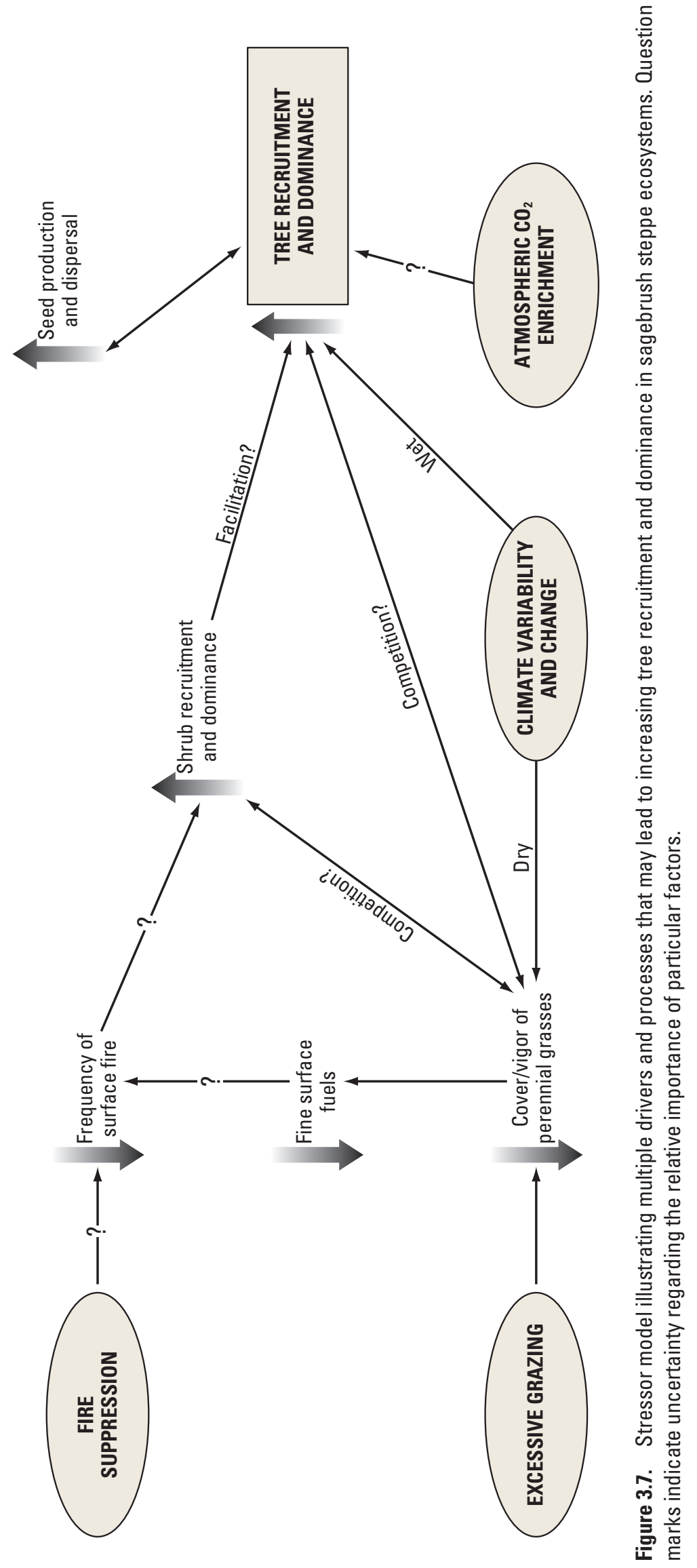


Soil Erosion and Loss of Site Potential.-Figure 3.8 illustrates multiple drivers and processes that may lead to increasing rates of soil loss and redistribution in sagebrush steppe and other types of dryland ecosystems. Soil resources can be eroded and redistributed by wind and water. The relative importance of wind- versus water-driven erosion depends on soil properties, topography, vegetation structure, and the relative frequency and magnitude of erosive wind versus precipitation events (Breshears and others, 2003). Wind erosion has been determined to greatly exceed water erosion in some shrubland ecosystems (Breshears and others, 2003), although such comparisons have not been conducted for sagebrush steppe.

Whether wind or water is the driving force, factors leading to accelerated rates of soil erosion and redistribution are similar. Trampling and other soil-surface disturbances reduce soil stability by disrupting biological soil crusts that protect and retain soils against erosive forces of wind, rain, and runoff (Williams and others, 1995a; Belnap and Gillette, 1998; Okin and others, 2001). Soil-surface disturbances also disrupt stable soil aggregates that enhance soil stability and soil infiltration capacity (Thurow, 1991). By reducing herbaceous cover and organic-matter inputs from litter and roots, excessive grazing can diminish soil protection and soil aggregate stability (Thurow, 1991). Decreases in vegetative ground cover and biological soil crusts also can result in accelerated erosion due to diminished capacity to obstruct erosive wind and overland flow of water (Davenport and others, 1998; Reid and others, 1999; Ludwig and Tongway, 2000). Yeo (2005) examined vegetation and soil-surface properties inside and outside 19 long-term grazing exclosures in sagebrush steppe and salt desert scrub in east central Idaho and determined that erosional features (for example, pedestals and evidence of soil movement and overland water flow) were more pronounced outside the exclosures - indicating greater soil stability and hydrologic functioning inside exclosures where interspaces were no longer subject to trampling by livestock. Increasing dominance of shrubs and trees may result in accelerated rates of runoff and erosion due to competitive reductions in herbaceous ground cover and its capacity to stabilize soils, obstruct overland flow, and capture sediment in interspaces among woody plants (Wilcox and others, 1996). This process may be accelerated further where intercanopy soil-surface disturbances increase the connectivity of flow paths on hillslopes and reduce the capacity of shrub or tree mounds to capture overland flow (Spaeth and others, 1996; Eldridge and Rosentreter, 2004). In some settings, relatively small reductions in herbaceous ground cover may trigger large increases in runoff and erosion (Davenport and others, 1998). Factors contributing to the occurrence of such erosion thresholds include soil structure, texture and rock content; slope length and gradient; and the spatial distribution of vegetation patches, biological soil crusts, and other features that control the connectivity of flow paths (Davenport and others, 1998).
Increasing dominance of exotic annual grasses, mechanical land treatments, and fire also may result in accelerated soil loss. Relative to perennial plants and biological soil crusts, annual plants are likely to experience greater climate-driven fluctuations in cover. Thus, dominance by annuals may result in greater exposure of bare ground to erosive forces of wind and water during drought periods if annuals fail to germinate. Mechanical land treatments, such as use of an anchor chain or pipe harrow (Stevens and Monsen, 2004), can have multiple effects on erosional processes. Where such treatments are conducted to remove intact vegetation, reductions in vegetation structure and associated soil disturbance may result in significant short-term increases in soil erosion by wind. Treatments may reduce erosion by water where they disrupt existing flow paths, enhance soil-surface roughness, and thus facilitate retention of overland water flow. However, net effects of treatments on soil loss will depend on factors that determine the relative magnitude of water- versus wind-driven erosion as well as long-term treatment effects on vegetation cover and soil stability. Although most treatments are undertaken with the intent of reducing soil loss through long-term increases in cover of perennial grasses, monitoring efforts rarely are adequate for evaluating short- versus longterm treatment effects. Similarly, removal of vegetation by fire can generate large increases in soil erosion by wind (Whicker and others, 2002) and water (Johansen and others, 2001), but net effects on soil loss will depend on rates of post-fire vegetation recovery, soil properties, and topographic setting. Finally, climate plays a key role in erosion due to effects on vegetation cover (for example, rates of post-treatment and post-fire vegetation responses) and the frequency of erosive wind and precipitation events. As soil resources are lost due to erosional processes, declining resource availability may generate a positive feedback that facilitates further decreases in vegetative ground cover and further increases in erosion (for example, Friedel and others, 2003; Sparrow and others, 2003; Tongway and others, 2003).

\section{Pinyon-Juniper Woodlands}

Figure 3.9 illustrates a general state-and-transition model for pinyon-juniper ecosystems (persistent-woodland types) of the Great Basin. The structure of the model is similar to that depicted for sagebrush steppe ecosystems, with the Reference Condition (fig. 3.9, Box A) characterized by biotic and abiotic ecosystem components and processes present and functioning within their natural range of variability, but potentially drifting away from historic conditions due to effects of changing climate and atmospheric $\mathrm{CO}_{2}$ concentrations. The model depicts four additional persistent conditions of pinyon-juniper ecosystems. Key characteristics of a degraded woodland (fig. 3.9, Box B) are altered understory plant community composition (shift in relative dominance from native perennial grasses and shrubs to dominance by exotic annual grasses), a depleted native seedbank, and loss of soil 


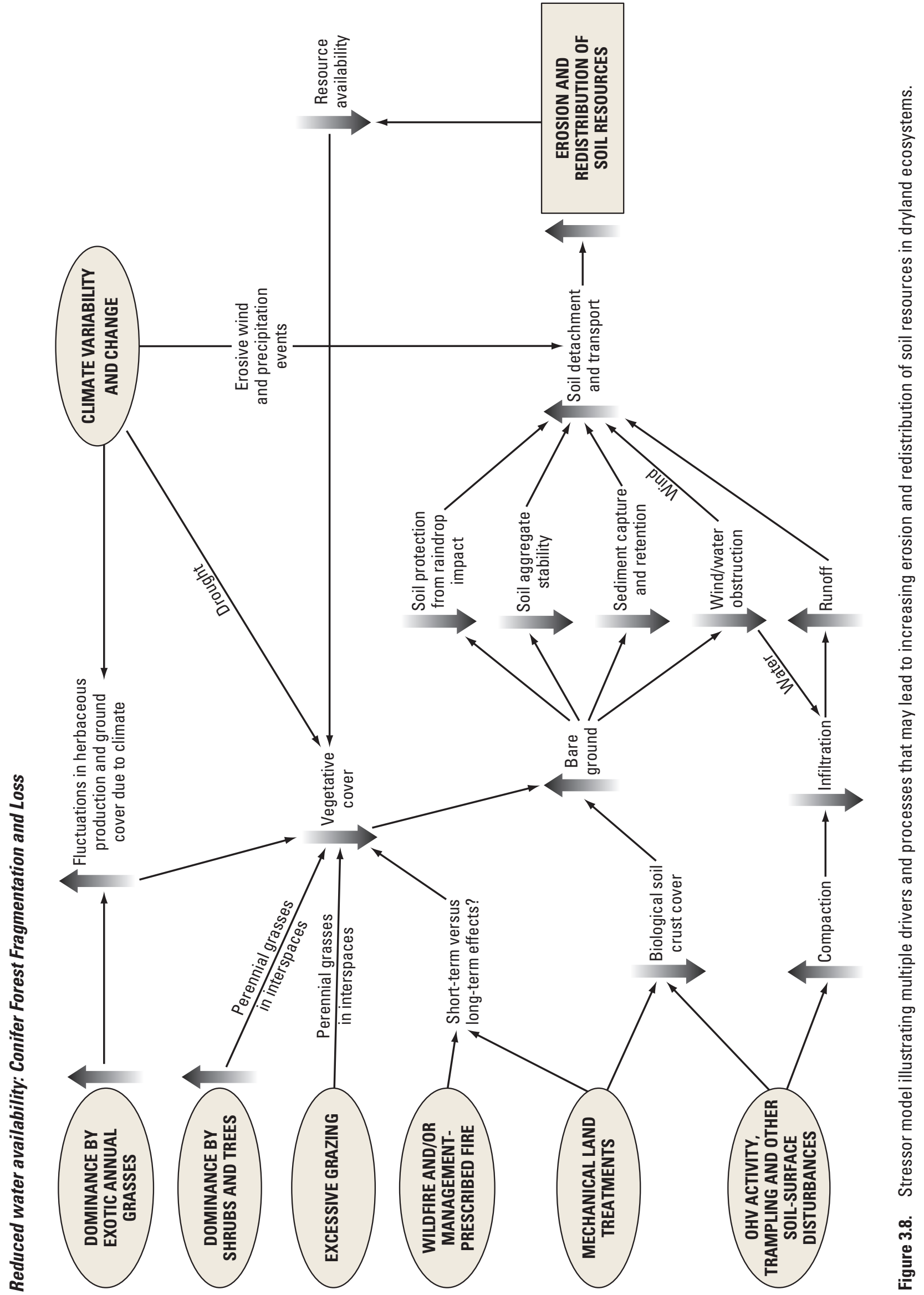



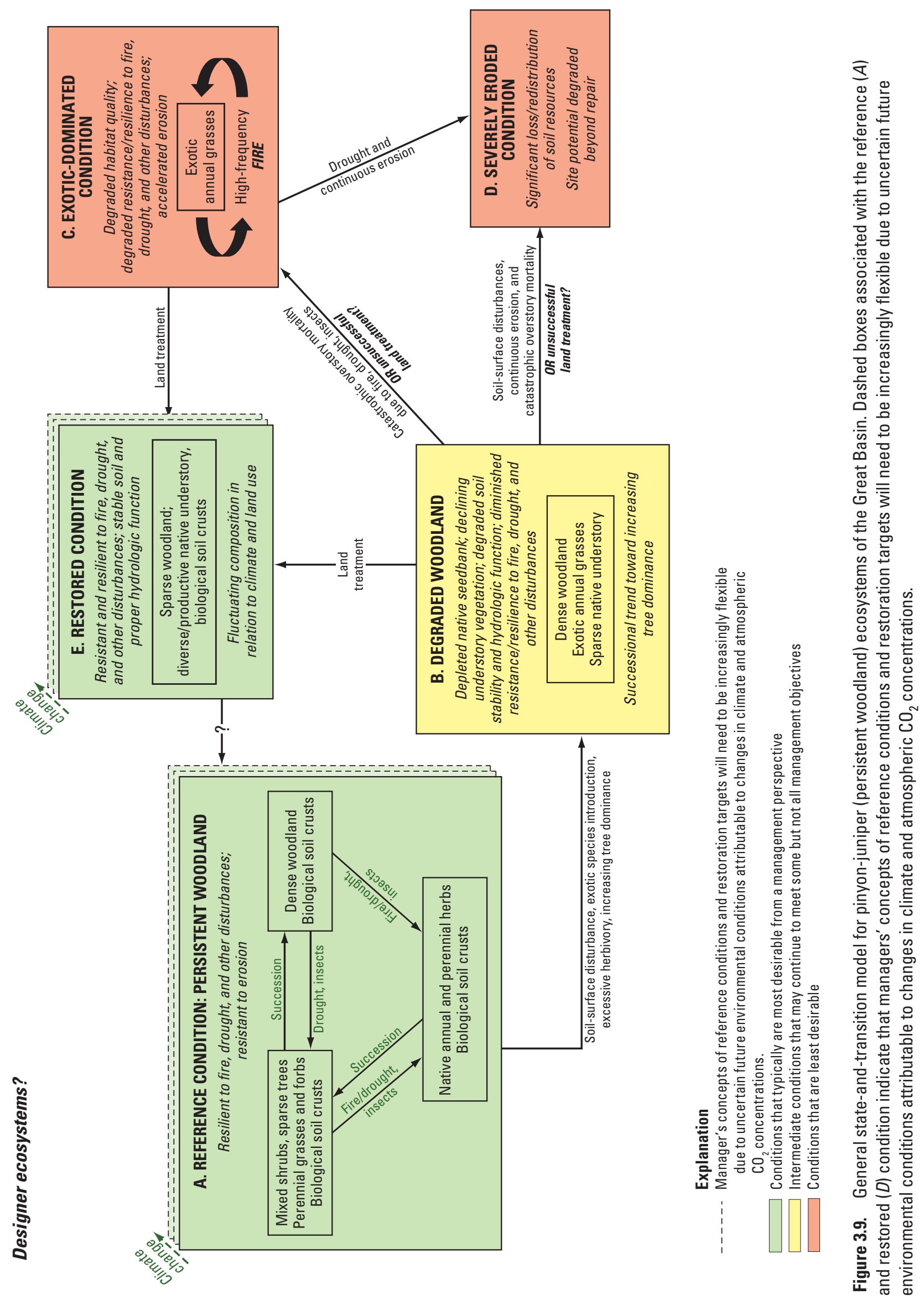
stability due to soil-surface disturbances. As a consequence of altered understory composition, resilience to drivers such as high-severity fire is reduced and the risk of conversion to dominance by exotic annual grasses is increased relative to the reference condition (West, 1999; Romme and others, 2003) - even if high-severity fire is considered to be "natural" for pinyon-juniper ecosystems. Processes leading to increasing dominance by exotic annual grasses (fig. 3.6) and to soil erosion and redistribution (fig. 3.8) are similar to those described for sagebrush steppe ecosystems. Depending on sitespecific ecosystem properties (for example, specific pinyonjuniper ecological sites), there may be numerous expressions and intergradations of these basic types of altered or degraded pinyon-juniper ecosystems.

\section{Summary Points}

Sagebrush steppe and pinyon-juniper woodlands together account for about 60 percent of the land area in the Great Basin. These ecosystems are dominated by varying proportions of shrubs, perennial grasses, and other herbaceous plants, trees, and biological soil crusts, and they provide numerous benefits to society including habitat for valued wildlife species, livestock forage, fuel wood, watershed services, and recreational opportunities. The capacity of these systems to provide this suite of benefits is threatened by numerous processes that can lead to persistent alterations in vegetation composition and structure, soil resources, and patterns of ecosystem dynamics. In sagebrush steppe, dominance by invasive exotic grasses and dominance by encroaching tree populations are the two most persistent and pervasive vegetation changes that have had widespread implications for ecosystem dynamics and management. In pinyon-juniper woodlands, increasing dominance by invasive exotic plants likewise has significant management implications through potential effects on risks attributable to wildland fire. Some of the most important anthropogenic stressors that contribute to the occurrence of these persistent changes include excessive herbivory by livestock, altered fire regimes, and soil-surface disturbances by livestock trampling and off-highway vehicle use. Ecosystem responses to these and other anthropogenic factors commonly depend on climatic conditions and natural disturbance regimes. Projecting the future dynamics and condition of these ecosystems over the next 50 years is hampered by the need to better understand effects of changing climatic conditions and atmospheric $\mathrm{CO}_{2}$ concentrations on soil resources, competitive relations among plants, and fire regimes. Future dynamics and condition of these ecosystems also are hampered by a need to understand how ecosystems responses to the interactive effects of climate and land use vary spatially in relation to soil-geomorphic properties, landscape configuration, and patterns of human growth and infrastructural development.

\section{Aspen Forests}

In the Great Basin, aspen forests grow in relatively pure stands associated with upland riparian corridors and in 'snow pockets' where delayed snowmelt results in mesic soil conditions later into the growing season. In both situations aspen forest stands tend to be small ( $\leq 8 \mathrm{ha}$ ) and individual trees often do not meet their growth potential due to environmental limitations. Nevertheless, aspen groves provide valuable habitat for a range of species, most notably cavity nesting birds and bats (DeByle and Winokur, 1985; Dobkin and others, 1995; Parsons and others, 2003) and also provide valuable forage. Aspen most commonly regenerates by means of vegetative sprouting from the root system following disturbances, such as a fire that kills the mature trees.

However, rare episodes of seedling recruitment occur (Jelinski and Cheliak, 1992). Aspen stands appear to be decreasing across the west (for example, Beever and others, 2005). Fire suppression has been identified as the most widespread proximal factor, but elk browsing and domestic cattle grazing also have been recognized (Rogers, 2002; Larsen and Ripple, 2003). Developing a specific set of conceptual models for this system is beyond the scope of this study.

\section{Mixed Conifer Forest Model}

By S.P. Finn

\section{Distribution and Management Significance}

Coniferous forests (excluding pinyon-juniper woodlands) cover 4.4 percent of the Great Basin landscape (derived from Kuchler, 1970), typically at high elevations on many of the 300+ interior mountain ranges and in the Sierra, Cascade, Wasatch, and other ranges that form the west, north, and east margins. Interior forest stands are patchily distributed at the coarse-scale whereas peripheral stands are more continuous and grade into other forest-types in adjacent ecoregions (Cronquist and others, 1972). In spite of their limited distribution, Great Basin forests contribute significantly to the biodiversity of the ecoregion; a host of plants, animals, and fungi closely linked with coniferous forest structure and microclimate are not found in other Great Basin systems. In the arid Great Basin, the distribution of vegetative communities primarily is determined by soil moisture, which is a function of the amount and timing of precipitation, insolation, geomorphic setting, elevation, and local soil properties. Coniferous forest replaces lowerelevation woodland and shrubland cover-types only where water is abundant enough in the soil-root zone during the growing season such that the balance between soil moisture, groundwater, and transpiration favors evergreen trees (Charlet, 1996). Forests are limited at their upper elevational bound by the extreme weather (strong winds, blowing ice, winter drought) and late season snow cover of the alpine tundra (Stevens and Fox, 1991; Sveinbjornsson, 2000). 
Across the region, conifer forest stands are isolated by arid, shrub-dominated basins. Their present location is the result of either long-term climate trends that favored shrubland and grassland cover types at low elevations (Martin and Mehringer, 1965), or bird-aided conifer seed dispersal to suitable high-elevation growing locations that were (and are) separated by inhospitable interstices (Wells and Berger, 1967). Currently, the position of interior conifer forest patches on the Great Basin landscape is not unlike an archipelago of oceanic islands. The arrangement presents an ideal backdrop for natural experiments in continental island biogeography (Wells, 1983; Brown, 1978), as well as potential dispersal barriers for the many low-vagility plant and animal species that inhabit forest patches. The literature suggests that some borealassociated trees are capable of direct or bird-aided dispersal among mountain ranges (Wells, 1983). More vagile species of birds (Behle, 1978), mammals (Skaggs and Boecklen, 1996; Lawlor, 1998), and butterflies (Wilcox and others, 1986) also are capable of dispersal among isolated forest patches (Brown, 1971). However, individuals of many less-mobile taxa, including some birds and butterflies, are not likely to cross the vast shrubland matrix surrounding montane forest patches. Some of these disjunct or isolated populations may be particularly vulnerable to extirpation because they are unlikely to receive immigrants from nearby patches (Brown, 1971; Johnson, 1975; Wilcox and others, 1986; Beever and others, 2003; Grayson, 2005). Thus, changes in the rates or intensities of ecosystem drivers, like climate change or fire regime, that influence the location or continuity of Great Basin coniferous forests may have significant effects on the composition and diversity of associated biota.

Nearly all Great Basin forests are managed by the U.S. Forest Service (USFS) or BLM for multiple uses. Great Basin National Park is managed to conserve its natural and historic value and provide for visitor enjoyment. Historically, most forests in the region were heavily logged between 1860 -1890 when nearly all merchantable timber was harvested for mining and homesteading (M. Hampton, U.S. Forest Service, oral commun., 2008). Commercial timber harvest continues only in forests along the boundary and a few interior forests in southeast Oregon. Great Basin forests also produce wood for fuel and other local uses, livestock forage, watershed and ecosystem services, and a variety of recreational opportunities. Forests positioned on or near other desirable resources (for example, mineral deposits or wind energy potential) may be altered as a consequence of commodity production and transport.

\section{Components and Processes}

\section{Climate and the Physical Template - Determinants of Site Potential}

Interactions among a suite of abiotic factors (climate, elevation, landform, geology, and soils) determine the potential vegetative structure of a given site (Jenny, 1980; Long, 2003) and form integral portions of our conifer forest subsystem model (fig. 3.10).

Conifer forests in the Great Basin typically are found on sedimentary (limestone, dolomite, sandstone, siltstone) and igneous (rhyolite, andesite, basalt, granite) parent materials that mostly arose from continental rock uplifted in fault-block mountain ranges (Hunt, 1974). Those formations tend to be highly stable through human time scales, but forests also can develop locally on alluvium and colluvium, which are more prone to short-term geomorphic change and disturbances. In the Basin and Range Province, these landforms have been repeatedly modified during recurrent periods of active erosion and deposition as well as by soil formation during periods of greater landscape stability (Peterson, 1981). Spatial patterning of soil properties such as depth, particle size, and degree of profile development are highly complex across the landscape (Peterson, 1981). Coniferous forests are supported by a diversity of parent materials, landforms, and soils that complicate generalizations made about their physical and biotic characteristics. Different types of soils and plant communities tend to be associated with different landforms as well as with finer-scale elements of landforms (Peterson, 1981; Monger and Bestelmeyer, 2006).

Climatic factors are dynamic over much shorter temporal scales than topography and geology and therefore exert more proximate influences on the location and composition of Great Basin coniferous forest. Timing of precipitation is important to vegetative cover because it influences the annual hydrologic budget that determines factors such as soil moisture and evapotranspiration rates. Precipitation arrives primarily as winter snow throughout much of the region (Bailey, 1995) but the eastern part of the Great Basin often receives monsoon rainfall concentrated in late summer (Tyler and others, 1996). In the Great Basin, coniferous forests generally are found only on sites where average annual precipitation exceeds about 25 $\mathrm{cm}$ on south-facing slopes and about $17 \mathrm{~cm}$ on north-facing slopes (fig. 3.11). Climate effects, however, are mediated by elevation and landform. Increasing elevation generally leads to an increase in precipitation, solar radiation, and wind and a decrease in temperature (Peet, 2000). Temperature and solar radiation, among other climate variables, also are influenced by slope-aspect. For example, south-facing slopes tend to be drier and conifer forests there lie at higher elevations (fig. 2.13). Climate trends and climatic contributions to trends in other drivers (for example, fire regime) over the next $50+$ years are likely to exert the most significant influence on Great Basin coniferous forest ecology. 


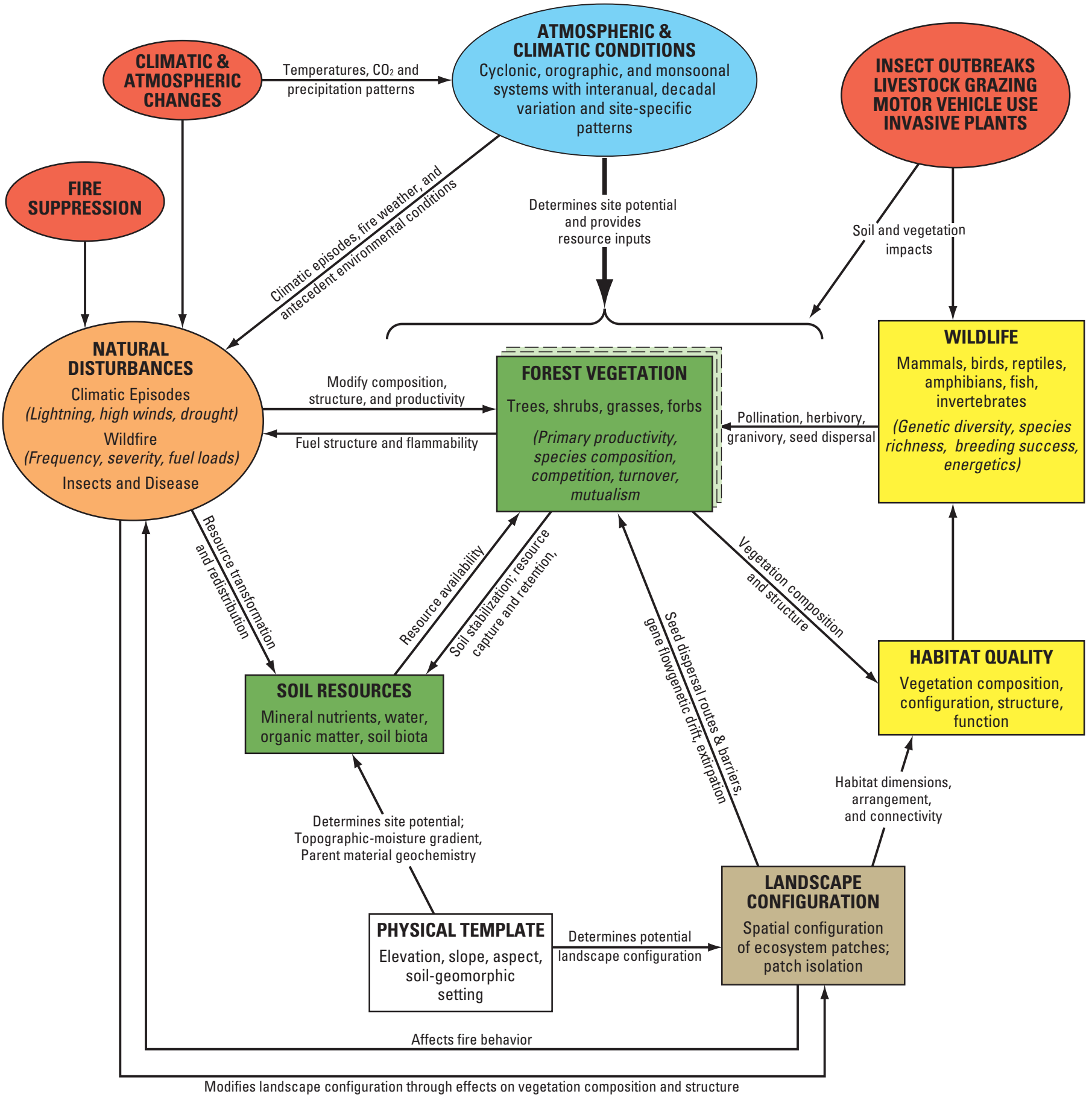

Figure 3.10. Conifer Forest Control Model illustrating key structural components (green rectangles), primary natural (blue oval) and anthropogenic (orange ovals) drivers, and functional relations (arrows) of Great Basin forest ecosystems. Heavy arrows indicate more important functional relations. Hypothetical alternate states that emphasize mountain sagebrush, mountain mahogany, aspen, or several conifer mixes, are indicated by the multiple dashed boxes for Forest Vegetation. States may change due to disturbances, climate variation, pest outbreaks, etc. 


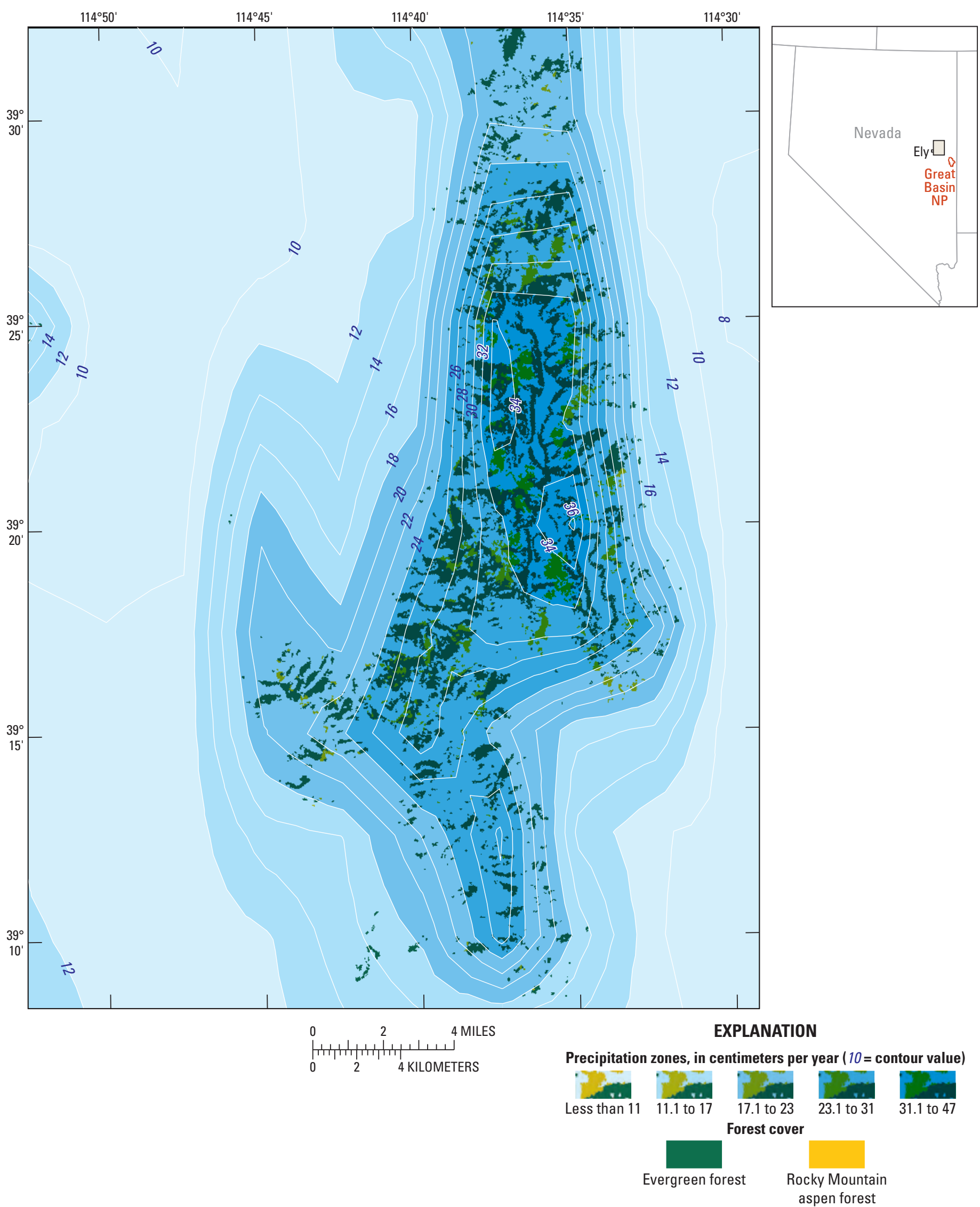

Figure 3.11. Coniferous and aspen forest distribution in the Great Basin is highly correlated with precipitation as shown here in the Schell Creek Range of eastern Nevada. Precipitation data from PRISM Group (2004). 


\section{Vegetation, Soil, and Wildlife Resources}

Vegetation.-Great Basin coniferous forest overstories are composed of a mix of tree species originating from Rocky Mountain or Sierra Nevada floras. In some places, relatively monotypic stands occur (Burns and Honkala, 1990; Charlet, 1996). Tree species richness generally decreases as distance from the western Rocky Mountains increases (Hamrick and others, 1994). Of the 15 species of Pinaceae in the Great Basin, ponderosa pine (Pinus ponderosa), limber pine (Pinus flexilis), and white fir (Abies concolor) are the most widely distributed (Pase and Brown, 1994; Charlet, 1996). In some places, fire adapted stands (that is, mature ponderosa pine) are being replaced by shade-tolerant species (that is, white fir) in part as a result of aggressive fire suppression. Douglas fir (Pseudotsuga menziesii) and Engelmann spruce (Picea engelmannii) are important components in some areas, for example Great Basin National Park. Bristlecone pine (Pinus longaeva), a species noted for its longevity, is an important constituent of the conifer community in many southern Great Basin mountain ranges. Bristlecone pine trees usually exist in open stands between 2,700 and 3,500 m elevation on exposed rocky sites above more densely stocked forest. At lower elevations and in mesic snow pockets, mixed conifer forests commonly include patches of deciduous trees dominated by quaking aspen (Populus tremuloides). Understory vegetation is an important part of the forest ecosystem although the composition and density varies with overstory species composition and closure and site disturbance regimes. Understories generally are composed of conifer seedlings, grasses (Poa spp., Pseudoroegneria spicata), forbs (Lupinus spp., Voila spp.), and shrubs (Ribes spp., Symphoricarpos $s p p$.) growing most densely in canopy gaps. Shade intolerant shrubs such as mountain big sagebrush (Artemisia tridentata vaseyana) and mountain mahogany (Cercocarpus ledifolius) may play successional roles in forest development or arise as alternate stable states in place of conifer forest (fig. 3.10). Other shrubby trees include dwarf maple (Acer glabrum), which grows in moist shady areas with broken canopy between 1,500 and 2,400 m, and serviceberry (Amelanchier spp.) most commonly found on shaded north-facing slopes.

Vascular plants perform many important functions in Great Basin forests. Their presence forestalls erosive effects of wind and precipitation; enhances the capture of nutrients, seeds and surface water; provides copious amounts of organic matter to the soil; and generates oxygen during photosynthesis. Additional functions performed by forest vegetation include sequestration of carbon, mediation of microclimates, and functions within the hydrological cycle. Large woody plants also provide coarse fuel which, in the arid Great Basin, retain relatively little moisture and are characterized by slow decomposition rates. Conifer trees and other forest vegetation provide food and shelter to a broad range of consumers and detritivores.
Soils.- - Soils and soil development are intricately tied to the vegetation community they support. Extant vegetation often is a critical contributor to the upper soil horizon where most biological activity in soils occurs. Ultimately, however, soils are a product of the underlying parent material that largely determines the chemical and physical properties of the soil. Soils supporting Great Basin coniferous forests tend to be gravelly to very gravelly loams and silt loams that have moderate to high permeability, and range from very shallow to deep. Mollisols, in the form of Xerolls and Ustolls, are dominant on Great Basin mountain slopes (U.S. Department of Agriculture, 1998). Xerolls are freely drained Mollisols found in parts of California, Idaho, Nevada, and western Utah. Xerolls tend to be dry for extended periods in summer, but moisture moves through most of the soils in winter and is stored above the deep layers or above bedrock in normal years. Ustolls (also known as Borolls) are Mollisols of the cold-winter semi-arid plains and steppes; they are associated with monsoonal precipitation patterns in the eastern part of the region. Xerolls and Ustolls tend to have a xeric, aridic, or ustic moisture regime, meaning limited amounts of soil water may be present but they generally experience moisture stress during much of the growing season. Xerolls and Ustolls typically have a frigid or cryic temperature regime.

Soils provide nearly all mineral nutrients used by the plant communities they support. In a healthy state, they are the site of most decomposition of organic material, retain water and facilitate infiltration, provide a stable substrate for plant roots, and harbor a diverse community of micro- and macroorganisms that contribute to stability and diversity to the biotic community.

Wildlife and Habitat Quality.-Great Basin coniferous forests host a diverse complement of vertebrate and invertebrate animals. Across the region, species such as silver-haired bat (Lasionycteris noctivagans), ermine (Mustela erminea), Nuttall's cottontail (Sylvilagus nuttallii), and an abundance of birds including band-tailed pigeon (Patagioenas fasciata), dusky grouse (Dendragapus obscurus), Williamson's sapsucker (Sphyrapicus thyroideus), and flammulated owl (Otus flammeolus) are associated with Great Basin coniferous forests. Because dispersal rates vary among species, some forest-associated wildlife populations exhibit a metapopulation structure whereas less-vagile species persist largely as isolated populations with little if any exchange of individuals or genes (Brown, 1978; Cutler, 1991).

Animals perform significant functional roles in Great Basin forest ecosystems. Acts of herbivory, granivory, and digging contribute to enhanced seed dispersal, altered plant distributions, and soil-nutrient turnover. An example is the Clark's nutcrackers (Nucifraga columbiana) role as dispersers of whitebark (Pinus albicaulis; Tomback, 1982) and limber pine (Tomback and Kramer, 1980) seeds. 
Ungulate herbivores, native and introduced, generally are not abundant in the upper elevation Great Basin conifer forests; therefore, their current influence on these systems probably is less than on low elevation shrub and grasslands (see Sagebrush Steppe Model). However, the legacy effects of historical livestock grazing in western coniferous forests is still not fully understood (Fleischner, 1994). Domestic herbivores tend to concentrate under the canopy of forest edges for shade. Effects on vegetation structure and composition and on soil and hydrologic processes from large ungulates in upland forest-types usually are greatest near lower treeline edges, access roads, and water sources (Fleischner, 1994; also see Chapter 4, Stream and Riparian Models).

We know very little about functional contributions of most vertebrates; however, we know even less about many aspects of invertebrate life-histories and their influence on Great Basin forests. Bark beetles (Coleoptera: Scolytidae) are one invertebrate group that is relatively well-studied and their influence on conifer forest health and function can be quite significant (Powers and others, 1999). The potential effect of insect outbreaks is addressed in the section, "Drivers of Ecosystem Change."

\section{Drivers of Ecosystem Change}

\section{Climate Variability and Change}

Climate, including variations across all spatial and temporal scales, is the overriding driver of landscape condition. Increasing temperature and $\mathrm{CO}_{2}$ concentrations in recent decades appear to be of an unprecedented magnitude and rate (Intergovernmental Panel on Climate Change Working Group I, 2001; Connely, 2003) prompting our scoping efforts to identify climate change as a key ecosystem driver in the Great Basin. From the perspective of ecosystem responses, the causes of climate changes are somewhat irrelevant; it is more important to understand the rate and directionality of climate-induced landscape change so we rely on appropriate models to evaluate future climate scenarios.

As described in the atmospheric model, existing climate models generally lack details necessary to understand climatic influences on the topographically diverse Great Basin. Nearly all climate models predict that warmer conditions will prevail in the Great Basin during the next few decades, but the same models disagree over the amount and timing of precipitation over the next 50-90 years. A decrease in precipitation would indicate that forest systems in the region may shrink, move upslope, or disappear from the landscape (for example, Diffenbaugh and others, 2003; Parmisan and Yohe, 2003). Indeed, resampled plots at Great Basin National Park demonstrate that Engelmann spruce is declining in permanent plots within riparian forest habitat at all but the highest elevations, and that the minimum elevation of the species' distribution rose 175-200 m from 1992 to 2001 in three of four drainages studied (Beever and others, 2005). Recent mortalities in some pinyon-juniper stands (Shaw and others, 2005) also might indicate changes in Great Basin vegetation due to climate change (Rehfeldt and others, 2006). Loss of forest would impact plant and wildlife communities associated with forest cover types.

Increased precipitation, especially that falling in winter and remaining as snowpack, may favor conifer forest cover at the expense of xeric shrubland (Thompson and others, 1998; National Assessment Synthesis Team, 2000). Still other models predict that Great Basin conifer forest distributions will remain relatively unaffected by climate shifts over the next century (Rehfeldt and others, 2006).

Because plants will respond to climate changes individualistically (Smith and others, 2000) communitylevel responses remain open to interpretation. Furthermore, forest cover changes resulting from increasing greenhouse gasses and consequent climate change likely will be mediated by many additional factors including nutrient cycling feedbacks, age-dependent responses, and species interactions (Diffenbaugh and others, 2003). Moreover, invasive species that disperse rapidly are likely to find opportunities in newly forming communities (Dukes and Mooney, 1999; National Assessment Synthesis Team, 2000). Thus, the species composition of future communities may differ substantially from those occupying similar habitats today.

\section{Wildfire}

As is the case throughout most of the intermountain west, upland forests of the Great Basin are disturbance-driven ecosystems. Wildfire is the most widespread and significant disturbance agent in the region (Peet, 2000). A direct effect of fire is the alteration of vegetation composition and structure due to the selective damaging or elimination of fire-intolerant life forms or age classes (Whelan, 1995). High-severity fires in woodlands and forests result in near-complete mortality of overstory trees, whereas low-severity fires consume primarily herbaceous surface fuels, litter, and fire-sensitive understory vegetation including seedling and sapling trees. Mixed-severity fires result in a mosaic of patches that can be caused by variations in topography, weather, fuel loading, and previous fire or other disturbance history (Noss and others, 2006). Effects of fire on vegetation structure have many ecosystem-level consequences. Reduction in vegetation cover reduces or eliminates food and cover for most forestdependent wildlife although post-fire vegetation recovery typically increases forage for some herbivores. Erosion of soils, nutrients, and organic matter by water and wind may be exacerbated by fire-caused reduction of vegetative cover and forest floor litter. Soils may become hydrophobic as a result of severe burns leading to accelerated water runoff and decreased infiltration. Fires also may positively or negatively affect nutrient cycles and other soil functions and properties on short- or long- time scales (Raison, 1979; Whicker and others, 2002). 
Natural fire return intervals are estimated to be between 7-30 years in Great Basin conifer forests (Miller and others, 2005; Stevens and others, 2007). Pre-settlement wildfires within conifers probably were low-severity and reduced fine fuels while having minimal effect on mature trees. However, fires impacting conifer patches are affected by adjacent cover types. Thus, severity of a specific fire is influenced by adjacent cover-types and the fire history of those patches as well as their topographic relationships. Because many lower elevation patches are now degraded sagebrush, pinyon-juniper, or annual grass-dominated sites, fire frequencies and intensities generally have increased in upslope conifer stands. Wildfires spreading from adjacent habitats are correspondingly expected to occur more frequently or more intensely, thereby affecting coniferous forest structure, composition, and location.

\section{Livestock Grazing}

Livestock management is arguably the most profound post-settlement human legacy on the Great Basin landscape. Introduction of cattle, sheep, and horses to a landscape nearly devoid of large herbivores in the late 1800s quickly resulted in the decline and eradication of many native grass species and other environmental consequences (Young, 1994). The vast majority of grazing effects were focused in low elevation shrublands, but forests were not spared from damage.

Theodore Rixon was quoted by P.H. Roberts (1963) as stating:

"At the beginning [of livestock grazing in the southwestern US] the mountains and heavily timbered areas were used but little, but as the situation grew more acute in the more accessible regions the use of these areas became more general and in course of time conditions within them were more grave than elsewhere... The mountains were denuded of their vegetative cover, forest reproduction was damaged or destroyed, the slopes were seamed with deep erosion gullies, and the water-conserving power of the drainage basins became seriously impaired."

The high elevation, slightly wetter pastures available in the Great Basin were useful to herders because they generally provided better summer forage than the more xeric basins. As rangeland resources declined due to overstocking, sometimes coupled with drought, forage in the conifer forest understory began to be heavily impacted. Although stocking rates have declined from the early years of livestock management and the sheep industry all but collapsed in the middle of the 20th century, livestock grazing management continues to be an important driver in Great Basin conifer forests and the effects of historic and current disturbance are priority considerations when evaluating landscape change.

\section{Invasive Plants}

Like many Great Basin ecosystem drivers, the effects of exotic, invasive plant infestations are better understood for lower-elevation shrublands and woodlands even though they are a significant forest management concern. Within the last decade, cheatgrass has expanded its range in the pine forests of the southern Sierra Nevada and central Great Basin. The ecological consequences of cheatgrass invasion into forested habitats are not as well documented as in shrub-dominated landscapes (for example: D'Antonio and Vitousek, 1992) although USGS scientists are beginning to assess its effects (M. Brooks, U.S. Geological Survey, oral commun., 2008). Other invasive species recorded in Great Basin forests include Dalmatian toadflax (Linaria dalmatica), diffuse knapweed (Centaurea diffusa), hoary cress (Cardaria draba), and Canada thistle (Cirsium arvense). However, very little specific information exists on the landscape-scale effects associated with these invasions.

\section{Motor Vehicle Use}

Motorized vehicle use is a relatively recent phenomenon in the Great Basin and, consequently, little information exists on its effects on ecosystem components and processes. Motor vehicle use is known to accelerate erosion, potentially increasing silt loads in spring pools and streams (Trombulak and Frissell, 2000). It also contributes to fragmentation of formerly contiguous land cover patches. Resource agencies expend significant time and money managing roads and vehicle access; however, enforcement of transportation policies in such a huge area can be cost-prohibitive. Thus, much of the landscape alteration that is occurring is not well regulated or documented. The quantitative effects of this disturbance across the ecoregion are virtually unknown and, although the effects on the spatially-restricted conifer forest may be less significant that the broader shrubland systems, forest cover is typically identified as a destination by recreationists, hunters, and firewood collectors. Therefore, conifer stands may be disproportionally impacted by motor vehicle use.

\section{Insect Outbreaks}

Native bark beetles (Coleoptera: Scolytidae and Curculionidae) were not initially identified as a priority ecosystem driver of coniferous forests but we include them here because future insect outbreaks may be closely linked with future climates and disturbance regime trends. At least five species of beetles cause natural, cyclical disturbances to conifer species found in the Great Basin. Beetle population abundances and distributions are likely to covary with climate change and historical land-use management practices (Bentz 
and others, 2008). For example, mountain pine beetle and spruce beetle activity is believed to have increased in direct response to warming temperatures (Hansen and others, 2001; Logan and Powell, 2001). Drought-driven moisture stress can increase tree susceptibility to insect colonization. Drought periods also increase the activity of the fir engraver (Scolytus ventralis) in fir stands throughout the Great Basin (Bentz and others, 2008). Bark beetles affect trees directly through their subcutaneous boring action and by facilitating fungal infestations that interrupt the tree's water transport system. Mortality or dieback resulting from insects is likely to interact with changing fire regimes and influence forest health and persistence. Recent concerns also have focused on the introduction of exotic tree pests (Lee and others, 2007).

\section{Ecosystem Dynamics}

The following section describes conceptual models of Great Basin coniferous forests. As hypotheses, these models will be iteratively refined on the basis of new knowledge. These simple models are unlikely to capture all possible ecological processes and outcomes. By themselves, the models do not provide any quantification or predictive framework that will enable managers to anticipate and mitigate change on a site-specific basis. However, they do provide a starting point for a framework. Our general models do not account for sitespecific factors and may require modification for application to a specific type of land unit. Some of the conceptualizations we present (figs. 3.11-3.14) are modified from work done for the National Park Service's Upper Columbia Basin and Northern Colorado Plateau Inventory and Monitoring Networks (Garrett and others, 2004; O'Dell and others, 2005). The models are best viewed as working hypotheses that can be improved with carefully designed monitoring and subsequent analyses.

\section{The Reference Condition}

Because a valid accurate conceptual model accounts for all important ecological states and processes it should accurately describe ecosystem-wide reference conditions. The significant system drivers and interactions are partially a function of a given site's history. Conversely, identifying an ecological reference point has temporal and spatial complications that are especially difficult for Great Basin forests. Indications are that conifers stands were nearly continuous in the early-Holocene Great Basin (Grayson, 1993). Grayson (1993) suggests that the Great Basin 'came to look as it looks today' during the middle Holocene, around 4,500 years before present, although he cautions that reference conditions will differ in different areas. A more practical reference point for conifer forests may be defined as the condition that existed when Europeans arrived in the region in the early 1800 s because timber removal to support mining and livestock introductions began in earnest by about 1860 .
Before that time Native Americans set landscape-altering fires in the Great Basin (Vale, 2002) and although the frequency and extent of ecosystem management and alteration caused by Native Americans is hotly debated (for example, Swetnam and Baisan, 1994; Anderson and Moratto, 1996), it is relatively certain that aboriginal influences on Great Basin forests had less impact than those of Euro-Americans (Fule and others, 1997).

The concept of the reference state, however, must be sufficiently flexible to account for uncertain future trajectories in environmental conditions because, given enough time, even the most identifiable reference conditions are subject to 'drift' based on millennial-scale trends in climate and landscape structure.

\section{State-and-Transition Model}

General patterns of ecosystem dynamics can be effectively illustrated using state-and-transition models (Westoby and others, 1989; Bestelmeyer and others, 2003). State-and-transition models are management-oriented tools for describing and classifying ecosystem conditions (or states) and posing hypotheses about ecological factors responsible for changes (or transitions) among different states (Bestelmeyer and others, 2004). Such models have been very effectively used by managers and researchers in shrubland and other systems but the modeling exercise rarely has been applied to forested systems of the Great Basin. We developed a generalized state-and-transition model for Great Basin coniferous forests (fig. 3.12), borrowing from work presented by Miller (Sagebrush Steppe models NRCS Ecological Site Descriptions, accessed June 23, 2009, at http://esis.sc.egov. usda.gov/Welcome/pgESDWelcome.aspx this volume; fig. 3.5, p. 82) and models being developed by NRCS (accessed June 23, 2009, at http://esis.sc.egov.usda.gov/esis report/fsReport. aspx?id=F030XC279NV\&rptLevel=communities\&approve d=yes) for their Ecological Site Description process. In this model, we depict three general states: the Reference Condition describing a healthy conifer forest experiencing cyclical, successional processes; a degraded forest impacted by some combination of system stressors; and a severely degraded condition, possibly leading to a permanent change in plant community (fig. 3.12; table 3.4). Factors driving transition from one state to another are analogous to the key drivers identified during our scoping effort and include: climate change, wildfire, livestock grazing, exotic plant invasions, motor vehicle use, and insect outbreak. We use our definitions of 'driver' and 'stressor' (see Glossary) to identify drivers within the reference condition when they are operating under natural ranges of variation and stressors in the transition portion of the model when individual or combined effects move the system outside natural successional processes. 


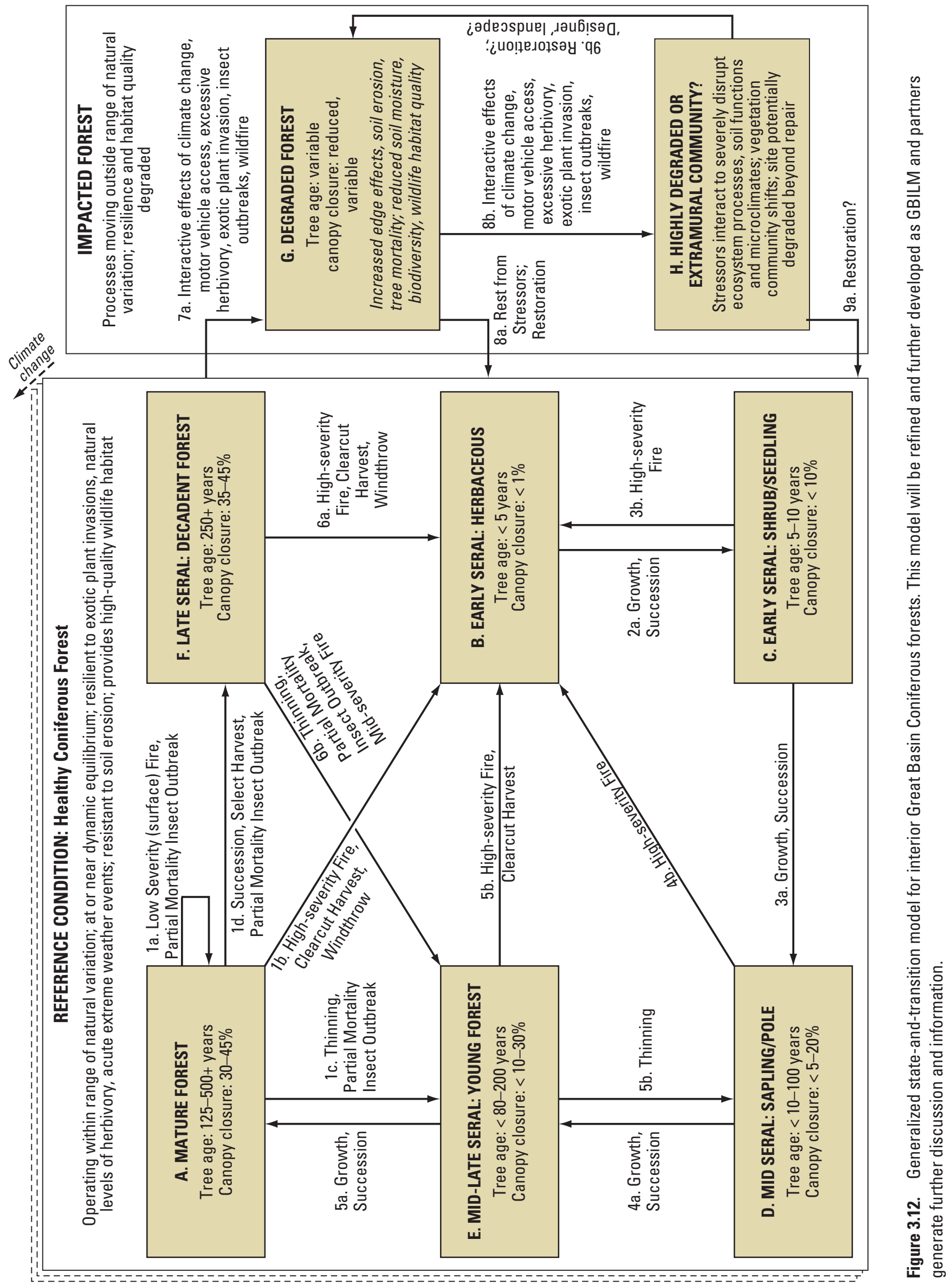


Table 3.4. Characteristics of three general states of coniferous forest systems in the Great Basin.

[Letters A-H refer to boxes depicted in figure 3.12]

State

A-F. Reference Condition

G. Degraded Forest

H. Highly Degraded

\section{General characteristics}

Climate and physical template within natural ranges of variation. Most of region dominated by mature or maturing conifer trees but portions in earlier successional stages and dominated by forbs, shrubs and/or sapling conifers. Soils, litter, and seed banks mostly intact though some erosion evident, especially on steep slopes in disturbance zones. Resilience to anthropogenic disturbances generally high. Native flora and fauna predominate. Predicted climate change likely to favor upslope movement of the entire community (for example, Parmesan and Yohe, 2003; Beever and others, 2005).

Dominant vegetation shifts in terms of species composition, overstory structure, and vigor. Edge effect increase due to driver impact on periphery of stand. Soil moisture and plant biomass reduced. Increased susceptibility to wildfire, plant invasions, herbivore effects, and extreme weather events. Resilience degraded; soil stability and hydrologic functions altered. Wildlife habitat quality reduced. System is likely restorable with rest from certain stressors and/or active restoration.

Characterized by depauperate vegetation community with increasing invasive species. Soil moisture severely reduced such that coniferous trees no longer favored. Overstory structure disrupted by interactive effects of insect damage, wildfire, motor vehicle use, invasives, and climate change. Wildlife habitat altered to the degree that assemblages change, with potential cascading effects. Some species extirpated. Highly degraded systems may not be restorable to reference condition due to ecological or financial limitations and novel, extramural communities may develop. Managers may need to consider targeting 'designer ecosystems' (for example, Pimm, 1996).
State-and-transition models are best applied to specific land units (for example, specific ecological sites) because of the importance of site-specific factors such as local climatic conditions, soil-geomorphic properties, and landscape configuration for determining ecosystem responses to management actions and other drivers of change. Our general model does not account for these site-specific factors or the broad diversity found in Great Basin coniferous forests. They will require modification for application to specific forest types and adjustments as our understanding of forest processes improve.

\section{Stressor Models}

Ecosystem drivers become system stressors when their effects move the system outside the range of natural variability that we characterize as the reference state. Hypothetical processes by which drivers/stressors singly or interactively cause persistent changes in the structure and functioning of coniferous ecosystems are depicted in figures 3.13-3.15. These mechanistic models illustrate potential landscape changes that alter conifer forest systems and are of concern with respect to management objectives. These Stressor Models were developed based on information found in Shafer and others (2001), Diffenbaugh and others (2003), Kupfer and others (2005), Vankat (2005), Rehfeldt and others (2006) and Millar and others (2007). Arrows and boxes in these models are potential monitoring targets. We hypothesize two possible outcomes of driver-stressor interactions that primarily are driven by water availability, the most limiting abiotic factor in these systems except near upper timberline. In one scenario, reduced water availability leads to decreasing forest patch size and potential extirpation of the entire stand (fig. 3.13). A second possible outcome is significant alteration of tree species composition, which may threaten individual species of plants and animals. This outcome could hypothetically result from a decrease (fig. 3.14) or increase (fig. 3.15) in water availability. Climate models generally agree that temperatures will increase, which will effectively reduce soil moisture. As a result, reduced water availability may represent the model needing the most study. Additional trajectories are likely and will be the subject of subsequent quantitative models.

Anthropogenic drivers include directional global climate change, the feedback loop generated by the combination of exotic plant invasions and fires, selective grazing and trampling by livestock, and motor vehicle use (primarily off highway vehicles). Natural drivers, which also may become stressors when compounded by other natural or anthropogenic drivers, include climate variability, lightning-caused wildfire, and insect outbreaks. 


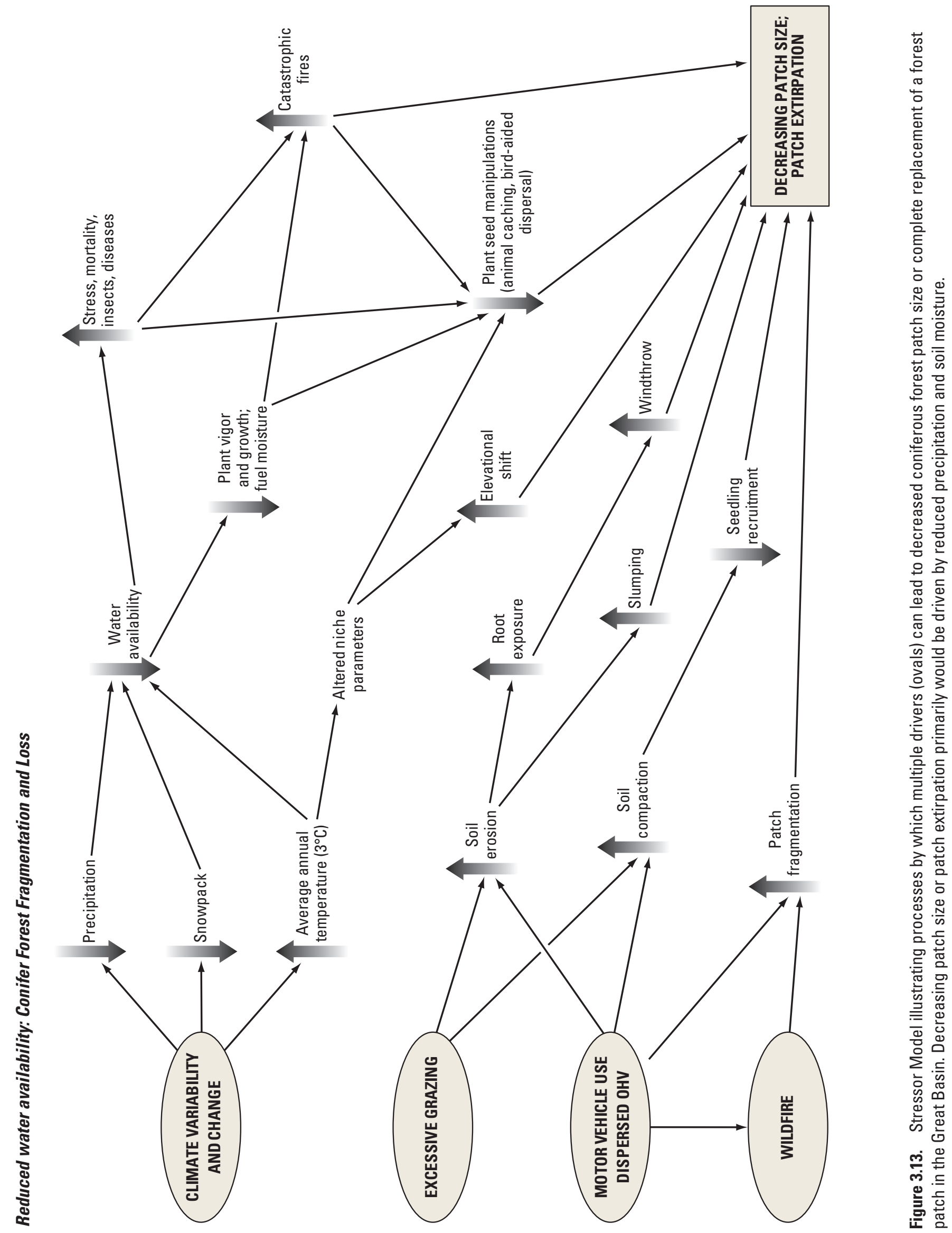




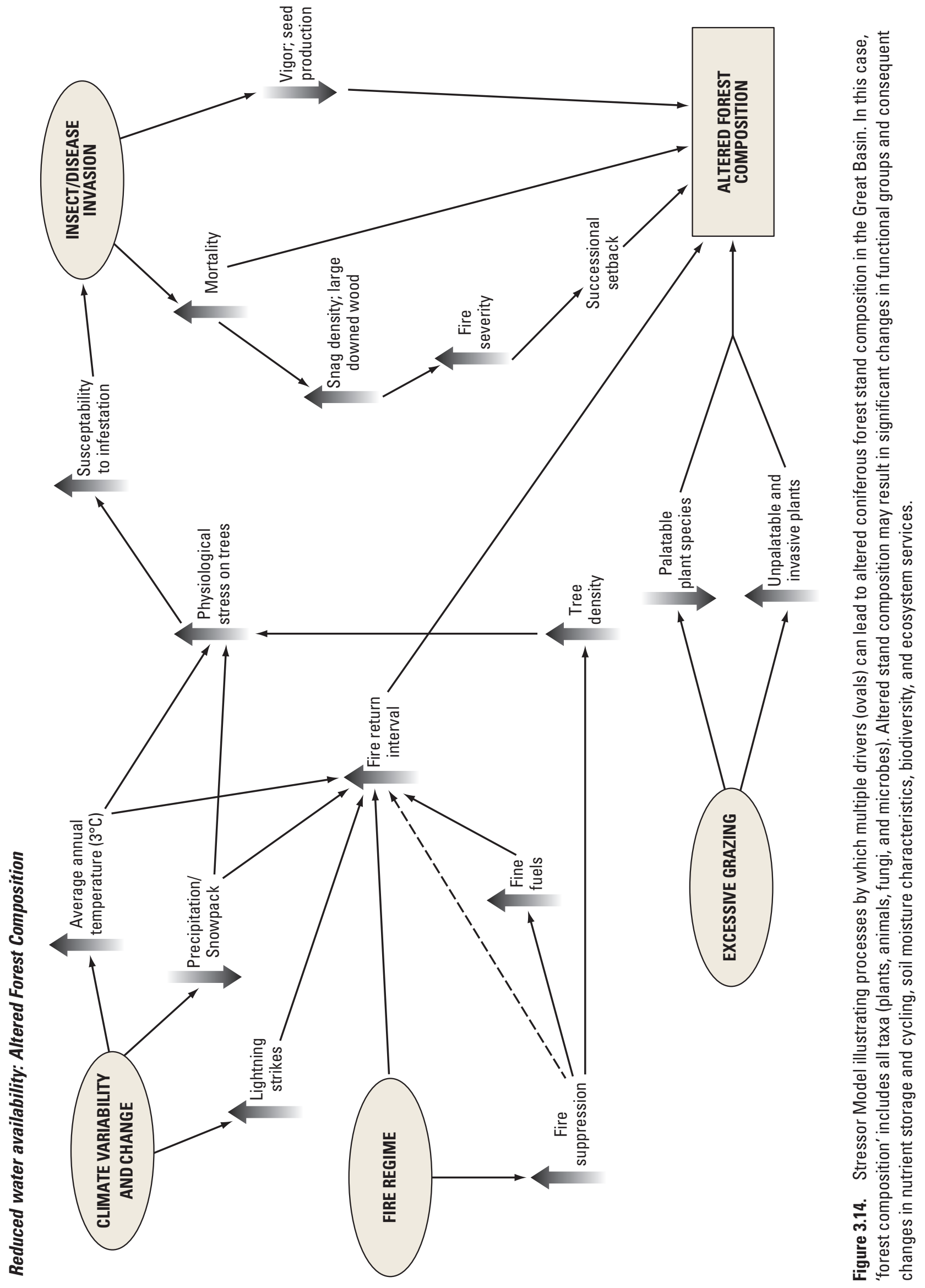




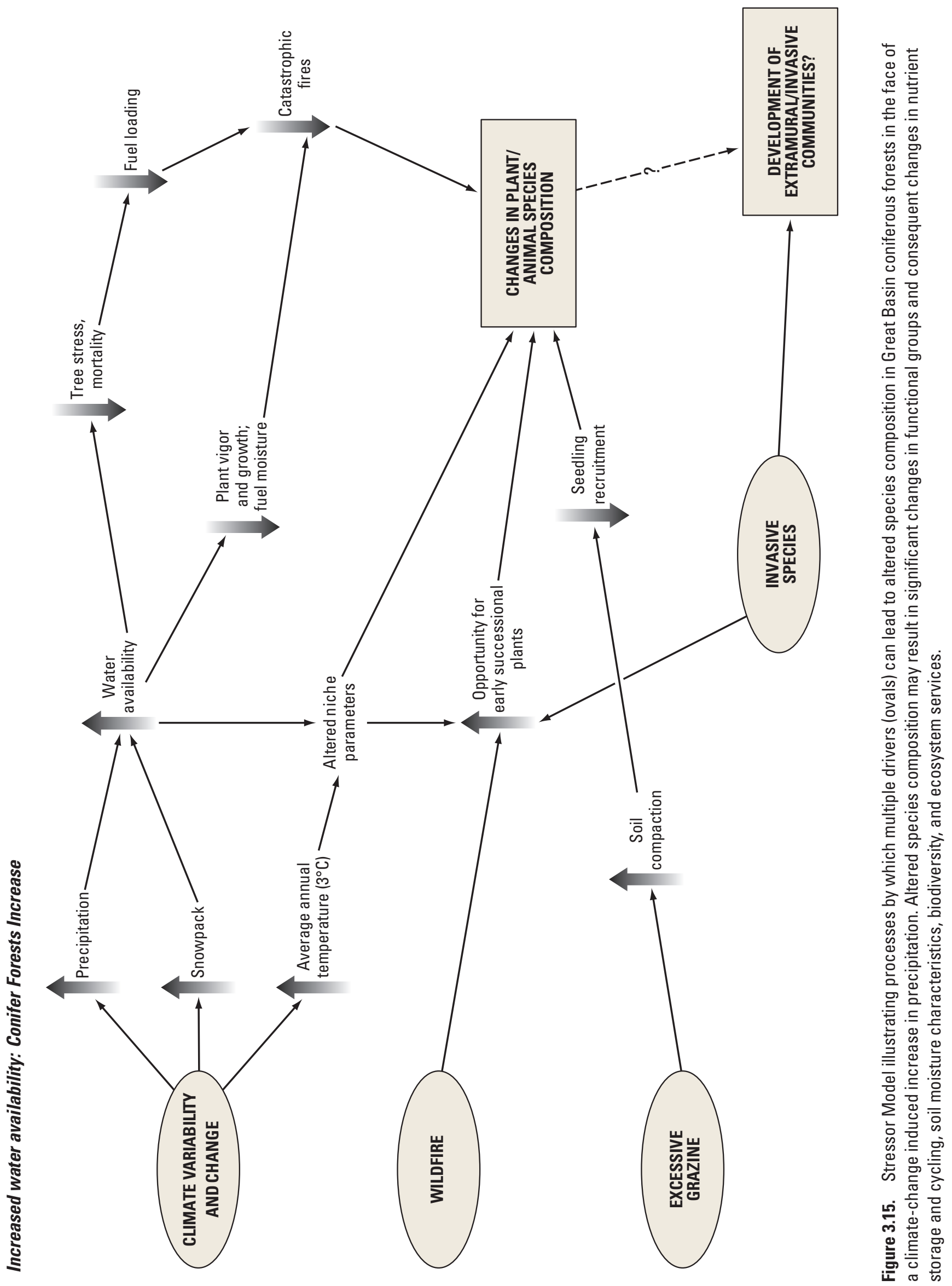


The landscape altering fire-invasive annual grass cycle has been thoroughly documented for low-elevation shrubland systems in the western U.S. (Mack, 1981) and current research is exploring the effects of exotic annual grass invasions in conifer forests (M. Brooks, U.S. Geological Survey, oral commun., 2009). Because impacted and at-risk shrublands abut conifer forest throughout the Great Basin, forest types may be threatened even if annual grass invasions are not altering fire return intervals within the forest cover types (for example, Swetnam and Betancourt, 1998). Fires ignited in shrubland may spread upslope and into conifer forest. However, fires driven by fine-fuel annual grasses tend to be lower in severity and, ignoring potential interactions, are likely to proliferate as ground fires in the forest. Although this may present significant alterations to understory plant communities and animals associated with them, forest cover is more devastatingly impacted by high-severity fires, especially if the fire extends to tree crowns. Fuel moisture in Great Basin conifer forests tends to be very low throughout most of the fire season, rendering a higher susceptibility to stand-altering fires. Records of forest patches being totally removed by catastrophic fire can be found, although total stand removal appears to be historically quite rare. Future scenarios that couple climate change and insect outbreaks with exotic plant invasions and fire indicate that conifer forest - especially smaller isolated stands - may be increasing in susceptibility.

Grazing effects, although not well documented in many coniferous forest types of the Great Basin, generally include alteration of ecosystem processes by decreasing the cover of herbaceous plants and litter, disturbing and compacting soils, decreasing water infiltration rates, and increasing soil erosion (Belsky and Blumenthal, 1997; Beever and Pyke, 2004). Long-term browsing of aspen saplings by wild and domestic ungulates probably accelerates the process of conifer expansion and leads to their eventual dominance over aspen communities (Miller and others, 2001). We hypothesize that grazing will continue to alter forage plant species composition and dominance and affect natural soil functions and movements. We hypothesize that grazing alone would have negligible effects on conifer forest integrity but when interacting with other drivers, these effects contribute to system alteration.

The effects of increased motor vehicle use in Great Basin forests have not been addressed in the ecological literature. However, accounts from other areas indicate that motor vehicle use can lead to increases in soil compaction and erosion (Helvey and Kochenderfer, 1990), opportunities for invasive species (Tyser and Worley, 1992; Gelbard and Belknap, 2003), high incidence of human-caused fire, and a reduction in habitat quality due to increasing fragmentation (Trombulak and Frissell, 2000).
The influence of human-induced climate change on Great Basin forests is more difficult to forecast. Numerous efforts have attempted to forecast potential climate-change induced shifts of western plant communities (Thompson and others, 1998; National Assessment Synthesis Team, 2000; Shafer and others, 2001; Diffenbaugh and others, 2003; Rehfeldt and others, 2006). Global and regional climate models generally agree that air temperatures will increase $3-5{ }^{\circ} \mathrm{C}$ over the next century primarily due to a two-fold increase in atmospheric $\mathrm{CO}_{2}$ (Intergovernmental Panel on Climate Change Working Group I, 2001). Some models predict an increase in moisture (National Assessment Synthesis Team, 2000) whereas others forecast decreased precipitation (Giorgi and others, 1998a; Thompson and others, 1998) or relatively constant precipitation (Diffenbaugh and others, 2003) in some or all seasons over the next century. Increased precipitation, especially that falling in winter and remaining as snowpack, likely would promote an increase in forest cover at the expense of shrub and woodland habitats (National Assessment Synthesis Team, 2000). If alternate models are correct and precipitation decreases couples with increased temperatures, forests are likely to migrate uphill, replace alpine habitat, and become reduced in size. We elected to conceptualize both possibilities (figs. 3.13-3.15). Long-term climate change also may increase storm intensity (Groisman and others, 2004) and increase climate variability overall (for example, Meehl and Tebaldi, 2004), which likely would increase lightning strikes and tree windthrow, potentially increasing fragmentation within forest patches.

\section{Summary Points}

Coniferous forest landcover is found on many of the high-elevation mountain ranges of the interior Great Basin and on the mountains forming the west, north, and east boundaries. Forests are usually positioned high on the slope between lower-elevation shrubland or pinyon-juniper woodland and upper elevational alpine tundra. Coniferous forests contribute a distinct flora and fauna to the region's biodiversity, perform important hydrological functions, sequester and store carbon, and provide a variety of other ecosystem services (air quality, recreation) and goods (fuel wood, forage), many of which are largely unquantified.

Our understanding of the function of Great Basin mixed conifer forests remains incomplete. Some common assumptions about forest ecosystem processes, including those presented here, need to be tested rigorously. The models of Vankat (2005) for Colorado Plateau montane forests contain additional submodels that may be applied to the Great Basin when sufficient data becomes available. If current climate predictions hold true, shifts in the location, 
extent, and composition of forests likely will occur. However, the magnitude and direction of change remains uncertain because climate models depicting local-scale effects, particularly models forecasting the amount and timing of precipitation, forecast a broad spectrum of potentials. Therefore, one primary need is improved weather monitoring to provide baseline data, understand the interactive effects of microclimate, topography, and soil moisture on species persistence, and validate downscaled global climate models. We also need data for predicting how fire severity and frequency, insect outbreaks, and plant and animal distributions will interact with future climates to influence forest-patch distribution and associated fauna. For example, although recent biogeographical analyses indicate that small mammals may use lowland riparian corridors as dispersal routes (for example, Lawlor, 1998), it is unclear whether these avenues will remain available under some climate change scenarios. Understanding the dispersal ability of a whole suite of plants and animal species will aid in predicting future persistence and composition of forest patches in the region.

Forest patches in the Great Basin are highly variable both within a mountain range and among similar forest-types on adjacent ranges. We need to improve our understanding of spatial variability to better elucidate the potential for dispersal and recolonization of depauperate patches and recovery of disturbed sites. What spatial factors facilitate or inhibit movement of individuals, seeds, and genes? Which plant and animal populations are truly isolated and which function as part of metapopulations? Rigorous, quantitative, spatially explicit models are needed to begin making testable predictions based on our qualitative conceptual models.

We also need better understanding of specific plant and animal habitat relationships in order to understand potential threats to species persistence and to prioritize management activities. Very few forest-associated species currently are understood well enough to integrate into our stressor models and generate species-response hypotheses. Information that is available needs to be cataloged and evaluated before initiation of specific modeling exercises that begin identifying vital monitoring indicators.

Limited empirical data (Shaw and others, 2005; Rehfeldt and others, 2006) support our hypothesized threats to coniferous forest persistence, vigor, and integrity. Researchers, modelers, and land managers should coordinate their efforts to monitor, understand, and respond to these trends.

\section{Alpine Tundra Models}

\author{
By D.M. Miller
}

\section{Distribution and Management Significance}

Alpine tundra occurs in only 0.3 percent of the Great Basin landscape. Specifically, it occupies patches on mountain tops at elevations ranging from 10,000 to $13,000 \mathrm{ft}$ and above sagebrush or tree communities. Alpine tundra is present in the Great Basin's highest peaks including the Snake (home of Great Basin National Park), White, Ruby, East Humboldt, Jarbidge, Sweetwater, Toiyabe, and Toquima Ranges and Steens Mountain. The alpine zone is subject to harsh climatic extremes that limit plants and animals to those specially adapted to narrow tolerances. As a result, the alpine is a fragile zone that is easily disrupted and also difficult to manage because of its remoteness. It includes transitional upper treeline species of concern such as the bristlecone pine (the State tree of Nevada) and the American pika (Ochotona princeps), a mammal threatened with extirpation.

\section{Ecosystem Components}

The alpine tundra environment generally is characterized by thin, weakly developed rocky soils and prostrate vegetative growth forms (Patten, 2005). The short, cold-restricted growing season, intense radiation, wide daily and annual temperature variations, extreme winds, thin air, and longlasting snow create a short and harsh growing season that greatly limits the flora and fauna (Scott and Billings, 1964). Short-stemmed perennial herbs, lichens, and mosses are common, as are prostrate forms of woody shrubs (Pase, 1994). At the transitional zone between timberline and alpine tundra, krummholz tree growth forms are common. Bristlecone pine and limber pine are typical species in this transitional zone in the southern Great Basin. Although this transitional zone supports larger woody vegetation, we treat it in our alpine models because of the predominant influence of harsh climatic and geomorphic processes.

The floras of the Great Basin alpine tundra total about 600 species, reflecting species in common with alpine zones of the Sierra to the west and the Rocky Mountains to the east. In fact, this diversity rivals that of the alpine zones found in these larger and more continuous mountain masses. Ground-dwelling animals that commonly inhabit the alpine tundra include yellow-bellied marmot (Marmota flaviventris), mountain pocket gopher (Thomomys monticola), alpine chipmunk (Tamias alpinus), Palmer's chipmunk (Tamias 
palmeri), western heather vole (Phenacomys intermedius), Inyo shrew (Sorex tenellus), long-legged myotis (Myotis volans), and the pika. Common nesting birds are the whitecrowned sparrow (Zonotrichia leucophrys), black rosy-finch (Leucosticte atrata), American pipit (Anthus rubescens), and horned lark (Eremophila alpestris).

Abiotic factors, especially climate, tend to overwhelm biotic factors in structuring the alpine tundra (Cannone and others, 2007). The plant and animal communities of the alpine tundra are subject to natural disturbances from geologic processes, making these environments potentially very sensitive to climate changes. Current response to the last 50 years of increasing temperatures includes uphill shifts of many species distributions (Kullman, 2002; Beever and others, 2005) and associated changes in plant community composition. The delicate balance between persistence and extirpation in these extreme conditions could be altered with additional disruptions from climate change.

\section{Drivers of Ecosystem Change}

\section{Natural Drivers}

Natural drivers in the alpine tundra primarily are climatic and geologic processes (fig. 3.16), which combine with limitations of plant and animal physiological processes to limit growth and diversity of the biota. Climatic influences chiefly are extreme cold, short growing season, fierce, abrasive winds carrying ice and snow particles, and large temperature variations on all times scales from daily to annual. High-intensity solar radiation, particularly ultraviolet (UV) radiation, forces plant adaptations such as epidermal reflection. Lower partial pressure of $\mathrm{CO}_{2}$ reduces photosynthetic rates and requires adaptations by alpine tundra plants (Richalet, 2007). Geologic processes include a wide range of effects of freeze-thaw cycles, such as soil disturbance on a daily to annual basis and movement of rocks. Steep slopes may have little plant stabilization, resulting in repeated movement of talus and scree. Geologic effects in a few places may include glacial activity (for example, possible rock glaciers in Great Basin National Park).

\section{Anthropogenic Drivers}

Anthropogenic drivers include climate change, direct trampling and contamination by humans and livestock, wet and dry deposition of air pollution, introduced fire, road effects, and plant harvesting (fig. 3.17). Climate change, the single most pervasive driver, is causing increased temperatures that may limit environments suitable for many alpine species due to limitations to upward migration. Climate change is likely to increase storm intensity by increasing the variability of climate overall, leading to increased intensity and frequency of wind related impacts. Increased solar radiation from reduced atmospheric ozone will slowly increase incident $\mathrm{UV}$ radiation. High $\mathrm{CO}_{2}$ concentrations may reduce the competitive advantage of photosynthetically efficient plants thereby changing the ratio of $\mathrm{C} 3$ to $\mathrm{C} 4$ plants, decreasing resistance to exotic plant invaders, and altering species composition. High temperatures probably will reduce the total area of tundra by upward migration of timberline (Kullman, 2002) through differential upward migration of specific tree species (Beever and others, 2005), and through alteration of freeze-thaw activity and intensity. A change from snow to rain precipitation may increase erosion, particularly in plantdiminished patches previously disturbed by trampling, or by late-summer drought caused by reduced snowmelt. Cannone and others (2007) inferred that soil instability and disturbance creates migration barriers inhibiting upward movement of plants, altering the plant community toward disturbanceadapted species. As a result, it may be particularly productive to monitor the plant and bare-ground mosaic in those alpine zones most sensitive to climate change effects.

Reduced snow cover from shorter winters also may affect plant species composition, in particular the plant species that occupy snowbank margins such as Eschscholtz's buttercup (Ranunculus eschscholtzii; Charlet, 1991). Human trampling and harvesting of plants disturbs soil crusts and surface horizons as well as plant mats, increasing wind and water erosion. Deposition of anthropogenic nitrogen may result in fast transmission downslope to streams without any biofiltering due to the high cover of rock and snow (Seastedt and others, 2004; Ashton and others, 2008). Impacts from nitrogen may aggregate at timberline, aggravating climate change effects where the bristlecone pine focal species is common.

American pikas have high energetic requirements and a disinclination for long-distance (>300 m) movements or dispersal making them especially sensitive to high temperatures (MacArthur and Wang, 1974; Smith, 1974; Peacock, 1997; Morrison and others, 2008). They are still widely distributed, and are locally common where they occur. Collectively, these traits make them valuable early-warning indicators of change in Great Basin alpine ecosystems. Numerous extirpations of historically recorded pika populations have occurred recently in the Great Basin (Beever and others 2003), and the rates of population loss and upslope migration of pika distributions have increased markedly in the last decade (Beever and others, unpub. data, 2008). Because pikas harvest, store, and process herbaceous vegetation and are important to seed dispersal and banking, their extirpation may significantly impact tundra plant communities. Pikas also redistribute nitrogen and other minerals and act as prey for alpine carnivores, and thus may be considered keystone species. 


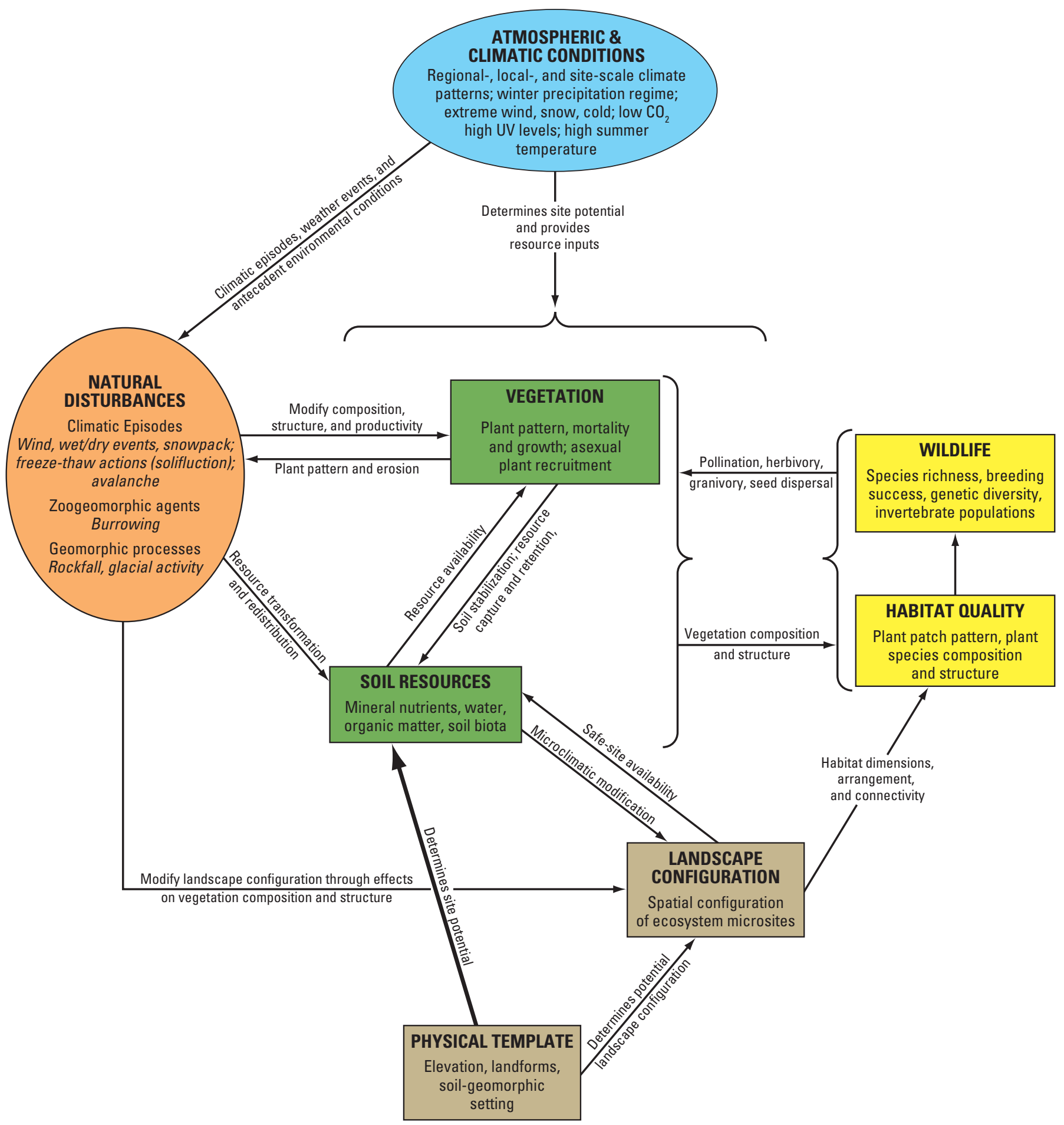

Figure 3.16. Control model showing major components, drivers, and processes in the alpine tundra system. Ovals represent drivers and rectangles represent major functional components of the ecosystem. Note that, unlike other dry systems, the physical template is shown as a participating component for the timescales of interest because geomorphic processes can rapidly change the template in the alpine tundra. Plant pattern, species composition, and mortality rates might all be useful attributes to monitor, as well as mammal populations and ecotone movement such as upward movement of timberline. 


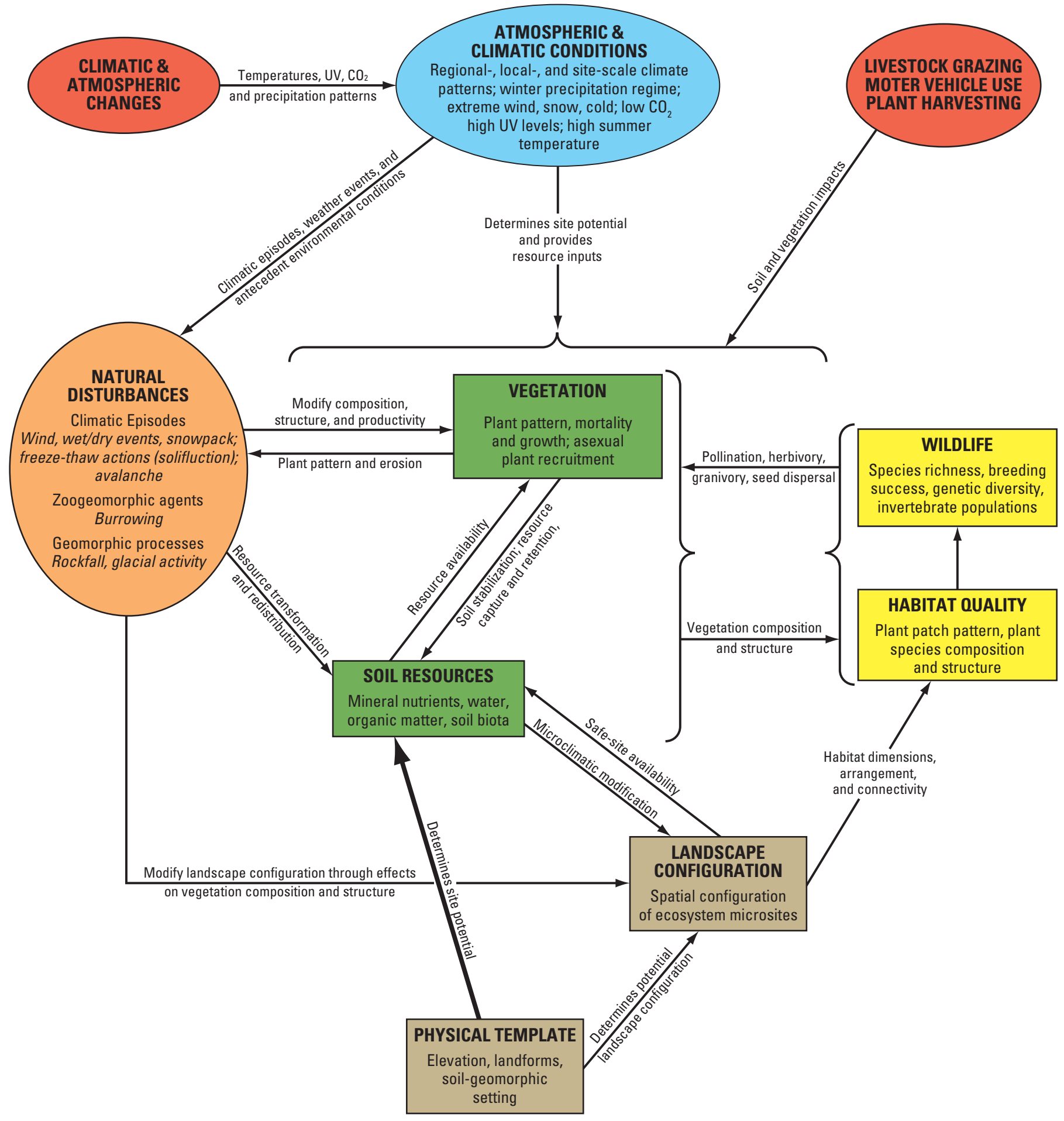

Figure 3.17. Major anthropogenic stressors for the alpine tundra system (ovals). 


\section{Ecosystem Dynamics}

The control model (fig. 3.16) illustrates several components and processes important to the alpine tundra environment, many of which are common to the previously described dry systems models. Extreme climatic conditions and steep topographic gradients produce large variations from site to site in terms of microclimate, soils, and hydrology. Physical characteristics such as rocky talus slopes are crucial shelter sites for animals. As a result, the alpine tundra consists of small patches of different soil types, plant communities, and habitat. This fine scale patch interaction links several components within the control model: landscape configuration, soil configuration, and microsite potential are components that vary on the scale of meters in many cases and differs from the presumably coarser scale variation in low-elevation dryland systems.

Geomorphic processes change the landscape of alpine tundra more rapidly than communities in low elevations. Geomorphic processes include freeze-thaw of rock and soil, as well as rockfall to create talus, creep of colluvium, landsliding, creeping of solifluction lobes, and even glacial activity. Snowpack is a critical feature of the alpine zone and illustrates the connection between biotic and abiotic features. The combination of snowfall and wind creates patterns of snow accumulation on lee sides of ridge crests (fig. 3.18). Snowbanks that persist into summer gradually melt back and successively foster plant communities that vary in accordance with - and are dependent on - the timing of snow retreat. Changes in timing and amount of snowfall, temperature and associated timing of snowmelt, and winds associated with snow deposition can all alter the snowbank processes.
Over long periods of time, nivation hollows develop linear depressions formed below and parallel to ridgelines. Nivation hollows form by sub-snowpack processes of sediment transport by meltwater as snowbanks recede. The hollows enhance future snow capture and thus feed back into the snowpack-driven processes. Long-term effects include more mesic or hydric soils in downslope positions in meltwater meadows. Relatively dry rocky crests, snowdrifts, and areas below the drifts have characteristic plant communities and soils governed by water availability and timing of snowmelt and subsequent drying. The snowfield and associated plant community patterns may shift rapidly with climate change as historical geomorphic-climate combinations spatially decouple.

Zoogeomorphic agents including grazing, trampling, and burrowing are prominent as well (Hall and Lamont, 2003); these are dependent on soil depth and soil moisture, which vary by climate factors, topography, and plant cover, and therefore are linked to patch-scale processes described above (fig. 3.19).

One monitoring objective in Great Basin alpine environs is to identify reliable monitoring cues. Vegetation composition and cover, including spatial patterns, are fundamental indicators of environmental stress (Kammer and Mohl, 2002). Along with climate factors (including snowcover and atmospheric pollutant deposition) and visitor use, monitoring plant communities should signal alterations to the tundra environment. Identifying reliably responding plants for monitoring should be a primary goal of future research. Animals well adapted to alpine conditions may be strongly affected by altered conditions mediated by climate change. Mammalian and invertebrate responses to changing

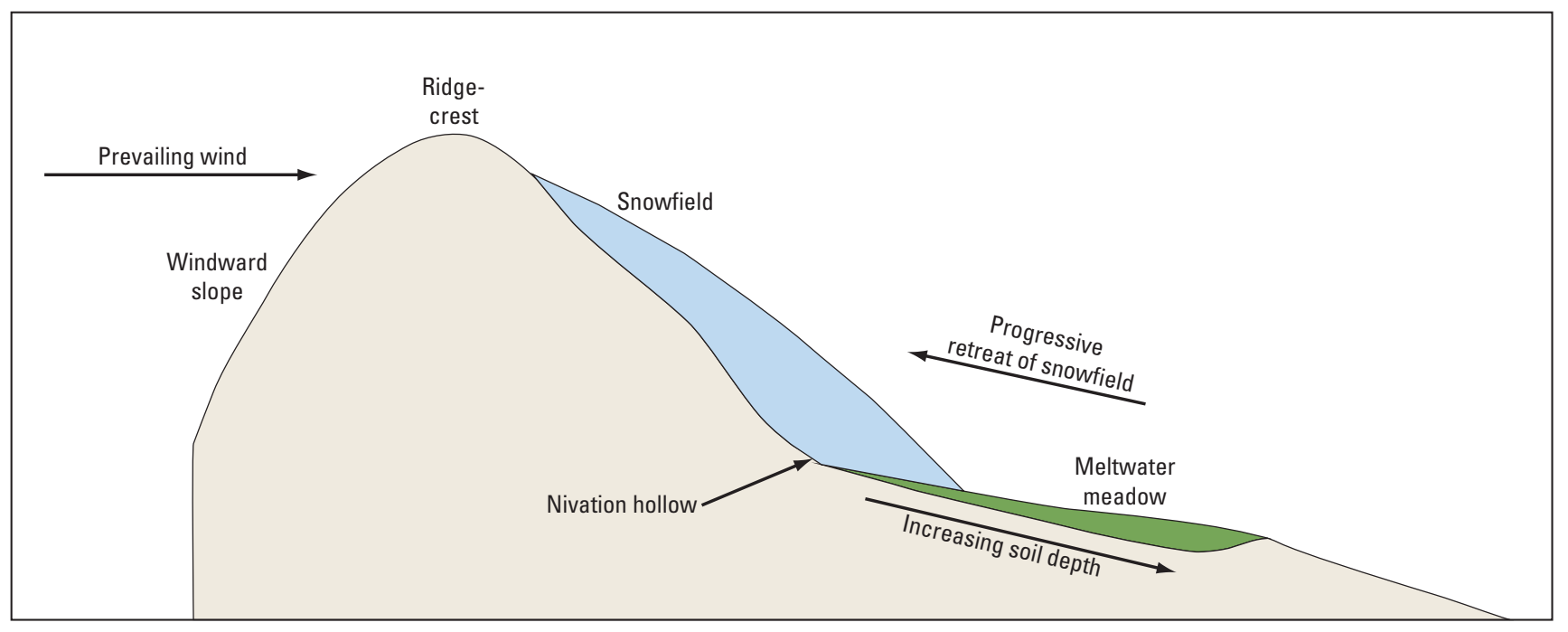

Figure 3.18. Simplified illustration of topographic and climatic effects in the alpine tundra zone. Plant communities vary with position from the meltwater meadow upward, because they are tuned to the timing of snowfield retreat and the long-term accumulation of soil, which is unevenly distributed. 


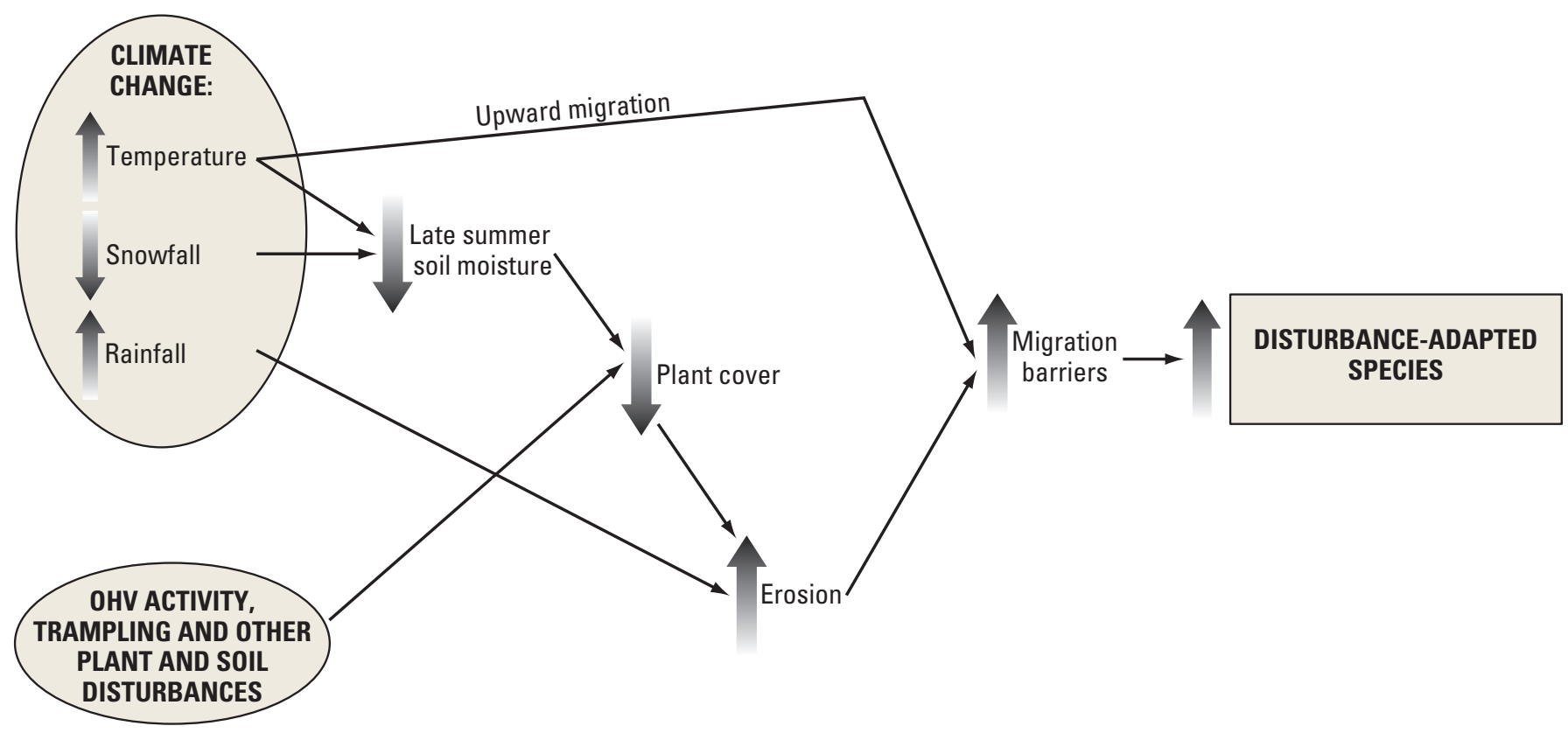

Figure 3.19. Stressor model showing climatic and other effects in the alpine-tundra zone. Plant communities are impacted by changing climate conditions directly and by inhibited upward migration caused by increased eroded and disturbed ground. Both contribute to an increase in disturbance-adapted species.

temperature regimes such as acute or chronic metabolic stress from excessive heat or cold, or increased mortality due to alterations of food supply, could be tracked as changes in population dynamics making them excellent monitoring targets. Some animals also play important functional roles as described previously for the pika.

Loss of the tundra ecosystem due to climate change most likely will result in a large loss of gamma diversity with loss of populations and genotypes (McDonald and Brown, 1992; Hunter, 2002). The high mountains of the Great Basin will not recover quickly from loss of tundra because they lack connectivity with other tundra environments. Evidence from mammals in paleoecologic and recent time indicates that species differ in their vagility and their degree of obligate relationship to alpine habitats (Grayson and Livingston, 1993; Lawlor, 1998; Grayson and Madsen, 2000). As a result, changes in alpine habitat may have ripple effects in broader mammal communities.

\section{Summary Points}

It is probable that warming temperatures and other climatic factors associated with climate change will impact tundra environments by shifting plant and animal community distributions, as well as by altering geomorphic processes, but little research is available to allow projections to be made. It is an important topic for study, because transitions to new plant community states may make recovery of existing habitat difficult (Laycock, 1991; Stringham and others, 2001). Knowledge of the processes that link components of the alpine ecosystem generally are poorly understood in comparison with some low-elevation Great Basin biomes. As a result, nearly all aspects of the alpine ecosystems in the Great Basin are in need of further study. Paleoecological studies may shed light on which plant and animal populations survived past climate changes, and inform hypotheses for survival and extirpation in the future when characteristics of past climate is well known. 


\title{
Chapter 4: Subsystem Models for the Wet System
}

\author{
By D.R. Bedford and D.M. Miller
}

As described in the Wet Systems model, subsystem models can be built along many schemes, such as gradients between fresh and hypersaline water, between flowing and standing water, and between groundwater-controlled systems and runoff systems such as streams. In the Great Basin, most streams and lakes are interconnected with groundwater, which indicates that an approach using groundwater flow regime is best for a primary classification system. Secondary classifications we use are flowing versus standing water and salinity.

\section{Groundwater Model}

\section{By D.M. Miller and D.R. Bedford}

The following treatment of groundwater systems is based in large part on a report for the National Park Service Mojave Network (Miller and others, 2006), which included part of the Great Basin.

\section{Distribution and Management Significance}

By definition, groundwater systems occur wherever there is water in a porous medium (that is, rock and soil) beneath the Earth's surface. We restrict most of our discussion of groundwater systems to those that are saturated with respect to water. Most groundwater occurs in valley/basin sediments, and to a lesser degree, in bedrock in mountains. Surface expressions of groundwater occur in springs and seeps and a variety of ecosystems broadly categorized as "spring ecosystems" here. Groundwater systems often are connected to streams and rivers, and can be a source for streams (a gaining stream) or a net loss for streams (a losing stream).

The Great Basin region adopted by the GBILM project includes much of the northern Basin and Range physiographic province and parts of the Snake River Plain and adjacent plateaus; these provinces have distinctive hydrologic characteristics driven by distinctive geology. The Basin and Range province is marked by north-trending fault-block mountain ranges separated by wide valleys that have thick permeable valley-fill sequences. In the eastern part of the province, limestone and dolomite capable of transmitting and storing large quantities of water underlie the mountain blocks and valleys, creating an interconnected system generally known as the regional carbonate aquifer system. A consequence is that recharge in one mountain block aquifer may discharge in another area as a result of interbasin flow. On the scale of the entire Great Basin province, deep groundwater flow in the regional carbonate aquifer system generally is thought to be from the recharge area of eastern Nevada near and in Great Basin National Park; discharge occurs at low elevations such as Ash Meadows and Death Valley (Mifflin, 1968; Winograd and Thordarson, 1975) and the Bonneville Salt Flats. The Snake River Plain and adjacent plateaus primarily are underlain by volcanic rock that rapidly transmits water, and the region is drained externally by Snake River surface flow.

Groundwater maintains springs, wetlands, lakes, and many streams of the Great Basin, and thus is of primary importance for aquatic and riparian plants and animals. Many upland animals also depend on water supplied by these sources, as do migrating waterfowl.

\section{Ecosystem Components and Processes}

Very little is known about ecosystems in Great Basin groundwater systems. They likely support a wide array of microorganisms and potentially other life forms. Because the biology of surface ecosystems dependent on groundwater (springs and streams) is better understood, we focus the groundwater conceptual model on the physics and chemistry of groundwater systems, and describe how they may drive many of the spring and stream ecosystems, which are elaborated on as separate models.

As described in the wet systems conceptual model (figs. 2.14 and 2.15), water flows into an aquifer system primarily through mountain recharge, flows out at springs and playas, and is transpired by phreatophytic vegetation. Flow through porous media can be modeled with the use of a linear gradient law in hydrogeological models. This makes groundwater systems amenable to analytical techniques unlike biological systems, which are more commonly analyzed statistically. Uncertainty enters hydrogeological models due to the heterogeneity of geological materials, lack of data (for example, measurements of subsurface rock properties), and natural variability of some conditions, such as infiltration. A conceptual model of the hydrogeologic framework including recharge and discharge conditions is fundamental to any site-specific groundwater flow model. Hydraulic properties of rocks and sediment, and faults and other perturbations to groundwater flow comprise a hydrogeologic framework conceptual model. Subsurface properties can be interpreted 
remotely through geophysical techniques, well logs, surface maps, and pumping tests. Spring discharge can be measured with weirs and flumes, although discharge from combined plant and soil evapotranspiration is studied using heat and vapor flow methods. These measurements, combined with a hydrogeologic framework model and physical laws, can be used to model the response of a groundwater flow system.

The most fundamental law of groundwater flow is that mass must be conserved (that is, the sum of all flows into an aquifer, minus the sum of all flows out, must equal the change in aquifer storage; fig. 4.1). If the change in storage is negative then flow out of an aquifer is greater than flow in, groundwater levels are dropping, and the aquifer is being depleted. When groundwater levels and storage are static, it implies that flow into the aquifer (recharge) is equivalent to flow out of the aquifer (discharge). A steady state condition results when recharge is balanced by discharge over a sufficiently long time period.

A common conceptualization of an aquifer (fig. 4.2) presumes that recharge to the underlying formation is confined by the overlying impermeable layer so that the water level in a well penetrating the confining unit rises under pressure, perhaps even flowing to the ground surface in an artesian well. Water flows downhill from high elevations to low elevations and from high pressure to low pressure. Flow through a given cross-sectional area of a porous medium is proportional to the hydraulic gradient (difference in water-table elevation divided by the distance), where the constant of proportionality is called hydraulic conductivity-Darcy's Law (Darcy, 1856). A storage coefficient (either specific yield or storativity) and hydraulic conductivity are the core parameters of the groundwater flow conceptual model. Another useful parameter is aquifer transmissivity, which is the product of hydraulic conductivity and thickness of saturated material.

When an aquifer is perturbed from an equilibrium state by, for example, climatic variability or initiation of groundwater pumping, it responds at a rate controlled by its physical characteristics. The most important physical characteristic of an aquifer is its size, such that larger aquifers, both in area and volume, respond more slowly. Another important feature is whether the aquifer is confined by an impermeable layer and is under artesian pressure, or is an unconfined aquifer (fig. 4.2). Confined aquifers respond quickly — pulses of pressure are transmitted rapidly through the system; unconfined aquifers strongly dampen such pulses. Finally, there are the physical characteristics of the saturated thickness of the aquifer and the integrated hydraulic conductivity of its sediments, matrix, or fractures. Coarse gravel and fractured limestone more easily transmit water, whereas silt and clay layers and unfractured limestone do not. A larger transmissivity corresponds to a more rapid response. Estimating how quickly groundwater levels in an aquifer respond to perturbations requires information about the aquifer size, presence of a confining layer, depth to water, depth to bedrock, and hydraulic conductivity.

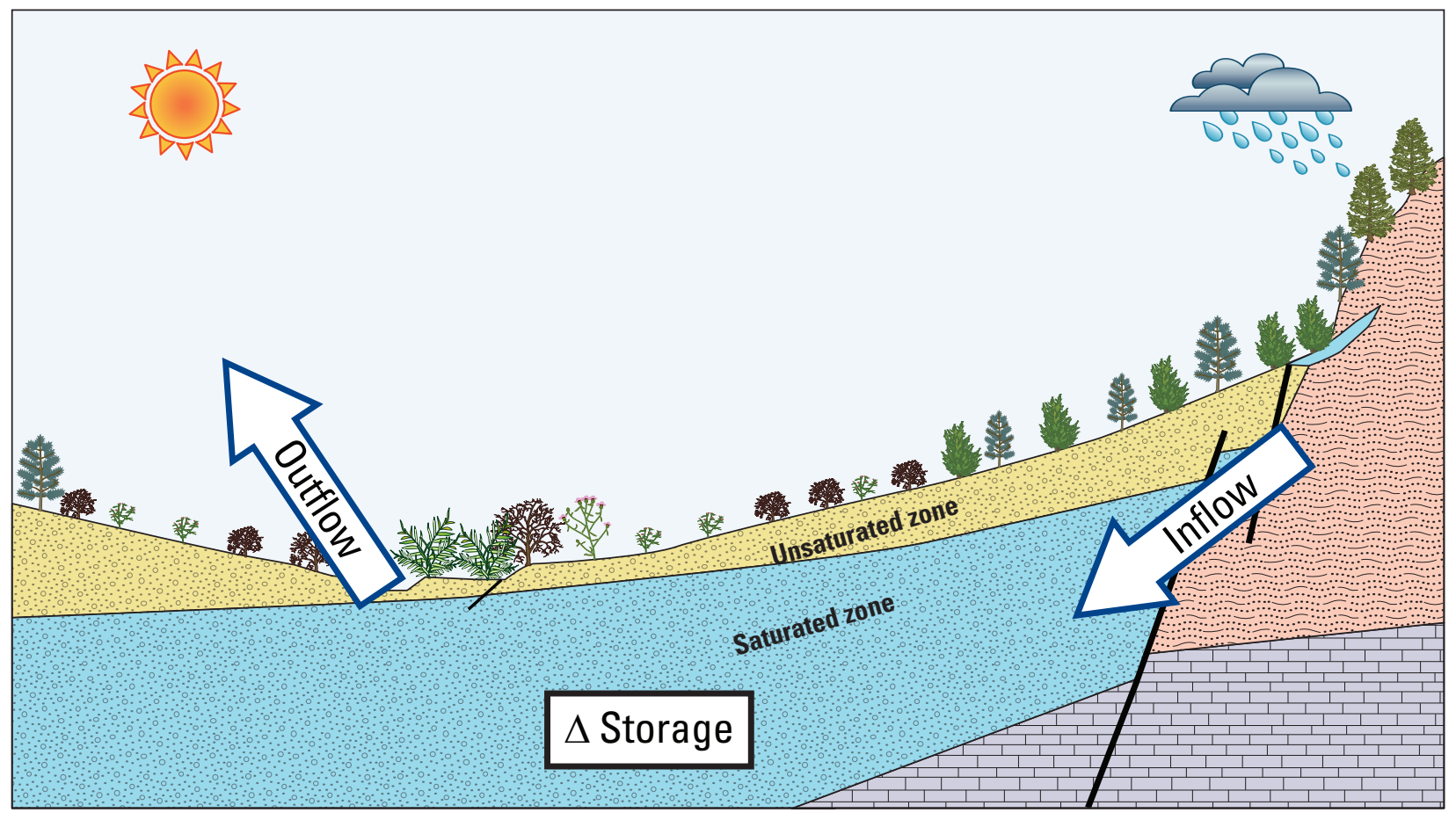

Figure 4.1. Conservation of mass implies that the difference between inflow (recharge) and outflow (discharge) is balanced by a change in aquifer storage. 


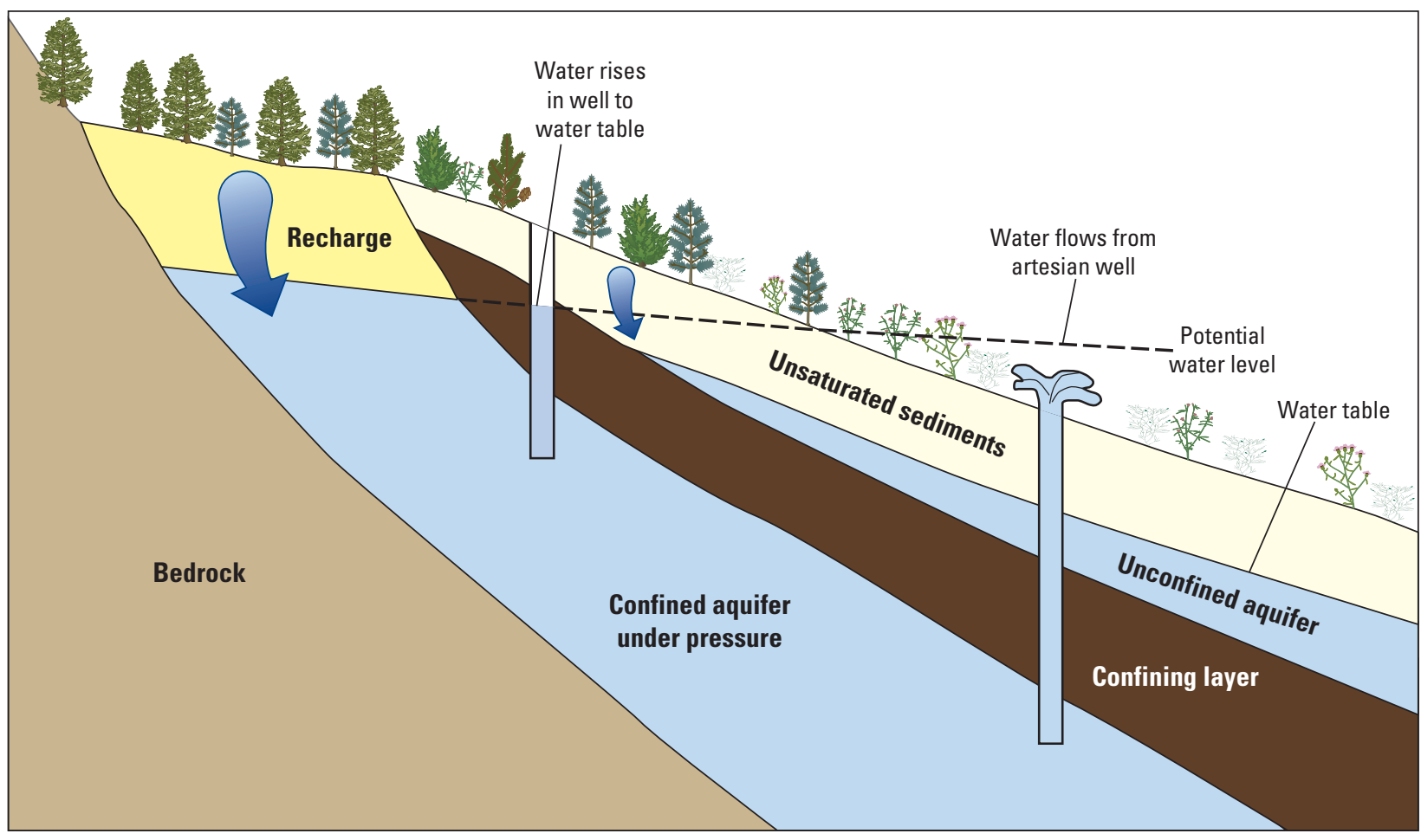

Figure 4.2. Illustration of confined and unconfined aquifers and associated potential water levels.

\section{Groundwater Chemistry and Contamination}

Evaporative moisture in the atmosphere, as well as transpiration from plants, is relatively pure water with little dissolved minerals. Condensation into raindrops, hail, snow, and sleet tends to form around dust particles, and precipitation delivers somewhat less pure water. Water is an effective solvent, reacting with most substances, and changes chemistry along its flowpath through the hydrologic cycle as it reacts with rock and sediment. Acidic precipitation facilitates dissolution of carbonate rocks, leading to enlarged solution cavities such as Lehman Cave in Great Basin National Park. Rock-water reactions dissolve mineral components so that the number of chemical species in solution and total concentration increases along a flowpath, usually measured in total dissolved solids (TDS). Groundwater in proximity to the zone of recharge at mountain fronts (usually high elevations) is generally low TDS (300-400 mg/L or less). Closer to discharge areas in valleys, TDS is usually greater than $1,000 \mathrm{mg} / \mathrm{L}$. Groundwater flowing through the Great Basin regional carbonate aquifer system becomes saturated in carbonate and bicarbonate in isolation from the atmosphere. At groundwater discharge areas, such as Ash Meadows in Death Valley National Park, carbonate minerals are precipitated when groundwater comes into contact with the atmosphere, degasses, and evaporates. Evaporation from wet playas such as Devils Golf Course in Death Valley also leaves behind near-surface concentrated brine with TDS in excess of 50,000 $\mathrm{mg} / \mathrm{L}$, along with salt deposits and other evaporite minerals. Ions in solution in groundwater reflect the geologic materials through which groundwater has passed.

Groundwater quality is affected by natural and anthropogenic compounds, such as arsenic, nitrates, iron, manganese, hexavalent chromium, petroleum hydrocarbons and volatile organic compounds, as well as radon. Arsenic is a common naturally occurring groundwater contaminant in the desert, associated with sedimentary rocks derived from volcanic areas and geothermal systems. Arsenic contamination can be exacerbated by mining waste piles and by changes in oxidation-reduction conditions in the aquifer. Major sources of nitrates are fertilizer, animal wastes, and domestic sewage. Oxygen reacts with iron and manganese to form precipitates, so groundwater high in dissolved oxygen tends to be low in iron and manganese. Deep circulating groundwater, not exposed to the atmosphere for a long time, becomes depleted in dissolved oxygen and readily dissolves iron and manganese carbonates. A common indicator of overall groundwater quality is TDS, usually expressed in milligrams per liter or the equivalent parts per million. 


\section{Drivers of Ecosystem Change}

\section{Natural Drivers}

Natural drivers of groundwater systems will vary in their significance depending on the aquifer type. For instance, regional groundwater systems are not likely to be affected by many biotic drivers, with the exception of evapotranspiration losses by phreatophytic vegetation. Smaller aquifers, particularly upland aquifers, are sensitive to climatic variations and biotic and physical losses in the form of evapotranspiration. Changes in discharge, water temperature, and water chemistry can be expected as a consequence of climate change.

\section{Anthropogenic Drivers}

Groundwater pumping has significant impacts on groundwater in the Great Basin. In addition to the direct effect on streams, diversion of streams that recharge aquifers also can affect groundwater systems. Pumping and diversion that reduce water tables can result in spring- and streamflow declines. Even when pumped at a rate that maintains water table levels, a pumped aquifer can alter the natural system by reducing water formerly available for plants and aquatic organisms, instead using the water for transpiring crops, for example.

Anthropogenic water contamination often is categorized as being derived from either a "point source" or a "non-point source." Point sources are leaking underground tanks, spills, landfills, mining spoils, and septic systems, whereas non-point sources are atmospheric nitrogen deposition, pesticides, and fertilizers sprayed on agricultural fields. Shallow, unconfined aquifers are most susceptible to contamination, especially near urban areas, farmland, and roads. Deep aquifers and confined aquifers are less susceptible, especially over the time span of a few decades. However, once large aquifer systems are contaminated they can remain contaminated for long periods.

\section{Ecosystem Dynamics}

Most aspects of ecosystem change are dealt with in ensuing aquatic models. As described above, changes in recharge can drive immediate or gradual changes in discharge, depending on aquifer characteristics. Likewise, contamination of aquifers can have immediate or gradual effects. Key to understanding the dynamics of groundwater is an understanding of the relevant aquifer system.

\section{Summary Points}

Knowledge of aquifer characteristics and climate is sparse in the Great Basin, save for a few areas with dense wells, large populations, and dense climate stations. Increased density of hydrologic and climate data will improve our ability to model aquifers. Improved modeling will increase our ability to respond to disasters such as contamination events and to anticipate effects of drivers, such as climate change and increased groundwater pumping.

\section{Wetland and Spring Models}

\author{
By D.R. Bedford and D.M. Miller
}

Spring systems in the Great Basin are found in settings ranging from alpine to desert valley floors and vary widely, and generally are poorly investigated and understood. The following treatment of spring systems is based in large part on a treatment of springs and wetlands for the National Park Service Mojave Network (Miller and others, 2006), which included part of the Great Basin.

\section{Distribution and Management Significance}

Spring systems in the most general sense are ecosystems formed where groundwater discharges at the Earth's surface. Here, we include a wide variety of discharging systems from seeps and wet meadows to springs and spring-marsh complexes. We exclude from this model (1) those marshes along the edges of lakes because those systems interact closely with lakes and are better described in lake models, and (2) wet (discharging) playas, which typically have no surface water or have extremely saline surface water, and support a unique ecosystem.

Spring systems vary widely, and can be described by a few fundamental variables that in general are related to aquifers. Aquifer characteristics (residence time, recharge source, lithology, chemistry) impart strong controls on groundwater discharge characteristics such as temperature, chemistry, and rates (Freeze and Cherry, 1979; Domenico and Schwartz, 1990; Fetter, 1994), as described in the groundwater model. In the Great Basin, springs often are the primary sources of water for small streams and riparian zones, and thus interact with surface-water systems. 
Three types of aquifers described in the wet model serve to differentiate springs: (1) small, upland aquifers; (2) local valley aquifers; and (3) regional aquifers. The characteristics of these aquifer types as they relate to springs are summarized in table 4.1. Springs fed by upland aquifers tend to have cool water $\left(<10^{\circ} \mathrm{C}\right)$ and commonly go dry during droughts. Springs fed from local aquifers also may change seasonally and go dry during extended droughts. Springs fed by regional aquifers tend to be warmer $\left(>20^{\circ} \mathrm{C}\right)$, and high in solutes due to the depth and length of flow paths, and tend to have discharge rates that remain fairly constant over time intervals exceeding 50,000 years (Winograd and others, 1992). Size of spring ecosystems is a strong function of groundwater discharge. At the low end of discharge, seeps tend to support upland and facultative wetland species adapted to drier conditions. At the high end of spring discharge, permanent ponds and riparian corridors are common and may support many endemic and endangered species.

From the perspective of aquatic and riparian ecology of spring systems, the position in the landscape, discharge rates and persistence, and water chemistry are determinants of the spring ecosystems. However, the ecology in combination with hydrologic characteristics dictates many of the characteristics such as morphology of the spring system. For instance, ephemeral seeps and wet meadows occur in and near mountains as a result of the very low and variable discharge from upland aquifers; water is fresh and cold, and plants in that environment include luxuriant xerophytic growth and in some cases phreatophytes. In contrast, springs with local aquifer sources typically occur in piedmont settings and range from low, fluctuating discharge with salty water, which may create salt grass systems that tend to trap fine materials and create spring mounds, to moderate discharge spring complexes with diverse phreatophytes, wildlife, and spring geometries. Regional aquifers form one end-member of the range of spring systems, for which large marsh complexes with open pools, situated in valley bottoms, are common. A general diagram of aquifers, flow paths, spring discharge types, and their typical locations in the landscape and associated hydrologic systems is shown in figure 2.14 .
Challenging issues regarding Great Basin spring ecosystems are important for nearly all land managers in the region. Because of their importance for surface and groundwater availability, springs often are managed under long-standing water rights legislation. They also tend to support species of interest, rare, threatened, and endangered species (for example, Devil's Hole pupfish [Cyprinodon diabolis] and redband trout [Oncorhynchus mykiss]) due to their isolation and endemism. Invasive species are common in springs, difficult to manage, and commonly alter habitat and lead to local extinction of native species.

Springs in arid regions may serve as keystone ecosystems, commonly providing the only available water and habitat for many plant and animal species. Steep gradients of moisture, soil types, biodiversity, competition, and productivity create abrupt ecotone boundaries. Springs also may serve as paleo-refugia and as habitats in which the evolutionary processes of natural selection, isolation, and adaptation are coupled to assemblage composition through island biogeographic and historical community development processes (Stevens and Springer, 2004).

\section{Ecosystem Components and Processes}

Spring systems are largely driven by spring morphology, and the persistence and physiochemistry of water discharge. Springs exhibit many morphologies and a single spring may change morphology with time. Common types range from lush open pools to seeps that exhibit damp earth with no open water; between these end members is a wide variety of wet meadows, marshes, permanently wet short stream segments in canyons, spring mounds, and saline springs with few vascular plants.

Aquatic organisms, riparian vegetation, and associated fauna all vary with spring type (Sada and others, 2005), but an anthropogenic influence is ubiquitous, complex, and severe. As a result, human modification of springs must be considered in classifications. For instance, a marsh that is cleared and dredged to provide open water for livestock may be functionally distinct from less-disturbed open-pool springs.

Table 4.1. Characteristics of springs related to three types of aquifers common in the Great Basin.

\begin{tabular}{llll}
\hline \multicolumn{1}{c}{ Characteristics } & \multicolumn{1}{c}{ Upland } & Lquifer type & Local \\
\cline { 2 - 4 } & \multicolumn{1}{c}{ Very small } & Small & Large \\
\hline Aquifer size & Cold & Cool & Warm \\
Water temperature & Very low & Low to moderate & Moderate to high \\
Solute concentration & Very low & Low & Moderate to high \\
Total discharge & Highly ephemeral & Ephemeral & Invariant \\
Discharge persistence & Mountain & Piedmont & Valley bottom \\
Discharge site & Wet meadow, seep, pothole & Small spring, seep, spring mound & Spring-marsh complex, wet playa \\
Typical discharge morphology & & &
\end{tabular}




\section{Groundwater Flow Regime}

Despite the human influence, groundwater characteristics are a primary determinant of many biotic characteristics of springs, providing a multi-dimensional space in which springs of various types lie. Figure 4.3 shows some of the primary dimensions that tend to structure biota, with biodiversity portrayed as one metric of biotic structuring. Springs and other discharge types also can be plotted in discharge-biodiversity space (fig. 4.4) with the observation that spring brook length and spring pool size correlate positively with biodiversity and negatively with spring salinity (Sada and Nachlinger, unpub. data, 2009).

Spring systems are dynamic systems with inherent and anthropogenic disturbance regimes. Excluding anthropogenic disturbance, spring variability mimics hydrologically determined environmental conditions, each of which can be mapped into biotic response. Variability of biota tends to be determined by aquifer size, gradients in microclimate (temperature and precipitation), variability in hydrologic regime, and size and length of runout spring brook, which is correlated with groundwater discharge. Figure 4.5 shows an idealized example of a spring system with associated runout stream, showing typical trends in environmental and biotic factors.

Mineral precipitation, which is driven by physiochemistry of water, flow rate, and evapotranspiration, may be important in springs. Precipitation of calcite (calcareous muds and travertine) or silica (opal or sinter) is especially pronounced in thermal springs but also occurs in cold water springs. Precipitation and sedimentation modifies discharge geomorphology, changing aquatic and riparian habitat.

\section{DIMENSIONS OF VARIABILITY THAT STRUCTURE BIOTA}
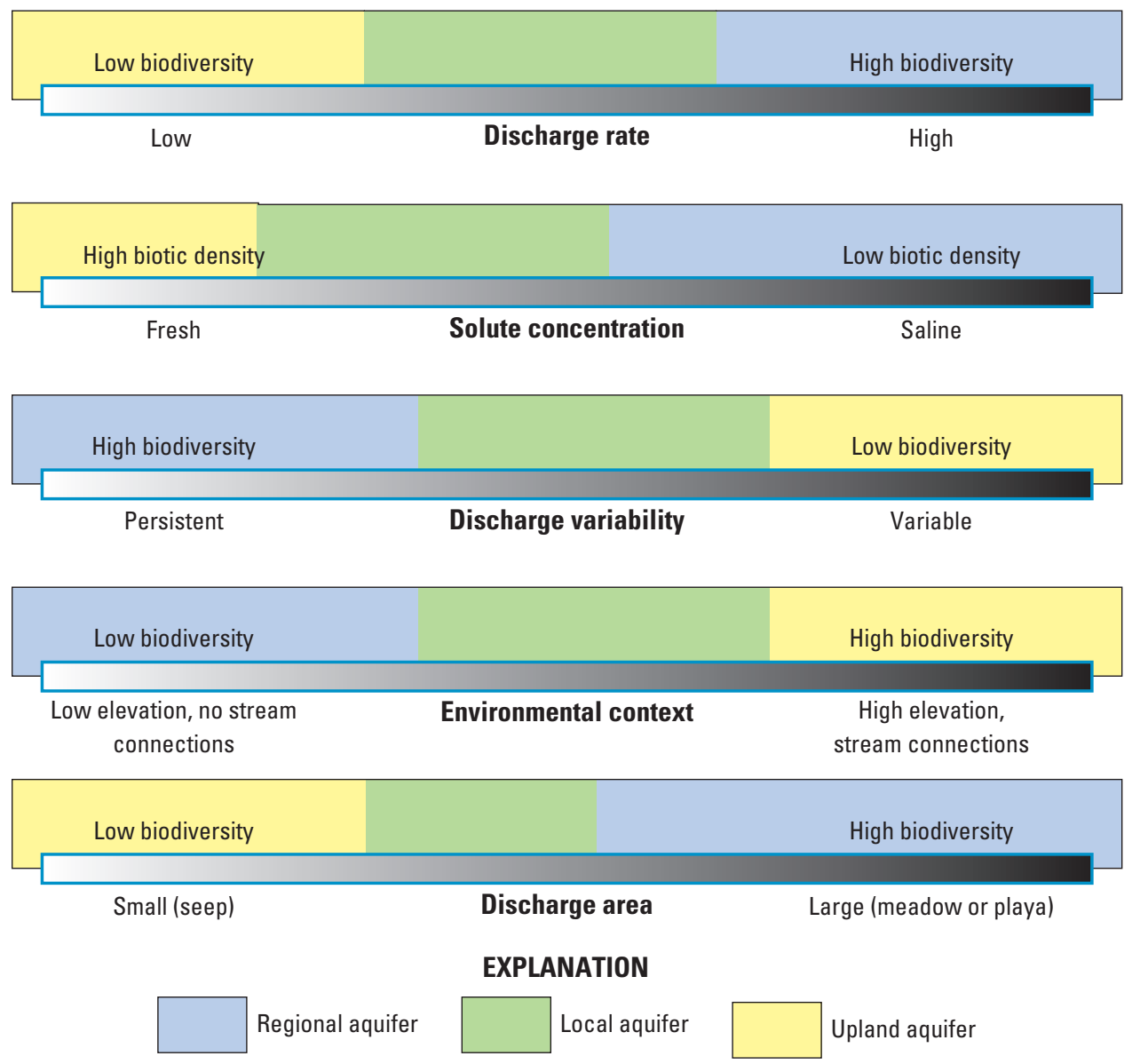

Figure 4.3. Illustration of five gradients in spring discharge environment and effects on biodiversity. Each gradient can be related to aquifer characteristics, as shown qualitatively with colors. 


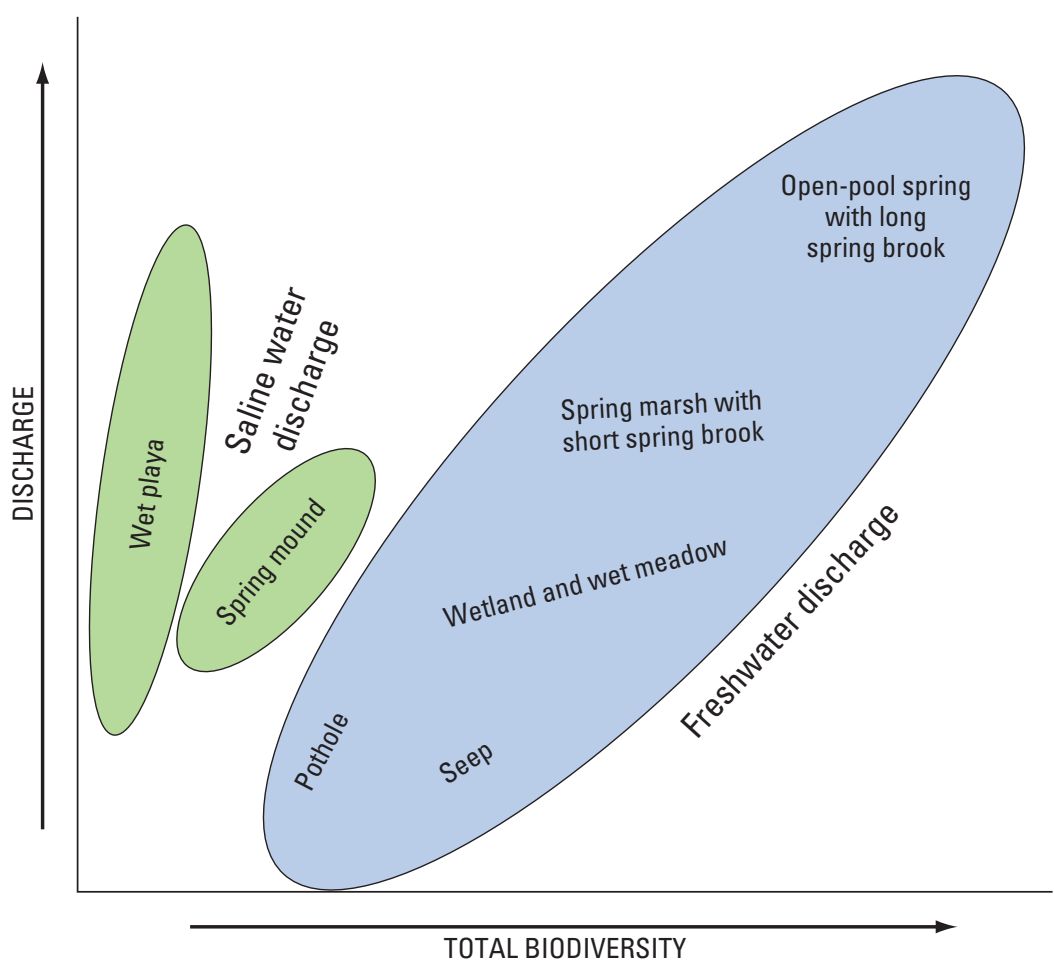

Explanation

Low solute concentrations

High solute concentrations

Figure 4.4. Illustration of spring types and how they vary with discharge and total biodiversity.

\section{Spring Vegetation}

With the exception of species that tolerate extremes in spring physiochemistry, such as geothermal, saline, alkaline, and anoxic conditions, spring vegetation is similar to stream-side riparian vegetation communities, particularly the presence of grasses and sedges. Large springs with associated streams may support riparian trees, as discussed in the stream and riparian model. In addition to emergent vegetation, spring systems typically include subaquatic macrophytes and planktonic and benthic algae.

Primary productivity in springs and wetlands primarily is determined by the amount and quality of flowing water. Stagnant or deep-water wetlands tend to have low productivity, while slowly flowing springs have high productivity (Mitsch and Gosselink, 2000).

Spring vegetation interacts with geomorphic processes by capturing fluvial and eolian sediment, causing infilling of open water. This alteration of habitat is counteracted by natural disturbance events such as scour by floods and digging by animals. In addition, algae-mediated calcite deposition as tufa or calcareous muds causes infilling.

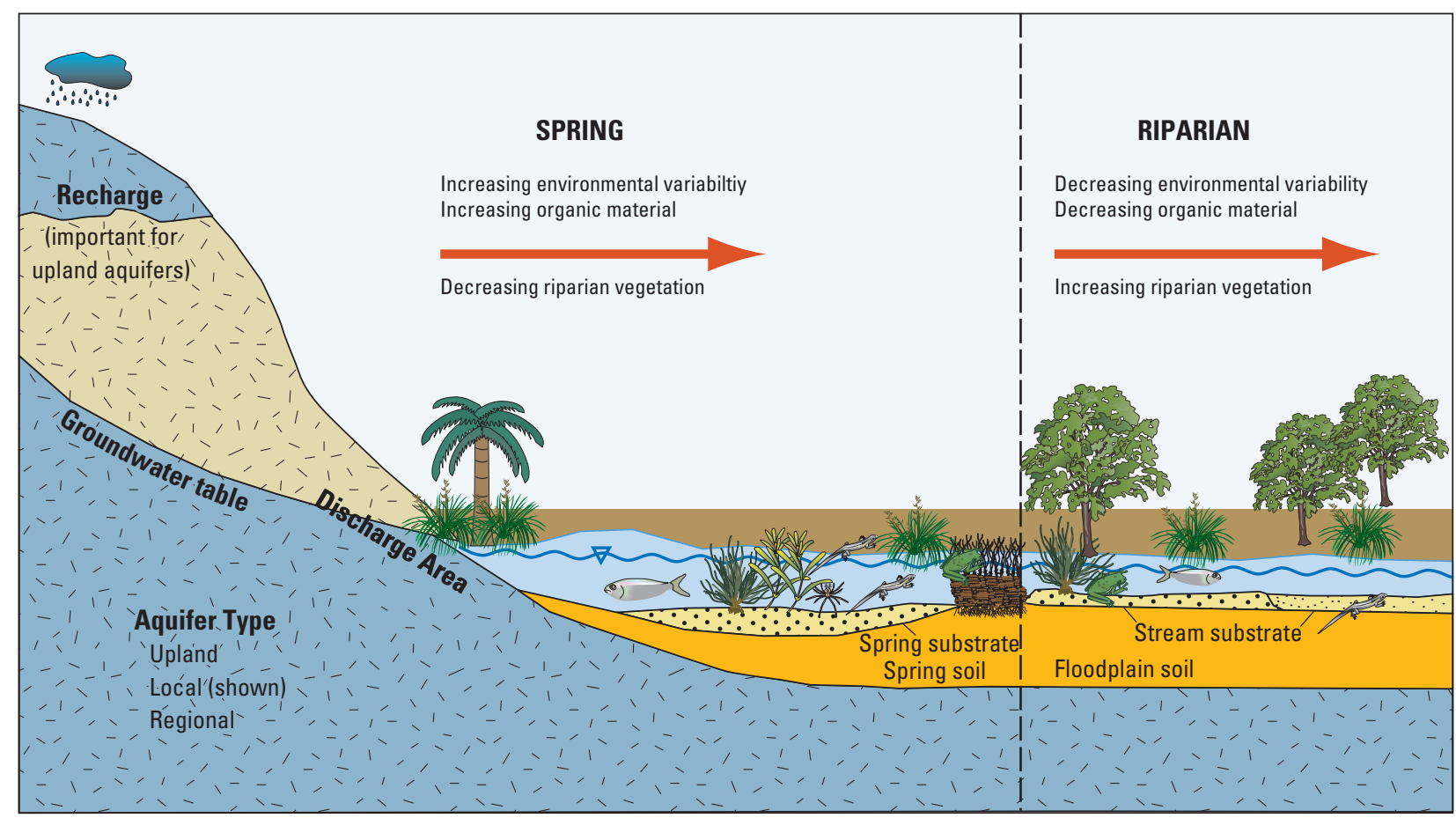

Figure 4.5. Illustration of typical components and gradients in open-pool springs and associated runout stream/riparian zone. 


\section{Geomorphic Processes}

The geomorphic setting of springs as well as processes dictated by the setting (for example, slope, substrate characteristics, soils) and discharge all affect spring orifice and stream runout characteristics. The geomorphic setting affects streams in numerous ways. Lithology and soil characteristics can determine how discharge is manifested spatially, for example, as point sources, seeps, and discharge lineaments. Surface slope determines the flow rates away from discharge locations, and aspect has strong effects on evaporation rates.

Geomorphic processes acting in or near spring systems can maintain and modify orifice and stream runout characteristics. Processes affecting springs include flooding, scouring, and filling. External processes include erosion/deposition of sediments, rockfall, and freeze-thaw disturbances. Little is known about potential feedbacks of springs on the surrounding landscape (Stevens and Springer, 2004).

\section{Spring Invertebrates and Vertebrates}

Spring invertebrates are important consumers, shredders, and detritovores whose life cycles are tied to hydrology, vegetation floristics, and physiognomy (Mitsch and Gosselink, 2000). Sada and others (2005) determined that species richness of aquatic macroinvertebrates may be greatest at intermediate levels of natural and anthropogenic disturbance, and that general macroinvertebrate characteristics could not be predicted from simple metrics of environment, such as elevation, and disturbance (that is, springs are highly individualistic, as are their macroinvertebrate characteristics at a large scale).

Fishes are important consumers in springs, and are affected by water level, spring "openness" (a function of hydrology, geomorphology, and vegetation), chemistry, and temperature (Mitsch and Gosselink, 2000; Andersen and Deacon, 2001). Birds are abundant at springs, including obligate and migratory species (Mitsch and Gosselink, 2000). Birds act as secondary consumers, can maintain moderate levels of disturbance through bottom feeding activities, and can be important vectors for transmittal of seeds and organisms into and out of spring systems. Little is known about the characteristics of springs that determine bird community characteristics. Mammals (for example, beaver and muskrat) probably are unevenly distributed among Great Basin springs. However, mammals of all types extensively use springs, and act as consumers, ecosystem engineers, and seed and organism vectors.

The relative degree of isolation of spring systems either leads to endemism or development of dispersal mechanisms. Dispersal mechanisms vary with organism type, and include passive or active dispersal. Passive dispersal includes dispersal by wind, water, gravity, or other organisms. Active dispersal is exhibited in strong-flying invertebrates, birds, bats, and larger mammals including humans (Stevens and Springer, 2004).

\section{General Spring Model}

Figure 4.6 presents a general spring system control model incorporating key system components, processes, and drivers. Springs are driven predominantly by groundwater discharge, which determines the amounts and basic physiochemistry of water emerging from an aquifer. The orifice type determines the general shape of a spring, which is in part determined by the landscape template (not shown). Orifices with large discharges and appropriate configurations will have outflow in pools, marshes, and streams that are important parts of spring habitat.

Water physiochemistry and the configuration (geometry, soils, etc) of the orifice and outflow channels determine habitat characteristics of spring systems because vegetation communities are dependent on spring water physiochemical conditions, as well as community dynamics. Spring systems often support aquatic and terrestrial organisms, which sets up interspecific and intraspecific competition, facilitation, and food webs. A more detailed treatment of aquatic terrestrial dynamics is provided in the "Aquatic Ecology Control Model" section.

Geomorphic processes in springs with sufficient discharge create a dynamic system. Fluvial erosion or deposition and dust trapping (not shown in conceptual model) is enhanced by vegetation and the presence of moisture at the surface. Dust-trapping and vegetation expansion compete with orifice flow and scour to maintain a dynamic spring pool and spring brook system.

\section{Geothermal Springs}

The Great Basin is home to dozens of thermal springs that have many characteristics that set them apart from cool springs. Although temperatures range widely, springs that are warm $\left(\sim 20^{\circ} \mathrm{C}\right)$ to hot $\left(>38^{\circ} \mathrm{C}\right)\left[70 ;>100^{\circ} \mathrm{F}\right]$ are generated from regional, deep aquifers that encounter hot rocks at great depth. Most occur in valley bottoms. They exhibit persistent flow but may have several spring pools and brooks with different temperatures and discharge. Edifices typically are large tufa mounds, although siliceous sinter complexes (for example, Fish Lake Valley) occur as well. Mineral deposition by precipitation and algal-mediated processes strongly shape edifices of many thermal springs. Complex ecosystems of thermophilic organisms may be present. However, these hot spring systems have been widely targeted for development by humans, and nearly all probably are highly disturbed. Water in runout brooks commonly is sufficiently cool to support cool spring aquatic communities and to be used by humans. However, some geothermal springs have unusually high concentrations of trace metals, minerals, or salts that make the waters toxic to many life forms. 


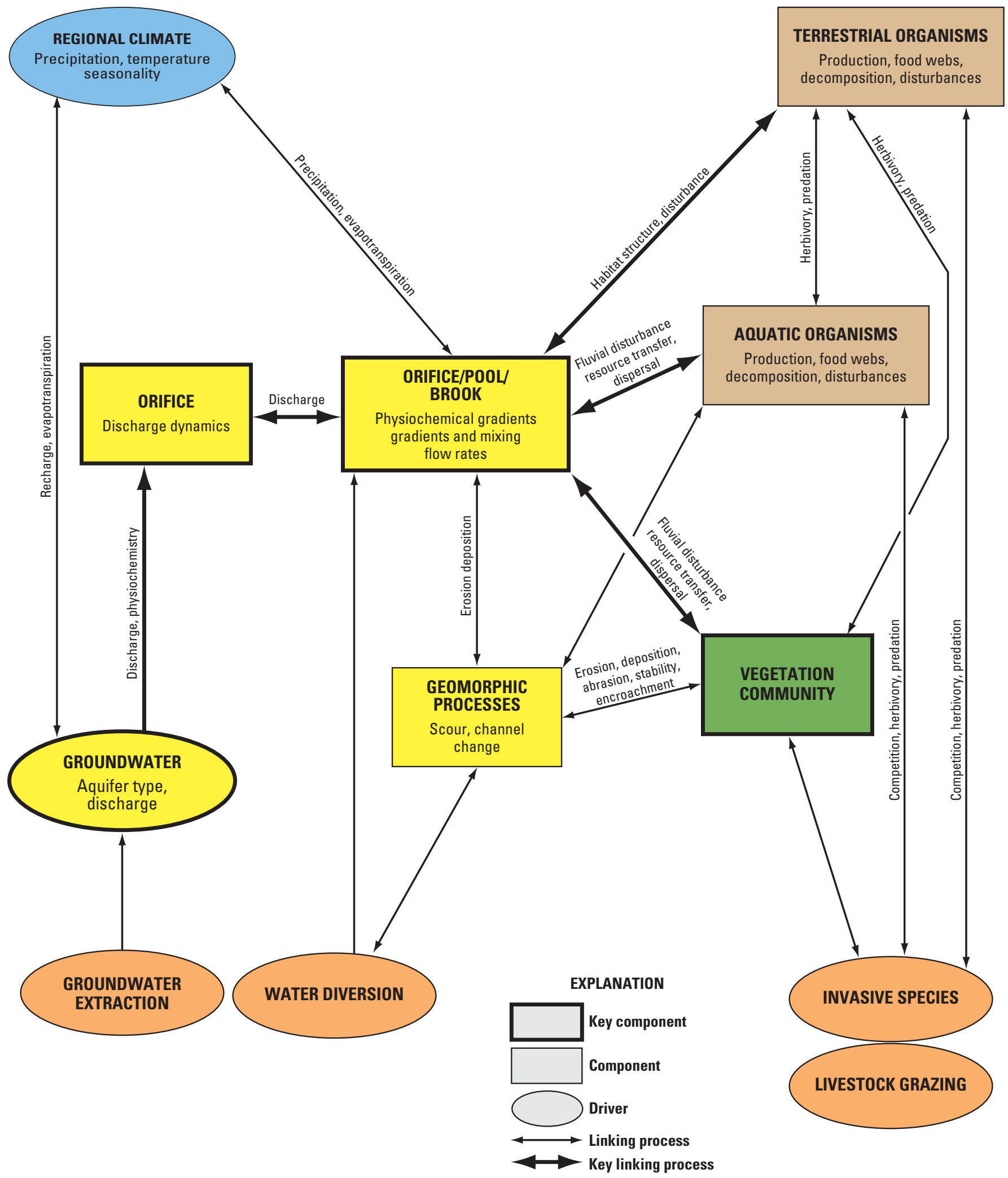

Figure 4.6. Control model of spring ecosystems including key processes (arrows), components (boxes), and drivers (ellipses). 


\section{Drivers of Ecosystem Change}

\section{Natural Drivers}

The primary determinates of spring ecosystem form and function are aquifer type/discharge characteristics, environmental gradients away from discharge site, and anthropogenic modifications. Springs, by definition, are where the groundwater table intersects the ground surface, thus groundwater is the primary determinate of the physiochemistry of water delivered to springs. Changes in discharge rates or physiochemistry can dramatically alter spring characteristics and function, as well as cause them to dry out. However, due to the nearly ubiquitous modification of springs in the Great Basin by human activities, land use disturbance clearly is an important anthropogenic driver.

\section{Anthropogenic Drivers}

Pre-historic and historic use of large flowing springs is important to understand for assessments of modern spring biotic conditions. Seeps, spring mounds, and wet meadows have been widely developed as local water supplies that are not robust enough for irrigation. Nearly all springs and wetlands in arid environments have been severely impacted by human activity (Sada and Pohlmann, 2006). A survey of 505 springs in northern Nevada (Sada and others, 1992) determined that more than 85 percent of these springs were moderately or highly disturbed by diversion and livestock. Less than 5 percent of the springs in this study were unaffected by human activity. Shepard (1993) noted that human activities have altered the physical and biological condition of most springs in western North America. Anthropogenic stress factors include diversion (groundwater pumping, spring box capture and piping to troughs, channelization, etc.), impoundment, nutrient pollution, introduction of non-native plants and animals, and trampling by humans and non-native ungulates (Sada and Pohlmann, 2006). Water diversions, predation by exotic species, grazing, pollution, urbanization, and recreation have caused extinctions of spring populations since the late 1800s. Across the Great Basin, there is a loss exhibited by 60 percent of the endemic species (virtually all fishes, insects, and amphibians), of which all but 2 percent have had major declines, and 8 percent have been extirpated. Spring habitat and population loss peaked after each world war and was static during wars, indicating a tight connection to economic conditions (Sada and Vinyard, 2002).

Historical ecology has many potentially large applications for springs and wetlands. Paleoclimate and paleobotanical records describe the sediments under springs and marshes, and faunal records, though limited, typically are available as well. Study of past hydrologic and ecologic conditions can be valuable for establishing reference conditions with which modern conditions can be compared (Swetnam and others, 1999) and future conditions projected.
Decreased discharge increases the variability of the spring environment and shortens spring runout length, which alters aquatic species composition. Native Americans and early settlers commonly increased access to water by excavating the pools and digging shallow wells. It is difficult to determine original characteristics for these modified springs. Some of the anthropogenic modification likely involved removal of phreatophytic vegetation to enhance water availability.

Introduction of non-native species also has been a consequence of historical activities. Sport fish, aquarium fish, and mosquitofish introductions were widespread. Trampling by non-native ungulates such as livestock, wild horse, and burro populations has impacted springs in ways similar to excessive grazing in riparian systems by increasing temperature, fine substrate sediments, and nutrient loading (Kauffman and Krueger, 1984; Fleischner, 1994). More recently, groundwater contamination by pollution, increased nutrient concentrations, and refuse disposal from mine stockpiles and tailings, landfills, sewage treatment ponds, fertilizers and pesticides, hazardous waste disposal, and accidental spills of hazardous chemicals and waste have become significant problems.

Modern increases in groundwater extraction is likely the single greatest threat to springs by reducing or eliminating discharge. Paving over or otherwise disturbing groundwater recharge zones, especially in mountainous areas and along mountain fronts, may significantly impact groundwater flow systems. The effects of groundwater extraction may take decades to centuries to manifest. Effects of water diversions and pumping are similar to the consequences of drought. Reduced discharge results in loss of endemic species and reduction of biodiversity. Drought-intolerant aquatic species (for example, mayflies, caddisflies, and crenobiontics) are replaced by drought tolerant taxa (for example, midges, beetles, corixids, etc.) and non-native and upland vegetation may become dominant members of the riparian community following reduction or elimination of surface discharge (Sada and Pohlmann, 2006).

Changes in climate can stress all aquifers but effects will be most immediate in upland and local aquifers with short flow paths. Alterations in watershed budgets through increased aridity (that is, little recharge occurs) or altered amounts and timing of snowmelt can decrease discharge or otherwise disturb spring ecosystems. Springs in deserts are highly likely to respond to climate changes and such changes can have cascading effects on wildlife dependent on the water sources.

Invasive species threaten nearly all water sources in the Great Basin, and include invasive plants (for example, saltcedar and annual grasses), invertebrates, fish, and mammals. 


\section{Ecosystem Dynamics}

Spring ecology in arid regions generally remains unsynthesized and relatively poorly studied. Studies have focused on characteristics of springs (for example, flow and water quality), individual taxa or biota, or on selected topics at local, or rarely, regional scales. High demands for water in arid lands and the inherent complexity of springs likely have retarded development of comprehensive understandings of spring ecosystem (Stevens and Springer, 2004). As a result, much is known about biotic composition of Great Basin spring systems, and little is known about the processes and dynamics that act in them. Consequently, we develop our conceptual model primarily around studies from other regions that have applicability to Great Basin springs.

Benthic macroinvertebrates, aquatic insects, reptiles, amphibians, and (mostly endemic) fish species in springs and seeps in the Great Basin have been identified as a high priority by land management agencies, highlighting a need for integrated eco-hydrologic models for these systems. Rather than attempt over-simplified, and probably incorrect, conceptual models on the basis of inadequate data, the approach taken here is to present conceptual models of what is known about spring-fed ecosystems and highlight information gaps. This approach emphasizes springs with pools and outflow streams, about which most is known.

Despite the unique characteristics of individual desert springs, some aspects of their ecological relationships may be generalized. Small springs tend to be autotrophic, with little dependence on allochothonous carbon sources (Minshall, 1978; Cushing and Wolf, 1984). Within large spring systems, environmental variation tends to be lowest near the source, where conditions are more stable, and higher downgradient where variability in temperature, discharge, and dissolved oxygen concentration is greater (Deacon and Minckley, 1974). Abundance of plant and animal populations may vary seasonally as a function of food availability, temperature, reproduction, and migration of species along a spring brook (Sada and Pohlmann, 2006), although spring morphology influences the types of species present. Habitats may be partitioned based on factors such as water depth and velocity, and substrate (Deacon and Deacon, 1979; Sada and Herbst, unpub. data, 1999). Aquatic organisms in thermally and geochemically stressed springs, where osmoregulation and respiration are difficult (Brock, 1994; McCabe, 1998), tend to be tolerant of harsh conditions; some flies and cyanobacteria are examples.

Most springs in the Great Basin host saltgrass (Distichlis spicata) and many host sedges (Carex $s p$.). Deeper waters commonly have bulrushes (Scirpus $s p$.) and lizardtail, and larger marshes and riparian zones may have mesquite (Prosopis sp.), willow (Salix sp.), or salt cedar (Tamarix ramosissima). Marsh birds and waterfowl use springs during migration, and nesting by blue-winged teal (Anas discors), cinnamon teal (A. cyanoptera), and ruddy ducks (Oxyura jamaicensis) is common. There are many aquatic amphibians such as toads and salamanders. Spring ecosystems also support enhanced populations of mammals such as rodents, bats, rabbits and ungulates (Minckley and Brown, 1994).

The biota of arid land spring systems show characteristics attributed to the colonization and extirpation dynamics of small, isolated habitats (Sada and Pohlmann, 2006). Isolation of springs and relatively small habitat patch size may promote aspects of island biogeography, including endemism and rarity. Both the occurrence and geographic sparseness of Great Basin springs certainly has significant effects on birds, reptiles, amphibians, and mammals. Ephemeral springs, and springs with harsh thermal and geochemical conditions, tend to have low species richness whereas perennial springs typically include more species and larger populations (Erman and Erman, 1995). Compared to perennial springs, ephemeral springs tend to harbor more upland and drought resistant plant species and include more vagile aquatic organisms capable of rapid colonization and recolonization. Spring ecosystems also are influenced by elevation-determined climatic gradients and by natural and anthropogenic disturbance stressors.

\section{Groundwater Orifice and Discharge Dynamics}

Discharge is determined by groundwater characteristics and orifice type, and may be augmented by stream runoff (fig. 4.7). Local slope and microtopography may allow runout (that is draining of springs), which creates (commonly short-length) streams and associated riparian features. Flow conditions (depth, velocity) and local soils (texture, structure) determine sediment transport rates, which can result in erosion or deposition in runout channels or the spring orifice. Organisms are sensitive to water depth; for instance, the Devils Hole pupfish is extremely sensitive to small changes in water levels and other environmental factors (Chernoff, 1985; Andersen and Deacon, 2001). Vegetation communities and associated invertebrates (not shown) respond to water physiochemical conditions (temperature, chemistry, flow rates) depending on their adaptations to those types of environments and disturbances. As stated previously, vegetation (possibly facilitated by dust deposition) may encroach into runout or orifice features given appropriate (that is low velocity, aerobic) water conditions. 


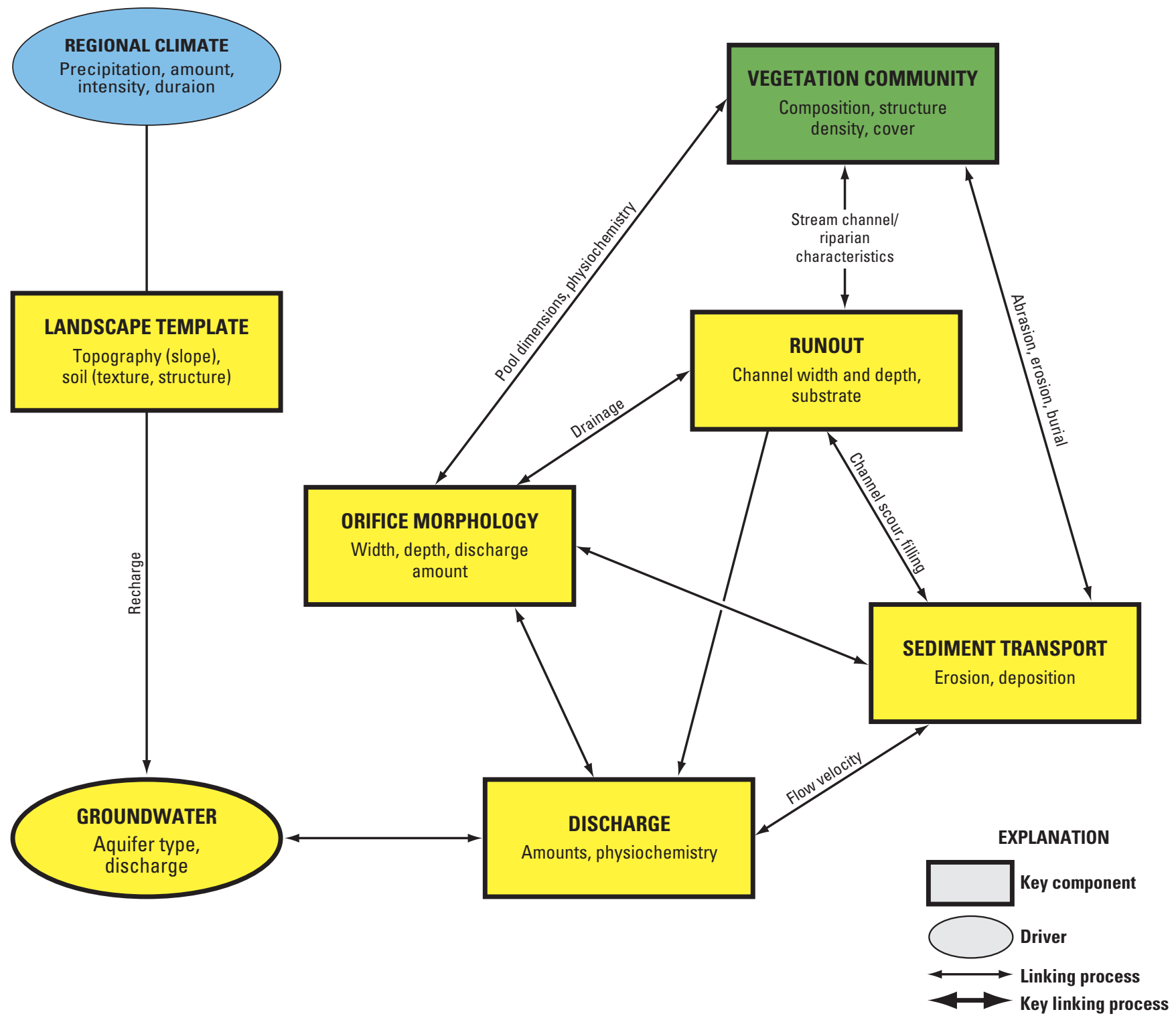

Figure 4.7. Control model emphasizing interactions between discharge dynamics and geomorphology. Bold outline indicates key components.

\section{Spring Vegetation Dynamics}

A more detailed model of emergent vegetation dynamics in spring systems (fig. 4.8) is based on Stevens and Springer (2004) and Plumb and others (2005). The structure, composition, density, and cover of vegetation communities are determined by discharge/flow dynamics, which may be modified by trampling, other natural causes, or through anthropogenic mechanisms. The model considers how ungulates and other mammals interact with predators, and how both affect the local environment through trampling, seed dispersal, and as consumers. Riparian overstory and understory plants tend to be denser near spring brook channel heads, where flow is most consistent, and less dense and spread more widely farther down the spring brook. Plant diversity tends to increase with distance from the spring as well. Wildlife habitat varies with these plant patterns. Invasive species may create new disturbances or may out-compete native species. 


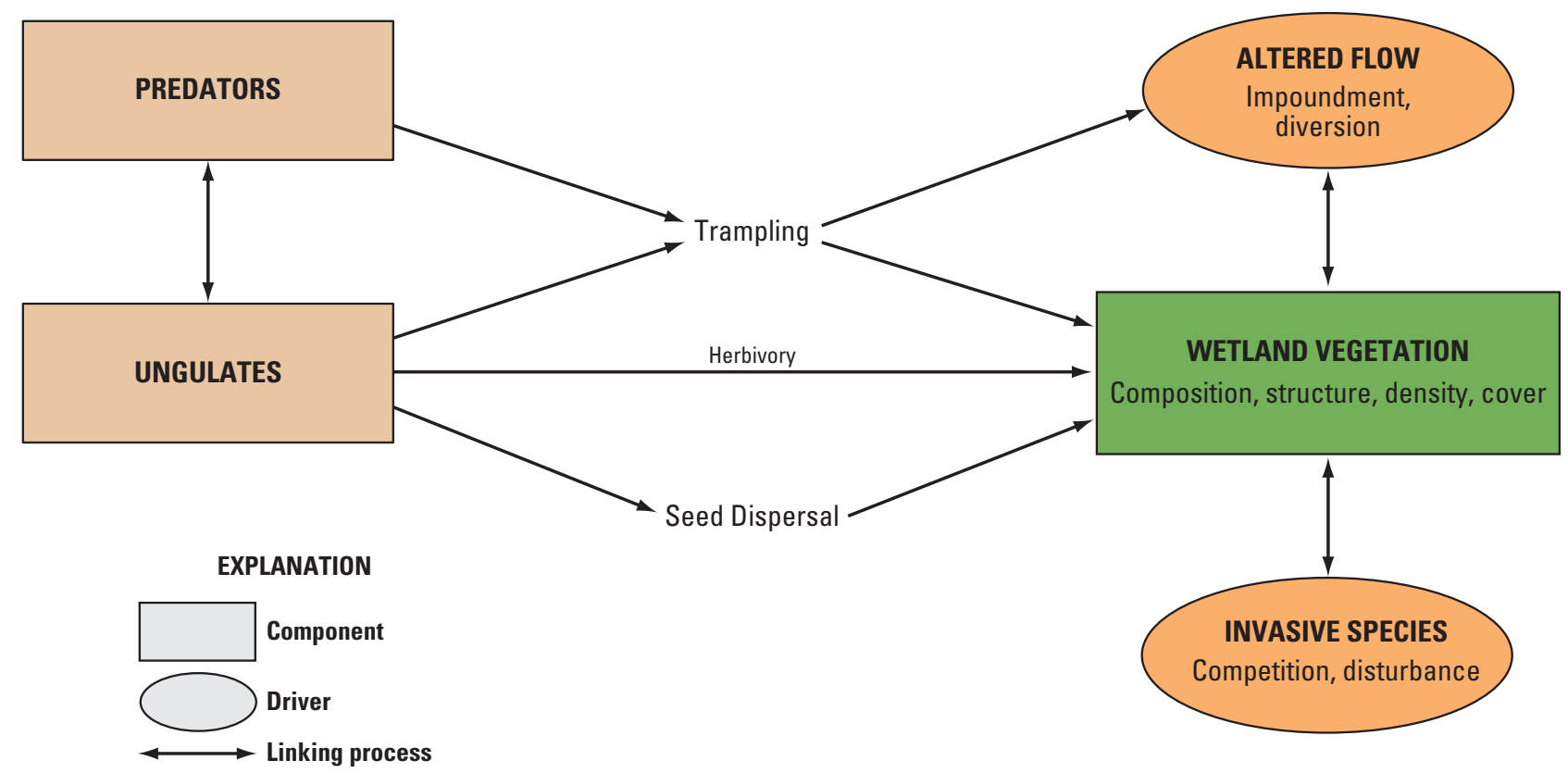

Figure 4.8. Stressor model of emergent vegetation in spring systems showing structural components (rectangles), anthropogenic (ovals) drivers, and functional relations (arrows).

\section{Spring Fauna}

Variability in physiochemical properties is small near spring mouths and increases farther downstream, leading to variations in fauna according to their tolerance for environmental variability. Aquatic communities structured by variability are further modified by availability of organic material, which typically is limited near the spring source but increases downstream (Thorup, 1974). As a result of these environmental factors, aquatic communities tend to be low diversity in and near spring sources. Species richness also is correlated with variable substrate composition and current velocity (Sada and Nachlinger, unpub. data, 2009). Greater amphibian density is found downstream in open and varied vegetation than near springs (Bradford and others, 2003).

\section{Summary Points}

Wetland and spring ecosystems involve complex interactions of groundwater systems, discharge regime, orifice geometries, vegetation, and faunal use. They are very sensitive to physical and chemical disturbances as well as groundwater withdrawals and diversions. Nearly all spring and wetlands in the Great Basin have experienced anthropogenic impacts for as much as several thousands of years. There is much research needed to understand the ecology of Great Basin spring ecosystems because they commonly are isolated and contain endemic organisms that may make many systems unique. More information also is needed to assess the resilience of spring systems to climate change, increased water pumping and diversion, invasive species, fire regimes, and pollution.

\section{Stream and Riparian Models}

\author{
By D.R. Bedford
}

\section{Distribution and Management Significance}

Streams and their adjacent riparian zones are widespread in the Great Basin, and yet encompass less than 3 percent of the area. Several alluvial-valley rivers lie within the Great Basin area: Humboldt, Snake, and White Rivers, and Meadow Valley Wash. In addition, lower reaches of several rivers that head in the Sierra Nevada, Uinta Mountains, and the Owyhee and Colorado Plateaus also lie within the Great Basin.

Countless small streams lie in mountain blocks, the larger of which have lower reaches that extend onto adjacent alluvial piedmonts. More ephemeral, intermittent streams exist; these flow only in response to seasonal snowmelt or rainfall-induced flooding.

The widespread distribution of countless perennial and ephemeral streams in the Great Basin has been a resource for ranchers, farmers, miners, and many others in need of water. As a consequence, most of these streams have been significantly modified in historic and prehistoric times.

Stream and streambank (riparian) systems consist of flowing water and associated channel bed and floodplain environments. Two aspects of stream and riparian zones separate them from other systems in semi-arid regions. The presence of (1) perennially or intermittently flowing water that typically spans multiple environmental zones creates, (2) unique mosaics of heterogeneous flow and bank environments 
that support a high degree of biodiversity. However, because all streams and rivers are dynamic and adjust their characteristics to climate, geology, topography, base level, and vegetation (Fitzpatrick, 2001), they often share common processes, features, and interactions across a wide range of environments (Patten, 1998). Streams with intermittent flow generally lack riparian zones and aquatic species, although enhanced xerophytic growth adjacent to channels is common in these areas. Ephemeral streamflow provides some geomorphic and hydrologic spanning across environmental zones, similar to perennial streams. The following model development does not consider the poorly studied intermittent streams further.

Stream and riparian areas of semi-arid landscapes, despite their small total cover, are among the biologically most diverse and important ecosystem components in the Great Basin (Naiman and Decamps, 1997; Patten, 1998). In addition to obligate aquatic species, up to 80 percent of all vertebrates depend on stream and riparian areas for at least one-half of their life cycles, and more than one-half are completely dependent on these habitats (Chaney and others, 1993). Stream and riparian areas also serve as important connectors for energy and materials among nearly all Great Basin ecosystem components. They integrate effects from upstream and downstream regions, and in essence affect and are affected by all ecosystems.

The primary distinction in Great Basin riparian systems is between alluvial rivers and mountain streams. Most perennial streams in the Great Basin are mountain streams. Mountain streams tend to have distinct channel morphology because they are constrained by bedrock. Habitat in mountain streams varies relatively systematically with position in the watershed (Montgomery and Buffington, 1997). Mountain streams respond more quickly to precipitation and snowmelt and tend to be connected to small (and thus more climatically sensitive) aquifers. In contrast, alluvial rivers occupy wide, low relief valleys, and tend to have relatively high and mobile sediment concentrations. The course of alluvial rivers in wide valleys vary with dynamics of channel form determined through interactions with water and sediment supply, and riparian vegetation (Montgomery and Buffington, 1997; Murray and Paola, 2003), and these systems largely are driven by longterm groundwater and climate characteristics. In this section, we focus on the majority of riparian systems: mountain streams.

\section{Ecosystem Components and Processes}

Stream and riparian systems are best described by the interactions among precipitation, flow, and geomorphic dynamics through the channel and floodplain, and aquatic and riparian biota. These systems commonly transect large areas with significant altitude ranges and thus interact with diverse dryland systems in the watershed. Because stream and riparian systems integrate processes in the watershed, we use upland watersheds models and theory as part of our modeling construct. The complex interactions among the upland systems are not treated here, and much more work is needed in order to better understand stream riparian connections with each other.

Figure 4.9 presents our conceptual model for riparian systems, which is modified from models for adjacent ecosystems (Miller and others, 2006). The top-level driver is regional climate, which affects riparian systems by adding water through precipitation and determining environmental gradients in wind, radiation, and temperature. This, in turn, affects water and energy budgets (for example evapotranspiration, snowmelt). Precipitation is partitioned into soil moisture, streamflow, and recharge to groundwater as represented in the model by "Upland Watershed Hydrology." The upland watershed configuration also controls sediment delivery and flux of organic matter and nutrients to stream channels. Depending on upland watershed characteristics, groundwater may significantly affect stream levels. The flow regime determines magnitudes and temporal characteristics of streamflow, which interacts dynamically with the stream channel and sediment load to determine channel geometry. The channel and its flow interact with vegetation and floodplain soils, determining the water, chemical, and sediment budgets for each. The vegetation community and fauna experience facilitation and competition among various species and functional types.

Anthropogenic drivers (orange ovals) also are shown in figure 4.9 to illustrate where each has its greatest effects on the stream-riparian system. The drivers are discussed in section, "Drivers of Ecosystem Change."

\section{Upland Watershed Hydrology}

Most water in any section of stream and riparian zones has sources in the upland watershed. Water entering the watershed as precipitation or snowmelt must make its way to stream channels by surface or subsurface (groundwater) flow. The partitioning of precipitation into surface and groundwater will be determined by the type of precipitation, other climate parameters such as temperature, as well as the spatial configuration of watershed characteristics, which integrates its long-term geomorphic history. An example of the effects of upland watershed characteristics and processes on riparian form and function is through long- and short-term effects on basin shape and interactions with groundwater. Steep, narrow basins tend to have narrow riparian zones with plant communities dominated by alder (Alnus $s p$.), and gentle, wider basins tend to have wide riparian zones with complex riparian vegetation and aquatic community structure (Patten, 1998; see fig. 4.10). 


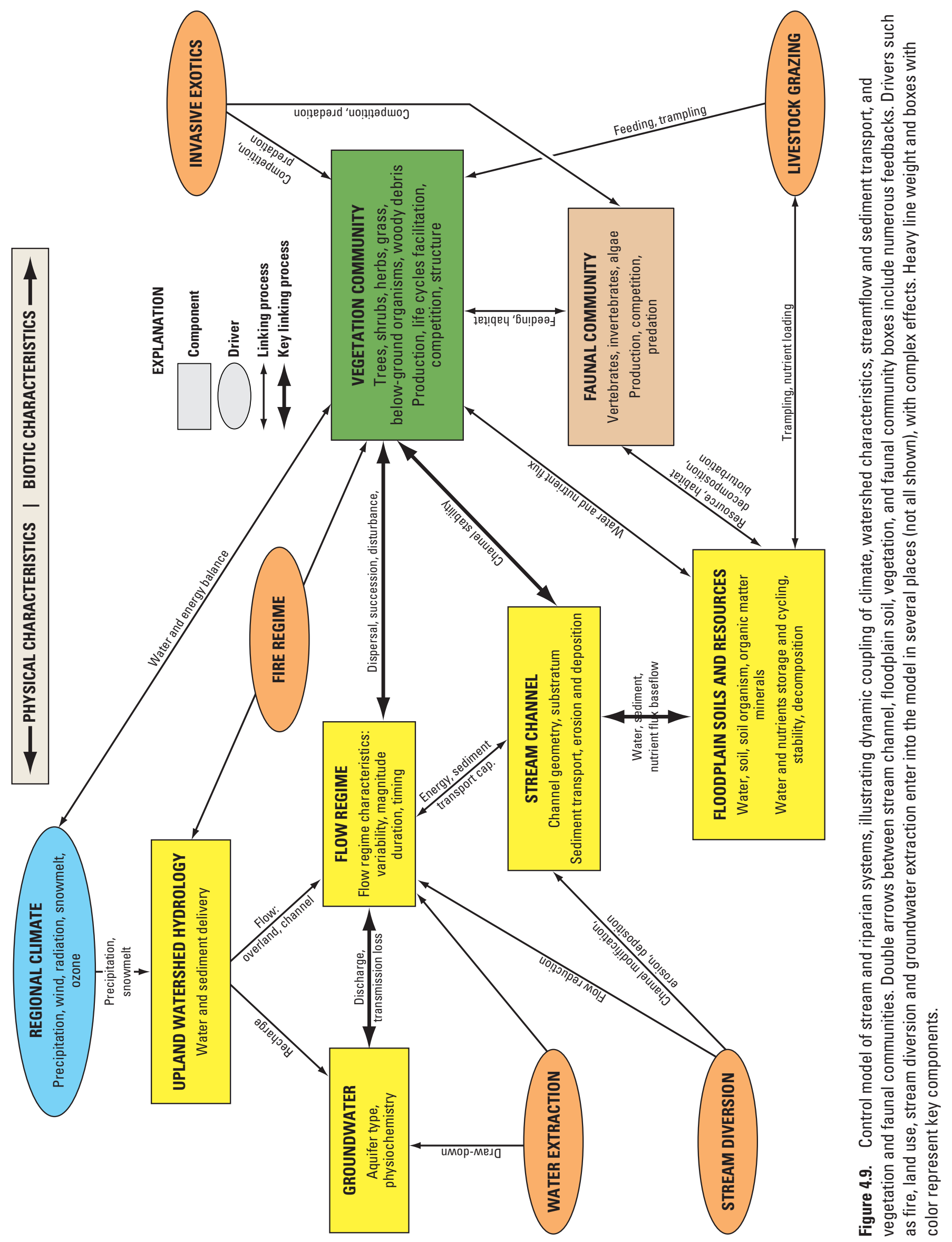



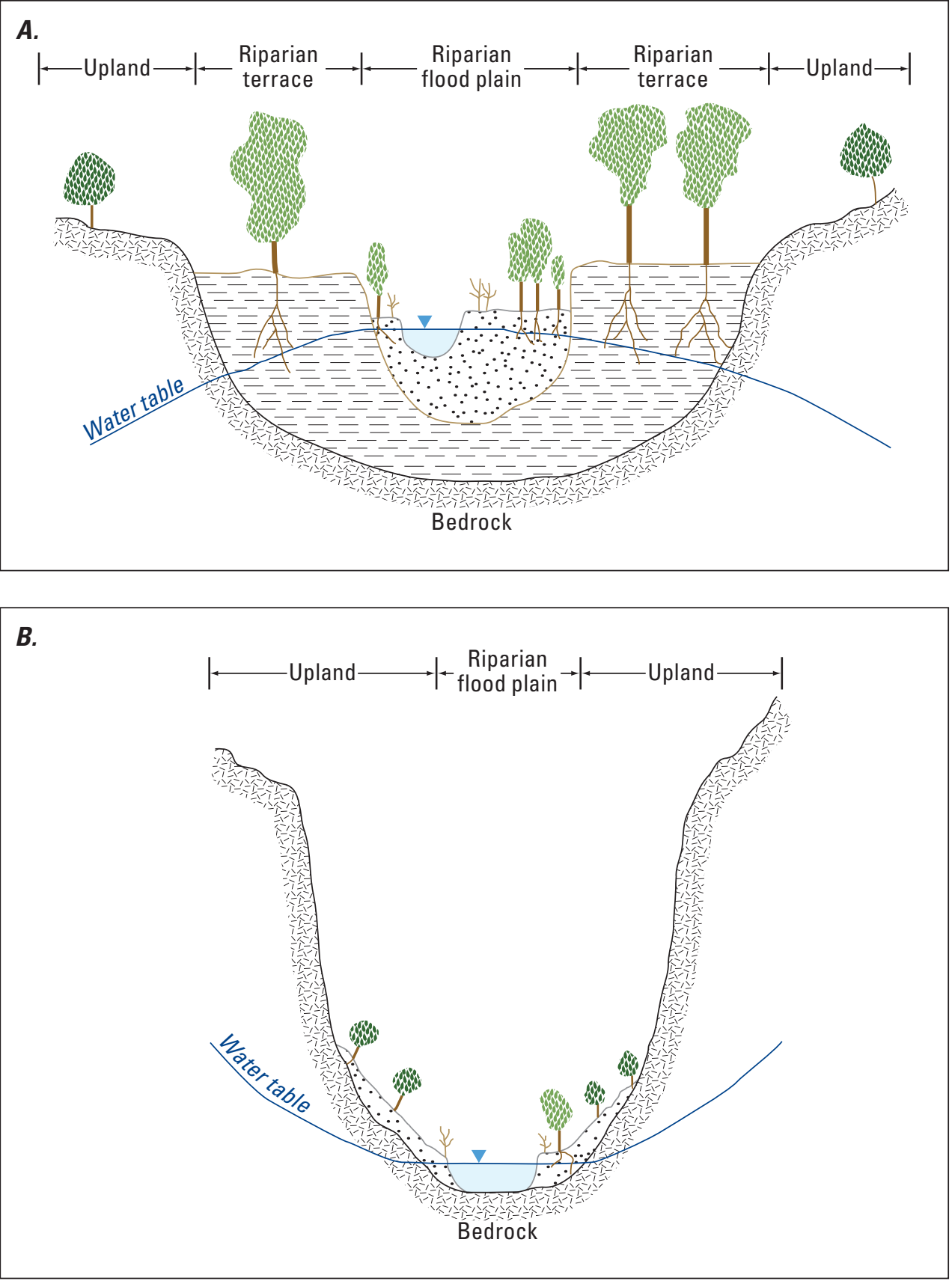

Figure 4.10. Influence of upland watersheds through basin geometry on the structure of riparian system components. $(A)$ wide valley with a losing stream, $(B)$ narrow valley with a gaining stream. (From Scott and others, 2005, which is modified from Goodwin and others, 1997.) 
The delivery of materials from upland watersheds also is determined by the dry upland ecosystems. Stream channel networks act as a template for organizing vegetation and hydrological (ecosystem) dynamics within the upland watershed through processes such as incision and aggradation (Caylor and others, 2005). In turn, the timing, amounts, and quality of water, organic material, nutrients, and sediments delivered to channels from upland watersheds exerts strong controls on riparian systems (Frissell and others, 1986) as well as helping to shape the long-term evolution of drainage basins (Collins and others, 2004).

\section{Flow Regime}

The streamflow regime describes magnitude and timing of flowing water and varies greatly depending on the spatial and temporal scales. Modern theory of streams and rivers recognizes that they are complex networks that include distinct zones where hydrogeomorphological processes and ecology are very similar (Poole, 2002; Benda and others, 2004; Thorp and others, 2006). These zones form in response to long-term geomorphic processes and, barring anthropogenic modification, set the inherent scale in determining a flow regime. In short, determining the flow regime for monitoring goals depends on the location and time scale of interest and the geomorphic history.

The flow regime is one of the primary determinates of ecosystem form and function in stream and riparian systems (Chambers and others, 2004). Ecologically important aspects of flow regime include the magnitude, frequency, duration, predictability, and rate of change of flow conditions (Poff and others, 1997; Lytle and Poff, 2004). Morphological, behavioral, and life history adaptations of numerous aquatic and riparian organisms appear to have evolved in response to different components of the flow regime (Lytle and Poff, 2004) and are discussed in subsequent sections. Flood-related disturbances are important ecological processes, contributing to temporary loss of vegetation, but also expanding riparian habitats and allowing establishment of riparian vegetation (Naiman and Decamps, 1997; Friedman and Lee, 2002).

\section{Stream Channel}

Interactions between flowing water (defined by the flow regime) and stream channel geometry dictate most of the characteristics of stream and riparian ecosystems. Fluvial geomorphic processes are responsible for the entrainment, transport, and deposition of sediments in streams and rivers, and determine stream channel geometry, stability, and water physiochemistry. Stream channels adjust their geometry, bed substrate characteristics, and sediment loads to variations in water discharge and size and amount of sediment delivered to channels from upland watersheds. Channel geometry plays a significant ecological role by structuring flow width, depth, and velocity conditions. These stream conditions are crucial for stream and streambank communities because they determine disturbance (shear stress) on the channel bed, stability of channel walls, and light and temperature regimes (Allan, 1995). Over the long term, geomorphic processes shape drainage basins, and over short terms, they structure ecological processes, habitat characteristics, and their interactions (Frissell and others, 1986; Montgomery, 2001). Fluvial geomorphic processes are affected by streambed and bank vegetation through stability provided by roots and algae and decreases in flow velocity by vegetation. Riparian vegetation is implicated in providing channel stability in wide valley alluvial rivers (for example, Murray and Paola, 2003), and degradation of vegetation commonly precedes gully formation (Prosser and Slade, 1994).

\section{Floodplain Soils and Resources}

Floodplain soils are those immediately adjacent to streams that are continuously or periodically inundated by shallow stream-related groundwater or by overtopping of streambanks. Floodplain soils and resources provide many important ecosystem services. Repeated flooding of floodplain soils commonly limits their nutrient and water holding capacity (Scott and others, 2005). Recently flooded or scoured floodplain soils commonly are occupied by early colonizing vegetation, which is replaced by later succession vegetation as soil resources develop (Allan, 1995).

Water-table depth in floodplains is critical for riparian vegetation, and fluctuations can create lethal moisture stress (Busch and Smith, 1995; Shafroth and others, 2000; Snyder and Williams, 2000). Typically, depth to water is less than $4 \mathrm{~m}$ and needs to be 1-2 $\mathrm{m}$ deep for riparian vegetation recruitment (Stromberg and others, 1996; Horton and others, 2001). Floodplain microorganisms play important roles in watershed-wide nutrient dynamics. Organic matter from riparian vegetation is converted to particulate and dissolved organic matter for use by floodplain and stream organisms (Naiman and Decamps, 1997). Nitrogen uptake by riparian vegetation and microbes may render riparian zones as sites of net accumulation, which may help remediate nitrogen loading in upper watersheds (Naiman and Decamps, 1997). 


\section{Vegetation Community}

Stream and riparian vegetation communities serve several ecosystem functions. Aquatic plants serve as filters for water, sediment, and nutrients, and can help control non-point sources of pollution. Aquatic and riparian plants provide detritus as a raw material for nutrient cycles on which riparian vegetation and aquatic communities rely (Naiman and Decamps, 1997). Aquatic plants provide microclimate control on extreme temperature and water-level fluctuations and stabilize streambanks (Naiman and Decamps, 1997; Patten, 1998). The many physiological and structural adaptations of riparian plants to their environments facilitate the utilization and conservation of resource flushes. Habitat for many vertebrates, such as birds and mammals, is linked to canopy structure (physiognomy) and structure variability (Mac Nally and others, 2002), which are maximized in riparian habitat.

Native riparian tree species are early successional, colonizing bare wet surfaces, and are tolerant of nutrient-poor soils and burial. Their life cycles are intimately tied to flow regime dynamics: release of seeds and dispersal occurs during periods of high flood flows, and recruitment occurs during intervening low flow periods (Bagstad and others, 2005; Scott and others, 2005). The invasive Eurasian species salt cedar and Russian-olive (Elaeagnus angustifolia) reproduce opportunistically, are tolerant of stress, high salinity, drought, and repeated burning (Stromberg, 2001), and particularly for saltcedar, have expanded rapidly throughout the Southwest (Webb and Leake, 2006). Recruitment of saltcedar is similar to cottonwood and willows, although saltcedar appears to be able to actively recruit on floodplains without being flooded (Birken and Cooper, 2006). Saltcedar appears to tolerate low water tables by using unsaturated zone moisture, which can lead to complete replacement of native trees; replacement in some cases increases total vegetative cover (Busch and others, 1992; Birken and Cooper, 2006; Webb and Leake, 2006), but reduces biodiversity.

\section{Faunal Community}

Insects and other invertebrates play important roles in food webs of stream and riparian ecosystems as secondary consumers and as prey for fish, other insects, birds, and mammals (Power and Dietrich, 2002; Paetzold and Tockner, 2005). Aquatic species commonly respond to pulses in stream water or chemistry, which leads to similar pulses in aquatic and streambank predator populations (Paetzold and others,
2006). Fish act as consumers for many ecosystem components (algae, benthic invertebrates, insects, vertebrates), and as prey for other vertebrates. Fish and other aquatic fauna are structured by flow regimes, as well as water quality and temperature. Geomorphic processes determine channel form and in conjunction with flow regime influence habitat features, such as bed substrate characteristics (Biggs and others, 2005).

Riparian vegetation is an important determinant of bird communities. Birds are widely used as targets for management strategies, ecological assessments, and monitoring programs because they are scientifically and socially well known, and responsive to natural and anthropogenic environmental change (Fleishman and Mac Nally, 2006). Studies of desert bird species show that they are sensitive to total vegetation volume, and that the spatial structure of vegetation composition is reflected by bird assemblages, rather than metrics such as vegetation structure or primary productivity (Fleishman and others, 2003, 2004; Fleishman and Mac Nally, 2006). Birds also serve in nearly all trophic roles and as vectors for seed and organism dispersal from isolated habitats.

\section{Aquatic Ecology Control Model}

The conceptual model for aquatic ecosystems portrayed in figure 4.11 is modified from Scott and others (2005). The model expands the stream and riparian model (fig. 4.9) to emphasize aquatic biota. Stream physiochemistry represents physical characteristics such as bed and bank characteristics (grain-size distributions and roughness, temperature and velocity profiles), as well as chemical properties such as $\mathrm{pH}$, conductivity, dissolved and suspended organic material, and potential contaminants. Stream physiochemistry plays a key role in aquatic ecosystems and is a dynamic function of climate, streamflow, riparian and floodplain vegetation, and fluvial geomorphic processes. Stream physiochemistry sets the habitat and resource template for aquatic biota. Streamflow directly affects aquatic biota by fluvial disturbances affecting flow and sediment transport and indirectly through its influence on temperature. Streamflow characteristics such as timing of flooding can influence behavioral characteristics, such as dispersal mechanisms and developmental cues (Stevens and Springer, 2004; Scott and others, 2005). Fluvial disturbance is technically a function of bed characteristics (and thus stream physiochemistry in the aquatic model) because bed geometry determines velocity profiles; we show it as directly affecting aquatic biota for simplicity. 


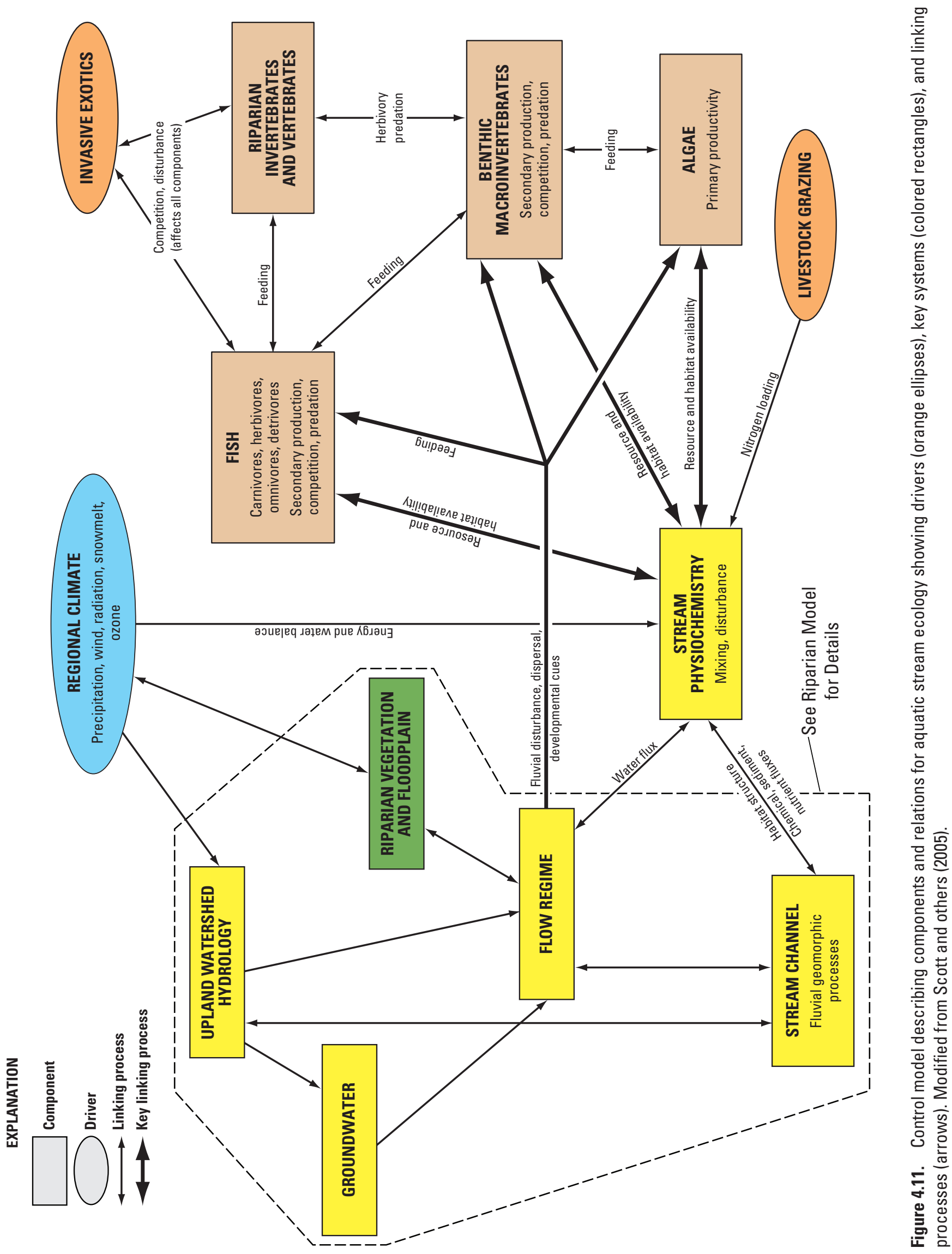


Algae serve as primary producers in riparian aquatic systems and are consumed by benthic macroinvertebrates, fish, and riparian invertebrates and vertebrates. Benthic macroinvertebrates play key roles in aquatic ecosystems as secondary producers; functional behavior includes shredders, grazers, omnivores, detritovores, filter feeders, and decomposers. Fish functional types include carnivores, herbivores, omnivores, and detritovores; thus, all other biotic components impact and are impacted by fish.

\section{Drivers of Ecosystem Change}

\section{Natural Drivers}

Climate is a key driver of stream and riparian ecosystems at all temporal scales. Great Basin riparian areas are strongly affected by past and present climatic characteristics, largely through climatic effects on the coupling of geomorphic processes and vegetation (Chambers and others, 2004). Magnitude and timing of precipitation and snowmelt drive many ecosystem processes (Loik and others, 2004), and despite inherent high variability of precipitation, semi-arid ecosystems are adapted to an envelope or reference range of climatic variability.

Groundwater levels generally determine water levels in stream and riparian systems and vice versa in losing reaches. The aquifer type for a given system determines sensitivity to drivers such as climate and land use. Stream and riparian zones fed by regional aquifers may be relatively insensitive to precipitation over the short term (but not necessarily climatic affects on other ecosystem processes and drivers) because regional aquifers have slow response to changes in climate.

Stream and riparian zones are inherently dynamic, interrelated systems encompassing external and internal processes and their feedbacks. However, the primary characteristic in arid stream and riparian zones for describing ecosystem function (including biotic and abiotic characteristics) is that of the hydrologic flow regime (Naiman and Decamps, 1997; Poff and others, 1997; Patten, 1998; Ward and Tockner, 2001; Friedman and Lee, 2002; Power and Dietrich, 2002; Carsey and others, 2003; Benda and others, 2004; Bagstad and others, 2005; Biggs and others, 2005; Thorp and others, 2006). The flow regime determines, and is determined by, hillslope hydrology and ecology of the watershed (including climatic processes), geomorphic processes, vegetation communities, fire regimes, and macro and micro invertebrates and vertebrate dynamics. Conceptual frameworks for riparian ecosystems and how they function in landscapes are remarkably similar across semi-arid regions.

\section{Anthropogenic Drivers}

Land uses that act as drivers in stream and riparian systems include stream diversion, livestock grazing, groundwater extraction, logging and other land treatments, irrigated agriculture, urbanization, and mining activities. Each of these can affect stream and riparian zones directly through physical disruptions to streams and floodplains, vegetation, and other biota. Indirectly, these land uses can impact riparian ecosystems through effects in adjacent dryland systems that may modify water or sediment budgets (Chaney and others, 1993; Naiman and Decamps, 1997; Patten, 1998).

Future climate change may include increased variability in timing and amount of precipitation, and warm water temperatures (see Chapter 2, section "Climate Change and Forecasts"). Perched and local aquifers likely will be affected strongly by climate change because residence times for water in these aquifers generally is short. Riparian trees are sensitive to groundwater depth, and invasive species may be more tolerant of low groundwater levels (Horton and others, 2001), high $\mathrm{CO}_{2}$, and high air temperatures.

Riparian vegetation is particularly susceptible to impacts from livestock grazing because livestock tend to congregate in riparian areas due to the presence of water, nutrient-rich forage, and shade (Beever and others, 2005). Livestock foraging and trampling can alter vegetation characteristics such as height, density, connectedness, complexity, and composition, as well as alter soils by compaction and other disturbances (Fleischner, 1994; Belnap, 1995; Beever and others, 2005). These effects can cascade into destabilizing stream banks causing increased erosion.

Fire regime plays an important role in riparian ecosystems, with potential feedback mechanisms between riparian zones and upland dry ecosystems. Fire may affect riparian ecosystems more than xeric systems because of the greater density of connected fuels than in xeric systems, but this effect is balanced by greater moisture content of riparian plants. Erosion may be increased following fires due to reduced riparian vegetation, and may lead to altered channel geometry and flow regime, causing significant changes to stream and riparian processes such as incision of channels. Fire regimes in adjacent dry ecosystems may alter the sediment budget to streams and riparian zones, affecting geomorphic processes, flow regime, and aquatic and riparian ecosystems.

Invasive species can out-compete native biota and introduce new disturbance regimes. If invasive species alter the structure of ecosystems (for example, monospecific stands of riparian trees with simple canopy structure), the effects may 
be expressed in other biota that rely on structural diversity such as birds (Fleishman and others, 2003). Saltcedar and Russian olive are present, if not dominant, in most Great Basin riparian areas (Friedman and others, 2005; Webb and Leake, 2006). Saltcedar is associated with modification of vegetation structure, reduced groundwater depths, and has been causally linked to floodplain development and channel narrowing (Busch and Smith, 1995; Stromberg and others, 1996; Birken and Cooper, 2006). Exotic fish and snails are prevalent in many streams and rivers, and often out-compete natives, lowering gene pool diversity. Hybridization of fish can lead to extirpation of native species.

Other drivers include non-point source pollution introduced through overland flow and groundwater, animal harvesting, and nutrient loading (particularly nitrogen). Increased nitrogen deposition occurs through anthropogenic airborne sources as well as local pollution.

\section{Ecosystem Dynamics}

Streams and riparian areas are highly dynamic systems. Although described in detail in the section, "Drivers of Ecosystem Change," they involve interactions with groundwater systems, climate, the landscape configuration and natural and anthropogenic drivers, such as climate, grazing, and fire.

\section{Summary Points}

Great Basin riparian systems involve complex interactions between groundwater, surface water, vegetation, and climate. Because of this, they are sensitive to all natural and anthropogenic impacts that affect the interacting systems. They are particularly sensitive due to the high demand from the availability of water in this desert landscape. Historical ecology and paleoclimate are not well studied, but can provide a reference range of conditions to compare with current and future conditions. This is particularly important for wetland ecosystems in which human modification occurred prior to scientific and most historical records. Invasive riparian plants, such as saltcedar, potentially change habitat and affect local and migratory species, but studies are inadequate to fully document these effects. Improved understanding of the ecology and drivers of ephemeral streams is needed. Do they function similar to dryland or wetland ecosystems, or as a hybrid? What changes to stream flow regime will cause transitions in vegetation from riparian assemblages to xeric assemblages and vice versa? Little is known about nitrogen deposition in Western riparian ecosystems. Because most streams are in the alpine, subalpine, and forest biomes, nitrogen deposition and other pollutants may be rapidly transferred to streams and their biota. Improved understanding of the buffering capacity of alpine streams is needed in order to predict the effects of wet and dry deposition.

\section{Freshwater Lakes Model}

Freshwater lakes of the Great Basin can be divided into three types: (1) manmade reservoirs and ponds, (2) valleybottom natural terminal lakes that are fed by perennial streams and springs, and (3) high-mountain small lakes, commonly restricted to glacial cirque basins. Reservoirs are managed systems that are not conducive to ecological modeling. Valley-bottom lakes such as Pyramid Lake fluctuate markedly in depth and water quality with climatic episodes, and thus tend to have sparsely vegetated shores. Mountain lakes are small and range from deep, perennial rocky lakes with lush lake-edge vegetation to shallow, seasonally variable lakes in moraines that have sparsely vegetated shores. Developing a specific set of conceptual models for this system is beyond the scope of this study.

\section{Saline Lakes and Marshes Model}

Saline and hypersaline lakes are common in valley bottoms of the Great Basin. Great Salt Lake, the most famous of these lakes, is a terminal lake fed by major streams and springs. Hypersaline waters in these lakes support a limited flora and fauna, but brackish marshes bordering them often teem with wildlife and support a diverse flora. Developing a specific set of conceptual models for this system is beyond the scope of this study. 
This page left intentionally blank 


\title{
Chapter 5: Integration Models
}

\author{
By Alicia Torregrosa and Andrea Woodward
}

\section{Introduction}

Federal lands cover about 78 percent of the Great Basin region, and are managed to provide for multiple societal values including potentially conflicting goals such as supporting cattle grazing and protecting habitat for endangered species. Many decisions required to achieve these goals, such as when to remove cattle from an allotment, require that local managers evaluate information from a larger spatial and longer temporal context than what is directly under local control. In particular, habitat quality over large spatial extents is important for some species of concern. For example, home ranges for the Greater Sage-grouse commonly encompass multiple management units and several seasonally variable habitat needs such as meadows for chick rearing and sagebrush for nesting (Connelly and others, 2000). A broad landscape-level perspective also is necessary for evaluating processes such as disturbance, fragmentation, and connectivity that affect the local extent but are detectable only from an extensive view. Temporal extents are important because landscape patterns are created by the time-dependent transport of energy, matter, and organisms (Farina, 2000). Consequently, decisions made by local managers are improved with knowledge about management actions in adjacent or similar areas beyond their local jurisdiction and by observations over time frames longer than individual growing seasons or annual budget cycles. Local decisions also are affected by policy changes that impose additional constraints on allotments, for example by allowing higher ORV use levels. Hence, landmanagement agencies also must understand how multiple management activities and decisions covering various spatial extents will be impacted by events happening at other spatial extents and over various timeframes.

In addition to improving decisions with knowledge from spatial and temporal contexts larger than the typical individual management unit, managers also must consider the concurrent effects of multiple drivers. For example, the local manager's decision regarding a grazing allotment depends not only on the effects of cattle, but also on an evaluation of other stressors and drivers that impact the condition of the allotment. The capacity for the allotment to maintain an expected level of productivity following a given level of grazing depends on soil properties, local precipitation, disturbance regimes, prior conditions, and human activities, among other factors. This complicated estimate may become more difficult to make in the face of unpredictable climate or other environmental change, which may invalidate previously understood relationships. Conceptual models assist in developing a capacity to anticipate future management opportunities and constraints by identifying the most important relationships among multiple drivers of ecosystem function. This document has described these relationships for subsystems; now the goal is to describe how to combine subsystems and to scale up to the region.

A major challenge to scaling is the mismatch between ecosystem structure and function and the human institutions that are available to manage and study them. The spatial scales at which habitat features are perceived and used typically differ among organisms in relation to body size and mobility, and they often do not correspond to the scales at which researchers and land managers focus their efforts (fig. 5.1; Wiens and others, 2002). A diagram similar to figure 5.1 could be produced for temporal scales because ecologists commonly sample and describe the environment at spatial and temporal scales that are not directly relevant to most organisms and management decisions. This document attempts to bridge these gaps by providing a regional or landscape view to help inform the decisions that are required at multiple scales across the Great Basin. A region-wide understanding of the interacting ecosystems of the Great Basin derived from conceptual modeling helps us develop a predictive capability to evaluate the cumulative effects of multiple stressors on target resources. Predictions, in the form of landscape change hypotheses, become the basis for a monitoring strategy to detect the predicted changes. Accomplishing this goal for the Great Basin involves linking the stressor and control models, described in chapters 3 and $\underline{4}$, with analytical models to facilitate the compilation of data from multiple scales and to simulate landscape change.

\section{Integrated Ecosystem Framework}

\section{Spatial Structure}

In previous chapters, the Great Basin ecoregion was deconstructed into 10 subsystems (fig. 1.3), each of which represents groups of related ecological elements. Discrete, generalized conceptual models were presented of the significant interactions among environmental drivers, stressors, and biotic components and processes within these subsystems (Chapters 3 and $\underline{4}$ ). The next step in integration is to recognize that subsystems are distributed across the landscape in predictable patterns based on biophysical conditions and previous management actions, 


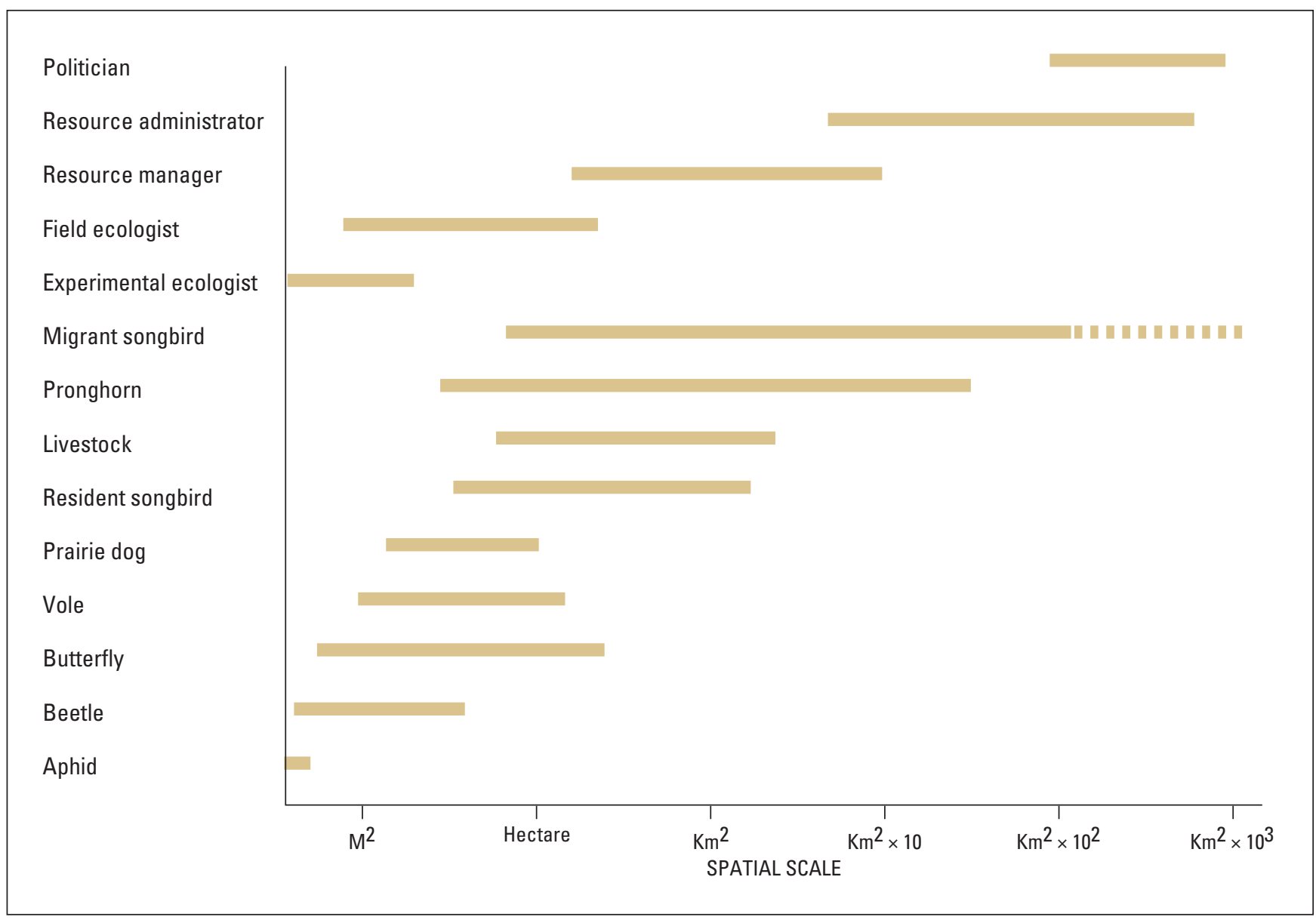

Figure 5.1. Diagram illustrating how scaling windows differ among species that use, investigate, or have management responsibilities for sagebrush steppe ecosystems. A scaling window is defined by the minimum resolution at which organisms perceive spatial variation and the maximum spatial domain experienced by organisms over a fixed period of time (after Wiens and others, 2002).

and that multi-scale, multiple-driver linkages exist among subsystems. Supporting effective management decisions by predicting ecosystem responses requires developing tools that address these patterns and model these linkages. The spatial foundation for such a model is a digital representation of the subsystems in their mosaic arrangement across the Great Basin (figs. 5.2 and 5.3; see fig. 2.1).

\section{Hierarchical Structure}

Ecologists recognize that ecological systems can be viewed as being organized hierarchically, with larger slower-changing units composed of smaller units with faster process cycles (Allen and Hoekstra, 1992; Holling, 2001). Examples of commonly useful hierarchies include individual $\rightarrow$ population $\rightarrow$ community $\rightarrow$ biome, and site $\rightarrow$ drainage $\rightarrow$ watershed $\rightarrow$ basin $\rightarrow$ region. Each hierarchical level has novel emergent properties that arise from the combination of its subunits. For example, erosion-driven changes to small drainages occur frequently during a season and affect the establishment of individual plants. Over several seasons, these changes can accumulate and lead to changes at a larger extent such as mass wasting, which alters not only topography and soil quality, but also land cover with consequent changes in movement patterns of migratory species or new opportunities for invasive colonizers. This example shows how the smaller scale can be viewed as providing the mechanism for changes at the next larger scale (Allen and Starr, 1982; Giampietro, 2003) and shows how temporal and spatial scales are hierarchical. These properties of hierarchical structure can be used as a framework for the integrative model. 


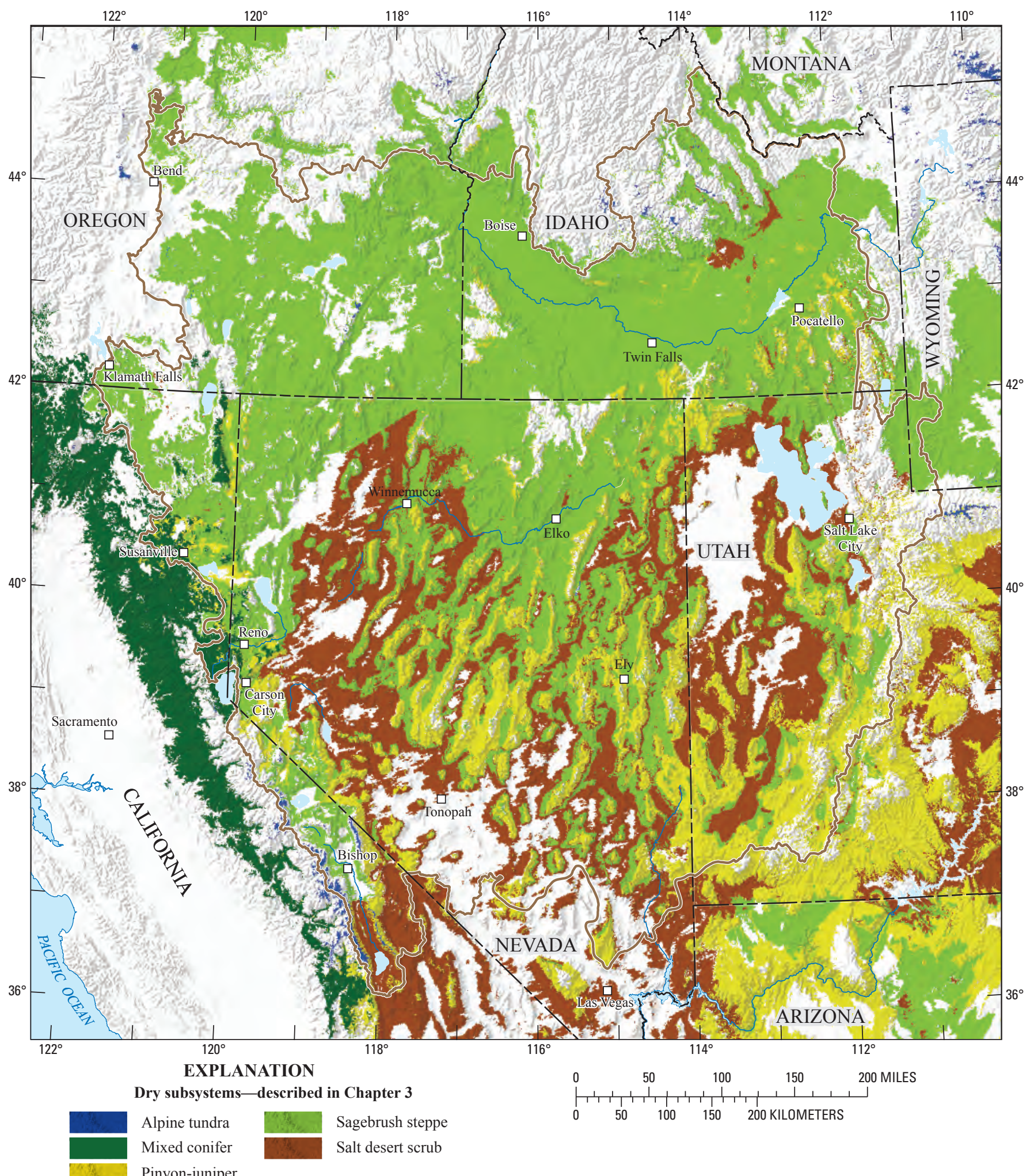

Note: Gray represents areas either outside the GBILM study boundary or other subsystems.

Figure 5.2. Map of dry subsystems described in Chapter 3 (see fig. 2.1) and also salt desert scrub. 


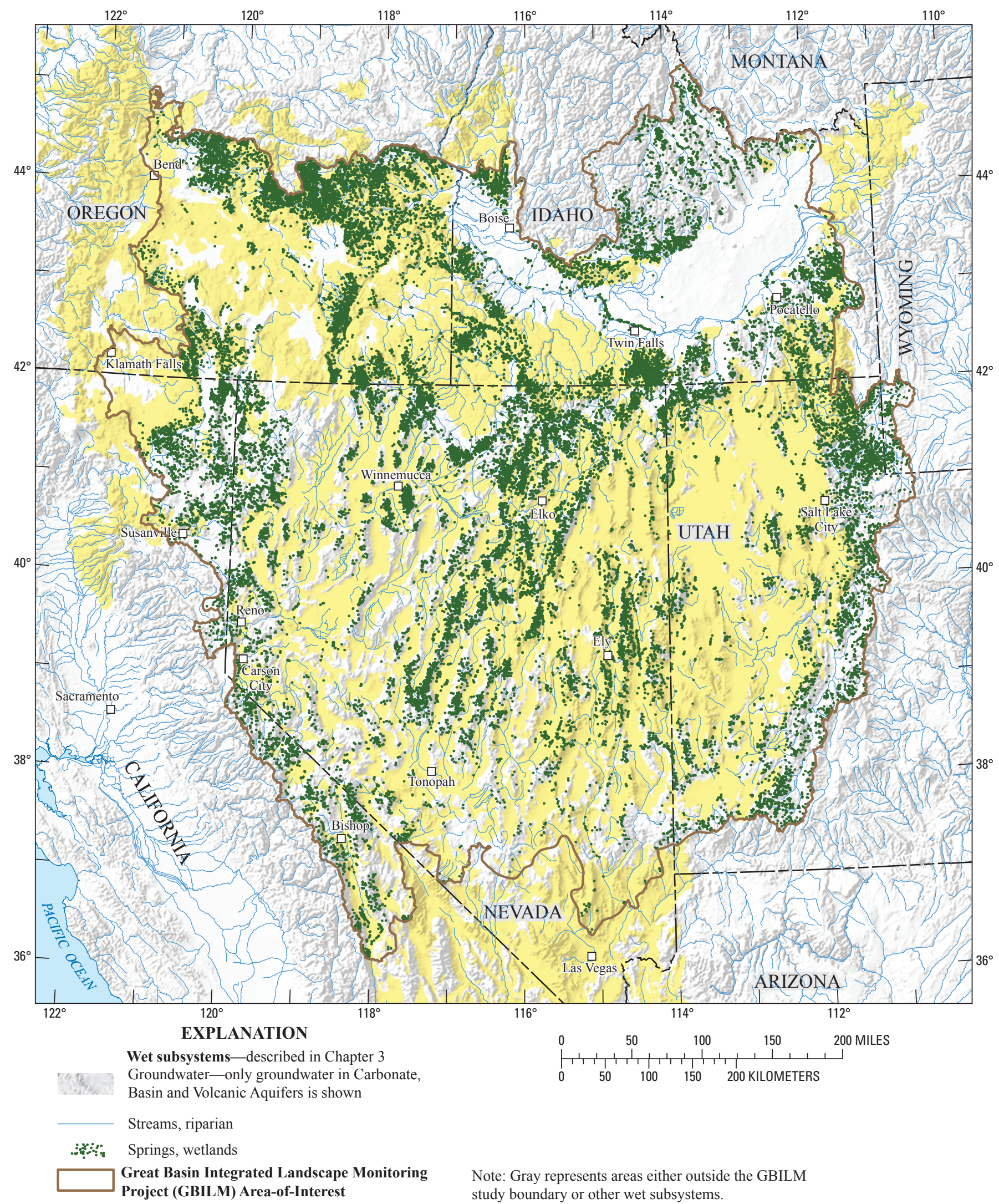

Figure 5.3. Map of subsystems described in Chapter 4 (see fig. 2.1) and also lakes and discharging (wet) playas. 
Different hierarchical systems can be used to describe the same set of resources and spatial extents depending on the process of interest and the management or research question. When describing the generic scaling process linked to the GBILM hierarchy of system models (fig. 1.2), a threetiered hierarchy (fig. 5.4) is used: sites within each subsystem $\rightarrow$ mosaic of site classes within subsystem $\rightarrow$ mosaic of subsystems (or landscapes). The smallest hierarchical unit in this system is a site, which can be viewed as a study plot, transect, or an allotment. The next hierarchical unit, the site mosaic, is used to describe the aggregation of different site conditions for areas with similar vegetation potential (a function of the underlying ecological conditions of soil, geomorphology, and climate). For example, sites with the same ecological potential for Wyoming big sagebrush may have different site conditions. due to different disturbance regimes acting at the site over time. Sites that are within their ecological resilience capacity can be found as Wyoming big sagebrush with a high percent cover of perennial and annual

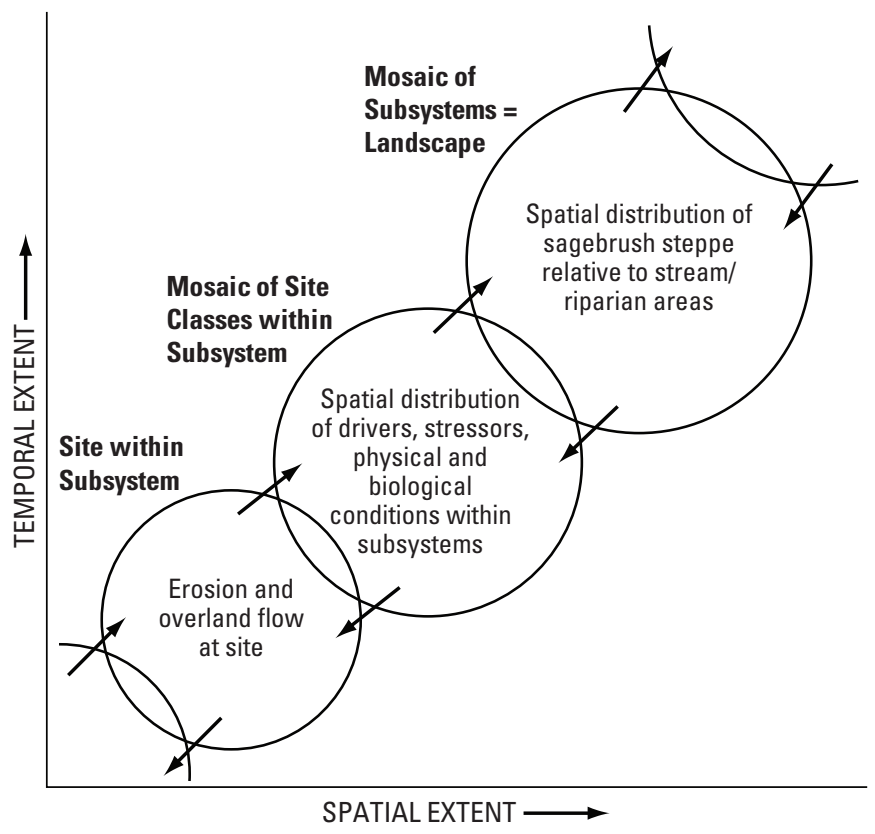

Figure 5.4. Domains of scale from site to landscape including properties and processes especially relevant to determining the effects of erosion from sagebrush steppe on adjacent riparian areas. Examples at the site level include differential infiltration, runoff, and erosion because individual plant, animal, and microbial species affect site-specific soil conditions. At the level of the mosaic of site classes within the sagebrush steppe subsystem, mass wasting and other geomorphic changes in drainage areas are important. At the mosaic of subsystems, or landscape, level, differential precipitation and infiltration due to land cover and topography affect regional drainage patterns. native understory - this is the reference condition. Sites that have been stressed by excessive grazing and subject to exotic plant exposure may become Wyoming big sagebrush with a cheatgrass understory. Sites that have experienced an extremely hot fire may have no Wyoming big sagebrush, just herbaceous cover, but they still have the ecological potential for Wyoming big sagebrush, in the absence of further disturbance. Site classes are a result of both the ecological potential of the site and the stressors the site is subject to over time. A mosaic of site classes is aggregated to describe the sagebrush steppe subsystem; the mosaic of subsystems is aggregated to form the landscape level of the three-tier hierarchy. The approach that is taken is to scale across hierarchical levels - either upscaling, going from the site to subsystem to landscape, or downscaling - depends on the management question(s) and data availability. For example, when satellite data such as Landsat are the best available data, or the goal is to conduct a stratified random sampling design across a landscape, a downscaling approach is called for. Figure 5.4 uses an example of a three-tier spatially and temporally defined hierarchical structure to illustrate the model. Specific management questions may require more hierarchical levels depending on the temporal and spatial scales of the driving variable(s).

\section{Interactions Within and Among Subsystems}

Interactions within major subsystems of the Great Basin are described by their control models (Chapters 3 and 4). The dominant processes illustrated in the control models are those that contribute strongly to the biophysical structure of each subsystem. The responses of subsystems to stressors are outlined in the stressor models. Just as the entire ecoregion was deconstructed into subsystems to more easily understand and articulate the dominant controlling processes, the control and stressor models can be further disassembled, using spatial hierarchical levels (or scales), to describe the dominant processes occurring within subsystems. An illustration of the cross-scale approach for understanding subsystem controls and stressors will be described, from an upscaling perspective, using the sagebrush steppe and stream/riparian subsystems and the processes of overland flow and erosion across hierarchical scales. Factors relating to the specific example of soil hydrology, runoff, and erosion in the sagebrush steppe subsystem can be organized using domains of scale (fig. 5.5). At the site level, one can measure the number and depth of rills caused by erosion, which will depend primarily on soil characteristics, vegetation, and weather patterns. These site-based data describe the results of overland flow and erosion at specific places with a specific combination of variables, and can be statistically used to quantify relationships among them. At the next higher spatial domain, the sagebrush steppe subsystem consists of a mosaic 


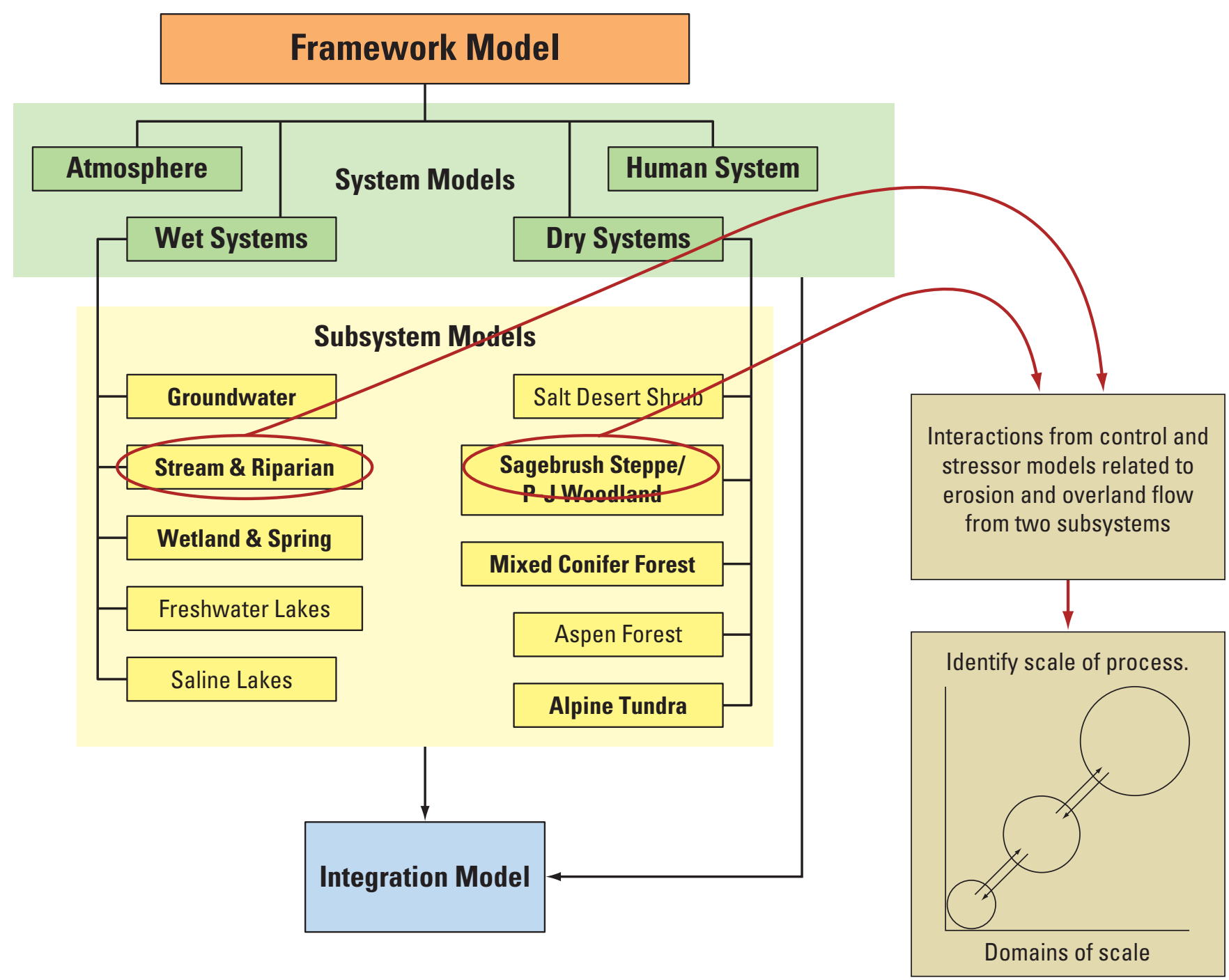

Figure 5.5. Context for example in text explaining how site-based data and conceptual models (control and stressor) from two subsystems are spatially and temporally identified within the appropriate hierarchical scale for analysis.

of vegetation community states (site classes), whose pattern depends on broader environmental factors, such as soil patterns and topographic features, as well as relict impacts of anthropogenic stressors, all of which determine the pattern of erosion among the mosaic of site class units. At the landscape scale, the aggregated patterns of erosion within the sagebrush steppe subsystem can be quantified as they interact with other subsystems (for example, riparian and aquatic), depending on the spatial pattern of subsystems as well as the pattern of erosion within the sagebrush steppe subsystem. As is shown in figure 5.6, cross-scale interactions occur within subsystems, as this example describes, or across subsystems.

A model of interactions among subsystems begins to address the complexity of an integrated landscape approach to monitoring because patterns and processes at spatial scales larger and smaller than the area of interest are relevant. The comparable statement with respect to temporal scales also holds. An important step in this conceptual approach is to select the appropriate spatial and temporal domains for the processes represented by the control and stressor models (fig. 5.5). Cross-scale interactions then can be categorized, as illustrated using the sagebrush steppe and stream/riparian subsystems for the processes of runoff as overland flow and erosion. For graphing purposes, space and time are combined on the vertical axis reflecting increases with each higher domain of scale (fig. 5.6). In this way, multiple subsystems can be displayed on the horizontal axis.

To keep this example simple, only uni-directional water flow from sagebrush steppe to stream/riparian areas is considered, but we recognize that other relationships exist 


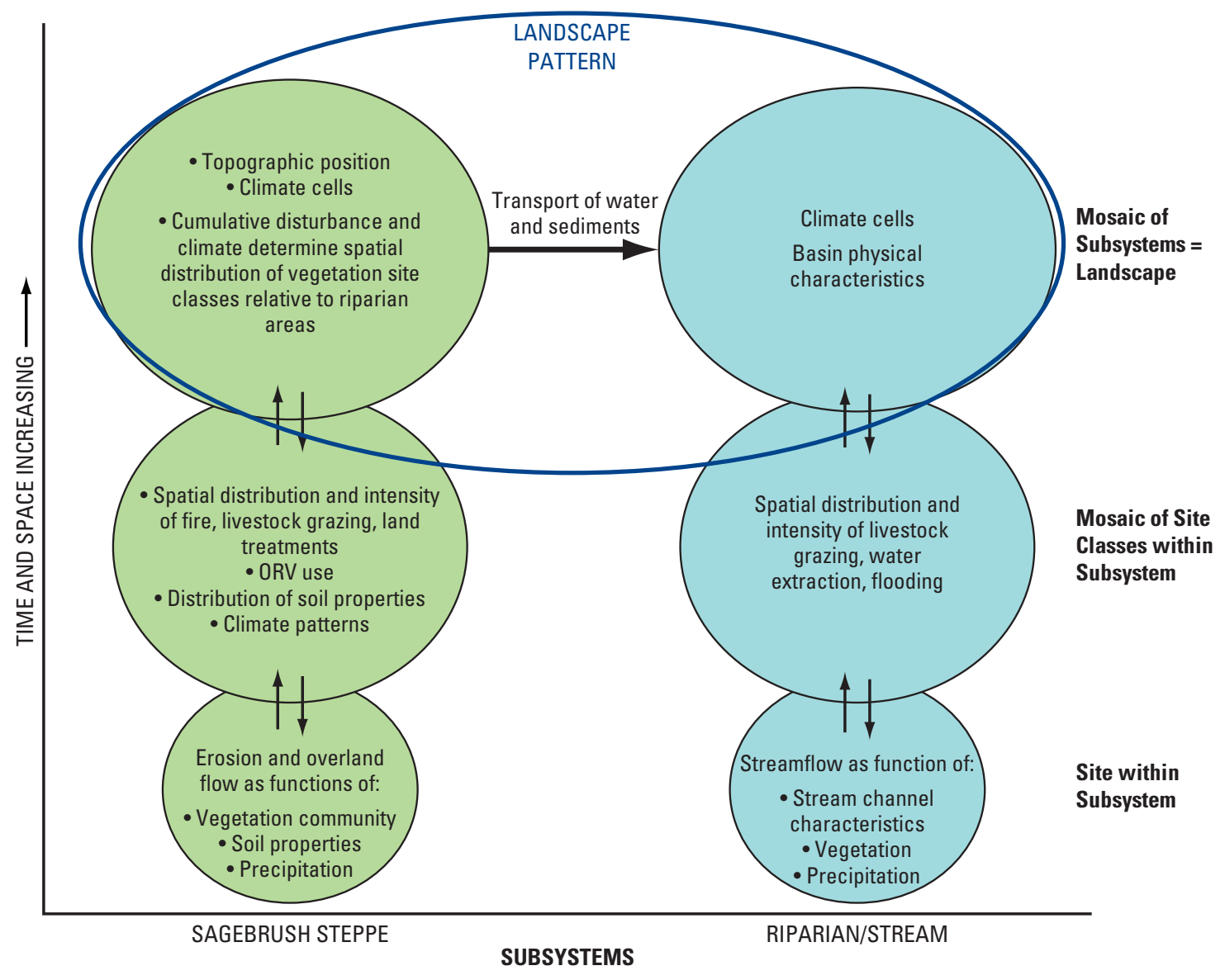

Figure 5.6. Example of interactions between two Great Basin subsystems regarding erosion and overland flow.

(for example, flow from stream-riparian to sagebrush steppe due to flooding). For a given rainfall event, vegetation cover, topography, and soil structure determine rate of overland flow, and streamflow rate determines residence time of sediment for the stream/riparian subsystem. The spatial pattern of site characteristics that influence overland flow can be overlaid with data about the occurrences of stressors and drivers (for example, fire, invasive species, local disturbance). The result is a spatial representation of patches having different properties relative to erosion and overland flow. A spatial model (see section "Models for Monitoring Landscape Change") then can be used to predict how this specific configuration of patches will respond, for example, to a given rainfall event or changes in climate pattern, depending on the specific management concern.

Changes at the landscape level in response to system drivers are described in terms of changes to the spatial distribution of sagebrush steppe relative to stream/riparian areas. These changes will, in turn, affect the processes of erosion and overland flow at all other scales (fig. 5.7) and feedback loops within and across scales likely will need to be addressed.
Many processes and management issues in the Great Basin involve more than two subsystems (fig. 5.8). Some interact more directly than others and interactions can involve various combinations of hierarchical levels. A comprehensive model of the Great Basin would include all subsystems. However, many priority management questions likely can be answered by focusing on the details of a few key subsystems.

By integrating the effects of multiple stressors and drivers across multiple subsystems, the integrated spatial modeling should improve decision-support for land managers. Predicting the consequences of changes in particular system drivers and stressors, including management actions, will help managers direct resource management decisions in the context of a large spatial extent, potentially as large as the entire Great Basin. In addition, assumptions and hypotheses about change will help identify the most effective indicators in which to invest monitoring efforts. Monitoring results can alert managers to changes resulting from changes in global, regional, and local drivers. As changes develop, they also can be used to improve model parameterization, and therefore the predictive ability, of the models. 


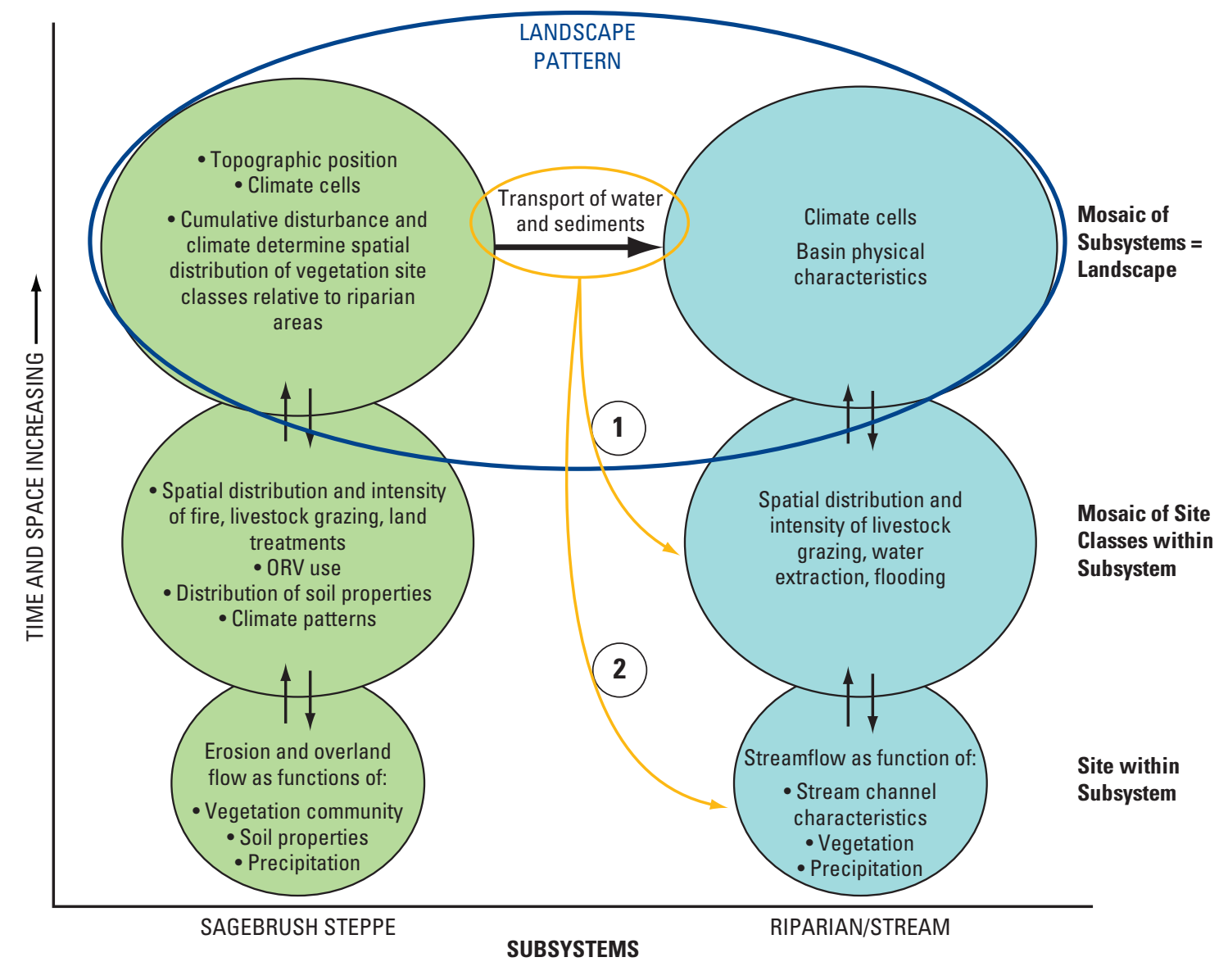

Figure 5.7. Landscape-level processes will have effects at other hierarchical levels. Arrow 1 could indicate the role of water and sediment transport to alter the spatial distribution of riparian and stream site classes, for example, by changing the spatial distribution of new surfaces for colonization by vegetation. Arrow 2 could indicate the effect of sediment transport to scour riparian vegetation and change the stability of a particular streambank.

\section{Models for Monitoring Landscape Change}

Converting the knowledge embodied in the conceptual models of the Great Basin subsystems into a form that is useful to management decisions is the key to the landscape monitoring challenge (fig. 5.9). One useful approach, which we expand upon below, is to use frame-based simulation models (Starfield and others, 1994) to integrate plot-level data collected by local managers along with expert knowledge and measures of uncertainty to provide alternative predictions of the effects of multiple stressors over time. Predictions (results) from the simulation models provide a means for selecting indicators that track ecosystem responses over time and that serve as early warnings of possible altered ecosystem function. The results of the simulation model can be used to extrapolate the knowledge gained with site-specific conditions to explore management options across a landscape (fig. 5.10). An advantage of using spatially explicit frame-based simulations to inform indicator selection is that they map the conceptual model results to expected changes at actual locations on the ground. Identifying indicators using status and trends analysis of ecosystem elements or control and stressor models is an important first step, but indicators developed without addressing geography are likely to overlook significant aspects. Surprising relationships arise as a direct result of processes that are spatially and temporally cross-scale dependent. To increase the possibility of uncovering these surprises, and to do so before significant time and resources have been invested in indicator sampling design and implementation, the GBILM team proposes the use of landscape level simulation models to explore spatially and temporally explicit conceptual model results. The simulation models can facilitate an iterative planning - or at least increased dialogue - to ensure common purpose among the stakeholders responsible for funding and implementing an integrated landscape-level monitoring effort. 


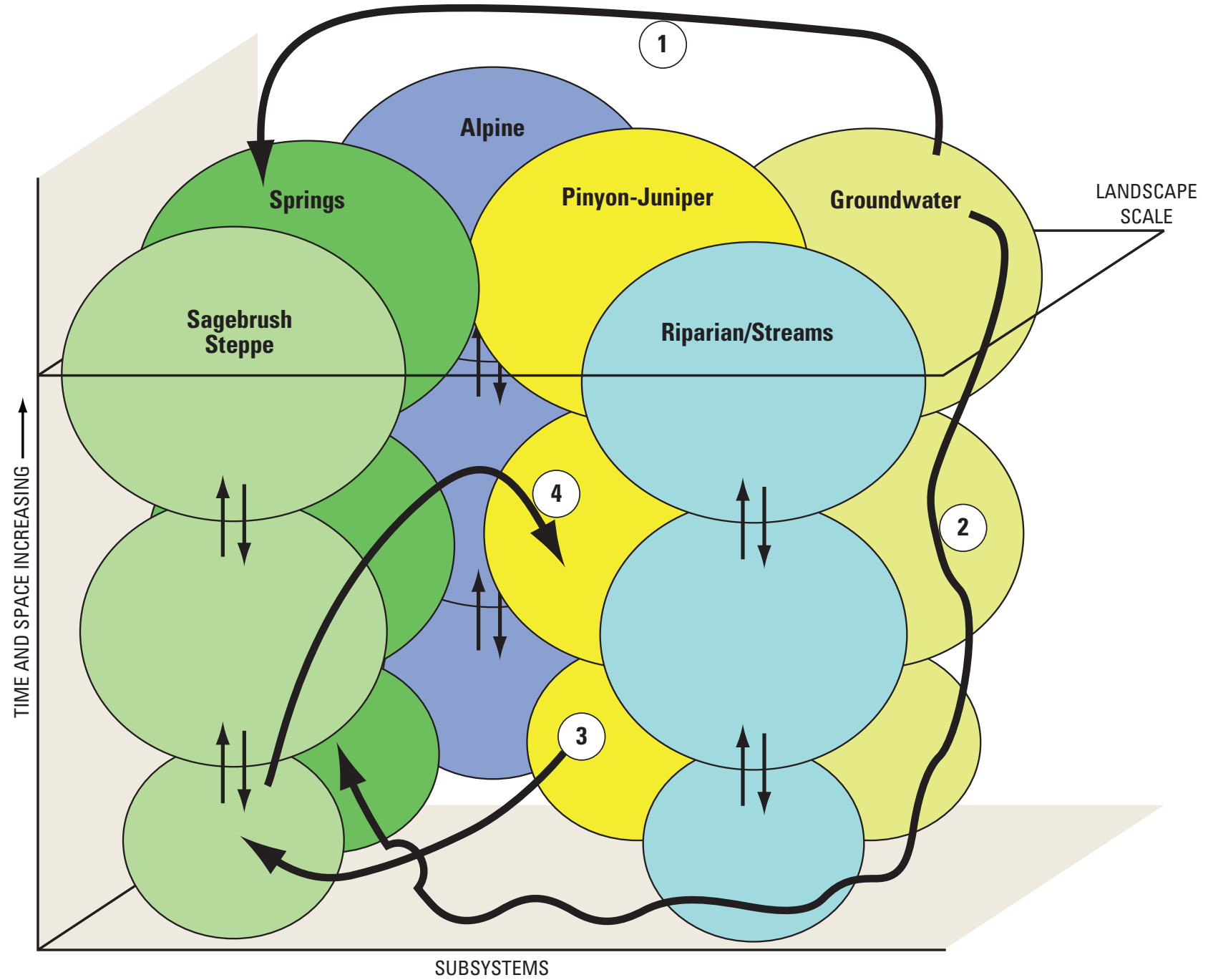

Figure 5.8. Multiple subsystems interacting on the landscape. Arrows indicate that a hierarchical level of one subsystem may interact with one or more levels of another system. Arrow 1 represents the landscape level interaction where groundwater levels control spring discharge. Arrow 2 represents how spring discharge at a particular site depends on the spatial pattern of groundwater level (which may be altered by urban withdrawal). Arrow 3 represents the site-to-site interaction between sagebrush steppe and pinyon juniper because they are usually adjacent on the landscape, and spread of pinyon-juniper into sagebrush steppe. Processes represented tat the local scale are plant dispersal mechanisms and effects of recent fire. Arrow 4 shows that a pattern of vegetation within the pinyon-juniper subsystem can affect site level sagebrush steppe vegetation. These arrows are just a few examples of the important interactions.

Frame-based models are dynamic versions of statetransition models, such as those described in Chapter 3, section "Ecosystem Dynamics." They are based on the same idea that a site's state is maintained by a number of interacting processes until a threshold of change is reached, which precipitates a switch to a different system state. For example, a sagebrush steppe-bunch grass site can be converted to sagebrush steppe-cheatgrass with the frequent occurrence of fire (fig. 3.6). Frame-based models incorporate site-specific ecological accounting, which means that these models keep track of and account for the prior or existing condition, the causative factors altering these conditions, and, if the conditions cumulatively cross a threshold, the subsequent changed condition. This ecological accounting is conducted at regular time steps (frames) defined by the management decision (question) that structures the model itself. The management questions also define which states and drivers must be tracked. Spatially explicit frame-based models use geographic information systems (GIS) to include measures of the site's geographic relationships that affect the ecological processes such as landscape patterns and measures of adjacency, proximity, diffusion, and fragmentation. Until 


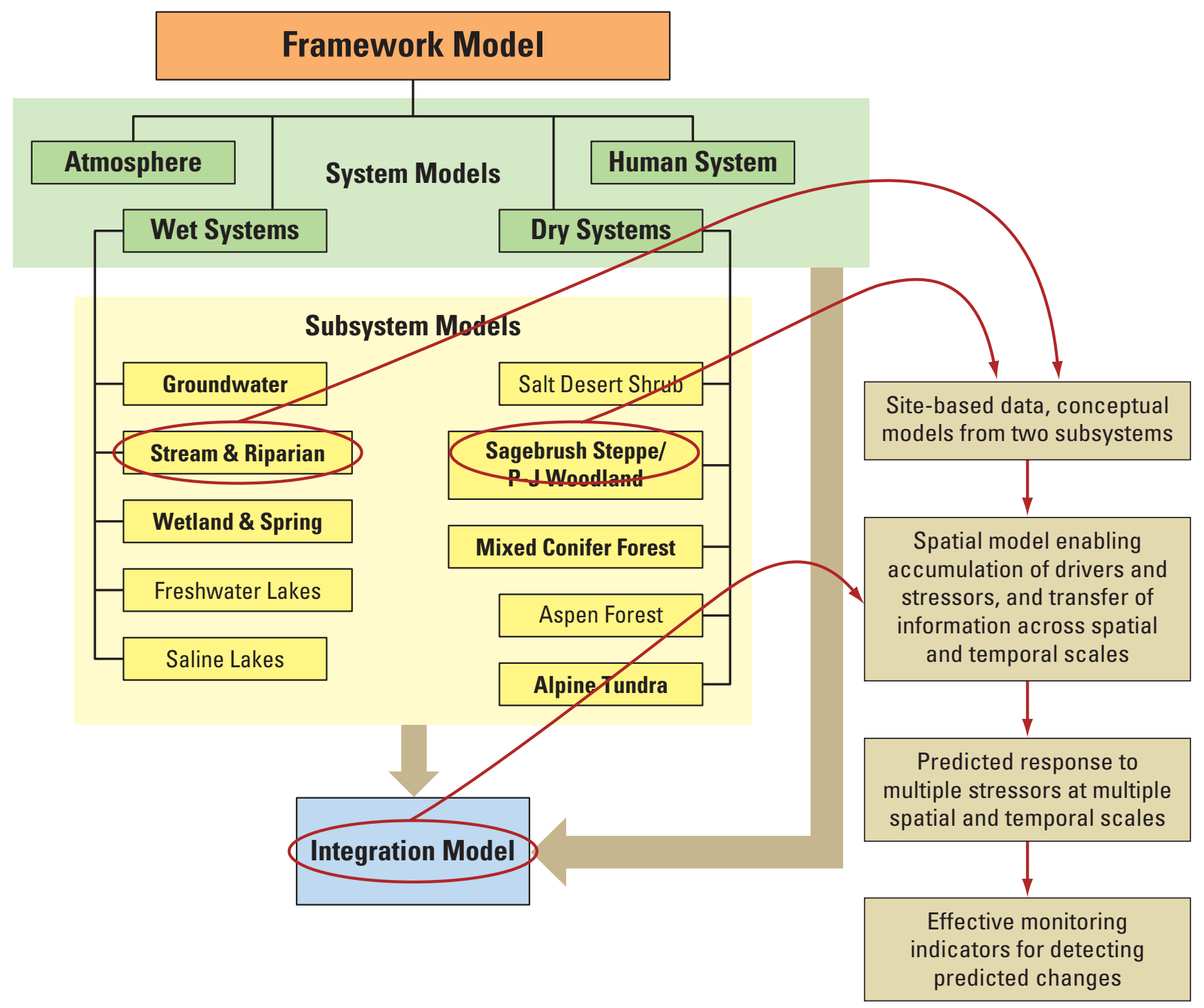

Figure 5.9. Overview of the relationship between outcomes from subsystem models, the integration model, and specific management needs. The diagram provides context for the example in the text explaining how site-based data and conceptual models (control, stressor, and integration) are identified spatially and temporally within the appropriate hierarchical scale for analysis.

recently, compiling an ecological accounting framework for an area the size of the GBILM was unrealistic. However, with advances in GIS, remote sensing, digital archiving, computer technology, and networking, it is feasible to develop the required framework.

A necessary step for ecological accounting is to distill the information embodied in the control and stressor models. Model relationships must be compiled into a library of probabilities that can be used for the frame-based model in the form of parameters. The parameters represent the probability of occurrence of the agents of landscape change. For the example used in this chapter, the most common agents of change are fire return intervals, rates of invasion of exotic species, relative intensity of biological pests, anthropogenic aquifer drawdown, and climate parameters used to model the probability of droughts and floods. Within frame-based models, these probability parameters are the switches from one state to another. When the probability of an occurrence is high enough that a tipping point is reached, the system switches to an alternative state (fig. 5.11).

Each land unit has its own particular set of conditions that is part of its legacy within the landscape. Prior conditions that led to a degraded current condition can hold for parcels occurring adjacent to parcels with healthy reference 


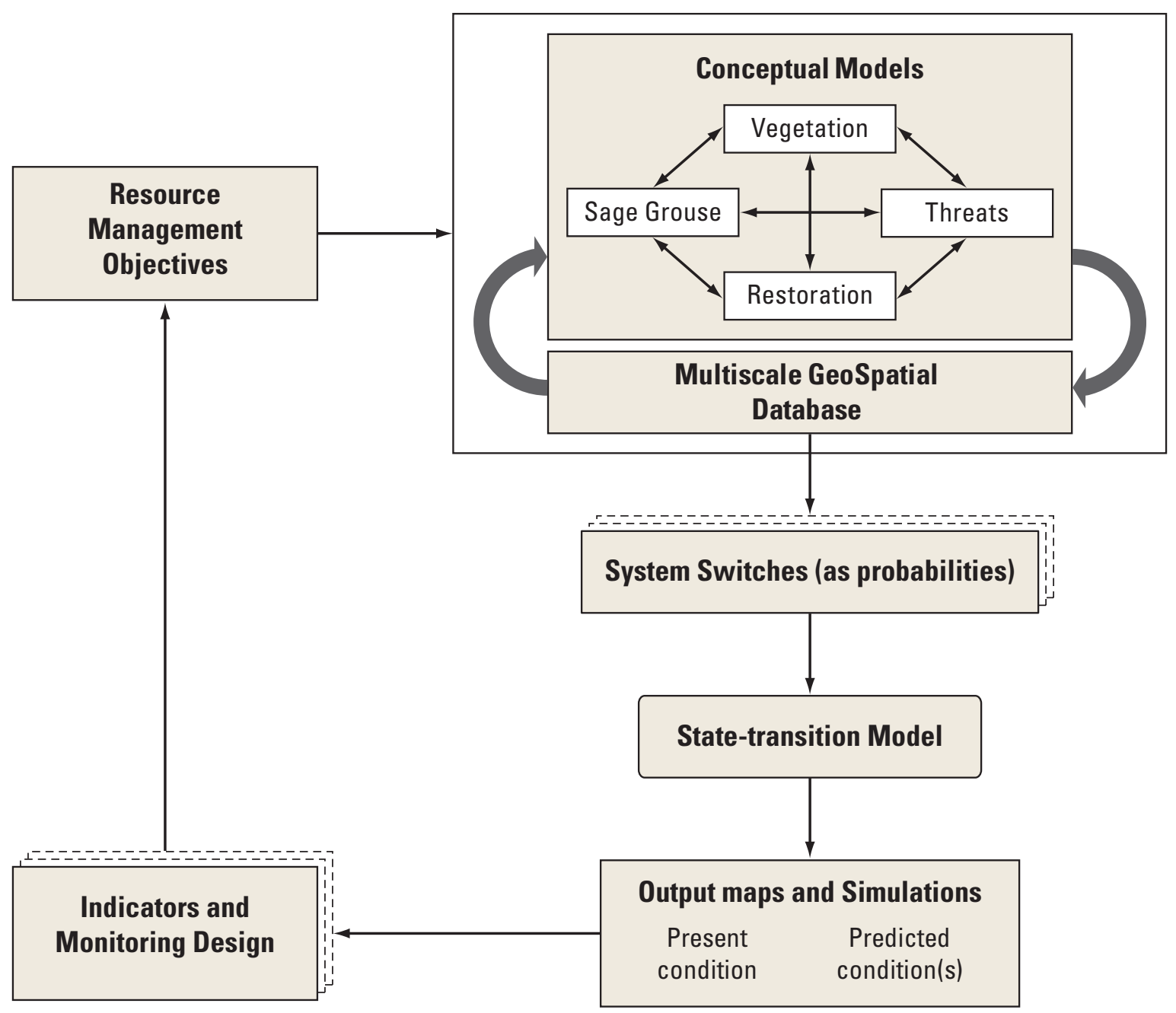

Figure 5.10. Overview of Integration Model. Depending on the objectives defined by resource managers, a subset of conceptual models is selected that provides a mechanistic understanding of the social, hydrologic, and ecological processes relevant for understanding management options. The conceptual models inform the development of a geographic information service (GIS) database to "map" the mechanisms onto a spatially explicit multi-scale framework. Using information from the mechanistic models and, if lacking, from sensitivity analysis or other techniques, probabilities are derived and used in frame-based state-transition models to begin to explore the effects of stressors on the focus areas. The outputs from the frame-based state-transition models are mapped back into the GIS to provide spatially explicit predictions to be tested as hypotheses. Results from the hypothesis testing provide information for management consideration for issues such as selecting indicators.

conditions. The frame-based model predicts the changes for one land unit area in a specific initial condition given differing scenarios of probable occurrences. Frame-based models are made spatially explicit by merging them with GIS geodatabases where each polygon (or pixel) on a map can be categorized with the condition of its vegetation community and other attributes. In addition to the drivers/stressors shown in figure 5.11, other probabilities of occurrences associated with spatial patterns are included such as distance to a neighboring polygon with cheatgrass, distance to road features, relative topographic position, and measures of fragmentation or connectivity. The model is run on each individual land unit to produce landscape level change predictions.

Running the simulation over time and across space can provide a systematic framework to explore the responses of various sagebrush steppe sites to drivers and stressors. Using regionwide site-based data will help to quantify the relative influence of site conditions and drivers to expected changes in climate and other anthropogenic impacts. 
Frame Year $1 \quad \longrightarrow \longrightarrow \longrightarrow$

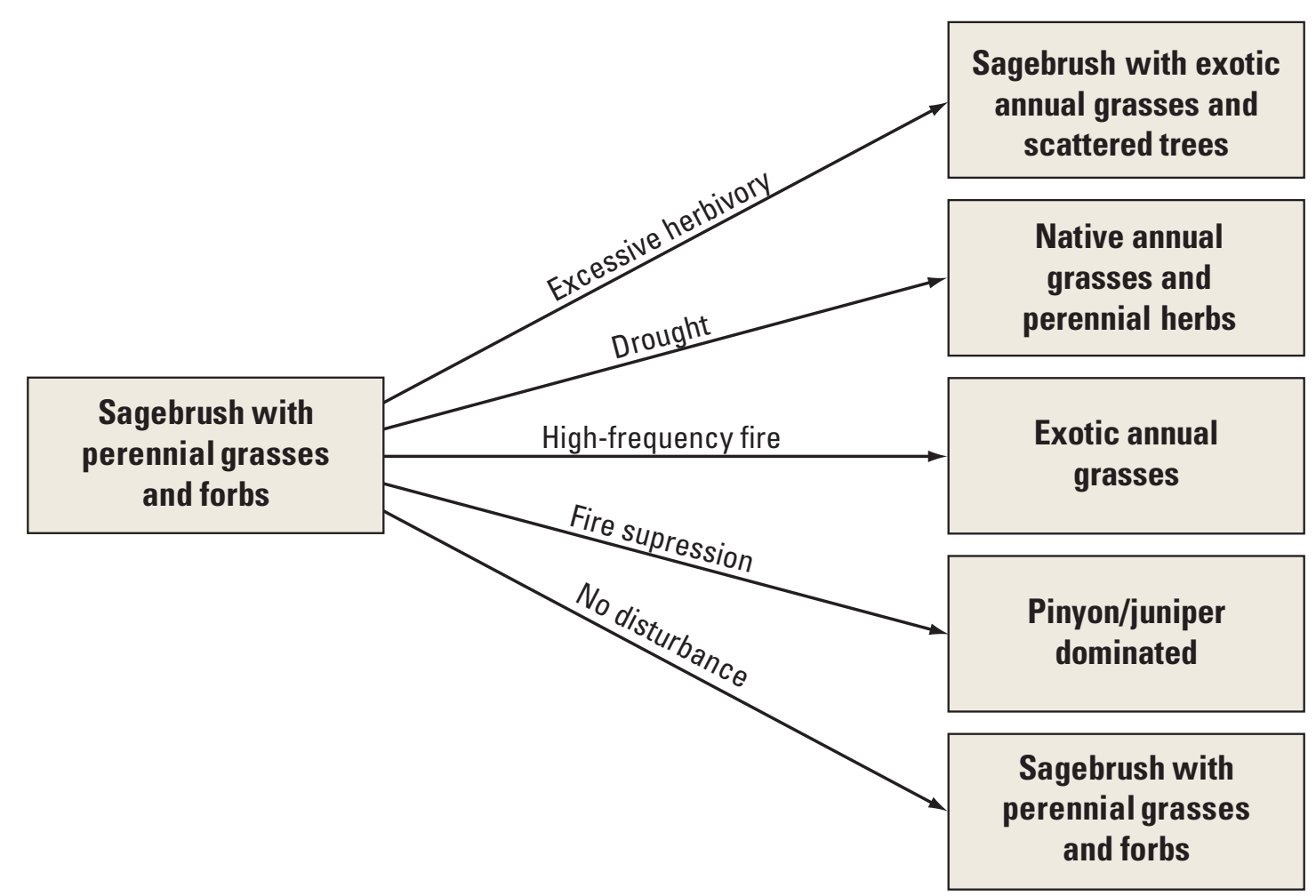

Figure 5.11. Frame-based model for simplified sagebrush steppe example. The single box on the left represents the state of one specific area of the map that was classified (for example, in year one, the initial condition) as "Sagebrush with perennial grasses and forbs." The five boxes on the right represent the condition of the site after five yearly time steps (frames) under five scenarios each represented by a different driver. For simplicity, each driver is assumed to operate for the full 5 years and the transition result (for example, Frame YR 5) for each scenario is the result of a single driver.

\section{Summary Points}

The integration model described in this section seeks to link the components of the Great Basin within a multi-scale framework to provide insights for management decisions. A three-tiered hierarchical structure in which the ecological systems and the associated processes that structure these systems - described through control and stressor modelsforms the spatial and temporal skeleton of the integration model. The model is intended to improve understanding of cross-scale interactions and cumulative effects.

The model approach assumes that simulation model results from frame-based state-transition models (or other kinds of models) are hypotheses that summarize the current state of scientific knowledge and project these into the areas of management interest. These hypotheses then must be evaluated to validate the model. Evaluating hypotheses requires access to monitoring data, which in turn requires resources to extract and convert these data into the parameters that drive the model. Archived data such as remotely sensed imagery or land treatment data, for example, could be useful for generating and testing the hypotheses.
Many issues related to data development will continue to challenge model integration. Data compilation, aggregation, and transformation are being advanced through informatic, geostatistical, and mathematical research. Keeping abreast of and incorporating innovative methods to integrate data from different sources will be important.

As ecosystems continue to respond to anthropogenic pressures, novel conditions may arise that our current model categories have not captured. Maintaining flexibility in our ecological accounting framework will be an important design element so that new categories can be added as needed. Unexpected synergistic effects, either between stressors or as feedback loops between drivers and ecosystem responses, also are a category of surprise that a flexible accounting structure can accommodate.

Much research effort from many organizations is pointed toward creating model-based applications to work more effectively with changing geographic units over time. Given the resources, the challenge will be to communicate among land managers, scientists, modelers, computer application designers, and database designers to create systems that provide results and then develop visualization tools to share the results with society. 


\title{
Chapter 6: Summary and Conclusions
}

\author{
By Andrea Woodward, S.P. Finn, and D.M. Miller
}

The goal of GBILM is to develop landscape monitoring approaches, including methods for monitoring environmental stressors and responses at the landscape level, and methods for scaling from plot-level data collected by land managers to larger spatial extents to describe cumulative effects. The need for a landscape approach primarily stems from the increasing impact from regional and global stressors (such as climate change, water withdrawal, invasive plant species, and air pollution), which affects areas larger than those under the authority of individual land managers. In addition, anthropogenic stressors (such as urbanization, off highway vehicle use, land treatments, and wildfire) that often are considered to be local are becoming more numerous and pervasive such that their aggregated impacts affect broad regions. Stressor effects accumulate and interact with each other in complex fashions that require understanding and assessment at the landscape level. For example, responses of biota to environmental change depend on inherent biophysical potential, in addition to past and current conditions of the individual sites and surroundings, and the responses may be directly and indirectly related to stressors. Streamflow, soil erosion, and water temperature in springs also respond to local and regional stressors and in turn drive changes in biota. In particular, changes in the Great Basin are threatening extinction of species whose habitat requirements span multiple management jurisdictions and require a landscape perspective for effective protection. The highly varied topography, strong climate gradients, and effective isolation of many biotic zones in the Great Basin compound these challenges and make the design of monitoring systems difficult.

Land managers often are charged with conserving environments within well-defined spatial and temporal bounds even though natural processes and disturbance regimes extend beyond those boundaries. Jurisdictional boundaries and duration-specific resource management plans place somewhat arbitrary hindrances on fully understanding and managing resources experiencing multiple interactions ranging from short-term and site-specific to long-term and regional. Our landscape perspective provides managers with perspectives and conceptual tools for evaluating external and antecedent inputs into their system of interest and applying landscape-context management principles to local resources. Furthermore, the conceptual models in this report can help land managers understand how individual management actions interact with one another and how these interactions may lead to the emergence of impacts unlike those of single actions.
Conceptual models should be the foundation for all products GBILM aims to provide to land managers. Fundamentally, conceptual models describe the most salient components of ecosystems and the interactions among them. They express current understanding and hypotheses regarding system function, by integrating information from disparate sources including research results and expert opinion and experience. They facilitate communication to create agreement on, and common vision of, the system in question. Having a common perception insures that land managers, researchers, and other interested parties agree on the important components and processes related to the issue being addressed. A compilation of information sources insures that mechanistic models are as accurate as possible. The conceptual models can illustrate the relevant interactions and functions for any given problem or situation. The models provide a foundation for developing quantitative spatial models that will enable the integration of multiple stressors acting at various spatial scales to give managers a landscape context.

In this document we presented a hierarchy of conceptual models, beginning with a framework model that describes the relationships among the major biotic and abiotic systems in the Great Basin: the atmospheric system, the human social system, and the dry and wet ecosystems. Each of these systems is described in more detail in separate general system models. The atmospheric system model describes how atmospheric processes are fundamental drivers of Great Basin ecosystems, hydrology, and geomorphology; the human-social system model describes social and cultural factors resulting in patterns of land and water use and their evolution; the dry and wet system models describe the broad landscape patterns and relationships among the subsystems. For the dry and wet systems, we developed more detailed models for high-priority subsystems that describe components, their functional relationships, and potential effects of key stressors. Dry subsystem models are differentiated by biophysical potential on the landscape (biomes) and include sagebrush steppe, pinyon-juniper woodlands, mixed conifer forest, and alpine tundra. Wet subsystem models distinguish fundamental hydrologic entities, and include the groundwater system, stream and riparian systems, and wetland and spring systems. 
We have not yet developed subsystem models for salt desert scrub, aspen forests, freshwater lakes and saline lakes and marshes, as well as for specialized environments such as dry playas and sand dunes, but these models are needed for complete evaluation of the Great Basin. Descriptions of each subsystem model identify knowledge gaps and research needs to acknowledge what is not understood and provide direction to future work.

In addition to the models in this report, GBILM is creating information products and analytical techniques that will assist with reinterpretation of the models in conjunction with the development of a long-term regional monitoring strategy. For example, we are creating a regional map of phreatophytic vegetation communities to identify areas that might be most responsive to groundwater development. Such products will have multiple applications, which our conceptual models will help scientists and managers to visualize. In this case, a manager interested in the effects of overland flow and erosion might use the phreatophytic vegetation layer to evaluate the combined effects of water withdrawal and erosion (for example, fig. 5.8). We believe these and other data products can be used effectively with our conceptual models to increase a manager's ability to evaluate multiple actions and better understand the broader context within which management decisions are made.

Ultimately, this group of conceptual models will contribute to GBILM's goal of developing a comprehensive landscape-level monitoring strategy for the Great Basin. Initially, conceptual models will identify elements of ecosystems that are predicted to respond to stressors based on our current understanding of system function. These elements are potentially valuable to monitor. Eventually, predictive spatial models, built according to the concepts presented in Chapter 5, can focus attention on ecosystem components and processes that will manifest the effects of multiple stressors and drivers. Predictive models also can combine conceptual models with empirical data to explore predicted stressor impacts. This modeling effort helps to visualize ecosystem responses and interactions, which can lead to identification of efficient or sensitive monitoring indicators.

Our Great Basin conceptual models remain incomplete because we focused our limited resources on high priority subsystems and we lacked the expertise to fully develop some models. Furthermore, the models we present here are subject to modification in an adaptive management context. Because management priorities change and scientific understanding increases, all models are expected to undergo episodic development and increased scrutiny, particularly as new threats emerge. To have maximum effect, these models require data for validation and testing by targeted field studies. A logical step is to mine historical data to validate the models, an effort that GBILM has begun with promising early results (Land Treatments Digital Library project, accessed June 24, 2009, at http://www.usgs.gov/features/greatbasin/projects/ treatments.html). After assembling and cataloging the data, analysis can follow. Analyses will feed back to the appropriate conceptual models for validation and application, help to identify data gaps and research needs, and help parameterize integrative predictive models.

We expect the conceptual models in this report to stimulate and inform efforts to build efficient, comprehensive monitoring plans. When combined with programs that collect a body of data for trend evaluation, collect needed baseline data, and conduct field studies to investigate knowledge gaps, the conceptual models provide the basis for a comprehensive investigation of Great Basin landscape threats, on which comprehensive monitoring programs can be constructed. GBILM investigations provide long-term value over large extents, yielding benefits to society but only through sustained commitments from the U.S. Geological Survey and its landmanagement partners. 


\section{Acknowledgments}

This report is large, wide-ranging, was long in the making, and was developed as part of an interdisciplinary group project. As a consequence, its authors have benefited from interactions with a large group of scientists, land managers, and decision-makers; a group too large to acknowledge individually.

The initial conceptual models workshop members who contributed to developing the approach and the eventual design of the report deserve credit: Matt Brooks, Marie Denn, Nora Devoe, Kimball Goddard, Tom Owens, Mike Pellant, and Dave Pyke. These members continued in several roles, including providing informal reviews of early drafts of parts of the report. Contributions to water system models came from Debra Hughson and Kimball Goddard. Later meetings designed to develop specific models benefited greatly from contributions from Kimball Goddard, Debra Hughson, Steve Knick, Mike Casazza, and Don Sada. In addition, Eric Beever, Victor Heilweil, and Erika Fleishman provided informal reviews of draft models. Technical assistance from Linda Rogers, Janet Erickson, Ruth Jacobs, and Susan Powell is gratefully acknowledged.

The unwavering support and encouragement from project leaders Carol Schuler and Kate Kitchell played a vital role in seeing this document to completion. However, the technical reviews of the report by Dave Busch and Debra Hughson possibly required the largest individual commitments and had the largest impact. This report is more complete and much stronger as a result of their insightful questions and comments. We only wish it were within the scope of the report to carry out all of their recommendations.

\section{References Cited}

Alberti, M., Marzluff, J.M., Shulenberger, E., Bradley, G., Ryan, C., and Zumbrunnen, C., 2003, Integrating humans into ecology - Opportunities and challenges for studying urban ecosystems: BioScience, v. 53, p. 1169-1179.

Allan, J.D., 1995, Stream ecology—Structure and functioning of running waters: London, Chapman and Hall.

Allen, T.F.H., and Hoekstra, T.W., 1992, Toward a unified ecology: New York, Columbia University Press.

Allen, T.F.H., and Starr, T.B., 1982, Hierarchy-Perspectives for ecological complexity: Chicago, IL, University of Chicago Press.

Andersen, M.E., and Deacon, J.E., 2001, Population size of Devils Hole pupfish (Cyprinodon diabolis) correlates with water level: Copeia, v. 2001, p. 224-228.
Anderson, M.K., 2005, Tending the wild: Native American knowledge and the management of California's natural resources: University of California Press, $555 \mathrm{p}$.

Anderson, M.K., and Moratto, M.J., 1996, Native American land use practices and ecological impacts, in Sierra Nevada ecosystem project-Final report to Congress, v. II, Assessments and scientific basis for management options: University of California, Davis Centers for Water and Wildland Resources, p. 187-206.

Archer, S., 1994, Woody plant encroachment into southwestern grasslands and savannas - Rates, patterns and proximate causes, in Vavra, M., Laycock, W.A., and Pieper, R.D., eds., Ecological implications of livestock herbivory in the west: Denver, Colo., Society for Range Management, p. 13-68.

Archer, S., and Bowman, A., 2002, Understanding and managing rangeland plant communities, in Grice, A.C., and Hodgkinson, K.C., eds., Global rangelands-Progress and Prospects: Wallingford, UK, CABI Publishing, p. 63-80.

Archer, S., Schimel, D.S., and Holland, E.A., 1995, Mechanisms of shrubland expansion - Land use, climate or $\mathrm{CO}_{2}$ ?: Climatic Change, v. 29, p. 91-99.

Archer, S., and Smeins, F.E., 1991, Ecosystem-level processes, in Heitschmidt, R.K., and Stuth, J.W., eds., Grazing management-An ecological perspective: Portland, Oreg., Timber Press, p. 109-139.

Archer, S., and Stokes, C., 2000, Stress, disturbance and change in rangeland ecosystems, in Arnalds, O., and Archer, S., eds., Rangeland desertification: Dordrecht, Germany, Kluwer, p. 17-38.

Ashton, I.W., Miller, A.E., Bowman, W.D., and Suding, K.N., 2008, Nitrogen preferences and plant-soil feedbacks as influenced by neighbors in the alpine tundra: Oecologia, v. 156, p. $625-636$.

Asner, G.P., Archer, S.A., Hughes, R.F., Ansley, J.R., and Wessman, C.A., 2003, Net changes in regional woody vegetation cover and carbon storage in Texas drylands, 1937-1999: Global Change Biology, v. 9, p. 316-335.

Austin, M.P., and Smith, T.M., 1989, A new model for the continuum concept: Vegetatio, v. 83, p. 35-47.

Bagstad, K.J., Stromberg, J.C., and Lite, S.J., 2005, Response of herbaceous riparian plants to rain and flooding on the San Pedro River, Arizona, USA: Wetlands, v. 25, p. 210-223.

Bailey, R.G., 1978, Description of the ecoregions of the United States: Ogden, Utah, U.S. Department of Agriculture Forest Service, Intermountain Region.

Bailey, R.G., 1995, Descriptions of the ecoregions of the United States (2d ed.): United States Forest Service, Miscellaneous Publication 1391. 
Baker, W.L., 2006, Fire and restoration of sagebrush ecosystems: Wildlife Society Bulletin, v. 34, p. 177-185.

Baker, W.L., and Shinneman, D.J., 2004, Fire and restoration of piñon-juniper woodlands in the western United States-A review: Forest Ecology and Management, v. 189, p. 1-21.

Baldwin, C.K., 2003, Historical climate analysis, in Wagner, F.H., ed., Rocky Mountain/Great Basin regional climatechange assessment, Report for the U.S. Global Change Research Program: Logan, Utah, Utah State University, p. 58-72.

Barrett, G.W., Van Dyne, G.M., and Odum, E.P., 1976, Stress ecology: BioScience, v. 26, p. 192-194.

Beck, J.L., and Mitchell, D.L., 2000, Influences of livestock grazing on sage grouse habitat: Wildlife Society Bulletin, v. 28 , p. $993-1002$.

Beever, E.A., Brussard, P.F., and Berger, J., 2003, Patterns of apparent extirpation among isolated populations of pikas (Ochotona princeps) in the Great Basin: Journal of Mammalogy, v. 84, p. 37-54.

Beever, E.A., and Pyke, D.A., 2004, Integrated monitoring of hydrogeomorphic, vegetative, and edaphic conditions in riparian ecosystems of Great Basin National Park, Nevada: U.S. Geological Survey Scientific Investigations Report 2004-5185.

Beever, E.A., Pyke, D.A., Chambers, J.C., Landau, F., and Smith, S.D., 2005, Monitoring temporal change in riparian vegetation of Great Basin National Park: Western North American Naturalist, v. 65, p. 382-402.

Behle, W.H., 1978, Avian biogeography of the Great Basin and intermountain region: Great Basin Naturalist Memoirs, v. 2, p. 55-80.

Belnap, J., 1995, Surface disturbances: Their role in accelerating desertification: Environmental Monitoring and Assessment, v. 37, p. 39-57.

Belnap, J., 2002, Nitrogen fixation in biological soil crusts from southeast Utah, USA: Biology and Fertility of Soils, v. 35 , p. $128-135$.

Belnap, J., 2003, Microbes and microfauna associated with biological soil crusts, in Belnap, J., and Lange, O.L., eds., Biological soil crusts-Structure, function, and management (2d ed.): Springer-Verlag, p. 167-174.

Belnap, J., 2006, The potential roles of biological soil crusts in dryland hydrologic cycles: Hydrological Processes, v. 20, p. 3159-3178.

Belnap, J., and Gillette, D.A., 1998, Vulnerability of desert biological crusts to wind erosion: the influences of crust development, soil texture, and disturbance: Journal of Arid Environments, v. 39, p. 133-142.
Belnap, J., and Lange, O.L., 2003, Biological soil crusts: Structure, function, and management ( $2 \mathrm{~d}$ ed.): SpringerVerlag.

Belnap, J., Prasse, R., and Harper, K.T., 2003, Influence of biological soil crusts on soil environments and vascular plants, in Belnap, J., and Lange, O.L., eds., Biological soil crusts-Structure, function, and management $(2 \mathrm{~d}$ ed.): Berlin, Springer-Verlag, p. 281-300.

Belnap, J., Webb, R.H., Miller, M.E., Miller, D.M., DeFalco, L.A., Medica, P.A., Brooks, M.L., Esque, T.C., and Bedford, D., 2008, Monitoring ecosystem quality and function in arid settings of the Mojave Desert: U.S. Geological Survey Scientific Investigations Report 2008-5064, accessed June 17, 2009, at http://pubs.usgs.gov/sir/2008/5064/.

Belsky, A.J., and Blumenthal, D.M., 1997, Effects of livestock grazing on stand dynamics and soils on upland forests of the interior west: Conservation Biology, v. 11, p. 315-327.

Benda, L., Poff, N.L., Miller, D., Dunne, T., Reeves, G., Pess, G., and Pollock, M., 2004, The network dynamics hypothesis: How channel networks structure riverine habitats: BioScience, v. 54, p. 413-427.

Benson, L.V., Currey, D.R., Dorn, R.I., Lajoie, K.R., Oviatt, C.G., Robinson, S.W., Smith, G.I., and Stine, S., 1990, Chronology of expansion and contraction of four Great Basin lake systems during the past 35,000 years: Palaeogeography, Palaeoclimatology, Palaeoecology, v. 78, p. 241-286.

Bentz, B., Alston, D., and Evans, T., 2008, Great Basin insect outbreaks, in Chambers, J.C., Devoe, N., and Evenden, A., eds., Collaborative management and research in the Great Basin-Examining the issues and developing a framework for action: Fort Collins, Colo., USDA Forest Service, Rocky Mountain Research Station, Gen. Tech. Rep. RMRSGTR-204, p. 45-48.

Bestelmeyer, B.T., Brown, J.R., Havstad, K.M., Alexander, R., Chavez, G., and Herrick, J.E., 2003, Development and use of state-and-transition models for rangelands: Journal of Range Management, v. 56, p. 114-126.

Bestelmeyer, B.T., Herrick, J.E., Brown, J.R., Trujillo, D.A., and Havstad, K.M., 2004, Land management in the American southwest-A state-and-transition approach to ecosystem complexity: Environmental Management, v. 34, p. 38-51.

Bethlenfalvay, G.J., and Dakessian, S., 1984, Grazing effects on mycorrhizal colonization and floristic composition of the vegetation on a semi-arid range in northern Nevada: Journal of Range Management, v. 37, p. 312-316. 
Bich, B.S., Butler, J.L., and Schmidt, C.A., 1995, Effects of differential livestock use on key plant species and rodent populations within selected Oryzopsis hymenoides/Hilaria jamesii communities of Glen Canyon National Recreation Area: The Southwest Naturalist, v. 40, p. 281-287.

Biggs, B.J.F., Nikora, V.I., and Snelder, T.H., 2005, Linking scales of flow variability to lotic ecosystem structure and function: River Research and Applications, v. 21, p. 283298.

Billings, W.D., 1951, Vegetational zonation in the Great Basin of western North America: International Union of Biological Sciences, Series B, No. 9. p. 101-122.

Billings, W.D., 1970, Plants and the ecosystem: Belmont, Calif., Wadsworth Publishing Company, Inc.

Billings, W.D., 1990, Bromus tectorum, a biotic cause of ecosystem impoverishment in the Great Basin, in Woodwell, G.M., ed., The earth in transition-Patterns and processes of biotic impoverishment: Cambridge, UK, Cambridge University Press, p. 301-322.

Birken, A.S., and Cooper, D.J., 2006, Processes of Tamarix invasion and floodplain development along the lower Green River, Utah: Ecological Applications, v. 16, p. 1103-1120.

Blank, R.R., Allen, F., and Young, J.A., 1994a, Extractable anions in soils following wildfire in a sagebrush/grass community: Soil Science Society of America Journal, v. 58, p. 564-570.

Blank, R.R., Allen, F., and Young, J.A., 1994b, Growth and elemental content of several sagebrush-steppe species in unburned and post-wildfire soil and plant effects on soil attributes: Plant and Soil, v. 164, p. 35-41.

Blank, R., and Sforza, R., 2007, Plant-soil relationships of the invasive annual grass Taeniatherum caput-medusae-A reciprocal transplant experiment: Plant and Soil, v. 298, p. 7-19.

Bock, C.E., Jones, Z.F., and Bock, J.H., 2008, The Oasis effect: Response of birds to exurban development in a southwestern savanna; Ecological Applications, v. 18, no.5, p. 1093-1106.

Bonan, G., 2002, Ecological climatology-Concepts and applications: Cambridge, UK, Cambridge University Press.

Booth, M.S., Caldwell, M.M., and Stark, J.M., 2003, Overlapping resource use in three Great Basin speciesImplications for community invasibility and vegetation dynamics: Journal of Ecology, v. 91, p. 36-48.

Bradford, D.F., Neale, A.C., Nash, M.S., Sada, D.W., and Jaeger, J.R., 2003, Habitat patch occupancy by toads (Bufo punctatus) in a naturally fragmented desert landscape: Ecology, v. 84, p. 1012-1023.
Bradley, R.S., 1985, Quaternary paleoclimatology: Boston, Mass., Allen and Unwin.

Breshears, D.D., and Allen, C.D., 2002, The importance of rapid disturbance-induced losses in Carbon management and sequestration: Global Ecology and Biogeography, v. 11, p. 1-5.

Breshears, D.D., Rich, P.M., Barnes, F.J., and Campbell, K., 1997, Overstory-imposed heterogeneity in solar radiation and soil moisture in a semi-arid woodland: Ecological Applications, v. 7, p. 1201-1215.

Breshears, D.D., Whicker, J.J., Johansen, M.P., and Pinder III, J.E., 2003, Wind and water erosion and transport in semi-arid shrubland, grassland and forest ecosystemsQuantifying dominance of horizontal wind-driven transport: Earth Surface Processes and Landforms, v. 28, p. 11891209.

Briske, D.D., 1991, Developmental morphology and physiology of grasses, in Heitschmidt, R.K., and Stuth, J.W., eds., Grazing management-An ecological perspective: Portland, Oreg., Timber Press, p. 85-108.

Briske, D.D., Bestelmeyer, B.T., Stringham, T.K., and Shaver, P.L., 2008, Recommendations for development of resilience-based state-and-transition models: Rangeland Ecology and Management, v. 61, p. 359-367.

Briske, D.D., Fuhlendorf, S.D., and Smeins, F.E., 2005, Stateand-transition models, thresholds, and rangeland health-A synthesis of ecological concepts and perspectives: Rangeland Ecology and Management, v. 58, p. 1-10.

Briske, D.D., and Richards, J.H., 1994, Physiological responses of individual plants to grazing - Current status and ecological significance, in Vavra, M., Laycock, W.A., and Pieper, R.D., eds., Ecological implications of livestock herbivory in the west: Denver, Colo., Society for Range Management, p. 147-176.

Brock, T.D., 1994, Life at High Temperatures: West Yellowstone, Mont., Yellowstone Association for Natural Science, History and Education, Inc.

Brooker, R.W., Maestre, F.T., Callaway, R.M., Lortie, C.L., Cavieres, L.A., Kunstler, G., Liancourt, P., Tielborger, K., Travis, J.M.J., Anthelme, F., Armas, C., Coll, L., Corcket, E., Delzon, S., Forey, E., Kikvidze, Z., Olofsson, J., Pugnaire, F., Quiroz, C.L., Saccone, P., Schiffers, K., Seifan, M., Touzard, B., and Michalet, R., 2008, Facilitation in plant communities-The past, the present, and the future: Journal of Ecology, v. 96, p. 18-34.

Brooks, M.L., D’Antonio, C.M., Richardson, D.M., Grace, J.B., Keeley, J.E., DiTomaso, J.M., Hobbs, R.J., Pellant, M., and Pyke, D.A., 2004, Effects of invasive alien plants on fire regimes: BioScience, v. 54, p. 677-688. 
Brown, J.H., 1971, Mammals on mountaintops-Nonequilibrium insular biogeography: American Naturalist, v. 105, p. 467-478.

Brown, J.H., 1978, The theory of insular biogeography and the distribution of boreal birds and mammals: Great Basin Naturalist Memoirs, v. 2, p. 209-227.

Buckingham Shum, S. 1997, Representing hard-to-formalise, contextualised, multidisciplinary, organisational knowledge: Association for the Advancement of Artificial Intelligence Spring Symposium on Artificial Intelligence in Knowledge Management, Palo Alto, Calif., March 24-26, 1997, Proceedings: Palo Alto, Calif., Stanford University, AAAI Press.

Burns, R.M., and Honkala, B.H., 1990, Agriculture Handbook 654-Silvics of North America:. Washington, DC, U.S. Department of Agriculture, Forest Service, 877 p., accessed June 17, 2009, at http://www.na.fs.fed.us/spfo/pubs/silvics manual/table_of_contents.htm.

Busch, D.E., Ingraham, N.L., and Smith, S.D., 1992, Water uptake in woody riparian phreatophytes of the southwestern U.S.-A stable isotope study: Ecological Applications, v. 2, p. $450-459$.

Busch, D.E., and Smith, S.D., 1995, Mechanisms associated with decline of woody species in riparian ecosystems of the southwestern U.S.: Ecological Monographs, v. 65, p. 347370.

Caldwell, M., 1985, Cold deserts, in Chabot, B.F., and Mooney, H.A., eds., Physiological ecology of North American plant communities: New York, Chapman and Hall, p. 98-212.

Caldwell, M.M., Richards, J.H., Manwaring, J.H., and Eissenstat, D.M., 1987, Rapid shifts in phosphate acquisition show direct competition between neighbouring plants: Nature, v. 327, p. 615-616.

Callaway, R.M., 1995, Positive interactions among plants: The Botanical Review, v. 61, p. 306-349.

Cannone, N., Sgorbati, S., and Guglielmin, M., 2007, Unexpected impacts of climate change on alpine vegetation: Frontiers of Ecological Environments, v. 5, p. 360-364.

Carsey, K., Kittel, G., Decker, K., Cooper, D.J., and Culver, D., 2003, Field guide to the wetland and riparian plant associations of Colorado: Fort Collins, Colo., Colorado Natural Heritage Program.

Cayan, D.R., Redmond, K.T., and Riddle, L.G., 1999, ENSO and hydrologic extremes in the western United States: Journal of Climate, v. 12, p. 2881-2893.

Caylor, K.K., Manfreda, S., Rodriguez-Iturbe, I., 2005, On the coupled geomorphological and ecohydrological organization of river basins: Advances in Water Resources v. 28 , p. $69-86$.
Chambers, J.C., 2001, Pinus monophylla establishment in an expanding Pinus-Juniperus woodland: Environmental conditions, facilitation and interacting factors: Journal of Vegetation Science, v. 12, p. 27-40.

Chambers, J.C., 2008, Great Basin sagebrush ecosystems, in Chambers, J.C., Devoe, N., and Evenden, A., eds., Collaborative management and research in the Great Basin-Examining the issues and developing a framework for action: Fort Collins, Colo., U.S. Department of Agriculture, Forest Service, Rocky Mountain Research Station, p. 53-56.

Chambers, J.C., Roundy, B.A., Blank, R.R., Meyer, S.E., and Whittaker, A., 2007, What makes Great Basin sagebrush ecosystems invasible by Bromus tectorum?: Ecological Monographs, v. 77, p. 117-145.

Chambers, J.C., Tausch, R.J., Korfmacher, J.L., Germanoski, D., Miller, J.R., and Jewett, D., 2004, Effects of geomorphic processes and hydrologic regimes on riparian vegetation, in Chambers, J.C., and Miller, J.R., eds., Great Basin riparian ecosystems ecology, management, and restoration: Washington, D.C., Island Press, p. 196-231.

Chambers, J.C., Vander Wall, S.B., and Schupp, E.W., 1999, Seed and seedling ecology of piñyon and juniper species in the pygmy woodlands of western North America: The Botanical Review, v. 65, p. 1-38.

Chaney, E., Elmore, W., and Platts, W.S., 1993, Livestock grazing on western riparian areas: Prepared for U.S. Environmental Protection Agency by The Northwest Resource Information Center.

Chapin III, F.S., Torn, M.S., and Tateno, M., 1996, Principles of ecosystem sustainability: The American Naturalist, v. 148 , p. 1016-1037.

Charlet, D.A., 1991, Relationships of the Great Basin alpine flora-A quantitative analysis: University of Nevada, Reno, Master's thesis.

Charlet, D.A., 1996, Atlas of Nevada conifers-A phytogeographic reference: Reno, Nev., University of Nevada Press.

Chernoff, B., 1985, Population-dynamics of the Devils Hole pupfish: Environmental Biology of Fishes, v. 13, p. 139147.

Christensen, N.L., Bartuska, A.M., Brown, J.H., Carpenter, J.H., D’Antonio, C., Francis, R., Franklin, J.F., MacMahon, J.A., Noss, R.F., Parsons, D.J., Peterson, C.H., Turner, M.G., and Woodmansee, R.G., 1996, The report of the Ecological Society of America committee on the scientific basis for ecosystem management: Ecological Applications, v. 6, p. 665-691. 
Claassen, R., Cattaneo, A., and Johansson, R., 2008. Costeffective design of agri-environmental payment programs: US experience in theory and practice: Ecological Economics 65, 737-752.

Clements, F.E., 1916, Plant succession-An analysis of the development of vegetation, Pub. 242: Washington, D.C., Carnegie Institute.

Cole, J.E., Overpeck, J.T., and Cook, E.R., 2002, Multiyear La Niña and persistent drought in the contiguous United States: Geophysical Research Letters, v. 29, p. 25-1.

Collins, D.B.G., Bras, R.L., and Tucker, G.E., 2004, Modeling the effects of vegetation-erosion coupling on landscape evolution: Journal of Geophysical Research-Earth Surface, v. 109.

Comstock, J.P., and Ehleringer, J.R., 1992, Plant adaptation in the Great Basin and Colorado Plateau: The Great Basin Naturalist, v. 52, p. 195-215.

Connelly, J.W., Knick, S.T., Schroeder, M.A., and Stiver, S.J., 2004, Conservation assessment of greater sage-grouse and sagebrush habitats: Cheyenne, WY, Western Association of Fish and Wildlife Agencies, accessed April 15, 2010, at http://sagemap.wr.usgs.gov/Docs/Greater_Sage-grouse Conservation_Assessment 060404.pdf.

Connelly, J.W., Schroeder, M.A., Sands, A.R., and Braun, C.E., 2000, Guidelines to manage sage grouse populations and their habitats: Wildlife Society Bulletin, v. 28, p. 967985.

Connely, B.K., 2003, Historical climate analysis, in Wagner, F.H., ed., Rocky Mountain/Great Basin Regional ClimateChange Assessment, Report for the U.S. Global Change Research Program: Logan, Utah, Utah State University, p. 58-72.

Constanza, R., Mageau, M., Norton, B., and Patten, B.C., 1998, Predictors of ecosystem health, in Rapport, D., Constanza, R., Epstein, P.R., Gaudet, C., and Levins, R., eds., Ecosystem Health: Malden, Mass., Blackwell Science.

Crawley, M.J., 1983, Herbivory-The dynamics of animalplant interactions: Berkeley, Calif., University of California Press.

Crawley, M.J., 1997, Plant-herbivore dynamics, in Crawley, M.J., ed., Plant ecology (2d ed.): Oxford, UK, Blackwell Science, p. 401-474.

Cronquist, A., Holmgren, A.H., Holmgren, N.H., and Reveal, J.L., 1972, Intermountain flora: New York, Hafner Publishing Co.

Crowley, J.M., 1967, Biogeography in Canada: Canadian Geographer, v. 11, p. 312-326.
Cushing, C.E., and Wolf, E.G., 1984, Primary production in Rattlesnake Springs, a cold desert spring-stream: Hydrobiologia, v. 114, p. 229-236.

Cutler, A., 1991, Nested fauna and extinction in fragmented habitats: Conservation Biology, v. 5, p. 496-505.

D’Antonio, C.M., and Vitousek, P.M., 1992, Biological invasions by exotic grasses, the grass/fire cycle, and global change: Annual Review of Ecology and Systematics, v. 23, p. 63-87.

Darcy, H., 1856, Les Fontaines publiques de la ville de Dijon: Paris, Victor Dalmont.

Davenport, D.W., Breshears, D.D., Wilcox, B.P., and Allen, C.D., 1998, Viewpoint: Sustainability of piñyon-juniper ecosystems-A unifying perspective of soil erosion thresholds: Journal of Range Management, v. 51, p. 231240.

Davies, K.W., Bates, J.D., and Miller, R.F., 2007, The influence of Artemisia tridentata spp. wyomingensis on microsite and herbaceous vegetation heterogeneity: Journal of Arid Environments, v. 96, p. 441-457.

Davis, M.A., Grime, J.P., and Thompson, K., 2000, Fluctuating resources in plant communities-A general theory of invisibility: Journal of Ecology, v. 88, p. 528-534.

d'Azavedo, W., 1986, Handbook of North American Indians, Volume 11-Great Basin: Washington, D.C., Smithsonian Institution.

Deacon, J.E., and Deacon, M.S., 1979, Research on endangered fishes in the national parks with special emphasis on the Devil's Hole pupfish, in Linn, R.M., ed., Proceedings of the first conference on scientific research in the national parks, Transactions and Proceedings Series No. 5: Washington D.C., U.S. Department of the Interior, National Park Service, p. 9-19.

Deacon, J.E., and Minckley, W.L., 1974, Desert fishes, Desert biology, Volume II: New York, Academic Press, p. 385-487.

DeByle, N.V., and Winokur, R.P., 1985, Aspen-Ecology and management in the Western United States: Fort Collins, Colo., U.S. Department of Agriculture, Forest Service, Rocky Mountain Research Station, 283 p.

deGroot, R., Van der Perk, J., Chiesura, A., and van Vliet, A., 2003, Importance and threat as determining factors for criticality of natural capital: Ecological Economics, v. 44, p. 187-204.

Deines, L., Rosentreter, R., Eldridge, D., and Serpe, M., 2007, Germination and seedling establishment of two annual grasses on lichen-dominated biological soil crusts: Plant and Soil, v. 295, p. 23-35. 
Diaz, S., and Cabido, M., 2001, Vive la différence: Plant functional diversity matters to ecosystem properties: Trends in ecology and evolution, v. 16, p. 646-655.

Diffenbaugh, N.S., Sloan, L.C., Snyder, M.A., Bell, J.L., Kaplan, J., Shafer, S.L., and Bartlein, P.B., 2003, Vegetation sensitivity to global anthropogenic carbon dioxide emissions in a topographically complex region: Global Biogeochemical Cycles, v. 17, no. 2, p. 1067.

Dobkin, D.S., Rich, A.C., Pretare, J.A., and Pyle, W.H., 1995, Nest-site relationships among cavity-nesting birds of riparian and snow pocket aspen woodlands in the northwestern Great Basin: Condor, v. 94, p. 694-707.

Domenico, P.A., and Schwartz, F.W., 1990, Physical and chemical hydrogeology: New York, John Wiley and Sons.

Dukes, J.S., 2007, Tomorrow's plant communities-Different, but how?: New Phytologist, v. 176, p. 235-237.

Dukes, J.S., and Mooney, H.A., 1999, Does global change increase the success of biological invaders?: Tree, v. 14, p. 135-139.

Dungan, J.L., Perry, J.N., Dale, M.R.T., Legendre, P., CitronPousty, S., Fortin, M.-J., Jakomulska, A., Miriti, M., and Rosenberg, M.S., 2002, A balanced view of scale in spatial statistical analysis: Ecography, v. 25, p. 626-640.

Ehleringer, J.R., Schwinning, S., and Gebauer, R.L., 1999, Water use in arid land ecosystems, in Press, M.C., ed., Advances in plant physiological ecology: Oxford, UK, Blackwell Science, p. 347-365.

Eldridge, D.J., and Rosentreter, R., 2004, Shrub mounds enhance water flow in a shrub-steppe community in southwestern Idaho, U.S.A., in Hild, A.L., Shaw, N.L., Meyer, S.E., Booth, D.T., and McArthur, E.D., eds., Seed and soil dynamics in shrubland ecosystems: Laramie, Wyo., U.S. Department of Agriculture, Forest Service, Rocky Mountain Research Station, p. 77-83.

Elzinga, C., Salzer, D.W., Gibbs, J., and Willoughby, J.W., 2001, Monitoring plant and animal populations: Oxford, UK, Blackwell Science.

Environmental Protection Agency Risk Assessment Forum, 1992, Framework for ecological risk assessment: Washington D.C., U.S. Environmental Protection Agency, EPA/630/R92/001.

Erman, N.A., and Erman, D.C., 1995, Spring permanence, Trichoptera species richness, and the role of drought: Journal of the Kansas Entomological Society, v. 68, p. 50-64.

Escudero, A., Martinez, I., de la Cruz, A., Otalora, M.A.G., and Maestre, F.T., 2007, Soil lichens have species-specific effects on the seedling emergence of three gypsophile plant species: Journal of Arid Environments, v. 70, p. 18-28.
Euliss, Jr., N.H., LaBaugh, J.W., Fredrickson, L.H., Mushet, D.M., Laubhan, M.K., Swanson, G.A., Winter, T.C., Rosenberry, D.O., and Nelson, R.D., 2004, The wetland continuum-A conceptual framework for interpreting biological studies: Wetlands, v. 24, p. 448-458.

Evans, R.D., and Lange, O.L., 2003, Biological soil crusts and ecosystem nitrogen and carbon dynamics, in Belnap, J., and Lange, O.L., eds., Biological soil crusts: Structure, function, and management ( $2 \mathrm{~d}$ ed.): Berlin, Germany, SpringerVerlag, Ecological Study Series, p. 217-240.

Evans, R.D., and Ehleringer, J.R., 1993, A break in the nitrogen cycle in arid lands? Evidence from $\delta^{15} \mathrm{~N}$ of soils: Oecologia, v. 94, p. 263-279.

Farina, A., 2000, Landscape ecology in action: Dordrecht, The Netherlands, Kluwer Publishers.

Fetter, C.W., 1994, Applied hydrogeology: Englewood Cliffs, N.J., Prentice-Hall.

Fitzpatrick, F.A., 2001, A comparison of multi-disciplinary methods for measuring physical conditions of streams, in Dorava, J.M., Montgomery, D.R., Palcsak, B.B., and Fitzpatrick, F.A., eds., Geomorphic processes and riverine habitat: American Geophysical Union Water Science and Application, v. 4, p. 7-18.

Fleischner, T.L., 1994, Ecological costs of livestock grazing in western North-America: Conservation Biology, v. 8, p. 629644.

Fleishman, E., Dunham, J.B., Murphy, D.D., and Brussard, P.F., 2004, Explanation, prediction, and maintenance of native species richness and composition, in Chambers, J.C., and Miller, J.R., eds., Great Basin riparian ecosystems ecology, management, and restoration: Washington, D.C., Island Press, p. 232-260.

Fleishman, E., and Mac Nally, R., 2006, Patterns of spatial autocorrelation of assemblages of birds, floristics, physiognomy, and primary productivity in the central Great Basin, USA: Diversity and Distributions, v. 12, p. 236-243.

Fleishman, E., McDonal, N., MacNally, R., Murphy, D. D., Walters, J., and Floyd, T., 2003, Effects of floristics, physiognomy and non-native vegetation on riparian bird communities in a Mojave Desert watershed: Journal of Animal Ecology, v. 72, p. 484-490.

Folke, C., Carpenter, S.R., Walker, B., Scheffer, M., Elmqvist, T., Gunderson, L., and Holling, C.S., 2004, Regime shifts, resilience, and biodiversity in ecosystem management: Annual Review of Ecology, Evolution, and Systematics, v. 35 , p. 557-581.

Fowler, N., 1986, The role of competition in plant communities in arid and semiarid regions: Annual Review of Ecology and Systematics, v. 17, p. 89-110. 
Freeze, R.A., and Cherry, J.A., 1979, Groundwater: Englewood Cliffs, N.J., Prentice-Hall.

Friedel, M.H., Sparrow, A.D., Kinloch, J.E., and Tongway, D.J., 2003, Degradation and recovery processes in arid grazing lands of central Australia, Part 2-Vegetation: Journal of Arid Environments, v. 55, p. 327-348.

Friedman, J.M., Auble, G.T., Shafroth, P.B., Scott, M.L., Merigliano, M.F., Preehling, M.D., and Griffin, E.K., 2005, Dominance of non-native riparian trees in western USA: Biological Invasions, v. 7, p. 747-751.

Friedman, J.M., and Lee, V.J., 2002, Extreme floods, channel change, and riparian forests along ephemeral streams: Ecological Monographs, v. 72, p. 409-425.

Frischknecht, N.C., 1975, Native faunal relationships within the piñyon-juniper ecosystem, in Gifford G.F., and Busby, F.E., eds., The piñyon-juniper ecosystem-A symposium: Logan, Utah, Utah State University, p. 55-65.

Frissell, C.A., Liss, W.J., Warren, C.E., and Hurley, M.D., 1986, A hierarchical framework for stream habitat classification-Viewing streams in a watershed context: Environmental Management, v. 10, p. 199-214.

Fule, P.Z., Covington, W.W., and Moore, M.M., 1997, Determining reference conditions for ecosystem management of southwest ponderosa pine forests: Ecological Applications, v. 7, p. 895-908.

Garrett, L., Rodhouse, T., and Svancara, L., 2004, Vital signs monitoring plan_-Phase I Report: U.S. Department of the Interior, National Park Service, Inventory and Monitoring Program, Upper Columbia Basin Network.

Gates, D.H., 1964, Sagebrush infested by leaf defoliating moth: Journal of Range Management, v. 17, p. 209-210.

Gelbard, J.L., and Belknap, J., 2003, Roads as conduits for exotic plant invasions in a semiarid landscape: Conservation Biology, v. 17, p. 420-432.

Giampietro, M., 2003, Multi-scale integrated analysis of agroecosystems: Boca Raton, Fla., CRC Press.

Giorgi, F., Mearns, L.O., Shields, C., and McDaniel, L., 1998a, Regional nested model simulations of present day and $2 \mathrm{xCO}_{2}$ climate over the central plains of the United States: Climate Change, v. 40, p. 457-493.

Giorgi, F., Meehl, G.A., Kattenberg, A., Grassl, H., Mitchell, J.F.B., Stouffer, R.J., Tokioka, T., Weaver A.J., and Wigley, T.M.L., 1998b, Simulation of regional climate change with global coupled climate models and regional modeling techniques, in Watson, R.T., Zinyowera, M.C., and Moss, R.H., eds., The regional impacts of climate change: New York, N.Y., Cambridge University Press, p. 427-437.
Giorgi, F., Whetton, P.H., Jones, R.G., Christensen, J.H., Mearns, L.O., Hewitson, B., von Storch, H., Francisco, R., and Jack, C., 2001, Emerging patterns of simulated regional climatic changes for the 21 st century due to anthropogenic forcings: Geophysical Research Letters, v. 28, p. $3317-$ 3320 .

Goddard Space Flight Center, 2004, Landcover changes affect U.S. summer climate: National Aeronautics and Space Administration, accessed June 22, 2009, at http://www.nasa. gov/centers/goddard/news/topstory/2004/0223landsummer. $\underline{\mathrm{html}}$.

Goldberg, D.E., 1990, Components of resource competition in plant communities, in Grace, J.B., and Tilman, D., eds., Perspectives on plant competition: San Diego, Calif., Academic Press, p. 27-49.

Goodwin, C.N., Archer, C.P., and Kershner, J.L., 1997, Riparian restoration in the western United States: Overview and perspective: Restoration Ecology, v. 5, p. 4-14.

Grayson, D.K., 1993, The desert's past: A natural prehistory of the Great Basin: Washington, D.C., Smithsonian Institution Press.

Grayson, D.K., 2005, A brief history of Great Basin pikas: Biogeography, v. 32, p. 2103-2111.

Grayson, D.K., and Livingston, S.D., 1993, Missing mammals on Great Basin mountains-Holocene extinctions and inadequate knowledge: Conservation Biology, v. 7, p. 527532.

Grayson, D.K., and Madsen, D.B., 2000, Biogeographic implications of recent low-elevation recolonization by Neotoma cinerea in the Great Basin: Journal of Mammalogy, v. 81, p. 1100-1105.

Grimm, N.B., Arrowsmith, R.J., Eisinger, C., Heffernan, J., Lewis, D.B., MacLeod, A., Prashad, L., Roach, W.J., Rychener, T., and Sheibley, R.W., 2004, Effects of urbanization on nutrient biogeochemistry of aridland streams, in DeFries, R., Asner, G., and Houghton R., eds., Ecosystem interactions with land use change: Washington, D.C., American Geophysical Union, Geophysical Monograph Series 153, p. 129-146.

Grimm, N.B., and Redman, C.L., 2004, Approaches to the study of urban ecosystems: The case of central ArizonaPhoenix: Urban Ecosystems, v. 7, p. 199-213.

Groisman, P.Y., Knight, R.W., Karl, T.R., Easterling, D.R., Sun, B., and Lawrimore, J.H., 2004, Contemporary changes of the hydrological cycle over the contiguous United States-Trends derived from in situ observations: Journal of Hydrometeorology, v. 5, p. 64-85. 
Gross, J.E., 2003, Developing conceptual models for monitoring programs, National Park Service Inventory and Monitoring Program, Ft. Collins, CO, [http://science.nature. nps.gov/im/monitor/].

Gunderson, L.H., 1999, Stepping back-Assessing for understanding in complex regional systems, in Johnson, N.K., Swanson, F., Herring, M., and Greene, S., eds., Bioregional assessments - Science at the crossroads of management and policy: Washington, D.C., Island Press, p. $127-140$.

Hall, E.R., 1946, Mammals of Nevada: Berkeley, Calif., University of California Press.

Hall, K., and Lamont, N., 2003, Zoogeomorphology in the alpine-Some observations on abiotic-biotic interactions: Geomorphology, v. 55, p. 219-234.

Hamilton, S.F., Lustig, T.D., Roberts Jr., T.C., Albrecht, S.W., Campbell, J., Nelson, K.E., Czech, B., and Kuhlman, K., 2003, Indicators of legal, institutional, and economic framework for rangeland conservation and sustainable management, in Sustainable Rangelands Roundtable, ed., Criteria and indicators for sustainable rangelands - A first approximation report: Fort Collins, Colo., Colorado State University, p. 200-244, accessed June 19, 2009, at http:// SustainableRangelands.cnr.colostate.edu.

Hamrick, J.L., Schnabel, A., and Wells, P.V., 1994, Distributions of genetic diversity within and among populations of Great Basin conifers, in Harper, K.T., St. Clair, L.L., Thorne, K.H., and Hess, W.W., eds., Natural History of the Colorado Plateau and Great Basin: Niwot, Colo., University of Colorado Press, p. 147-161.

Hansen, E.M., Bentz, B.J., and Turner, D.L., 2001, Temperature-based model for predicting univoltine brood proportions in spruce beetle (Coleoptera: Scolytidae): The Canadian Entomologist, v. 133, p. 827-841.

Hansen, A.J., Knight, R.L., Marzluff, J. , Powell, S., Brown, K., Gude, P.H., and Jones, K., 2005, Effects of exurban development on biodiversity: Patterns, mechanisms, and research needs: Ecological Applications, v.15, p. 18931905.

Harper, J.L., 1977, Population biology of plants: New York, Academic Press.

Harper, K.T., and Belnap, J., 2001, The influence of biological soil crusts on mineral uptake by associated vascular plants: Journal of Arid Environments, v. 47, p. 347-357.

Helvey, J.D., and Kochenderfer, J.N., 1990, Soil density and moisture content on two unused forest roads during the first 30 months after construction, Research Paper NE-629: Broomhall, Pa., U.S. Department of Agriculture, Forest Service Northeast Forest Experiment Station.
Herrick, J.E., 2000, Soil quality: An indicator of sustainable management?: Applied Soil Ecology, v. 15, p. 75-84.

Herrick, J.E., Bestelmeyer, B.T., Archer, S., Tugel, A.J., and Brown, J.R., 2006, An integrated framework for sciencebased arid land management: Journal of Arid Environments, v. 65, p. $319-335$.

Herrick, J.E., Brown, J.R., Tugel, A.J., Shaver, P.L., and Havstad, K.M., 2002, Application of soil quality to monitoring and management_-Paradigms from rangeland ecology: Agronomy Journal, v. 94, p. 3-11.

Herrick, J.E., Van Zee, J.W., Havstad, K.M., Burkett, L.M., and Whitford, W.G., 2005, Monitoring manual for grassland, shrubland and savanna ecosystems: Las Cruces, N. Mex., U.S. Department of Agriculture Agriculture Research Service Jornada Experimental Range.

Hinkel, J., 2008, Transdisciplinary knowledge integrationCases from integrated assessment and vulnerability assessment: Wageningen, The Netherlands, Wageningen University, Ph.D. thesis.

Hobbs, R.J., Arico, S., Aronson, J., Baron, J.S., Bridgewater, P., Cramer, V.A., Epstein, P.R., Ewel, J.J., Klink, C.A., Lugo, A.E., Norton, D., Ojima, D., Richardson, D.M., Sanderson, E.W., Valladares, F., Vila, M., Zamora, R., and Zobel, M., 2006, Novel ecosystems-Theoretical and management aspects of the new ecological world order: Global Ecology and Biogeography, v. 15, p. 1-7.

Holechek, J.L., Gomes, H., Molinar, F., Galt, D., and Valdez, R., 2000, Short-duration grazing-The facts in 1999: Rangelands, v. 22, p. 18-22.

Holling, C.S., 1996, Surprise for science, resilience for ecosystems, and incentives for people: Ecological Applications, v. 6, p. 733-735.

Holling, C.S., 2001, Understanding the complexity of economic, ecological, and social systems: Ecosystems, v. 4, p. 390-405.

Holmgren, N., 1972, Plant geography of the Intermountain Region, in Cronquist, A., Holmgren, A.H., Holmgren, N., and Reveal, J.L., eds., Intermountain flora-Vascular plants of the Intermountain West, U.S.A., (v. 1): New York, New York Botanical Garden, p. 77-161.

Horton, J.L., Kolb, T.E., and Hart, S.C., 2001, Physiological response to groundwater depth varies among species and with river flow regulation: Ecological Applications, v. 11, p. 1046-1059.

Houghton, J.T., Ding, Y., Griggs, D., Noguer, M., van der Linden, P.J., Dai, X., Maskell, K., and Johnson, C.A., eds., 2001, Climate change 2001-The science of climate change: Cambridge, UK, Cambridge University Press. 
Hsiao, T.H., 1986, Biology and demography of the sagebrush defoliator and its impacts on big sagebrush, in McArthur, E.D., and Welch, B.L., comps., Proceedings-Symposium on the biology of Artemisia and Chrysothamnus: Provo and Ogden, Utah, U.S. Department of Agriculture, Forest Service Intermountain Research Station, p. 191-198.

Hunt, C.B., 1967, Physiography of the United States: San Francisco, Calif., W.H. Freeman.

Hunt, C.B., 1974, Natural regions of the United States and Canada: San Francisco, Calif., W.H. Freeman.

Hunter, Jr., M., 2002, Fundamentals of conservation biology (2d ed.): Boston, Mass., Blackwell Science.

Hutchinson, G.E., 1957, Concluding remarks - Cold Spring Harbor Symposium on Quantitative Ecology: v. 22, p. 415427.

Intergovernmental Panel on Climate Change Working Group I, 2001, Climate change 2001-The scientific basis: New York, Cambridge University Press.

Jelinski, D.E., and Cheliak, W.M., 1992, Genetic diversity and spatial subdivision of Populus tremuloides (Salicaceae) in a heterogeneous landscape: American Journal of Botany, v. 79 , p. $728-736$.

Jenny, H., 1980, The soil resource-Origin and behavior: New York, Springer-Verlag.

Johansen, M.P., Hakonson, T.E., and Breshears, D.D., 2001, Post-fire runoff and erosion from rainfall simulationContrasting forests with shrublands and grasslands: Hydrological Processes, v. 15, p. 2953-2965.

Johnson, N.K., 1975, Controls of number of bird species on montane islands in the Great Basin: Evolution, v. 29, p. 545-567.

Johnstone, I.M., 1986, Plant invasion windows-A time-based classification of invasion potential: Biological Review, v. 61 , p. $369-394$.

Kammer, P.M., and Mohl, A., 2002, Factors controlling species richness in alpine plant communities - An assessment of the importance of stress and disturbance: Arctic, Antarctic, and Alpine Research, v. 34, p. 398-407.

Karlen, D.L., Mausbach, M.J., Doran, J.W., Cline, R.G., Harris, R.F., and Schuman, G.E., 1997, Soil quality-A concept, definition, and framework for evaluation: Soil Science Society of America Journal, v. 61, p. 4-10.

Kauffman, J.B., and Krueger, W.C., 1984, Livestock impacts on riparian ecosystems and streamside management implications - A review: Journal of Range Management, v. 37 , p. $430-438$.
Kay, C.E., 2007, Are lightning fires unnatural? A comparison of aboriginal and lightning ignition rates in the United States, Pages 16-28 in Masters, R.E., and Galley, K.E.M., (eds.), Proceedings of the 23rd Tall Timbers Fire Ecology Conference: Fire in Grassland and Shrubland Ecosystems. Tall Timbers Research Station, Tallahassee, FL.

Klein, J.T., 2008, Evaluation of interdisciplinary and transdisciplinary research: American Journal of Preventive Medicine, v. 35, p. S116-S123.

Knick, S.T., Dobkin, D.S., Rotenberry, J.T., Schroeder, M.A., Vander Haegen, W.M., and van Riper, III, C., 2003, Teetering on the edge or too late-Conservation and research issues for avifauna of sagebrush habitats: Condor, v. 105, p. 611-634.

Kroeber, A.L., 1934, Native American population: American Anthropologist, New Series, v. 36, no. 1, p. 1 - 25, Blackwell Publishing, Küchler, A.W., 1970, Potential natural vegetation (map at scale of 1:7,500,000), in The National Atlas of the U.S.A.: Washington, D.C., Government Printing Office, p. 90-91.

Kullman, L., 2002, Rapid recent range-margin rise of tree and shrub species in the Swedish Scandes: Journal of Ecology, v. 90 , p. 68-77.

Kupfer, J.A., Balmat, J., and Smith, J.L., 2005, Shifts in the potential distribution of sky island plant communities in response to climate change, in Gottfried, G.J., Gebow, B.S., Eskew, L.G., and Edminster, C.B., eds., Connecting mountain islands and desert seas: Biodiversity and management of the Madrean Archipelago II: Fort Collins, Colo., U.S. Department of Agriculture, Forest Service Rocky Mountain Research Station, p. 485-490.

Lamm, R.D., and McCarthy, M., 1982, The angry west: Boston, Mass., Houghton Mifflin Company.

Landres, P.B., Morgan, P., and Swanson, F.J., 1999, Overview of the use of natural variability concepts in managing ecological systems: Ecological Applications, v. 9, p. 11751188.

Lange, O.L., 2003, Photosynthesis of soil-crust biota as dependent on environmental factors, in Belnap, J., and Lange, O.L., eds., Biological soil crusts-Structure, function, and management (2d ed.): Berlin, Springer-Verlag, Ecological Study Series, p. 217-240.

Larson, E.J., and Ripple, W.J., 2003, Aspen age structure in the northern Yellowstone ecosystem-USA: Forest Ecology and Management, v. 179, p. 469-482.

Lawrence, R.J., and Despres, C., 2004, Introduction-Futures of transdiciplinarity: Futures, v. 36, p. 397-405.

Lawlor, T.E., 1998, Biogeography of Great Basin mammalsParadigm lost?: Journal of Mammalogy, v. 79, p. 1111-1130. 
Laycock, W.A., 1991, Stable states and thresholds of range condition on North American rangelands - A viewpoint: Journal of Range Management, v. 44, p. 427-434.

Leatherman, D.A., and Kondratieff, B.C., 2003, Insects associated with the piñon-juniper woodlands of Mesa Verde country, in Floyd, M.L., Hanna, D.D., Romme, W.H., and Colyer, M., eds., Ancient piñon-juniper woodlands-A natural history of Mesa Verde country: Boulder, Colo., University Press of Colorado, p. 167-180.

Lee, J.C., Haack, R.A., Negrón, J.F., Witcosky, J.J., and Seybold, S.J., 2007, Invasive bark beetles, Forest insect and disease leaflet 176: Washington D.C., U.S. Department of Agriculture Forest Service.

Legendre, P., and Legendre, L., 1998, Numerical ecology (2nd ed.): Amsterdam, Elsevier.

Leopold, A., 1941, Cheat takes over: The land, v. 1, p. 310313.

Leung, L.R., Qian, Y., Bian, X., Washington, W.M., Han, J., and Roads, J.O., 2004, Mid-century ensemble of regional climate change scenarios for the western United States: Climate Change, v. 62, p. 75-113.

Likens, G., 1992, The ecosystem approach-Its use and abuse, Excellence in ecology, book 3: Oldendorf/Luhe, Germany, Ecology Institute.

Little Jr., E.L., 1971, Atlas of United States trees, volume 1, conifers and important hardwoods, Miscellaneous Publication 1146: Washington D.C., U.S. Department of Agriculture, accessed June 19, 2009, at http://esp.cr.usgs. gov/data/atlas/little/.

Little Jr., E.L., 1976, Atlas of United States trees, v. 3-Minor Western Hardwoods, Miscellaneous Publication 1314: Washington, D.C., U.S. Department of Agriculture Forest Service, U.S. Government Printing Office.

Liu, J.G., Dietz, T., Carpenter, S.R., Alberti, M., Folke, C., Moran, E., Pell, A.N., Deadman, P., Kratz, T., Lubchenco, J., Ostrom, E., Ouyang, Z., Provencher, W., Redman, C.L., Schneider, S.H., and Taylor, W.W., 2007, Complexity of coupled human and natural systems; Science, v. 317 , p. $1513-1516$.

Logan, J.A., and Powell, J.A., 2001, Ghost forests, global warming, and the mountain pine beetle: American Entomologist, v. 47, p. 160-173.

Logan, J.A., Régnière, J., and Powell, J.A., 2003, Assessing the impacts of global warming on forest pest dynamics: Frontiers in Ecology and the Environment, v. 1, p. 130-137.

Loik, M.E., Breshears, D.D., Lauenroth, W.K., and Belnap, J., 2004, A multi-scale perspective of water pulses in dryland ecosystems - Climatology and ecohydrology of the western USA: Oecologia, v. 141, p. 269-281.
Long, J., 2003, Diversity, complexity, and interactions-An overview of Rocky Mountain forest ecosystems: Tree Physiology, v. 23, p. 1091-1099.

Ludwig, J.A., and Tongway, D.J., 2000, Viewing rangelands as landscape systems, in Arnalds, O., and Archer, S., eds., Rangeland desertification: Dordrecht, Germany, Kluwer, p. 39-52.

Lytle, D.A., and Poff, N.L., 2004, Adaptation to natural flow regimes: Trends in Ecology \& Evolution, v. 19, p. 94-100.

MacArthur, R.A., and Wang, L.C.H., 1974, Behavioral thermoregulation in the pika, Ochotona princeps-A field study using radio-telemetry: Canadian Journal of Zoology, v. 52, p. 353-358.

MacDonald, L.H., and Huffman, E.L., 2004, Post-fire soil water repellency-Persistence and soil moisture thresholds: Soil Science Society of America Journal, v. 68, p. 17291734.

Mack, R.N., 1981, Invasion of Bromus tectorum L into western North America-An ecological chronicle: AgroEcosystems, v. 7, p. 145-165.

Mack, R.N., and Thompson, J.N., 1982, Evolution of steppe with few large, hooved mammals: American Naturalist, v. 119 , p. 757-773.

MacMahon, J.A. ,1988, Warm deserts, p. 231-264 in Barbour, M.G., and Billings, W.D., eds., North American terrestrial vegetation: Cambridge University Press, New York.

Mac Nally, R., Bennett, A.F., Brown, G.W., Lumsden, L.F., Yen, A., Hinkley, S., Lillywhite, P., and Ward, D.A., 2002, How well do ecosystem-based planning units represent different components of biodiversity?: Ecological Applications, v. 12, p. 900-912.

Maczko, K.A., Bryant, L.D., Thompson, D.W., and Borchard, S.J., 2004, Putting the pieces together: Assessing social, ecological, and economic rangeland sustainability: Rangelands, v. 26, p. 3-14.

Maddox, G.D., Poiani, K.E., and Unnasch, R.E., 1999, Evaluating management success-Using ecological models to ask the right monitoring questions, in Johnson, N., ed., The ecological stewardship project - A common reference for ecosystem management (3 Volumes): Oxford, UK, Elsevier Science.

Mantua, N.J., and Hare, S.R., 2002, The Pacific decadal oscillation: Journal of Oceanography, v. 58, p. 35-42.

Martin, P.S., and Mehringer Jr., P.J., 1965, Pleistocene pollen analysis and biogeography of the southwest, in Wright Jr., H.E., and Frey, D.G., eds., The Quaternary of the United States: Princeton, N.J., Princeton University Press, p. 433451. 
McCabe, D.J., 1998, Biological communities in springbrooks, in Botosaneau, L., ed., Studies in Crenobiology, The biology of springs and springbrooks: Leiden, The Netherlands, Backhuys Publishers, p. 221-228.

McCabe, G.J., Palecki, M.A., and Betancourt, J.L., 2004, Pacific and Atlantic Ocean influences on multidecadal drought frequency in the United States: Proceedings of the National Academy of Sciences, v. 101, p. 4136-4141.

McDonald, K.A., and Brown, J.H., 1992, Using montane mammals to model extinctions due to global change: Conservation Biology, v. 6, p. 409-415.

Meehl, G.A., and Tebaldi, C., 2004, More intense, more frequent, and longer lasting heat waves in the 21 st century: Science, v. 305, p. 994-997.

Merriam, C.H., 1890, Results of a biological survey of the San Francisco Mountain region and desert of the Little Colorado, Arizona, North American Fauna Series No. 3: Washington, D.C., U.S. Department of Agriculture, Division of Ornithology and Mammalogy, Government Printing Office.

Mifflin, M.D., 1968, Delineation of ground-water flow systems in Nevada, Research Technical Report H-W, no. 4: Reno, Nev., Desert Research Institute Center for Water Resources, Nevada University.

Milder, J.C., Lassoie, J.P., and Bedford, B.L., 2008, Conserving biodiversity and ecosystem function through limited development: An empirical evaluation: Conservation Biology, v. 22, no. 1, p. 70-79.

Millar, C.I., Westfall, R.D., and Delany, D.L., 2007, Response of high-elevation limber pine (Pinus flexilis) to multiyear droughts and 20th-century warming, Sierra Nevada, California, USA: Canadian Journal Forest Research, v. 37, p. $2508-2520$.

Miller, R., Rose, J., Svejcar, T., Bates, J., and Paintner, K., 1995, Western juniper woodlands: 100 years of plant succession, in Shaw, D.W., Aldon, E.F., LoSapio, C., tech. coords., Desired future conditions for piñon-juniper ecosystems; 1994 August 8-12; Flagstaff, AZ. Gen. Tech. Rep. RM-258. Fort Collins, CO: U.S. Department of Agriculture, Forest Service, Rocky Mountain Forest and Range Experiment Station.
Miller, D.M., Esque, T.C., Bedford, D.R., Finn, S., Webb, R.H., and Hughson, D., 2006, Appendix S-Conceptual ecological models, in Bedford, D.R., Chung-MacCoubrey, A.L., Esque, T.C., Heister, K.M., Hughson, D.L., Miller, D.M., Palmer, C.J., Siderius, J.R., Truitt, R.E., Truitt, V.A., and Webb, R.H., Mojave inventory and monitoring network report, Phase II: Fort Collins, Colo., U.S. Department of Agriculture, National Park Service, Natural Resource Program Center, 189 p., accessed July 19, 2009, at http:// science.nature.nps.gov/im/units/MOJN/rpts_pubs/ Downloads/PhaseII/AppendixS GeneralEcologicalModels. pdf.

Miller, M.E., 2005, The structure and functioning of dryland ecosystems - Conceptual models to inform long-term ecological monitoring: U.S. Geological Survey Scientific Investigations Report 2005-5197, accessed July 19, 2009, at http://pubs.usgs.gov/sir/2005/5197/.

Miller, M.E., Belnap, J., Beatty, S.W., and Reynolds, R.L., 2006, Performance of Bromus tectorum L. in relation to soil properties, water additions, and chemical amendments in calcareous soils of southeastern Utah, USA: Plant and Soil, v. 288 , p. 1-18.

Miller, R.F., Baisan, C., Rose, J., and Pacioretty, D., 2001, Preand post-settlement fire regimes in mountain big sagebrush steppe and aspen-The northwestern Great Basin: Oregon State University and U.S. Department of Agriculture Agricultural Research Service, Eastern Oregon Agricultural Research Center.

Miller, R.F., Bates, J.D., Svejcar, T.J., Pierson, F.B., and Eddleman, L.E., 2005, Biology, ecology, and management of western juniper (Juniperus occidentalis), Technical Bulletin 152: Corvallis, Oreg., Oregon State University Agricultural Experiment Station.

Miller, R.F., and Rose, J.A., 1999, Fire history and western juniper encroachment in sagebrush steppe: Journal of Range Management, v. 52, p. 550-559.

Miller, R.F., Svejcar, T.J., and West, N.E., 1994, Implications of livestock grazing in the Intermountain sagebrush region-Plant composition, in Vavra, M., Laycock, W.A., and Pieper, R.D., eds., Ecological implications of livestock herbivory in the west: Denver, Colo., Society for Range Management, p. 101-146.

Miller, R.F., and Tausch, R.J., 2001, The role of fire in juniper and piñyon woodlands-A descriptive analysis, in Galley, K.E.M., and Wilson, T.P., eds., Proceedings of the Invasive Species Workshop-The Role of Fire in the Control and Spread of Invasive Species, Fire Conference 2000, San Diego, Calif.: Tallahassee, Fla., Miscellaneous Publication No. 11, The First National Congress on Fire Ecology, Prevention, and Management, Tall Timbers Research Station, p. 15-30. 
Minckley, W.L., and Brown, D.E., 1994, Wetlands, in Brown, D.E., ed., Biotic communities in the southwestern United States and northwestern Mexico: Salt Lake City, Utah, University of Utah Press, p. 237-287.

Minnesota Population Center, 2004, National historical geographic information system: Pre-release Version 0.1: Minneapolis, MN, University of Minnesota, available at http://www.nhgis.org.

Minshall, G.W., 1978, Autotrophy in stream ecosystems: Bioscience, v. 28, p. 767-770.

Mitsch, W.J., and Gosselink, J.G., 2000, Wetlands: New York, Van Nostrand Reinhold.

Monger, H.C., and Bestelmeyer, B.T., 2006, The soilgeomorphic template and biotic change in arid and semiarid ecosystems: Journal of Arid Environments, v. 65, p. 207-218.

Monin, A.S., and Shishkov, Y.A., 2000, Climate as a problem of physics: Physics-Uspedkhi, v. 43, p. 381-406.

Montgomery, D.R., 2001, Geomorphology, river ecology, and ecosystem management, in Dorava, J.M., Montgomery, D.R., Palcsak, B.B., and Fitzpatrick, F.A., eds., Geomorphic processes and riverine habitat: American Geophysical Union Water Science and Application, v. 4, 253 p.

Montgomery, D.R., and Buffington, J.M., 1997, Channelreach morphology in mountain drainage basins: Geological Society of America Bulletin, v. 109, p. 596-611.

Morrison, S.F., and Hik, D.S., 2008, When? where? and for how long? Census design considerations for an alpine lagomorph, the Collared Pika (Ochotona collaris), in Alves, P.C., Ferrand, N., and Hackländer, K., 2008, Lagomorph biology: Berlin, Springer.

Murphy, J., 1999, An evaluation of statistical and dynamical techniques for downscaling local climate: Journal of Climate, v. 12, p. 2256-2284.

Murray, A.B., and Paola, C., 2003, Modelling the effect of vegetation on channel pattern in bedload rivers: Earth Surface Processes and Landforms, v. 28, p. 131-143.

Naiman, R.J., and Decamps, H., 1997, The ecology of interfaces-Riparian zones: Annual Review of Ecology and Systematics, v. 28, p. 621-658.

National Assessment Synthesis Team, 2000, Climate change impacts on the United States-The potential consequences of climate variability and change: Washington D.C., U.S. Global Change Research Program.

Neff, J.C., Reynolds, R.L., Belnap, J., and Lamothe, P., 2005, Multi-decadal impacts of grazing on soil physical and biogeochemical properties in southeast Utah: Ecological Applications, v. 15, p. 87-95.
Noon, B.R., 2003, Conceptual issues in monitoring ecological systems, in Busch, D.E., and Trexler, J.C., eds., Monitoring ecosystems - Interdisciplinary approaches for evaluating ecoregional initiatives: Washington, D.C., Island Press, p. 27-71.

Norfleet, M.L., Ditzler, C.A., Puckett, W.E., Grossman, R.B., and Shaw, J.N., 2003, Soil quality and its relationship to pedology: Soil Science, v. 168, p. 149-155.

Norton, J., Monaco, T., and Norton, U., 2007, Mediterranean annual grasses in western North America-Kids in a candy store: Plant and Soil, v. 298, p. 1-5.

Noss, R.F., 1990, Indicators for monitoring biodiversity-A hierarchical approach: Conservation Biology, v. 4, p. 355-364.

Noss, R.F., Franklin, J.F., Baker, W.L., Schoennagel, T., and Moyle, P.B., 2006, Managing fire-prone forests in the western United States: Frontiers in Ecology and the Environment, v. 4. p. 481-487.

Noss, R.F., LaRoe III, E.T., and Scott, J.M., 1995, Endangered ecosystems of the United States: A preliminary assessment of loss and degradation, Biological Report 28: Washington, D.C., National Biological Service, accessed June 19, 2009, at http://biology.usgs.gov/pubs/ecosys.htm.

Noy-Meir, I., 1973, Desert ecosystems-Environment and producers: Annual Review of Ecology and Systematics, v. 4, p. 25-51.

O’Dell, T., Garman, S., Evenden, A., Beer, M., Nance, E., Perry, D., DenBleyker, R., Sharrow, D., Wynn, K., Brown, J., Miller, M., and Thomas, L., 2005, Northern Colorado plateau inventory and monitoring network, vital signs monitoring plan: Moab, Utah, National Park Service Inventory and Monitoring Network, $174 \mathrm{p}$.

Odum, E.P., 1959, Fundamentals of ecology: Philadelphia, Pa., Saunders.

Okin, G.S., Murray, B., and Schlesinger, W.H., 2001, Degradation of sandy arid shrubland environmentsObservations, process modeling, and management implications: Journal of Arid Environments, v. 47, p. 123-144.

Omernik, J.M., 1987, Map of ecoregions of the conterminous United States: Annals of the Association of American Geographers, v. 77, p. 118-125, scale 1:7,500,000.

Paetzold, A., Bernet, J.F., and Tockner, K., 2006, Consumerspecific responses to riverine subsidy pulses in a riparian arthropod assemblage: Freshwater Biology, v. 51, p.1103-1115.

Paetzold, A., and Tockner, K., 2005, Effects of riparian arthropod predation on the biomass and abundance of aquatic insect emergence: Journal of the North American Benthological Society, v. 24, p. 395-402. 
Paine, R.T., Tegner, M.J., and Johnson, E.A., 1998, Compounded perturbations yield ecological surprises: Ecosystems, v. 1, p. 535-545.

Palmer, M.A., Falk, D.A., and Zedler, J.B., 2006, Ecological theory and restoration ecology, in Falk, D.A., Palmer, M.A., and Zedler, J.B., eds., Foundations of restoration ecology: Washington, D.C., Island Press, p. 1-10.

Parmesan, C., and Yohe, G., 2003, A globally coherent fingerprint of climate change impacts across natural systems: Nature, v. 421, p. 37-42.

Parsons, S., Lewis, K.J., and Psyllakis, J.M., 2003, Relationships between roosting habitat of bats and decay of aspen in the sub-boreal forests of British Columbia: Forest Ecology and Management, v. 177, p. 559-570.

Pase, C.P., 1994, Arctic and alpine tundra, in Brown, D.E., ed., Biotic communities of the southwestern United States and northwestern Mexico: Salt Lake City, University of Utah Press, p. 27-33.

Pase, C.P., and Brown, D.E., 1994, Rocky Mountain (Petran) subalpine conifer forest, in Brown, D.E., ed., Biotic communities of the southwestern United States and northwestern Mexico: Salt Lake City, University of Utah Press, p. 37-39.

Patten, D.T., 1998, Riparian ecosystems of semi-arid North America-Diversity and human impacts: Wetlands, v. 18, p. $498-512$.

Patten, D.T., 2005, Alpine-timberline ecosystem narrative conceptual model, in Jean, C., Shrag, A.M., Bennetts, R.E., Daley, R., Crowe, E.A., and O’Ney, S., Vital signs monitoring plan for the Greater Yellowstone Network: Bozeman, Mont., National Park Service Greater Yellowstone Network, Appendix III, p. 37-46.

Paulin, K.M., Cook, J.J., and Dewey, S.R., 1999, Pinyonjuniper woodlands as sources of avian diversity, in Monson, S.B, and Stevens, R., eds., Proceedings: Ecology and management of pinyon-juniper communities within the Interior West: Fort Collins, Colo., U.S. Department of Agriculture Forest Service, Rocky Mountain Research Station P-9.

Peacock, M., 1997, Determining natal dispersal patterns in a population of North American pikas (Ochotona princeps) using direct mark-resight and indirect genetic methods: Behavioral Ecology, v.8, p. 340-350.

Pearce, L., 2003, Disaster management, community planning, and public participation: How to achieve sustainable hazard mitigation?: Nat Hazards v. 28(2-3), p. 211-228.

Peet, R.K., 2000, Forests and meadows of the Rocky Mountains, in Barbour, M.G., and Billings, W.D., eds., North American terrestrial vegetation. (2d ed.): Cambridge, UK, Cambridge University Press, p. 75-121.
Pellant, M., and Lysne, C.R., 2005, Strategies to enhance plant structure and diversity in crested wheatgrass seedings, in Shaw, N.L., Pellant, M., and Monsen, S.B., eds., Sagegrouse habitat restoration symposium proceedings: Fort Collins, Colo., U.S. Department of Agriculture Forest Service, Rocky Mountain Research Station, p. 81-92.

Pellant, M., Shaver, P.L., Pyke, D.A., and Herrick, J.E., 2005, Interpreting indicators of rangeland health, Version 4, Interagency Technical Reference TR-1734-6: Denver, Colo., U.S. Department of the Interior, Bureau of Land Management, National Science and Technology Center.

Peterson, F.F., 1981, Landforms of the basin \& range province defined for soil survey, Technical Bulletin 28: Reno, Nev., University of Nevada Agricultural Experiment Station.

Pimm, S.L., 1996, Designer ecosystems: Nature, v. 379, p. 217-218.

Plotkin, H.C., 2003, The imagined world made real—-Towards a natural science of culture: New Brunswick, N.J., Rutgers University Press.

Plumb, G., Tinker, D., Patten, D.T., Hall, B., Jaworowski, C., Heasler, H., and Jean, C., 2005, Conceptual models for dominant vegetation, aquatic and geothermal ecosystems in Bighorn Canyon National Recreation Area, Grand Teton National Park, and Yellowstone National Park: Bozeman, MT, National Park Service Vital Signs Monitoring Plan Appendix III.

Polley, H.W., Johnson, H.B., Mayeux, H.S., and Tischler, C.R., 1996, Are some of the recent changes in grassland communities a response to rising $\mathrm{CO}_{2}$ concentrations?, in Körner, C., and Bazzaz, F.A., eds., Carbon dioxide, populations, and communities: San Diego, Academic Press, p. 177-195.

Polley, H.W., Mayeux, H.S., Johnson, H.B., and Tischler, C.R., 1997, Viewpoint-Atmospheric $\mathrm{CO}_{2}$, soil water, and shrub/grass ratios on rangelands: Journal of Range Management, v. 50, p. 278-284.

Poff, N.L., Allan, J.D., Bain, M.B., Karr, J.R., Prestegaard, K.L., Richter, B.D., Sparks, R.E., and Stromberg, J.C., 1997, The natural flow regime: Bioscience, v. 47, p. $769-784$.

Poole, G.C., 2002, Fluvial landscape ecology_-Addressing uniqueness within the river discontinuum: Freshwater Biology, v. 47, p. 641-660.

Power, M.E., and Dietrich, W.E., 2002, Food webs in river networks: Ecological Research, v. 17, p. 451-471.

Powers, J.S., Sollins, P., Harmon, M.E., and Jones, J.A., 1999, Plant-pest interactions in time and space-A Douglas-fir bark beetle outbreak as a case study: Landscape Ecology, v. 14 , p. $105-120$. 
Prichard, D., Anderson, J., Correll, C., Fogg, J., Gebhardt, K., Krapf, R., Leonard, S., Mitchell, B., and Staats, J., 1998, Riparian area management - A user guide to assessing proper functioning condition and the supporting science for lotic areas: Denver, Colo., Bureau of Land Management.

PRISM Group, 2004., accessed May 13, 2010, at http://www. prism.oregonstate.edu/.

Prosser, I.P., and Slade, C.J., 1994, Gully formation and the role of valley-floor vegetation, southeastern Australia: Geology, v. 22, p. 1127-1130.

Pueyo, Y., Alados, C.L., García-Ávila, B., Kéfi, S., Maestro, M., and Rietkerk, M., 2008, Comparing direct abiotic amelioration and facilitation as tools for restoration of semiarid grasslands: Restoration Ecology, doi: 10.1111/j.1526-100X.2008.00474.x.

Raison, R.J., 1979, Modification of the soil environment by vegetation fires, with particular reference to nitrogen transformations-A review: Plant and Soil, v. 51, p. 73-108.

Rapport, D., Costanza, R., Epstein, P., Gaudet, C., and Levins, R., 1998, Ecosystem health: New York, Blackwell Scientific.

Rehfeldt, G.E., Crookston, N.L., Warwell, M.V., and Evans, J.S., 2006, Emperical analysis of plant-climate relationships for the western United States: International Journal of Plant Science, v. 167, p. 1123-1150.

Reichenberger, G., and Pyke, D.A., 1990, Impact of early root competition on fitness components of four semiarid species: Oecologia, v. 85, p. 159-166.

Reid, K.D., Wilcox, B.P., Breshears, D.D., and MacDonald, L., 1999, Runoff and erosion in a piñon-juniper woodlandInfluence of vegetation patches: Soil Science Society of America Journal, v. 63, p. 1869-1879.

Reynolds, R.L., Belnap, J., Reheis, M., Lamothe, P., and Luiszer, F., 2001, Aeolian dust in Colorado Plateau soilsNutrient inputs and recent change in source: Proceeding of the National Academy of Sciences, v. 98, p. 7123-7127.

Richalet, J.P., 2007, A proposed classification of environmental adaptation-The example of high altitude: Reviews in Environmental Science and Biotechnology, v. 6, p. 223-229.

Rickleffs, R.E., 1990, Ecology (3d ed.): New York, W.H. Freeman and Company.

Ritchey, T., 2002, Modelling complex socio-technical systems using morphological analysis, Address to the Swedish Parliamentary IT Commission: Stockholm, Sweden, Swedish Morphological Society, accessed June 19, 2009, at http://:www.swemorph.com/index.html.

Robbins, P., 2004, Political Ecology-A Critical Introduction: New York, Blackwell.
Roberts, P.H., 1963, Hoof prints on forest ranges: San Antonio, Tex., Naylor.

Rogers, P., 2002, Using forest health monitoring to assess aspen forest cover change in the southern Rockies ecoregion: Forest Ecology and Management, v. 155, p. 223-236.

Romme, W.H., Allen, C.D., Bailey, J., Baker, W.L., Bestelmeyer, B.T., Brown, P., Eisenhart, K.S., Floyd-Hanna, L., Huffman, D., Jacobs, B.F., Miller, R.F., Muldavin, E., Swetnam, T.W., Tausch, R., and Weisberg. P.J., 2007, Historical and modern disturbance regimes of piñonjuniper vegetation in the western U.S.: Fort Collins, Colo., Colorado Forest Restoration Institute, accessed June 19, 2009, at http://www.cfri.colostate.edu/.

Romme, W.H., Floyd-Hanna, M.L., and Hanna, D.D., 2003, Ancient piñon-juniper forests of Mesa Verde and the west-A cautionary note for forest restoration programs, in Omi, P.N., and Joyce, L.A., eds., Fire, fuel treatments, and ecological restoration: Fort Collins, Colo., U.S. Department of Agriculture Forest Service, Rocky Mountain Research Station, p. 335-350.

Ropelewski, C., and Halpert, M., 1986, North American precipitation and temperature patterns associated with the El Niño/Southern Oscillation (ENSO): Monthly Weather Review, v. 114, p. 2352-2362.

Rosentreter, R., and Belnap, J., 2003, Biological soil crusts of North America, in Belnap, J., and Lange, O.L., eds., Biological soil crusts-Structure, function, and management (2d ed.): Berlin, Springer-Verlag, p. 31-50.

Rowe, J.S., 1997, Defining the ecosystem: Ecological Society of America Bulletin, v. 78, p. 95-97.

Sada, D.W., Fleishman, E., and Murphy, D.D., 2005, Associations among spring-dependent aquatic assemblages and environmental and land use gradients in a Mojave Desert mountain range: Diversity and Distributions, v. 11, p. 91-99.

Sada, D.W., and Herbst, D.B., 1999, Habitat use by rare aquatic macroinvertebrates in springbrooks of the upper Muddy River, Clark County, Nevada: Technical report to The Nature Conservancy: Las Vegas, Nev., Southern Nevada Projects Office.

Sada, D.W., and Pohlmann, K.F., 2006, U.S. National Park Service Mojave inventory and monitoring network spring survey protocols-Level I and level II: Nevada System of Higher Education, Desert Research Institute.

Sada, D.W., and Vinyard, G.L., 2002, Anthropogenic changes in biogeography of Great Basin aquatic biota, in Herschler, R., Madsen, D.B., and Currey, D.R., eds., Great Basin aquatic systems history: Washington D.C., Smithsonian Institution Press, p. 277-294. 
Sada, D.W., Vinyard, G.L., and Hershler, R., 1992, Environmental characteristics of small springs in northern Nevada [abs.], in Hendrickson, D.A., ed., Proceedings of the Desert Fishes Council, Volume XXIII, p.76.

Savory, A., 1988, Holistic resource management: Covelo, Calif., Island Press.

Savory, A., and Parsons, S.D., 1980, The Savory grazing method: Rangelands, v. 2, p. 234-237.

Scheffer, M., Carpenter, S., Foley, J.A., Folke, C., and Walker, B., 2001, Catastrophic shifts in ecosystems: Nature, v. 413, p. 591-596.

Schlesinger, W.H., 1997, Biogeochemistry: An analysis of global change. (2d ed.): San Diego, Calif., Academic Press.

Schmidt, K.M., and Webb, R.H., 2001, Researchers consider US southwest's response to warmer, drier conditions: EOS, Transactions American Geophysical Union, v. 82, p. $475-478$.

Scott, D., and Billings, W.D., 1964, Effects of environmental factors on standing crop and productivity of an alpine tundra: Ecological Monographs, v. 34, p. 243-270.

Scott, M.L., Brasher, A.M.D., Reynolds, E.W., Caires, A., and Miller, M.E., 2005, The structure and functioning of riparian and aquatic ecosystems of the Colorado PlateauConceptual models to inform monitoring: U.S. Geological Survey Technical Report, accessed August 13, 2010, at http://science.nature.nps.gov/im/units/scpn/Documents/ Supplements/SuppIII Riparian_Aquatic Model.pdf.

Seastedt, T.R., Hobbs, R.J., and Suding, K.N., 2008, Management of novel ecosystems-Are novel approaches required?: Frontiers in Ecology and the Environment, v. 6.

Seastedt, T.R., Bowman, W.D., Caine, T.N., McKnight, D., Townsend, A., and Williams, M.W., 2004, The landscape continuum - A model for high-elevation ecosystems: BioScience, v. 54, p. 111-121.

Serpe, M.D., Orm, J.M., Barkes, T., and Rosentreter, R., 2006, Germination and seed water status of four grasses on moss-dominated biological soil crusts from arid lands: Plant Ecology: v. 185, p. 163-178.

Seybold, C.A., Herrick, J.E., and Brejda, J.J., 1999, Soil resilience - A fundamental component of soil quality: Soil Science, v. 164, p. 224-234.

Shafer, S.L., Bartlein, P.J., and Thompson, R.S., 2001, Potential changes in the distribution of western North America tree and shrub taxa under future climate scenarios: Ecosystems, v. 4, p. 200-215.

Shafroth, P.B., Stromberg, J.C., and Patten, D.T., 2000, Woody riparian vegetation response to different alluvial water table regimes: Western North American Naturalist, v. 60, p. 66-76.
Shaw, J.D., Steed, S.E., and DeBlander, L.T., 2005, Forest inventory and analysis (FIA) annual inventory answers the question - What is happening to piñyon-juniper woodlands?: Journal of Forestry, v. 103, p. 280-285.

Shepard, W.D., 1993, Desert springs_-Both rare and endangered: Aquatic Conservation-Marine and Freshwater Ecosystems, v. 3, p. 351-359.

Shugart, H.H., 1998, Terrestrial ecosystems in changing environments: Cambridge, UK, Cambridge University Press.

Skaggs, R.W., and Boecklen, W.J., 1996, Extinctions of montane mammals reconsidered-Putting a global-warming scenario on ice: Biodiversity and Conservation, v. 5, p. 759-778.

Smith, A.T., 1974, The distribution and dispersal of pikasInfluences of behavior and climate: Ecology, v. 55, p. $1368-1376$.

Smith, S.D., Huxman, T.E., Zitzer, S.F., Charlet, T.N., Housman, D.C., Coleman, J.S., Fenstermaker, L.K., Seemann, J.R., and Nowak, R.S., 2000, Elevated $\mathrm{CO}_{2}$ increases productivity and invasive species success in an arid ecosystem: Nature, v. 408, p. 79-82.

Snipp, C.M., 1989, American indians: The first of this land, National Committee for Research on the 1980 Census: Russell Sage Foundation Publisher, 408 p.

Snyder, K.A., and Williams, D.G., 2000, Water sources used by riparian trees varies among stream types on the San Pedro River, Arizona: Agricultural and Forest Meteorology, v. 105 , p. 227-240.

Snyder, M.A., and Sloan, L.C., 2005, Transient future climate over the western U.S. using a regional climate model: Earth Interactions, v. 9, p. 1-21.

Society for Range Management Task Group on Unity in Concepts and Terminology Committee, 1995, New concepts for assessment of rangeland condition: Journal of Range Management, v. 48, p. 271-282.

Spaeth, K.E., Thurow, T.L., Blackburn, T.H., and Pierson, F.B., 1996, Ecological dynamics and management effects on rangeland hydrologic processes, in Spaeth, K.E., Pierson, F.B., Weltz, M.A., and Hendricks, R.G., eds., Grazingland hydrology issues-Perspectives for the 21st century: Denver, Colo., Society for Range Management, p. 25-51.

Sparrow, A.D., Friedel, M.H., and Tongway, D.J., 2003, Degradation and recovery processes in arid grazing lands of central Australia, Part 3-Implications at landscape scale: Journal of Arid Environments, v. 55, p. 349-360.

Starfield, A.M., Smith, K.A., and Bleloch, A.L., 1994, How to model it-Problem solving for the computer age: Edina, Minn., Interaction Book Co. 
Stegner, W., 1992, Beyond the hundreth meridian: Penguin Books, $432 \mathrm{p}$.

Stephenson, N.L., 1990, Climatic control of vegetation distribution: the role of the water balance: The American Naturalist, v. 135, p. 649-670.

Stevens, G.C., and Fox, G.F., 1991, The causes of treeline: Annual Review Ecological Systematics, v. 22, p. 177-191.

Stevens, L.E., and Springer, A.E., 2004, A conceptual model of spring ecosystem ecology, in Thomas, L., Lauver, C., Hendrie, M., Tancreto, N., Whittier, J., Atkins, J., Miller, M., and Cully, A., eds., Vital signs monitoring plan for the southern Colorado Plateau Network-Phase II Report, Supplement III: Flagstaff, Ariz., National Park Service, Southern Colorado Plateau Network.

Stevens, R., and Monsen, S.B., 2004, Mechanical plant control, in Monsen, S.B., Stevens, R., and Shaw, N.L., eds., Restoring western ranges and wildland: Fort Collins, Colo., U.S. Department of Agriculture Forest Service, Rocky Mountain Research Station, p. 65-87.

Stevens, S.L., Martin, R.E., and Clinton, N.E., 2007, Prehistoric fire area and emissions from California's forests, woodlands, shrublands, and grasslands: Forest Ecology and Management, v. 251, p. 205-216.

Stokols, D., Fuqua, J., Gress, J., Harvey, R., Phillips, K., Baezconde-Garbanati, L., Unger, J., Palmer, P., Clark, M.A., Colby, S.M., Morgan, G., and Trochim, W., 2003, Evaluating transdisciplinary science: Nicotine \& Tobacco Research, v. 5, p. S21-S39.

Stringham, T.K., Krueger, W.C., and Shaver, P.L., 2001, States, transitions, and thresholds-Further refinement for rangeland applications, Special Report 1024: Corvallis, Oreg., Oregon State University Agricultural Experiment Station.

Stringham, T.K., Krueger, W.C., and Shaver, P.L., 2003, State and transition modeling-An ecological process approach: Journal of Range Management, v. 56, p. 106-113.

Stromberg, J.C., 2001, Restoration of riparian vegetation in the south-western United States - Importance of flow regimes and fluvial dynamism: Journal of Arid Environments, v. 49, p. 17-34.

Stromberg, J.C., Tiller, R., and Richter, B., 1996, Effects of groundwater decline on riparian vegetation of semiarid regions-The San Pedro, Arizona: Ecological Applications, v. 6 , p. 113-131.

Sustainable Rangelands Roundtable, 2006, Progress Report, May 2003 to May 2005: accessed June 19, 2009, at http:// sustainablerangelands.warnercnr.colostate.edu/Images/ ProgressReport.pdf.
Sveinbjornsson, B., 2000, North American and European treelines-External forces and internal processes controlling position: Ambio, v. 29, p. 338-395.

Swetnam, T.W., Allen, C.D., and Betancourt, J.L., 1999, Applied historical ecology—Using the past to manage for the future: Ecological Applications, v. 9, p. 1189-1206.

Swetnam, T.W., and Baisan, C.H., 1994, Historical fire regime patterns in the southwestern United States since AD 1700, in Allen, C., ed., Fire effects in southwestern forests, Proceedings of the second La Mesa fire symposium: Los Alamos, N.M., U.S. Department of Agriculture Forest Service, Rocky Mountain Forest and Range Experiment Station, p. 11-32.

Swetnam, T.W., and Betancourt, J.L., 1998, Mesoscale disturbance and ecological response to decadal climatic variability in the American Southwest: Journal of Climate, v. 11, p. $3128-3147$.

Tanaka, J., Torell, L.A., Swanson, L.V., Brunson, M., McCollum, D., and Heintz Jr., H.T., 2003, Indicators for maintenance and enhancement of multiple economic and social benefits to current and future generations, in Sustainable Rangelands Roundtable, ed., Criteria and indicators for sustainable rangelands- $\mathrm{A}$ first approximation report: Fort Collins, Colo., Colorado State University, p. 171-199, accessed June 19, 2009, at http:// SustainableRangelands.cnr.colostate.edu.

Thines, N.J.S., Shipley, L.A., and Sayler, R.D., 2004, Effects of cattle grazing on ecology and habitat of Columbia Basin pygmy rabbits (Brachylagus idahoensis): Biological Conservation, v. 119, p. 525-534.

Thompson, R.S., Hostetler, S.W., Bartlein, P.J., and Anderson, K.H., 1998, A strategy for assessing potential future changes in climate, hydrology, and vegetation in the western United States: U.S. Geological Survey Circular 1153, 20 p.

Thorp, J.H., Thoms, M.C., and Delong, M.D., 2006, The riverine ecosystem synthesis-Biocomplexity in river networks across space and time: River Research and Applications, v. 22, p. 123-147.

Thorup, J., 1974, Occurrence and size-distribution of Simuliidae (Diptera) in a Danish spring: Archiv Fur Hydrobiologie, v. 74, p. 316-335.

Thurow, T.L., 1991, Hydrology and erosion, in Heitschmidt, R.K., and Stuth, J.W., eds., Grazing management-An ecological perspective: Portland, Oreg., Timber Press, p. 141-159.

Tomback, D.F., 1982, Dispersal of whitebark pine seeds by Clark's nutcracker-A mutualism hypothesis: Journal of Animal Ecology, v. 51, p. 451-467. 
Tomback, D.F., and Kramer, K.A., 1980, Limber pine seed harvest by Clarck's nutcracker in the Sierra NevadaTiming and foraging behavior: Condor, v. 82, p. 467-468.

Tongway, D.J., Sparrow, A.D., and Friedel, M.H., 2003, Degradation and recovery processes in arid grazing lands of central Australia, Part 1-Soil and land resources: Journal of Arid Environments, v. 55, p. 301-326.

Trombulak, S.C., and Frissell, C.A., 2000, Review of ecological effects of roads on terrestrial and aquatic communities: Conservation Biology, v. 14, p. 18-30.

Truett, J., 1996, Bison and elk in the American southwest-In search of the pristine: Environmental Management, v. 20, p. 195-206.

Tyler, S.W., Chapman, J.B., Conrad, S.H., Hammermeister, D.P., Blout, D.O., Miller, J.J., Sully, M.J., and Ginanni, J.M., 1996, Soil-water flux in the southern Great Basin, United States - Temporal and spatial variations over the last 120,000 years: Water Resources Research, v. 32, p. 1481-1499.

Tyser, R.W., and Worley, C.A., 1992, Alien flora in grasslands adjacent to road and trail corridors in Glacier National Park, Montana (U.S.A.): Conservation Biology, v. 6, p. 253-262.

U.S. Department of Agriculture Forest Service, 2001, Potential natural vegetation groups, version 2000: Missoula, MT, U.S. Department of Agriculture Forest Service Rocky Mountain Research Station Fire Sciences Laboratory.

U.S. Department of Agriculture Natural Resources Conservation Service, 1998, Keys to soil taxonomy, Eighth Edition: Soil Survey Staff.

U.S. Department of Agriculture Natural Resources Conservation Service, 2006, Land resource regions and major land resource areas of the United States, the Caribbean, and the Pacific Basin, Handbook 296: Washington, D.C., United States Department of Agriculture.

U.S. Geological Survey, 1999, Digital representation of “Atlas of United States Trees” by Elbert L. Little, Jr.: accessed March 19, 2008, at http://esp.cr.usgs.gov/info/veg-clim/.

Vale, T.R., 2002, Fire, native peoples, and the natural landscape: Washington, D.C., Island Press.

Vankat, J.L., 2005, Montane and subalpine terrestrial ecosystems of the southern Colorado Plateau-Literature review and conceptual models, Northern Colorado Plateau Vital Signs Monitoring Plan,: U.S. Department of the Interior, National Park Service, Northern Colorado Plateau Network, Inventory and Monitoring Program, Appendix I.

Vasek, F.C., and Barbour, M.G., 1977, Mojave Desert scrub vegetation, in Barbour, M.G., and Major, J., eds., Terrestrial vegetation of California: New York, Wiley, p. 835-867.
Veblen, T.T., 2003, Key issues in fire regime research for fuels management and ecological restoration, in Omi, P.N., and Joyce, L.A., eds., Fire, fuel treatments, and ecological restoration, Proceedings: Fort Collins, Colo., U.S. Department of Agriculture Forest Service, Rocky Mountain Research Station, p. 259-275.

Walker, B.H., 1993, Rangeland ecology_-Understanding and managing change: Ambio, v. 22, p. 80-87.

Ward, J.V., and Tockner, K., 2001, Biodiversity-Towards a unifying theme for river ecology: Freshwater Biology, v. 46, p. 807-819.

Wardle, D.A., 2002, Communities and ecosystems-Linking the aboveground and belowground components: Princeton, N.J., Princeton University Press.

Warfield, J., 2006, An introduction to systems science: Singapore, Indonesia, World Scientific Publishing Company.

Webb, R.H., and Leake, S.A., 2006, Ground-water surfacewater interactions and long-term change in riverine riparian vegetation in the southwestern United States: Journal of Hydrology, v. 320, p. 302-323.

Welch, B.L., 2005, Big sagebrush-A sea fragmented into lakes, ponds, and puddles: Fort Collins, Colo., U.S. Department of Agriculture Forest Service, Rocky Mountain Research Station.

Wells, P.V., 1983, Paleobiogeography of montaine islands in the Great Basin since the last glaciopluvial: Ecological Monographs, v. 53, p. 341-382.

Wells, P.V., and Berger, R., 1967, Late Pleistocene history of coniferous woodland in the Mojave Desert: Science, v. 155, p. $1640-1647$.

West, N.E., 1999, Distribution, composition, and classification of current juniper-piñyon woodlands and savannas across western North America, in Monsen, S.B., and Stevens, R., eds., Proceedings - Ecology and management of pinyonjuniper communities within the Interior West: Ogden, Utah, U.S. Department of Agriculture Forest Service, Rocky Mountain Research Station, p. 20-23.

West, N.E., and Young, J.A., 2000, Intermountain valleys and lower mountain slopes, in Barbour, M.G., and Billings, W.D., eds., North American terrestrial vegetation (2nd ed.): Cambridge, UK, Cambridge University Press, p. 255-284.

Western Water Policy Review Advisory Commission, 1998, Water in the west - Challenge for the next century: Albuquerque, N.M., University of New Mexico Press, accessed June 19, 2009, at http://www.preventionweb.net/ files/1785 VL102318.pdf. 
Westley, F.R., and Miller, P.S., eds., 2003, Experiments in consilience-Integrating social and scientific responses to save endangered species (1st ed.): Washington, DC, Island Press.

Westoby, M., Walker, B., and Noy-Meir., I., 1989, Opportunistic management for rangelands not at equilibrium: Journal of Range Management, v. 42, p. 266274.

Whelan, R.J., 1995, The ecology of fire: Cambridge, UK, Cambridge University Press.

Whicker, J.J., Breshears, D.D., Wasiolek, P.T., Kirchner, T.B., Tavani, R.A., Schoep, D.A., and Rodgers, J.C., 2002, Temporal and spatial variation of episodic wind erosion in unburned and burned semiarid shrubland: Journal of Environmental Quality, v. 31, p. 599-612.

White, P.S., and Walker, J.L., 1997, Approximating nature's variation-Selecting and using reference information in restoration ecology: Restoration Ecology, v. 5, p. 338-349.

White, P.S., Harrod, J., Romme, W.H., and Betancourt, J.L., 1999, Disturbance and temporal dynamics, in Szaro, R.C., Johnson, N.C., Sexton, W.T., and Malk, A.J., eds., Ecological stewardship-A common reference for ecosystem management, v. II: Oxford, UK., Elsevier Science, Ltd., p. 566-584.

White, P.S., and Pickett, S.T.A., 1985, Natural disturbance and patch dynamics-An introduction, in Pickett, S.T.A., and White, P.S., eds., The evolution of natural disturbance and patch dynamics: San Diego, Calif., Academic Press, p. 3-13.

Whitford, W.G., 2002, Ecology of desert systems: San Diego, Calif., Academic Press.

Whitford, W.G., de Soyza, A.G., Van Zee, J.W., Herrick, J.E. and Havstad, K.M., 1998, Vegetation, soil, and animal indicators of rangeland health: Environmental Monitoring and Assessment, v. 51, p. 179-200.

Wiens, J.A., Van Horne, B., and Noon, B.R., 2002, Integrating landscape structure and scale into natural resource management, in Liu, J., and Taylor, W.W., eds., Integrating landscape ecology into natural resource management: Cambridge, UK, Cambridge University Press, p. 23-67.

Wilcox, B.A, Murphy, D.D., Ehrlich, P.R., and Austin, G.T., 1986, Insular biogeography of the montane butterfly faunas in the Great Basin - Comparison with birds and mammals: Oecologia, v. 69, p. 188-194.
Wilcox, B.P., Pitlick, J., Allen, C.D., and Davenport, D.W., 1996, Runoff and erosion from a rapidly eroding pinyonjuniper hillslope, in Anderson, M.G., and Brooks, S.M., eds., Advances in hillslope processes: New York, John Wiley \& Sons, p. 61-77.

Williams, J.D., Dobrowski, J.P., and West, N.E., 1995a, Michrophytic crust influence on wind erosion: Transactions of the American Society of Agricultural Engineers, v. 38, p. 131-137.

Williams, J.D., Dobrowski, J.P., and West, N.E., 1995b, Microphytic crust influence on interrill erosion and infiltration capacity: Transactions of the American Society of Agricultural Engineers, v. 38, p. 139-146.

Winograd, I.J., Coplen, T.B., Landwehr, J.M., Riggs, A.C., Ludwig, K.R., Szabo, B.J., Kolesar, P.T., and Revesz, K.M., 1992, Continuous 500,000-year climate record from vein calcite in Devils-Hole, Nevada: Science, v. 258, p. 255-260.

Winograd, I.J., and Thordarson, W., 1975, Hydrogeologic and hydrochemical framework, south-central Great Basin, Nevada-California, with special reference to the Nevada Test Site: U.S. Geological Survey Professional Paper 712-C.

With, K.A., 2002, The landscape ecology of invasive spread: Conservation Biology, v. 16, p. 1192-1203.

Worster, D., 1985, Rivers of empire-Water, aridity and the growth of the American west: New York, Pantheon Books.

Yohe, G., Malone, E., Brenkert, A., Schlesinger, M., Meij, H., Xing, X., and Lee, D, 2006, Synthetic assessment of global distribution of vulnerability to climate change: Maps and data, 2005, 2050, and 2100 Palisades, NY: Socioeconomic Data and Applications Center (SEDAC), Columbia University. Available at: http://www.ciesin.columbia.edu/ data/climate/.

Yeo, J.J., 2005, Effects of grazing exclusion on rangeland vegetation and soils, east central Idaho: Western North American Naturalist, v. 65, p. 91-102.

Yohe, G., Malone, E., Brenkert, A., Schlesinger, M., Meij, H., Xing, X., and Lee, D, 2006, Synthetic assessment of global distribution of vulnerability to climate change: Maps and data, 2005, 2050, and 2100 Palisades, NY: Socioeconomic Data and Applications Center (SEDAC), Columbia University. Available at: http://www.ciesin.columbia.edu/ data/climate/.

Young, J.A., 1994, Changes in plant communities in the Great Basin induced by domestic livestock grazing, in Harper, K.T., St. Clair, L.L., Thorne, K.H., and Hess, W.M., eds., Natural history of the Colorado Plateau and Great Basin: Boulder, Colo., University Press of Colorado, p. 113-123. 


\section{Glossary}

Adaptive management A systematic process for continually improving management policies and practices by learning from the outcomes of operational programs. Its most effective form - "active" adaptive management — employs management programs that are designed to experimentally compare selected policies or practices by implementing management actions explicitly designed to generate information useful for evaluating alternative hypotheses about the system being managed (http://science.nature.nps.gov/im/monitor/Glossary. $\underline{\mathrm{cfm}})$.

Attributes Any living or nonliving feature or process of the environment that can be measured or estimated and that provides insights into the state of the ecosystem. The term Indicator is reserved for a subset of attributes that is particularly information-rich in the sense that their values are somehow indicative of the quality, health, or integrity of the larger ecological system to which they belong (Noon, 2003; http://science.nature.nps.gov/im/monitor/Glossary.cfm). Also see Indicator.

Climate change (Also called climatic change) a change of climate which is attributed directly or indirectly to human activity that alters the composition of the global atmosphere and which is in addition to natural climate variability observed over comparable time periods (United Nations Framework Convention on Climate Change, accessed June 24, 2009, at http://unfccc.int/2860.php).

Climate variability (Also called climatic variability) The temporal variations of the atmosphere- ocean system around a mean state. Typically, this term is used for timescales longer than those associated with synoptic weather events (that is, months to millennia and longer; Glossary of Meteorology, accessed June 24, 2009, at http://amsglossary.allenpress.com/ glossary/).

Community "All of the populations occupying a given area" (Odum 1959, 6); Odum's definition was adapted by the Risk Assessment Forum to read: "an assemblage of populations of different species within a specified location in space and time" (Environmental Protection Agency Risk Assessment Forum 1992, p. 37). "In ecology, a group of interacting populations in time and space. Sometimes, a particular subgrouping may be specified, such as the fish community in a lake or the soil arthropod community in a forest," (EPA, 1992, p. 6).

Composition The identity and variety of elements within an ecosystem, including species present and their population structure, abundance, and genetic diversity (Noss, 1990).
Conceptual Models Purposeful representations of reality that provide a mental picture of how something works to communicate that explanation to others (NPS I\&M glossary). A "conceptual model describes a series of working hypotheses of how a stressor(s) might affect an ecological component(s). The conceptual model also describes the ecosystem potentially at risk, the relationship between measurement endpoints and assessment endpoints, and exposure scenarios," (Environmental Protection Agency Risk Assessment Forum 1992, p. 37).

Control model Describe our understanding of how the systems work in response to the natural variation of drivers by depicting the principal components and processes of the subsystem. These models focus on the priority drivers for specific subsystems.

Cumulative effects Can appear as a stressor accumulating over space (for example, low levels of a water pollutant in tributaries accumulating in a river), time (for example, multiple land treatments of the same patch), or combinations of single and multiple stressors accumulating over time and space.

Disturbance "....any relatively discrete event in time that disrupts ecosystem, community, or population structure and changes resources, substrate availability, or the physical environment" (White and Pickett, 1985, p. 7). In relation to monitoring, disturbances are considered to be ecological factors that are within the evolutionary history of the ecosystem (for example, drought). These are differentiated from anthropogenic factors (stressors, below) that are outside the range of disturbances naturally experienced by the ecosystem (Whitford, 2002).

Disturbance regime Consists of the timing, predictability, frequency, and severity of a specified source of disturbance, or combination of disturbances, in a specific area.

Drivers and Stressors Physical, chemical, or biological perturbations to a system that are either (a) foreign to that system or (b) natural to the system but applied at an excessive (or deficient) level (Barrett and others, 1976, p. 192). Stressors cause significant changes in the ecological components, patterns and processes in natural systems.

Dry system For the purposes of these models, a dry system is wholly dependent on precipitation for its source of water. Dry systems have no dependence or association with groundwater or free surface water. 
Ecological integrity A concept that expresses the degree to which the physical, chemical, and biological components (including composition, structure, and process) of an ecosystem and their relations are present, functioning, and capable of self-renewal. Ecological integrity implies the presence of appropriate species, populations and communities and the occurrence of ecological processes at appropriate rates and scales as well as the environmental conditions that support these taxa and processes (http://science.nature.nps.gov/im/ monitor/Glossary.cfm).

Ecoregion A relatively homogeneous geographic area "perceived by simultaneously analyzing a combination of causal and integrative factors including land surface form, soils, land uses, and potential natural vegetation (Omernik, 1987, p. 123). Ecoregions "was coined by J.M. Crowley (1967) and popularized by R.G. Bailey (1978) to define a mapped classification of ecosystem regions of the U.S.... Ecoregions are generally considered to be the regions of relative homogeneity in ecological systems or in relationships between organisms and their environments".

Ecosystem A spatially explicit unit of the Earth that includes all of the organisms, along with all components of the abiotic environment within its boundaries (Likens 1992, cited by Christensen and others, 1996, p. 670).

Ecosystem functioning The flow of energy and materials through the arrangement of biotic and abiotic components of an ecosystem. Includes many ecosystem processes such as primary production, trophic transfer from plants to animals, nutrient cycling, water dynamics and heat transfer. In a broad sense, ecosystem functioning includes two components: ecosystem resource dynamics and ecosystem stability (Díaz and Cabido, 2001).

Ecosystem health A metaphor pertaining to the assessment and monitoring of ecosystem structure, function, and resilience in relation to the notion of ecosystem "sustainability" (following Rapport, 1998, and Costanza and others, 1998). A healthy ecosystem is sustainable (see Sustainable ecosystem, below).

Extent, Spatial The total length, area, or volume that exists or is observed or analyzed; or the duration of time under consideration.

Focal ecosystems Ecosystems that play significant functional roles in landscapes by their disproportionate contribution to the transfer of matter and energy, or by their disproportionate contribution to landscape-level biodiversity.

Framework Model The highest level of our model hierarchy; identifies the major biotic and abiotic systems of the Great Basin and how they are related.

Grain The size of the elementary sampling units. It may be expressed as the diameter, surface, or volume of the matter supporting the measurements (Legendre and Legendre, 1998).
Hierarchical model A construct in which component variables and systems of ecological entities are defined to have the smallest unit of spatial and temporal detail in the lowest level; each higher level reflects processes and interactions occurring at ever larger spatial and temporal scales. Behaviors of a particular level in the hierarchical model are determined by constraints imposed by the levels above and filtered or averaged behaviors of components and subsystems of levels below (Environmental Protection Agency e-map, accessed June 24, 2009, at http://www.epa.gov/emap/html/pubs/docs/ resdocs/mglossary.html).

Hydrologic function (upland systems) Capacity of a site to capture, store, and safely release water from rainfall, run-on, and snowmelt, to resist a reduction in this capacity, and to recover this capacity following degradation (Pellant and others, 2005). Soil hydrologic function is the ability of the soil to absorb, store, and transmit water, both vertically and horizontally. Changes in soil properties and ground cover can alter the hydrologic function of the soil.

Hydrologic function (lotic and lentic systems) Capacity of an area to: dissipate energies associated with (1) high stream flow (lotic); or (2) wind action, wave action, and overland flow (lentic); thereby reducing erosion and improving water quality; filter sediment, capture bedload, and aid floodplain development; improve flood-water retention and groundwater recharge; develop root masses that stabilize streambanks against cutting action; develop diverse ponding and channel characteristics to provide the habitat and the water depth, duration, and temperature necessary for fish production, waterfowl breeding, and other uses; support greater biodiversity (from Prichard and others, 1998).

Indicator (general use of term) A term reserved for a subset of environmental attributes that is particularly information-rich in the sense that their values somehow indicate the quality, health, or integrity of the larger ecological system to which they belong (Noon, 2003; http://science.nature.nps.gov/im/ monitor/Glossary.cfm). Indicators are a selected subset of the physical, chemical, and biological elements and processes of natural systems that are selected to represent the overall health or condition of the system.

\section{Indicators of ecosystem health (specific use of}

term) Measurable attributes of the environment (biotic or abiotic) that provide insights regarding (1) the functional status of one or more key ecosystem processes, (2) the status of ecosystem properties that are clearly related to these ecosystem processes, and/or (3) the capacity of ecosystem processes or properties to resist or recover from natural disturbances and/or anthropogenic stressors (modified from Whitford, 1998). In the context of ecosystem health, key ecosystem processes and properties are those that are most closely associated with the capacity of the ecosystem to maintain its characteristic structural and functional attributes over time (including natural variability). 
Integration Model Summary model(s) addressing cumulative effects and integration of multiple stressors and drivers through time and space. Integration requires transferring data across the range of spatial scales between the scale at which data are collected and the scale at which management questions are asked. Integration provides templates for addressing the multiple temporal scales at which ecosystem processes, drivers, and stressors operate (see Chapter 5).

Interactions Synergistic results of multiple stressors on a focal system and the mathematical expression that specifies the nature and strength of this effect.

Landscape A spatially structured mosaic of different types of ecosystems functionally interconnected by ecological flows of materials (for example, water and sediments) energy, and organisms.

Landscape change Changes in the types, relative proportions, and 'condition' (health, integrity, resiliency, and functioning) of ecosystems - particularly as these relate to mandates/management objectives of DOI land managers and other partner agencies.

Modeling A representation of a physical system or process intended to enhance our ability to understand, predict, or control its behavior. A conceptual model consists of a system's initial and boundary conditions and hypotheses and observations made about the system.

Monitoring Collection and analysis of repeated observations or measurements to evaluate changes in condition and progress toward meeting a management objective (Elzinga and others, 2001). Detection of a change or trend may trigger a management action, or it may generate a new line of inquiry. Monitoring is often done by sampling the same sites over time, and these sites may be a subset of the sites sampled for the initial inventory.

Nutrient cycling The circulation of chemical elements such as nitrogen, oxygen, carbon, and phosphorus in specific pathways from the abiotic (not involving or produced by organisms) portions of the environment into organic substances in plants and animals and then back into abiotic forms.

Reference state Or reference condition ideally is defined on a site-specific basis according to climate and soil-geomorphic setting framed with respect to a particular time period and place. A reference state can be thought of as the "natural" standard for management and monitoring; it explicitly identifies associated goals, assumptions, and value judgments (White and Walker, 1997; Landres and others, 1999).

Resolution The smallest object that can be reliably detected; the precision of a measurement.

Scale A general term with multiple, sometimes contradictory meanings. In this document, scale is defined by one of the following, depending on qualifying words that place 'scale' in context: A. the spatial or temporal dimension of an object or process, characterized by both grain and extent; B. the actual distance, direction, shape, and geometry; C. the cartographic ratio between a map and the ground it represents. For somewhat analogous, but distinct terms see: Grain, Extent, Resolution, and Support.

Social capacity "and economic capital state is comprised of the "traditional" economic notion of capital - all assets and liabilities present in the economy. Also included are the concepts of social capital or capacity representing the potential opportunities afforded by the way society exists" (Sustainable Rangelands Roundtable, 2006).

State-and-Transition Model A non-linear approach to describe ecological systems and processes often presented as an alternate to the traditional Clementsian (Clements, 1916) succession-climax community concept. State-and-transition models are management-oriented tools for describing and classifying ecosystem conditions (or states) and posing hypotheses about ecological factors responsible for changes (or transitions) among different states.

Stressor See Drivers and Stressors.

Stressor model An abstraction of a particular system or part of a system focused on the links between stressors, ecosystem responses, effects, and in some cases indicators. A stressor model does not necessarily incorporate all relevant system components, feedbacks, or interactions.

Subsystem In this document subsystem refers to a definable biophysical component of the wet or dry system and the specific subject of a Subsystem Model. A subsystem has a common suite of biota adapted to highly discernable climate and physical template properties.

Subsystem Model Aspatial descriptive models of subsystem components, drivers \& dynamics.

Support An N-dimensional volume, including its geometrical shape, size and orientation, within which average values of a variable may be computed (Dungan and others, 2002).

Sustainable ecosystem An ecosystem “...that, over the normal cycle of disturbance events, maintains its characteristic diversity of major functional groups, productivity, and rates of biogeochemical cycling" (Chapin and others, 1996, p. 1016).

System The complete set of components and their interactions of interest. A system could be a forest, a desert, a manufacturing plant, or a town. In our case, the system of interest usually encompasses terrestrial, atmospheric, hydrological, and human-dominated components.

System Model Graphic and narrative models that describe the landscape and relations among subsystems. 
Threshold As applied to state-and-transition models, a threshold is a point "...in space and time at which one or more of the primary ecological processes responsible for maintaining the sustained [dynamic] equilibrium of the state degrades beyond the point of self-repair. These processes must be actively restored before the return to the previous state is possible. In the absence of active restoration, a new state ... is formed" (Stringham and others, 2003, p. 109). Thresholds are defined in terms of the functional status of key ecosystem processes and are crossed when capacities for resistance and resilience are exceeded. Also see State-and-Transition Model.

Transition As applied to state-and-transition models, a transition is a trajectory of change that is precipitated by natural events and/or management actions which change the integrity of one or more of the primary ecological processes responsible for maintaining the dynamic equilibrium of the state. Transitions are vectors of system change that will lead to a new state without abatement of the stressor(s) and/or disturbance(s) prior to exceeding the system's capacities for resistance and resilience (adapted from Stringham and others, 2003). Also see state and threshold.

Water quality The chemical, physical, and biological characteristics of water, usually in respect to its suitability for a particular purpose.

Wet System For the purposes of these models, a wet system is an ecosystem or community that has direct input of free water sourcing from an underground aquifer (groundwater) or above-surface lotic or lentic system. Example wet systems include, springs, seeps, riparian systems, and lakes. 


\section{Appendix A. Ratings of System Drivers}

Complete list of drivers considered for use in wet and dry subsystem models. Highest priority drivers are listed at the top; those in bold type are identified as top priority drivers for constructing models. Some drivers ranked high but were not listed as top priority because they are part of the Human-Social Systems model. Models of the Atmospheric/Climate and Human/Social systems are already driver-specific models describing how their top drivers interact with other drivers to impact the entire Great Basin region.

\begin{tabular}{|c|c|c|c|}
\hline System & System Driver & System & System Driver \\
\hline Wet & $\begin{array}{l}\text { Flow Regime } \\
\text { Water Extraction \& Irrigation } \\
\text { Water Impoundment } \\
\text { Altered Flow Regime } \\
\text { Economic and Political Factors } \\
\text { Climate Variability } \\
\text { Land Use \& Land Cover } \\
\text { Invasive Exotics } \\
\text { Livestock Grazing } \\
\text { Agriculture } \\
\text { Urban-Exurban Development } \\
\text { Channelization } \\
\text { Water Pollution } \\
\text { Legal Mandates } \\
\text { Resource Extraction } \\
\text { Climate Change } \\
\text { Recreation } \\
\text { Erosion } \\
\text { Motorized Vehicle Use } \\
\text { Fire Acceleration } \\
\text { Linear Infrastructure } \\
\text { Pathogens } \\
\text { Fire Suppression } \\
\text { Livestock Grazing } \\
\text { Atmospheric Pollution/Deposition } \\
\text { Insects and Disease } \\
\text { Fire Regime } \\
\text { Particulates (Airborne \& Deposited) } \\
\text { Military Land Use } \\
\text { Light Pollution } \\
\text { Sound Pollution }\end{array}$ & Dry & $\begin{array}{l}\text { Fire Regime } \\
\text { Climate Variability (for example, drought) } \\
\text { Invasive Exotics } \\
\text { Land Use \& Land Cover } \\
\text { Livestock Grazing } \\
\text { Fire Acceleration } \\
\text { Economic and Political Factors } \\
\text { Motor Vehicle Use } \\
\text { Urban-Exurban Development } \\
\text { Fire Suppression }\end{array}$ \\
\hline
\end{tabular}


This page left intentionally blank 
Publishing support provided by the U.S. Geological Survey Publishing Network, Tacoma Publishing Service Center

For more information concerning the research in this report, contact the Director, Forest and Rangeland Ecosystem Science Center

U.S. Geological Survey

777 NW 9th Street

Corvallis, Oregon 97330

http://fresc.usgs.gov 
言

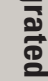

흄

긍

을

옿

목

$\stackrel{2}{\circ}$

罚

I

궁 